TÚLIO DA SILVA SIQUEIRA

\title{
PRODUÇÃO DE METANO EM AnSBBR TRATANDO SORO EM CONDIÇÃO TERMOFÍLICA
}

Túlio Da Silva SiQUeIRA

OrIEnTAdor: Prof. Dr. José Alberto Domingues RodrigueS 

TÚLIO DA SILVA SIQUEIRA

\section{PRODUÇÃO DE METANO EM AnSBBR TRATANDO SORO EM CONDIÇÃO TERMOFÍLICA}

Dissertação apresentada à Escola de Engenharia de São Carlos, da Universidade de São Paulo, como parte dos requisitos para obtenção do título de Mestre em Ciências: Engenharia Hidráulica e Saneamento.

Orientador: Prof. Dr. José Alberto Domingues Rodrigues

VERSÃO CORRIGIDA 


\section{AUTORIZO A REPRODUÇÃO TOTAL OU PARCIAL DESTE TRABALHO, POR QUALQUER MEIO CONVENCIONAL OU ELETRÔNICO, PARA FINS DE ESTUDO E PESQUISA, DESDE QUE CITADA A FONTE.}

D618p

da Silva Siqueira, Túlio

Produção de metano em AnSBBR tratando soro em condição termofilica. / Túlio da Silva Siqueira; orientador José Alberto Domingues Rodrigues. São Carlos, 2018.

Dissertação (Mestrado) - Programa de Pós-Graduação em Engenharia Hidráulica e Saneamento e Área de Concentração em Hidráulica e Saneamento -- Escola de Engenharia de São Carlos da Universidade de São Paulo, 2018 .

1. AnSBBR. 2. Metano. 3. Soro. 4. Termofilica. 5. Metanogênese. I. Título. 


\section{FOLHA DE JULGAMENTO}

Candidalo: Engenheiro TÚLIO DA SILVA SIQUERRA.

Título da dissertação: "Produção de metano em AnSBBR tratando soro em condição termofilica".

Data da defesa: 23/02/2018.

Comissão Julgadora:

Resultado:

Prof. Dr. José Alberto Domingues Rodrigues

IPRONDDO

(Orientador)

(Escola de Engenharia Mauá/EEM)

Prof. Dr. Arnaldo Sarti

APNOUSDO

(Universidade Estadual Paulisła "Júlió de Mésquila Filho"/Unesp - Araraquara)

Prof. Dr. Marce lo Loureiro Garcia

LPROVADO

(Universidade Estadual Paulista "Júlio de Mesquita Filho"/Unesp - Rio Claro)

Coordenador do Programa de Pós-Graduação em Engenharia Hidráulica e Saneamento:

Prof. Dr. Eduardo Mario Mendiondo

Presidente da Comissão de Pós-Graduaçôo:

Prof. Associado Luis Fernando Costa Alberto 



\section{AGRADECIMENTOS}

Aos meus pais, Joaquim e Lenice, por todo amor, pela ajuda em qualquer momento necessário e também pelo incentivo. Por sempre acreditarem em mim e, principalmente, por serem exemplos de caráter e dignidade. Também ao meu irmão, Lucas, por ser um grande amigo e a todos os familiares.

Ao meu orientador, José Alberto, pela orientação no projeto, mas também incentivo, conversas do dia-a-dia e pela transmissão de um pouco do seu conhecimento. Aos companheiros do laboratório, Suzana, Roberta, Giovanna, Juliane, Natália, Marcela, Lia, Marina e Jéssica, pela ajuda nas análises, perfis e também pela amizade.

À Tamires Koga, pelo carinho, incentivo, companheirismo, compreensão e apoio incondicional.

A todos os professores do Departamento de Hidráulica e Saneamento da EESC/USP, pelos quais tive o privilégio de ser ensinado, por todo conhecimento e por despertar ainda mais meu interesse na área.

Aos amigos do mestrado, Ambiental 09 e da república pelo companheirismo, grandes momentos vividos e amparo nos momentos de necessidade.

Aos amigos do Residencial Planalto, pelo convívio durante todos estes anos e por serem amigos com os quais sempre pude e sempre poderei contar nas horas mais importantes.

Ao Conselho Nacional de Desenvolvimento Científico e Tecnológico (CNPq), pelo incentivo da pesquisa num país que pouco reconhece seus pesquisadores e também pela bolsa de mestrado concedida, sem a qual este trabalho não seria possível.

E a todos que diretamente ou indiretamente contribuíram com o projeto. 



\section{RESUMO}

SIQUEIRA, T. S. Produção de metano em AnSBBR tratando soro em condição termofílica. 218p. Dissertação de Mestrado - Escola de Engenharia de São Carlos, Universidade de São Paulo, São Carlos, 2018.

Uma das alternativas para a recuperação de energia de resíduos é o tratamento anaeróbio de efluentes com produção de metano e hidrogênio, utilizando-se reatores anaeróbios. Dentre as configurações possíveis de reatores, os descontínuos, como o ASBR e o AnSBBR, destacam-se ao permitem maior flexibilidade e estabilidade na operação, bem como maior controle dos efluentes do processo e menores tempos de partida. O objetivo deste trabalho foi avaliar a produção de metano a partir da digestão anaeróbia do soro em condição termofílica, avaliando também a adequação ambiental deste resíduo. O soro de queijo é o maior subproduto da indústria de laticínios, sendo gerado na proporção de $90 \%$ do volume de leite utilizado, com concentração de matéria orgânica entre 2 e $80 \mathrm{~g}$ DQO.L ${ }^{-1}$, dependendo do processo produtivo. $\mathrm{O}$ reator foi operado de forma a permitir avaliar a influência da carga orgânica aplicada (limite de estabilidade), da estratégia de alimentação (tempo de enchimento - batelada ou batelada alimentada), e da relação entre tempo de ciclo e concentração afluente (flexibilidade operacional). $\mathrm{O}$ reator operou a $55^{\circ} \mathrm{C}$, com tempo de ciclo de 8 horas e velocidade de agitação (100 rpm), sendo o volume alimentado por ciclo de 1,0 litro, com 1,5 litros de volume residual. O reator teve um período inicial de adaptação de 29 dias. Após este período, estudou-se a influência do aumento da carga orgânica pelo aumento da carga orgânica volumétrica aplicada, variando de 6,20 a 30,34 gDQO.L' ${ }^{1} \cdot \mathrm{d}^{-1}$. A condição com carga orgânica volumétrica aplicada de 19,20 gDQO. $\mathrm{L}^{-1} \cdot \mathrm{d}^{-1}$ apresentou os melhores resultados globais, alcançando eficiência de remoção de matéria orgânica na forma de DQO de $85,8 \%$ e 99,6 \% de carboidratos. O rendimento de metano gerado em função da matéria orgânica consumida foi de 13,07 $\mathrm{mmolCH}_{4} \cdot \mathrm{gDQO}^{-1}$, sendo a produção de biogás de $6506 \mathrm{~mL}-\mathrm{CNTP}$.ciclo ${ }^{-1}$, com fração molar de metano equivalente a $73,7 \%$. A produtividade molar de metano alcançada nesta condição foi de $324,0 \mathrm{molCH}{ }_{4} \cdot \mathrm{m}^{-3} \cdot \mathrm{d}^{-1}$. Percebeu-se que as maiores cargas aplicadas acarretaram em perda de eficiência e instabilidade no reator. O modelo cinético de todas as condições foi ajustado corretamente, indicando que a rota de produção de metano preferencial foi a hidrogenotrófica em todo o período de estudo, porém, a via acetoclástica também foi presenciada em todas as condições. A mudança de estratégia de alimentação de batelada ( $2 \%$ do ciclo) para batelada alimentada (50\% do ciclo) não melhorou os resultados de eficiência, estabilidade e produção de metano no reator. Realizouse também a estimativa da recuperação energética estimando a produção de um pequeno, médio e grande produtor de queijo. A condição $\mathrm{V}$ apresentou os melhores resultados, possibilitando a recuperação de $826,10 \mathrm{MWh}$ por dia tratando o volume de soro gerado numa indústria de grande porte (1.000.000 kg.mês ${ }^{-1}$ ) enquanto a melhor condição global (VIII) apresentou recuperação de 548,40 MWh.

Palavras-chave: AnSBBR; Metano; Soro; Termofílica; Metanogênese. 


\section{ABSTRACT}

SIQUEIRA, T. S. AnSBBR applied to cheese whey treatment and methane production under termophilic condition. 218p. Master's Degree Dissertation - São Carlos School of Engineering, University of São Paulo, São Carlos, 2018.

One of the alternatives to recover energy from waste treatment is by the anaerobic treatment of effluents using discontinuous reactor configuration, such as ASBR and AnSBBR, aiming to produce methane and hydrogen. This reactors configuration allows greater flexibility and stability in the operation, a better controlled process, as well as shorter start-up. The objective of this project was to evaluate the methane production from the anaerobic digestion of cheese whey under thermophilic conditions. Cheese whey is the largest by-product of the dairy industry, it is generated in a proportion of $90 \%$ of the milk volume, its organic matter concentration can vary between 2 and $80 \mathrm{~g}$ COD. $\mathrm{L}^{-1}$ depending on the process. The evaluation of the environmental suitability of this residue was also analyzed. The reactor was operated to determinate the influence of the applied organic load (stability limit), feeding strategy (filling time - batch or fed-batch), and the relationship between cycle time and affluent concentration (operational flexibility). The reactor was operated at $55^{\circ} \mathrm{C}$, with cycle time of 8 hours and $100 \mathrm{rpm}$ of agitation speed. The volume fed per cycle was 1.0 liter with 1.5 liters of residual volume. The reactor had an initial adaptation period of 29 days. After this period, the influence of the organic load by increasing the applied volumetric organic load, ranging from 6.20 to $30.34 \mathrm{gDQO} . \mathrm{L}^{-1} \cdot \mathrm{d}^{-1}$, was studied. The condition with volumetric organic load of $19.20 \mathrm{gDQO} . \mathrm{L}^{-1} \cdot \mathrm{d}^{-1}$ presented the best overall results, reaching organic matter removal efficiency in the form of COD of $85.8 \pm 2.0 \%$ and $99.6 \pm 0.2 \%$ for carbohydrates. The yield of methane generated by organic matter consumed was $13.07 \mathrm{mmolCH}_{4} \cdot \mathrm{gDQO}^{-1}$, within biogas production of $6506 \pm 185 \mathrm{~mL}-\mathrm{CNTP}$. cycle $^{-1}$, with a methane molar fraction equivalent to $73.68 \pm 0,43 \%$. This condition molar productivity of methane achieved $324.0 \mathrm{molCH} 4 . \mathrm{m}^{-3} \cdot \mathrm{d}^{-1}$. It was noticed that the higher organic loads applied lead to loss of efficiency and instability of the reactor. The kinetic model of all conditions was correctly adjusted, indicating that the preferred methane production route was hydrogenotrophic throughout the study period, but the acetoclastic pathway was also observed in all conditions. Changing from batch feeding strategy ( $2 \%$ cycle) to fed batch (50\% cycle) did not improved the efficiency, stability and methane production results in the reactor. The energy recovery was also estimated by estimating the production of a small, medium and large cheese producer. Condition V presented the best results, allowing the recovery of $826.10 \mathrm{MW}$ per day by treating the volume of cheese whey generated in a large industry $\left(1.000 .000 \mathrm{~kg} \cdot \mathrm{month}^{-1}\right)$, while the best overall condition (VIII) recovered 548.40 MW.

Keywords: AnSBBR; Methane; Whey; Termophilic; Methanogenesis.

VERSÃO CORRIGIDA

SÃO CARLOS

FEVEREIRO 2018 


\section{LISTA DE FIGURAS}

Figura 3.1 - Esquema simplificado da digestão anaeróbia

Figura 4.1 - Representação esquemática do reator anaeróbio com agitação operado em batelada sequencial contendo biomassa imobilizada-AnSBBR. 40

Figura 4.2 - Fotografia do aparato experimental (esq.) e reator AnSBBR (dir.). 41

Figura 4.3 - Fotografia da espuma de poliuretano antes (esquerda) e depois (centro) da inoculação além do método de inoculação (direita)

Figura 5.1 - Variação dos parâmetros nas amostras de afluente e efluente durante a etapa I: (a) pH; (b) alcalinidade a bicarbonato; (c) ácidos voláteis totais. .58

Figura 5.2- Concentração da matéria orgânica na forma de DQO (a) e eficiência de remoção da DQO (b) durante a etapa I

Figura 5.3 - Concentração da matéria orgânica na forma de Carboidratos (a) e eficiência de remoção de Carboidratos

(b) durante a Etapa I

Figura 5.4 - Perfis de $\mathrm{pH}($ a), alcalinidade a bicarbonato e a ácidos voláteis totais (b) na condição I 65

Figura 5.5 - Perfis de concentração e eficiência de remoção de DQO (a) e carboidratos (b) na condição I 66

Figura 5.6 - Perfil das concentrações dos compostos intermediários ao longo do ciclo na Condição I.

Figura 5.7 - Perfis de volume nas CNTP de metano e $\mathrm{CO}_{2}(a)$, concentração dos gases e vazão molar (b) e volume e concentração ao longo do ciclo (c) na condição I.

Figura 5.8 - Dados experimentais (marcadores) e modelo (linha) do metano (a), substrato (b) e ácidos intermediários

(c) na Condição I.

Figura 5.9 - Perfis de $\mathrm{pH}($ a), alcalinidade a bicarbonato e a ácidos voláteis totais (b) na condição II 74

Figura 5.10 - Perfis de concentração e eficiência de remoção de DQO (a) e carboidratos (b) na condição II..................75

Figura 5.11 - Perfil das concentrações dos compostos intermediários ao longo do ciclo na condição II ..... .76

Figura 5.12 - Perfis de volume nas CNTP de metano e $\mathrm{CO}_{2}(a)$, concentração dos gases e vazão molar (b) e volume e concentração ao longo do ciclo (c) na condição II. 
Figura 5.13 - Dados experimentais (marcadores) e modelo (linha) do metano (a), substrato (b) e ácidos intermediários

(c) na condição II 79

Figura 5.14 - Perfis de $\mathrm{pH}(a)$, alcalinidade a bicarbonato e a ácidos voláteis totais (b) na condição III .84

Figura 5.15 - Perfis de concentração e eficiência de remoção de DQO (a) e carboidratos (b) na condição III ..... .85

Figura 5.16 - Perfil das concentrações dos compostos intermediários ao longo do ciclo na condição III .86

Figura 5.17 - Perfis de volume nas CNTP de metano e $\mathrm{CO}_{2}(a)$, concentração dos gases e vazão molar (b) e volume e concentração ao longo do ciclo (c) na condição III.

Figura 5.18 - Dados experimentais (marcadores) e modelo (linha) do metano (a), substrato (b) e ácidos intermediários

(c) na condição III .89

Figura 5.19 - Perfis de $\mathrm{pH}(\mathrm{a})$, alcalinidade a bicarbonato e a ácidos voláteis totais (b) na condição IV...... .94

Figura 5.20 - Perfis de concentração e eficiência de remoção de DQO (a) e carboidratos (b) na condição IV. .95

Figura 5.21 - Perfil das concentrações dos compostos intermediários ao longo do ciclo na condição IV ..... 96

Figura 5.22 - Perfis de volume nas CNTP de metano e $\mathrm{CO}_{2}(a)$, concentração dos gases e vazão molar (b) e volume e concentração ao longo do ciclo (c) na condição IV.

Figura 5.23 - Dados experimentais (marcadores) e modelo (linha) do metano (a), substrato (b) e ácidos intermediários

(c) na condição IV.

Figura 5.24 - Perfis de $\mathrm{pH}(a)$, alcalinidade a bicarbonato e a ácidos voláteis totais (b) na condição $\mathrm{V}$...... 104

Figura 5.25 - Perfis de concentração e eficiência de remoção de DQO (a) e carboidratos (b) na condição V. 105

Figura 5.26 - Perfil das concentrações dos compostos intermediários ao longo do ciclo na condição $\mathrm{V}$. 106

Figura 5.27 - Perfis de volume nas CNTP de metano e $\mathrm{CO}_{2}(a)$, concentração dos gases e vazão molar (b) e volume e concentração ao longo do ciclo (c) na condição $\mathrm{V}$.

Figura 5.28 - Dados experimentais (marcadores) e modelo (linha) do metano (a), substrato (b) e ácidos intermediários

(c) na condição $V$....... 109

Figura 5.29 - Perfis de $\mathrm{pH}(a)$, alcalinidade a bicarbonato e a ácidos voláteis totais (b) na condição VI 114

Figura 5.30 - Perfis de concentração e eficiência de remoção de DQO (a) e carboidratos (b) na condição VI. 115

Figura 5.31 - Perfil das concentrações dos compostos intermediários ao longo do ciclo na condição VI 116

Figura 5.32 - Perfis de volume nas CNTP de metano e $\mathrm{CO}_{2}(a)$, concentração dos gases e vazão molar (b) e volume e concentração ao longo do ciclo (c) na condição VI. 
Figura 5.33 - Dados experimentais (marcadores) e modelo (linha) do metano (a), substrato (b) e ácidos intermediários

(c) na condição VI.

Figura 5.34 - Perfis de pH (a), alcalinidade a bicarbonato e a ácidos voláteis totais (b) na condição VII . 124

Figura 5.35 - Perfis de concentração e eficiência de remoção de DQO (a) e carboidratos (b) na condição VII .125

Figura 5.36 - Perfil das concentrações dos compostos intermediários ao longo do ciclo na condição VII ...... 126

Figura 5.37 - Perfis de volume nas CNTP de metano e $\mathrm{CO}_{2}(a)$, concentração dos gases e vazão molar (b) e volume e concentração ao longo do ciclo (c) na condição VII.

Figura 5.38 - Dados experimentais (marcadores) e modelo (linha) do metano (a), substrato (b) e ácidos intermediários

(c) na condição VII. .129

Figura 5.39 - Perfis de pH (a), alcalinidade a bicarbonato e a ácidos voláteis totais (b) na condição VIII 134

Figura 5.40 - Perfis de concentração e eficiência de remoção de DQO (a) e carboidratos (b) na condição VIII .135

Figura 5.41 - Perfil das concentrações dos compostos intermediários ao longo do ciclo na condição VIII 136

Figura 5.42 - Perfis de volume nas CNTP de metano e $\mathrm{CO}_{2}(a)$, concentração dos gases e vazão molar (b) e volume e concentração ao longo do ciclo (c) na condição VIII.

Figura 5.43- Dados experimentais (marcadores) e modelo (linha) do metano (a), substrato (b) e ácidos intermediários

(c) na condição VIII. 139

Figura 5.44 - Perfis de pH (a), alcalinidade a bicarbonato e a ácidos voláteis totais (b) na condição IX...... 144

Figura 5.45 - Perfis de concentração e eficiência de remoção de DQO (a) e carboidratos (b) na condição IX. 145

Figura 5.46 - Perfil das concentrações dos compostos intermediários ao longo do ciclo na condição IX .146

Figura 5.47 - Perfis de volume nas CNTP de metano e $\mathrm{CO}_{2}(a)$, concentração dos gases e vazão molar (b) e volume e concentração ao longo do ciclo (c) na condição IX.

Figura 5.48- Dados experimentais (marcadores) e modelo (linha) do metano (a), substrato (b) e ácidos intermediários

(c) na condição IX. 149

Figura 5.49 - Perfis de $\mathrm{pH}(a)$, alcalinidade a bicarbonato e a ácidos voláteis totais (b) na condição X...... 154

Figura 5.50 - Perfis de concentração e eficiência de remoção de DQO (a) e carboidratos (b) na condição X...... 155

Figura 5.51 - Perfil das concentrações dos compostos intermediários ao longo do ciclo na condição X..... 156

\section{VERSÃO CORRIGIDA}


Figura 5.52 - Perfis de volume nas CNTP de metano e $\mathrm{CO}_{2}(a)$, concentração dos gases e vazão molar (b) e volume e concentração ao longo do ciclo (c) na condição X.

Figura 5.53- Dados experimentais (marcadores) e modelo (linha) do metano (a), substrato (b) e ácidos intermediários

(c) na condição $X$....... 159

Figura 5.54 - Comparação entre o início de operação (Etapa I) e fim de operação (condição XI - Etapa 3) ....... 161

Figura 5.55 - Perfis de $\mathrm{pH}(\mathrm{a})$, alcalinidade a bicarbonato e a ácidos voláteis totais (b) na condição X.... 164

Figura 5.56 - Perfis de concentração e eficiência de remoção de DQO (a) e carboidratos (b) na condição XI ... 165

Figura 5.57 - Perfil das concentrações dos compostos intermediários ao longo do ciclo na condição XI 166

Figura 5.58 - Perfis de volume nas CNTP de metano e $\mathrm{CO}_{2}$ (a), concentração dos gases e vazão molar (b) e volume e concentração ao longo do ciclo (c) na condição XI. 167

Figura 5.59- Dados experimentais (marcadores) e modelo (linha) do metano (a), substrato (b) e ácidos intermediários

(c) na condição XI 169

Figura 5.60 - Dados de $\mathrm{pH}($ (a), alcalinidade a bicarbonato (b) e alcalinidade a ácidos voláteis totais (c) durante a etapa de otimização do reator . 175

Figura 5.61 - Dados de concentração de matéria orgânica na forma de DQO (a) e sua eficiência de remoção (b) na etapa de otimização do reator......

Figura 5.62 - Dados de concentração de matéria orgânica na forma de carboidratos (a) e sua eficiência de remoção (b) na etapa de otimização do reator......

Figura 5.63 - Concentração de sólidos no afluente e efluente na etapa de otimização do reator.

Figura 5.64 - Volume de biogás gerado (a) e composição do biogás (b) durante etapa de otimização do reator 183 Figura 5.65 - Relação entre Carga orgânica volumétrica removida (a), produtividade molar (b) e rendimento molar de metano (c) pela carga orgânica aplicada na forma de DQO 186

Figura 5.66 - Comparação entre dados de $\mathrm{pH}(\mathrm{a})$, alcalinidade a bicarbonato (b) e a ácidos voláteis totais (c) após mudança de estratégia de alimentação 191 Figura 5.67 - Comparação entre dados de concentração de matéria orgânica na forma de DQO (a) e sua eficiência de remoção (b) após mudança de estratégia de alimentação 193

Figura 5.68 - Comparação entre dados de concentração de matéria orgânica na forma de Carboidratos (a) e sua eficiência de remoção (b) após mudança de estratégia de alimentação. 
Figura 5.69 - Comparação entre concentração de sólidos no afluente e efluente após mudança de estratégia de alimentação.

Figura 5.70 - Comparação entre volume de biogás gerado (a) e composição do biogás (b) após mudança de estratégia de alimentação 196

Figura 5.71 - Morfologia dos microrganismos presentes na biomassa imobilizada contida no reator na Condição I: 1000X sem fluorescência (a), 1000X com fluorescência (b).

Figura 5.72 - Morfologia dos microrganismos presentes na biomassa imobilizada contida no reator na Condição III: 1000X sem fluorescência (a), 1000X com fluorescência (b)

Figura 5.73 - Morfologia dos microrganismos presentes na biomassa imobilizada contida no reator na Condição IX: 1000X sem fluorescência (a), 1000X com fluorescência (b) .

Figura 5.74 - Morfologia dos microrganismos presentes na biomassa imobilizada contida no reator na Condição X: 1000X sem fluorescência (a), 1000X com fluorescência (b)

Figura 5.75 - Morfologia dos microrganismos presentes na biomassa imobilizada contida no reator na Condição XI: 1000X sem fluorescência (a), 1000X com fluorescência (b). 


\section{LISTA DE TABELAS}

Tabela 4.1 - Resumo das análises realizadas.

Tabela 4.2 - Ensaios realizados.....

Tabela 5.1 - Resumo dos valores médios obtidos no monitoramento do reator com concentração afluente de $5000 \mathrm{mgDQO} \cdot \mathrm{L}^{-1}$ na condição I.

Tabela 5.2 - Parâmetros cinéticos da rota metabólica ao longo do ciclo na Condição I.

Tabela 5.3 - Resumo dos valores médios obtidos no monitoramento do reator com concentração afluente de $6000 \mathrm{mgDQO} . \mathrm{L}^{-1}$ na condição II.

Tabela 5.4 - Parâmetros cinéticos da rota metabólica ao longo do ciclo na condição II

Tabela 5.5 - Resumo dos valores médios obtidos no monitoramento do reator com concentração afluente de $7000 \mathrm{mgDQO} \mathrm{L}^{-1}$ na condição III.

Tabela 5.6 - Parâmetros cinéticos da rota metabólica ao longo do ciclo na condição III . .88

Tabela 5.7 - Resumo dos valores médios obtidos no monitoramento do reator com concentração afluente de $8500 \mathrm{mgDQO} \cdot \mathrm{L}^{-1}$ na condição IV. .92

Tabela 5.8 - Parâmetros cinéticos da rota metabólica ao longo do ciclo na condição IV. .98

Tabela 5.9 - Resumo dos valores médios obtidos no monitoramento do reator com concentração afluente de $10000 \mathrm{mgDQO} \mathrm{L}^{-1}$ na condição $\mathrm{V}$ 102

Tabela 5.10 - Parâmetros cinéticos da rota metabólica ao longo do ciclo na condição V . 108

Tabela 5.11- Resumo dos valores médios obtidos no monitoramento do reator com concentração afluente de $12000 \mathrm{mgDQO} . \mathrm{L}^{-1}$ na condição VI.

Tabela 5.12 - Parâmetros cinéticos da rota metabólica ao longo do ciclo na condição VI 118

Tabela 5.13 - Resumo dos valores médios obtidos no monitoramento do reator com concentração afluente de $14000 \mathrm{mgDQO} . \mathrm{L}^{-1}$ na condição VII.

Tabela 5.14 - Parâmetros cinéticos da rota metabólica ao longo do ciclo na condição VII .....

Tabela 5.15 - Resumo dos valores médios obtidos no monitoramento do reator com concentração afluente de $16000 \mathrm{mgDQO} . \mathrm{L}^{-1}$ na condição VIII........ 132 
Tabela 5.16 - Parâmetros cinéticos da rota metabólica ao longo do ciclo na condição VIII

Tabela 5.17 - Resumo dos valores médios obtidos no monitoramento do reator com concentração afluente de $18000 \mathrm{mgDQO} \mathrm{L}^{-1}$ na condição IX.

Tabela 5.18 - Parâmetros cinéticos da rota metabólica ao longo do ciclo na condição IX 148

Tabela 5.19 - Resumo dos valores médios obtidos no monitoramento do reator com concentração afluente de $20000 \mathrm{mgDQO} \cdot \mathrm{L}^{-1}$ na condição X.

Tabela 5.20 - Parâmetros cinéticos da rota metabólica ao longo do ciclo na condição X

Tabela 5.21 - Resumo dos valores médios obtidos no monitoramento do reator operado em bateladas sequenciais com concentração afluente de $20000 \mathrm{mgDQO} .^{-1}$ na condição XI.

Tabela 5.22 - Parâmetros cinéticos da rota metabólica ao longo do ciclo na condição XI 168

Tabela 5.23 - Valores médios dos parâmetros e indicadores de desempenho do reator nas diferentes condições de otimização

Tabela 5.24 - Resumo dos parâmetros cinéticos durante a etapa de otimização do reator.....

Tabela 5.25 - Valores médios dos parâmetros e indicadores de desempenho do reator utilizando diferentes estratégias de alimentação 189

Tabela 5.26 - Resumo dos parâmetros cinéticos durante a mudança da estratégia de alimentação 198

Tabela 5.27 - Estimativa da recuperação energética para diferentes escalas de produção de queijo 200

Tabela 5.28 - Resumo da estimativa de aumento de escala e de abastecimento de população equivalente e economia em relação a uso de gás natural e óleo diesel na geração de energia para um grande produtor..... 201

Tabela 5.29 - Resumo da comparação do trabalho com a literatura 209 


\section{LISTA DE SIGLAS E NOMENCLATURAS}

\begin{tabular}{|c|c|}
\hline Abreviatura/Símbolo & Denominação \\
\hline$A M$ & Agitação Mecânica \\
\hline RFL & Recirculação da fase líquida \\
\hline \multirow{3}{*}{$A n S B B R$} & Reator Anaeróbio Operado em Batelada Sequencial com Biomassa \\
\hline & Imobilizada em Suporte Inerte (Anaerobic Sequencing Batch Biofilm Reactor) \\
\hline & Reator Anaeróbio Operado em Batelada Sequencial (Anaerobic Sequencing \\
\hline$A S B R$ & Batch Reactor) \\
\hline$A F B R$ & Reator Anaeróbio de Leito Fluidizado (Anaerobic Fluidized Bed Reactor) \\
\hline CSTR & Reator Anaeróbio de Fluxo Contínuo (Continuous Stirred-Tank Reactor) \\
\hline UASB & Reator Anaeróbio de Fluxo Ascendente (Upflow anaerobic sludge blanket) \\
\hline CNTP & Condições Normais de Temperatura e Pressão $\left(0^{\circ} \mathrm{C}\right.$ e 1atm) \\
\hline DQO & Demanda Química de Oxigênio \\
\hline AVT & Ácidos Voláteis Totais \\
\hline EESC & Escola de Engenharia de São Carlos \\
\hline USP & Universidade de São Paulo \\
\hline IMT & Instituto Mauá de Tecnologia \\
\hline EPS & Exopolissacarídeos \\
\hline
\end{tabular}

VERSÃO CORRIGIDA

SÃO CARLOS

FEVEREIRO 2018 


\begin{tabular}{|c|c|c|}
\hline Símbolo & Denominação & Unidade \\
\hline$V_{u}$ & Volume útil do reator & (L) \\
\hline$V_{R}$ & Volume de meio líquido total no reator & $(L)$ \\
\hline$V_{A}$ & Volume de água residuária alimentado por ciclo & $(L)$ \\
\hline$V_{\text {Res }}$ & Volume de meio líquido residual no reator após a descarga & $(L)$ \\
\hline$t_{c}$ & Tempo de ciclo & (h) \\
\hline$N$ & Número de ciclos por dia & $\left(\right.$ ciclos. $\left.d^{-1}\right)$ \\
\hline$C_{S}$ & Concentração de matéria orgânica afluente na forma de DQO & $\left(m g D Q O \cdot L^{-1}\right)$ \\
\hline$C_{S T}$ & $\begin{array}{l}\text { Concentração de matéria orgânica não filtrada na forma de } \\
\qquad Q Q O\end{array}$ & $\left(m g D Q O \cdot L^{-1}\right)$ \\
\hline$C_{S F}$ & Concentração de matéria orgânica filtrada na forma de DQO & $\left(m g D Q O \cdot L^{-1}\right)$ \\
\hline$\varepsilon_{S T}$ & $\begin{array}{l}\text { Eficiência de remoção da matéria orgânica não filtrada na } \\
\text { forma de DQO }\end{array}$ & (\%) \\
\hline$\varepsilon_{S F}$ & $\begin{array}{l}\text { Eficiência de remoção de matéria orgânica filtrada na forma } \\
\qquad \text { de DQO }\end{array}$ & (\%) \\
\hline$C_{C}$ & $\begin{array}{c}\text { Concentração de matéria orgânica afluente na forma de } \\
\text { carboidratos }\end{array}$ & (mgCarboidrato. $L^{-1}$ ) \\
\hline$C_{C T}$ & $\begin{array}{l}\text { Concentração de matéria orgânica não filtrada na forma de } \\
\text { carboidratos }\end{array}$ & (mgCarboidrato. $L^{-1}$ ) \\
\hline$C_{C F}$ & $\begin{array}{c}\text { Concentração de matéria orgânica filtrada na forma de } \\
\text { Carboidrato }\end{array}$ & (mgCarboidrato. $\left.L^{-1}\right)$ \\
\hline$\varepsilon_{C T}$ & $\begin{array}{l}\text { Eficiência de remoção de matéria orgânica não filtrada na } \\
\text { forma de carboidratos }\end{array}$ & (\%) \\
\hline$\varepsilon_{C F}$ & $\begin{array}{l}\text { Eficiência de remoção de matéria orgânica filtrada na forma } \\
\text { de carboidratos }\end{array}$ & (\%) \\
\hline $\operatorname{COVA}_{S}$ & $\begin{array}{c}\text { Carga orgânica volumétrica aplicada em termos de matéria } \\
\text { orgânica na forma de DQO }\end{array}$ & $\left(g D Q O \cdot L^{-1} \cdot d^{-1}\right)$ \\
\hline$C O E A_{S}$ & $\begin{array}{c}\text { Carga orgânica específica aplicada em termos de matéria } \\
\text { orgânica na forma de DQO }\end{array}$ & $\left(g D Q O . g S V T^{-1} \cdot d^{-1}\right)$ \\
\hline $\mathrm{COVR}_{S}$ & $\begin{array}{c}\text { Carga orgânica volumétrica removida em termos de matéria } \\
\text { orgânica na forma de DQO }\end{array}$ & (\%) $\left(g D Q O \cdot L^{-1} \cdot d^{-1}\right)$ \\
\hline$C O E R_{S}$ & $\begin{array}{c}\text { Carga orgânica específica removida em termos de matéria } \\
\text { orgânica na forma de DQO }\end{array}$ & $\left(g D Q O . g S V T^{1} \cdot d^{-1}\right)$ \\
\hline $\operatorname{COVA} A_{C}$ & $\begin{array}{c}\text { Carga orgânica volumétrica aplicada em termos de matéria } \\
\text { orgânica na forma de carboidratos }\end{array}$ & (gCarboidrato. $L^{-1} \cdot d^{-1}$ ) \\
\hline$C O E A_{C}$ & $\begin{array}{c}\text { Carga orgânica específica aplicada em termos de matéria } \\
\text { orgânica na forma de carboidratos }\end{array}$ & (gCarboidrato.gSVT $T^{-1} \cdot d^{-1}$ ) \\
\hline $\operatorname{COVR}_{C}$ & $\begin{array}{c}\text { Carga orgânica volumétrica removida em termos de matéria } \\
\text { orgânica na forma de carboidratos }\end{array}$ & (gCarboidrato. $L^{-1} \cdot d^{-1}$ ) \\
\hline $\operatorname{COER}_{C}$ & $\begin{array}{c}\text { Carga orgânica específica removida em termos de matéria } \\
\text { orgânica na forma de carboidratos }\end{array}$ & (gCarboidrato.gSVT $T^{-1} \cdot d^{-1}$ ) \\
\hline$p H$ & Potencial hidrogeniônico & (u) \\
\hline$A P$ & Alcalinidade parcial & $\left(m g \mathrm{CaCO}_{3} \cdot L^{-1}\right)$ \\
\hline$A l$ & Alcalinidade intermediária & $\left(m_{g C a C O} \cdot L^{-1}\right)$ \\
\hline$A T$ & Alcalinidade total & $\left(\mathrm{mgCaCO}_{3} \cdot \mathrm{L}^{-1}\right)$ \\
\hline$A B$ & Alcalinidade a bicarbonato & $\left(m_{g C a C O} \cdot L^{-1}\right)$ \\
\hline$A V T$ & Ácidos voláteis totais & $\left(m g H A c \cdot L^{-1}\right)$ \\
\hline $\mathrm{EtOH}$ & Concentração de etanol & $\left(m g \cdot L^{-1}\right)$ \\
\hline ButOH & Concentração de n-butanol & $\left(m g \cdot L^{-1}\right)$ \\
\hline$H A C$ & Concentração de ácido acético & $\left(m g \cdot L^{-1}\right)$ \\
\hline
\end{tabular}




\begin{tabular}{|c|c|c|}
\hline $\mathrm{HPr}$ & Concentração de ácido propiônico & $\left(m g \cdot L^{-1}\right)$ \\
\hline HlsoBut & Concentração de ácido iso-butírico & $\left(m g \cdot L^{-1}\right)$ \\
\hline HBut & Concentração de ácido butírico & $\left(m g \cdot L^{-1}\right)$ \\
\hline HIsoVal & Concentração de ácido iso-valérico & $\left(m g \cdot L^{-1}\right)$ \\
\hline HVal & Concentração de ácido valérico & $\left(m g \cdot L^{-1}\right)$ \\
\hline $\mathrm{HCa}$ & Concentração de ácido capróico & $\left(m g \cdot L^{-1}\right)$ \\
\hline$S T$ & Sólidos totais & $\left(m g \cdot L^{-1}\right)$ \\
\hline$S V T$ & Sólidos voláteis totais & $\left(m g \cdot L^{-1}\right)$ \\
\hline SST & Sólidos suspensos totais & $\left(m g \cdot L^{-1}\right)$ \\
\hline SSV & Sólidos suspensos voláteis & $\left(m g \cdot L^{-1}\right)$ \\
\hline SDT & Sólidos dissolvidos totais & $\left(m g \cdot L^{-1}\right)$ \\
\hline SSF & Sólidos suspensos fixos & $\left(m g \cdot L^{-1}\right)$ \\
\hline$S D V$ & Sólidos dissolvidos voláteis & $\left(m g \cdot L^{-1}\right)$ \\
\hline SDF & Sólidos dissolvidos fixos & $\left(m g \cdot L^{-1}\right)$ \\
\hline$M_{S I+B}$ & Massa de suporte inerte e biomassa do reator & (g) \\
\hline$m_{S I+B}$ & Massa da amostra de suporte inerte e biomassa do reator & (g) \\
\hline$m_{S T}$ & Massa de sólidos totais da amostra de biomassa & (g) \\
\hline$m_{S V T}$ & Massa de sólidos voláteis totais da amostra de biomassa & (g) \\
\hline$M_{S V T}$ & Massa de sólidos voláteis totais no interior do reator & $(g)$ \\
\hline$c_{x}$ & Massa de sólidos voláteis totais por volume de meio líquido & $\left(g . L^{-1}\right)$ \\
\hline$C_{X^{\prime}}$ & $\begin{array}{c}\text { Massa de sólidos voláteis totais por massa de material } \\
\text { Suporte }\end{array}$ & $\left(g \cdot g^{-1}\right)$ \\
\hline$V_{G}$ & Volume de biogás nas CNTP & (mL-CNTP.ciclo $\left.{ }^{-1}\right)$ \\
\hline$V_{C H 4}$ & Volume de metano nas CNTP & $\left(m L-C H 4 C N T P . c i c l o{ }^{-1}\right)$ \\
\hline $\mathrm{C}_{\mathrm{CH} 4}$ & Concentração de metano no biogás & $\left(\mathrm{mmolCH}_{4} \cdot \mathrm{ciclo}^{-1}\right)$ \\
\hline$C_{M}$ & Concentração de metano no meio líquido do reator & $\left(\mathrm{mmolCH} 4 . \mathrm{L}^{-1}\right)$ \\
\hline $\mathrm{C}_{\mathrm{CO} 2}$ & Concentração de gás carbônico no biogás & $\left(\mathrm{mmolCO}_{2} \cdot \mathrm{ciclo}^{-1}\right)$ \\
\hline$X_{C H 4}$ & Percentagem de metano no biogás & (\%) \\
\hline$x_{\mathrm{CO} 2}$ & Percentagem de gás carbônico no biogás & $(\%)$ \\
\hline$P_{a}$ & Pressão do ar no local da medição & (mbar) \\
\hline$P_{V}$ & Pressão parcial de vapor d'água & (mbar) \\
\hline$P_{N}$ & Pressão normal (1013,25 mbar) & (mbar) \\
\hline$T_{N}$ & Temperatura normal $(273,15 \mathrm{~K})$ & (K) \\
\hline$T_{a}$ & Temperatura no local da medição & (K) \\
\hline$n_{C H 4}$ & Vazão molar diária de metano & $\left(\mathrm{mmolCH}_{4} \cdot d^{-1}\right)$ \\
\hline PrM & Produtividade molar de metano volumétrica & $\left(\mathrm{molCH}_{4} \cdot \mathrm{m}^{-3} \cdot d^{-1}\right)$ \\
\hline PrME & Produtividade molar de metano específica & $\left(\mathrm{molCH}_{4} \cdot \mathrm{kgSVT}^{-1} \cdot d^{-1}\right)$ \\
\hline $\operatorname{PrV}$ & Produtividade volumétrica de metano volumétrica & $\left(\mathrm{molCH} 4 \cdot m^{-3} \cdot d^{-1}\right)$ \\
\hline
\end{tabular}

\section{VERSÃO CORRIGIDA}




\section{SUMÁRIO}

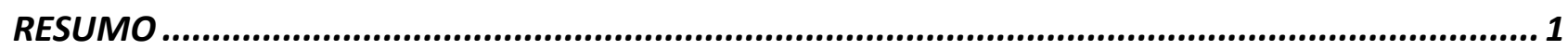

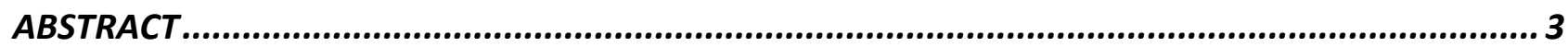

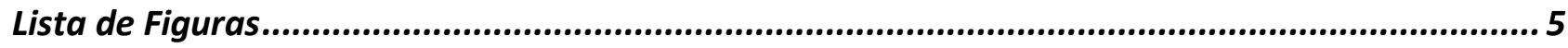

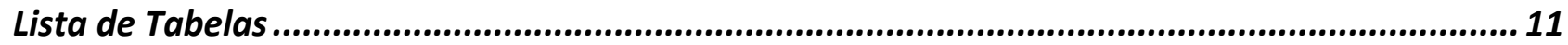

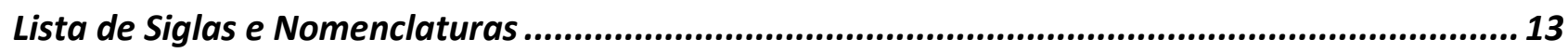

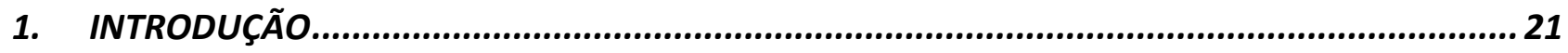

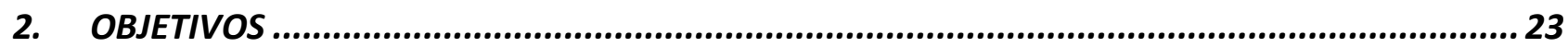

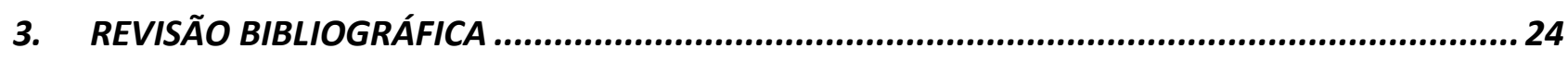

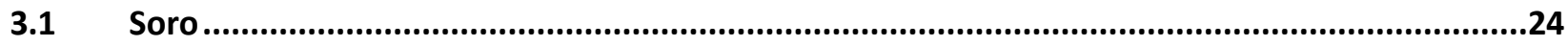

3.2 Reatores anaeróbios operados em batelada e/ou batelada alimentada sequenciais.................26

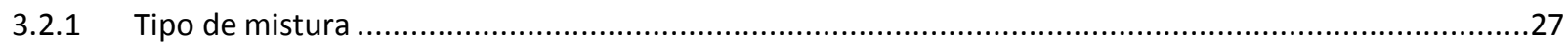

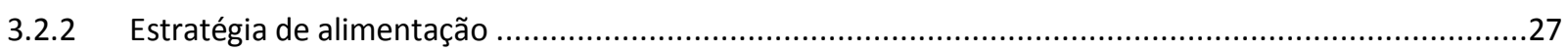

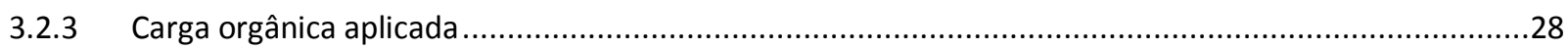

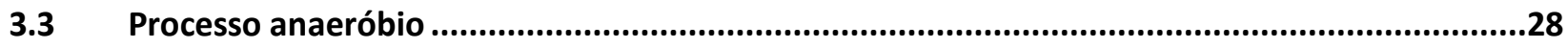

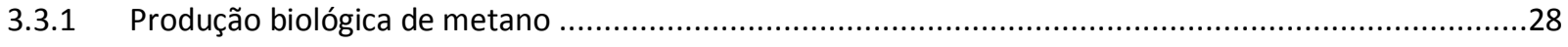

3.3.2 Influências de variáveis de processo sobre o desempenho ......................................................30

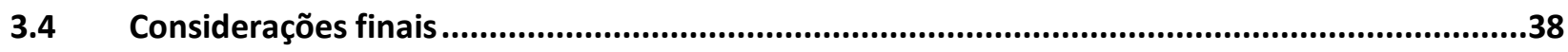

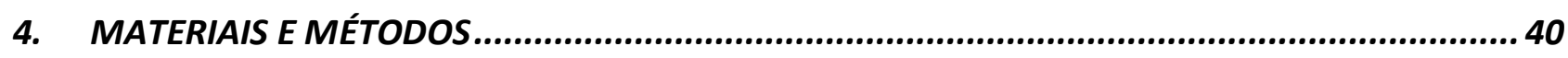

Configuração do reator.........................................................................................40

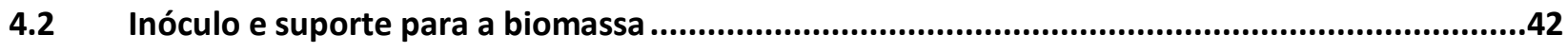




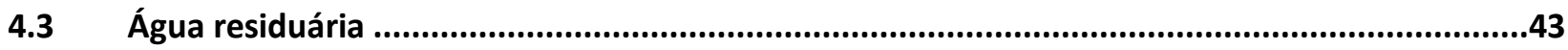

4.4 Análises físico-químicas e exame microbiológico .......................................................................43

4.5 Fundamentos teóricos dos indicadores de desempenho do reator ...........................................48

4.6 Fundamentos teóricos do modelo cinético do reator ...................................................................50

4.7 Fundamentos teóricos para estimativa de aumento de escala ...............................................53

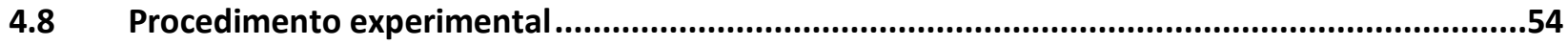

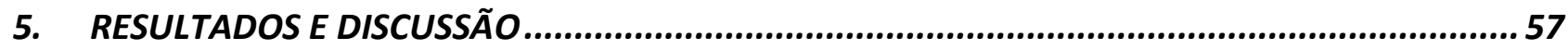

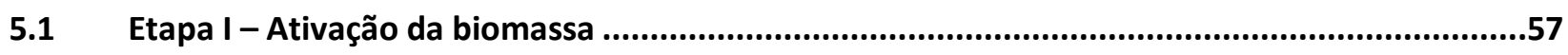

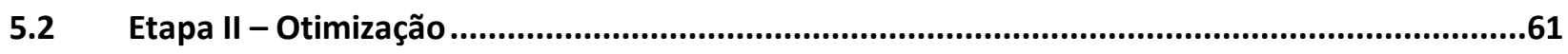

5.2.1 Condição I - 5.000 mg DQO L ${ }^{-1} ; 100 \%$ Soro; 50\% de bicarbonato; 55ㅇ C; Batelada ..............................61

5.2.2 Condição II $-6.000 \mathrm{mg} \mathrm{DQO} \mathrm{L}^{-1} ; 100 \%$ Soro; 50 a 33 \% de bicarbonato; 55으 C; Batelada .......................70

5.2.3 Condição III - $7.000 \mathrm{mg} \mathrm{DQO} \mathrm{L}^{-1}$; $100 \%$ Soro; 50 a $25 \%$ de bicarbonato; 55 o C; Batelada .......................79

5.2.4 Condição IV - 8.500 mg DQO L ${ }^{-1} ; 100 \%$ Soro; 25 a 20\% de bicarbonato; 55o C; Batelada.......................89

5.2.5 Condição V - $10.000 \mathrm{mg} \mathrm{DQO} \mathrm{L}^{-1}$; 100\% Soro; 20\% de bicarbonato; 55으 C; Batelada ............................99

5.2.6 Condição VI - $12.000 \mathrm{mg} \mathrm{DQO} \mathrm{L}{ }^{-1} ; 100 \%$ Soro; $20 \%$ de bicarbonato; 55ㅇ C; Batelada ..........................109

5.2.7 Condição VII - 14.000 mg DQO L ${ }^{-1} ; 100 \%$ Soro; 50\% de bicarbonato; 55 C; Batelada .........................119

5.2.8 Condição VIII - 16.000 mg DQO L ${ }^{-1}$; 100\% Soro; 50\% de bicarbonato; 55ㅇ C; Batelada ........................129

5.2.9 Condição IX - $18.000 \mathrm{mg} \mathrm{DQO} \mathrm{L}^{-1}$; 100\% Soro; 50\% de bicarbonato; 55 C; Batelada ..........................139

5.2.10 Condição X - $20.000 \mathrm{mg} \mathrm{DQO} \mathrm{L}^{-1}$; $100 \%$ Soro; 50\% de bicarbonato; 55o C; Batelada.......................149

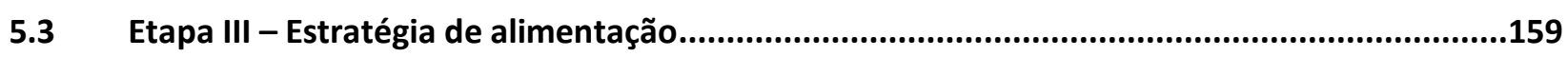

5.3.1 Condição XI - 20.000 mg DQO L ${ }^{-1}$; $100 \%$ Soro; 50\% de bicarbonato; 55o C; Batelada Alimentada ........159

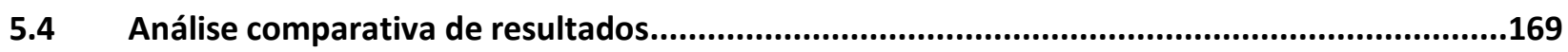

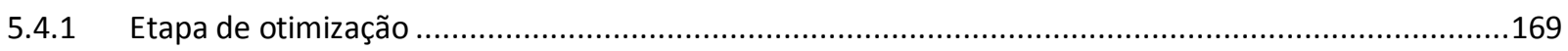

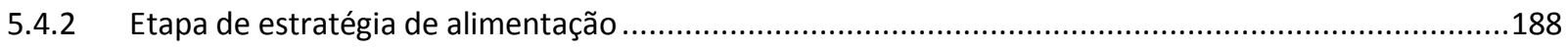


5.5 Estimativa de produção energética 198

5.6 Análise microbiológica .203

5.7 Comparação com a literatura . .207

6. CONCLUSÕES 210

7. SUGESTÕES PARA TRABALHOS FUTUROS 213

Referências Bibliográficas 214

VERSÃO CORRIGIDA 


\section{INTRODUÇÃO}

Os efluentes não podem ser mais considerados como resíduos da atividade humana e sim como fontes renováveis de energia. Atualmente, uma das formas mais viáveis de recuperar recursos destes efluentes é a produção de energia pelos produtos da digestão anaeróbia, $\mathrm{H}_{2}$ e $\mathrm{CH}_{4}$.

É sobre este contexto que se destaca o tratamento anaeróbio de efluentes da atividade humana. O tratamento anaeróbio é reconhecido como um processo eficaz no tratamento de águas residuárias com alto potencial poluidor. Dentre os vários efluentes utilizáveis, destaca-se o potencial do soro, um subproduto da indústria de laticínios. O soro, ou soro de queijo, ou de leite, é a parte aquosa que é separada no processo de fabricação de queijo. É o maior subproduto da indústria de laticínios e, devido à sua alta carga orgânica (de 2 a $70 \mathrm{~g} \mathrm{DQO} \mathrm{L} \mathrm{L}^{-1}$, dependendo do processo produtivo e produto final) (BEZERRA et al., 2007), possui alto potencial poluidor, podendo causar depleção da concentração de oxigênio se disposto de maneira direta em corpos hídricos (LOVATO et al., 2016). Quanto maior a carga orgânica aplicada, maior a formação de metano. Sendo assim, por ser uma água residuária rica em matéria orgânica, o soro tem alto potencial para a geração de metano pela atividade biológica anaeróbia.

Os reatores podem ser operados de modo contínuo, descontínuo (batelada) ou em batelada alimentada. Os reatores operados em batelada e/ou batelada alimentada sequenciais (ASBR ou AnSBBR) possuem maior controle do processo, resultando numa maior segurança em sua operação. Estes reatores podem ser utilizados para o tratamento das águas residuárias citadas anteriormente. As etapas de operação desses reatores consistem, inicialmente, da alimentação (batelada alimentada ou batelada, caso o tempo de enchimento em relação ao tempo de ciclo seja ou não significativo), do tratamento em si pelas biotransformações dos substratos contidos na água residuárias pelo metabolismo dos microrganismos, da sedimentação da biomassa (não necessária quando a biomassa 
se encontra imobilizada em suporte inerte - AnSBBR), e da descarga (ZAIAT et al., 2001). Esta configuração de reator é definida como descontínua, isto é, não há alimentação contínua de substrato no reator, sendo a alimentação caracterizada por enchimentos e descartes cíclicos, com tempo de ciclo pré-definido. Uma das principais vantagens deste tipo de configuração é sua flexibilidade de operação, além de sua segurança e o maior controle sobre a qualidade do efluente (LOVATO et al., 2016).

Nesse contexto, o objetivo desse trabalho foi avaliar a viabilidade da aplicação do biorreator AnSBBR para a produção de metano pela digestão do soro em condição termofílica. Dessa forma, o estudo esteve relacionado ao entendimento de aspectos fundamentais e tecnológicos, destacando-se o direcionamento para aspectos de otimização visando gerar conhecimento para a implementação em escala plena. A escolha desse biorreator e do protocolo experimental é justificada na opção de investigação da operação descontínua, a qual beneficia processos industriais com produção intermitente, como a de soro (ZIMMER et al., 2008), aplicada como uma alternativa à operação contínua, utilizada de modo mais frequente (DAMASCENO et al., 2008). Assim, foi possível avaliar as principais vantagens do controle operacional (carga, reação e descarga), da flexibilidade referente à concentração e estratégia de alimentação (carga orgânica e tempos de enchimento e de ciclo). Adicionalmente, foi possível avaliar as limitações referentes à possibilidade de sobrecarga (inibição microbiológica) devido à operação sequencial de carga e descarga, além do inerente comportamento transiente do modo descontínuo. 


\section{OBJETIVOS}

Esse projeto teve como objetivo geral principal avaliar o desempenho de um reator anaeróbio operado em batelada e/ou batelada alimentada sequenciais contendo biomassa imobilizada em suporte inerte (espuma de poliuretano) e agitação mecânica (AnSBBR) em condição termofílica $\left(55^{\circ} \mathrm{C}\right)$, visando a produção de metano a partir da digestão de soro, além da adequação ambiental deste resíduo.

Este desempenho do biorreator foi verificado por indicadores relacionados à remoção de matéria orgânica (na forma de DQO e carboidratos), estabilidade operacional (compostos intermediários do metabolismo anaeróbio), produtividade e composição do biogás (geração de metano), e do rendimento entre metano gerado e matéria orgânica consumida. Além disso, os aspectos de entendimento das rotas metabólicas anaeróbias foram estudados pelo ajuste de um modelo cinético matemático e pela estimativa da geração de metano e água de reúso, respectivamente.

Dessa forma, como objetivos específicos, foi avaliada a influência das seguintes variáveis de processo sobre os indicadores de desempenho citados:

(i) concentração afluente (máxima carga orgânica aplicável);

(ii) estratégia de alimentação (batelada e/ou batelada alimentada com carga orgânica constante); 


\section{REVISÃO BIBLIOGRÁFICA}

\subsection{Soro}

A indústria de laticínios é uma das maiores industriais alimentícias do Brasil. Por este motivo, a quantidade de subprodutos originários desta indústria segue tal proporção. Dentre os resíduos gerados nesse tipo de indústria, destaca-se o soro de queijo (ou simplesmente soro), água residuária formada em maior quantidade, que é resultante do processo de produção de queijos.

O soro é caracterizado por sua alta carga orgânica, que pode variar de 2 a 80 gDQO L ${ }^{-1}$ dependendo do processo produtivo. Sendo assim, o potencial poluidor deste resíduo também é bastante alto. Tendo em vista que grande parte dos laticínios brasileiros é de pequeno porte, é criada uma dificuldade no tratamento deste tipo de água residuária devido ao seu custo financeiro. Por este motivo, por vezes, o soro é despejado diretamente em corpos hídricos, causando problemas ambientais como a depleção da quantidade de oxigênio no corpo receptor (BEZERRA et al., 2007; LOVATO et al., 2016).

A geração do soro provém da coagulação do leite e redução de seu pH para a produção de queijos. Este processo gera um líquido com aspecto esverdeado e sabor que varia de acordo com o processo de coagulação ao qual o leite foi submetido (MAWSON, 1994; DAMASCENO, 2004). Este efluente é gerado numa proporção próxima de 80-90\% do volume de leite utilizado. Dados da ABIQ (Associação Brasileira das Indústrias de Queijo), fornecidos em 2010, indicam que a produção de queijos no Brasil, neste período, foi próxima de 745 mil toneladas.

A composição do soro varia conforme a produção, mas consiste basicamente de lactose, proteínas, gordura e minerais. Por causa disto, pode ser considerado como uma matéria-prima para 
nutrição animal ou humana, concentração e secagem e produção de lactose e proteínas (SCOTT et al., 1998; BRAILE E CAVALCANTI, 1993). Apesar disso, estes processos podem ser bastantes custosos para produtores de pequeno e médio porte. Sendo assim, o destino final desta agua residuária acaba sendo seu despejo sem reaproveitamento, condição não ideal. Uma possibilidade de despejo desse contaminante é a disposição no solo, atuando como recondicionante e fertilizante (JONES et al., 1993). Este procedimento tem se tornado mais restrito devido à possíveis problemas de transporte desse contaminante até corpos hídricos, segundo Scott et al. (1998). Estes autores indicam algumas outras possibilidades de utilização do soro, como a adição em pães e outros alimentos, aumentando seu valor nutritivo, precipitação de proteínas, produção de queijos de soro, como a ricota, ou até a fabricação de ácidos lático e propiônico, utilizáveis na indústria de alimentos, dentre outros.

Dentre as alternativas de tratamento do soro, destaca-se a digestão anaeróbia para recuperação de energia por meio da geração e utilização de metano e hidrogênio devido à sua alta carga orgânica. Entretanto, o soro tem algumas outras características que dificultam este processo, como baixa alcalinidade e alta biodegradabilidade (cerca de 99\%), o que faz com que haja acidificação muito rápida do reator. O soro ainda causa dificuldade na granulação da biomassa além de possibilitar a formação de um material polimérico viscoso que dificulta a sedimentação do lodo, dificultando a operação (YAN et al, 1988; HICKEY, 1991; PODLECH et al., 1991; MALASPINA et al., 1996).

A baixa alcalinidade do soro, aliada à rápida conversão da lactose em ácidos voláteis, faz com que haja o consumo da alcalinidade do sistema. Por este motivo, é necessária a suplementação de alcalinizante e controle do $\mathrm{pH}$ constante (WILDENAUER \& WINTER,1985; LO \& LIAO, 1986; BACKUS et al, 1988.). Bezerra et al. (2007) estudaram a suplementação de bicarbonato num

\section{VERSÃO CORRIGIDA}


reator $\mathrm{AnSBBR}$ operado a $30^{\circ} \mathrm{C}$ com recirculação da fase líquida. Os autores estudaram a suplementação com 100, 50 e $25 \%$ de bicarbonato (relação mg- $\mathrm{NaHCO}_{3} / \mathrm{mg}-\mathrm{DQO}$ ), com carga afluente constante de 6 gDQO L ${ }^{-1} \mathrm{~d}^{-1}$. Com $100 \%$ de relação o reator apresentou baixa eficiência. Ao se reduzir para $50 \%$ a relação, houve ganho de estabilidade e desempenho. Quando promovido o abaixamento da relação para $25 \%$ houve nova queda de desempenho. Ratusznei et al. (2003) observaram que a suplementação de alcalinidade deve ser superior durante a partida do reator, mas que pode ser reduzida após este período. Os autores utilizaram aproximadamente 20 a $30 \%$ de suplementação durante a partida, reduzindo até 10\%, mantendo-se a estabilidade e eficiência.

\subsection{Reatores anaeróbios operados em batelada e/ou batelada alimentada sequenciais}

Os reatores biológicos de maior destaque no tratamento biológico de soro são os reatores UASB, reatores em duas fases (uma acidogênica sucedida por uma metanogênica) e os reatores em batelada, ASBR e AnSBBR, este último, tema de enfoque deste projeto.

Reatores anaeróbios operados em bateladas sequenciais tem se mostrado uma excelente alternativa aos reatores contínuos. Sua facilidade de operação, aliado à sua flexibilidade operacional, tem mostrado grande potencial no tratamento anaeróbio de águas residuárias. É notável o crescimento na produção científica utilizando esta configuração de reator nos últimos anos.

Além disso, Zaiat et al. (2001) indicam que os reatores em batelada são apropriados para indústrias que geram efluentes de maneira descontínua ou que trabalham com padrões de lançamento mais restritivos. Além disso, também indicam esta configuração quando se tem a finalidade de reutilizar a agua residuária tratada, ou substancias que a compõem, haja vista que esses reatores permitem maior controle operacional. Ainda sobre sua aplicabilidade, os autores 
indicam que estes reatores são vantajosos quando se deseja aprofundar estudos sobre a digestão anaeróbia, uma vez que permitem maior controle e facilidade de instrumentação.

Os reatores operados em bateladas sequencias podem ter biomassa em suspensão (ASBR) ou imobilizada em suporte inerte (AnSBBR). O ciclo deste tipo de reator compreende de quatro etapas: inicialmente, da alimentação (batelada alimentada ou batelada, caso o tempo de enchimento em relação ao tempo de ciclo seja ou não significativo, respectivamente); do tratamento em si pelas biotransformações dos substratos contidos na água residuárias através do metabolismo dos microrganismos; da sedimentação da biomassa (não necessária quando a biomassa se encontra imobilizada em suporte inerte); e da descarga (ZAIAT et al., 2001).

Quanto ao desempenho do reator biológico, diversas variáveis de processo interferem sobre sua estabilidade, como mostrado a seguir.

\subsubsection{Tipo de mistura}

A agitação de um reator pode ser realizada de três diferentes maneiras: agitação mecânica (MICHELAN et al., 2009; NOVAES et al., 2010; SILVA et al., 2013; LULLIO et al., 2014), recirculação da fase líquida (BEZERRA et al., 2009; LOVATO et al., 2016) ou da fase gasosa, cada qual com suas vantagens e limitações. É interessante destacar que apesar de possível, a recirculação da fase gasosa pode gerar problemas como a liberação de ácidos voláteis presentes na solução ou a pouca mistura proporcionada, que pode ser insuficiente no caso de pouca produção de gás, como quando se utiliza substratos com baixa carga orgânica (ZAIAT et al., 2001);

\subsubsection{Estratégia de alimentação}

Esta característica influencia no comportamento dos reatores anaeróbios operados em batelada ou bateladas sequenciais pois variações no tempo de enchimento permitem amortecer o 
efeito de maiores cargas orgânicas ou variações significativas delas, uma vez que as concentrações podem ser mantidas em valores reduzidos no interior do reator como decorrência do controle da vazão afluente, ou seja, o efeito da inibição é minimizado (RODRIGUES et al., 2011).

\subsubsection{Carga orgânica aplicada}

Este fator é relevante pois quanto maior a disponibilidade de substrato para a comunidade acidogênica, maior a produção de ácidos e, consequentemente, maior a disponibilidade de acetato. Quando maior a concentração de acetato, maior produção de metano via rota acetoclástica, sendo, entretanto, necessário o conhecimento do limite metabólico do reator em assimilar a matéria orgânica disponibilizada na alimentação para manter a estabilidade do sistema (BEZERRA et al., 2009).

Na literatura atual, é cada vez mais comum a utilização desta configuração de reator na produção de metano ou hidrogênio pela viabilização da produção de bioenergia gerada a partir do tratamento de diversas águas residuárias, como vinhaça, soro, esgoto doméstico, efluente da produção de biodiesel e efluentes industriais ou até para remoção de sulfatos (SARTI et al., 2008; BEZERRA et al., 2009 e 2011; OLIVEIRA et al., 2009; RODRIGUES et al., 2011; LOVATO et al., 2012; ALBANEZ et al., 2016a; LIMA et al., 2016).

\subsection{Processo anaeróbio}

\subsubsection{Produção biológica de metano}

A digestão anaeróbia é um processo biológico natural que ocorre na ausência de oxigênio molecular, no qual diversos microrganismos interagem estritamente para promover a fermentação estável e auto-regulada da matéria orgânica, da qual resultam os gases metano e dióxido de 
carbono. Os microrganismos responsáveis pela produção de metano são conhecidos como arqueias metanogênicas. Estes microrganismos atuam na etapa final da decomposição da matéria orgânica, sendo encontradas abundantemente em pântanos, biodigestores, aterros sanitários e sistemas de tratamento de resíduos. A produção de metano segue um balanço de massa global através do qual é possível se estimar a quantidade de gás a ser produzido após a conversão da matéria orgânica. A equação é apresentada a seguir (MCCARTY, 1982; MOSEY, 1983).

$$
C_{n} H_{a} O_{b}+\left(n-\frac{a}{4}-\frac{b}{2}\right) H_{2} O=\left(\frac{n}{2}-\frac{a}{8}+\frac{b}{4}\right) C O_{2}+\left(\frac{n}{2}+\frac{a}{8}-\frac{b}{4}\right) C H_{4}
$$

A metanogênese é realizada em etapas sequenciais de atividades microbiológicas: hidrólise e acidogênese, acetogênese e metanogênese, explicadas sucintamente. Na primeira etapa, compostos orgânicos complexos são quebrados em compostos mais simples, tornando-se assimiláveis à comunidade bacteriana. Sucessivamente, as bactérias utilizarão os compostos formados na primeira etapa para a formação de ácidos acético, lático, butírico e propiônico, com ou sem liberação de gás $\mathrm{H}_{2}$ Esta etapa é realizada pelas bactérias hidrolíticas fermentativas. Na acetogênese, bactérias acetogênicas são capazes de transformar alguns ácidos voláteis (butírico e propiônico) em acetato, hidrogênio e dióxido de carbono. As comunidades responsáveis por essa etapa são as bactérias acetogênicas produtoras de hidrogênio e também as bactérias acetogênicas consumidoras de hidrogênio, que são capazes de transformar o $\mathrm{H}_{2}$ e $\mathrm{CO}_{2}$ em acetato. A última etapa, metanogênese, consiste na transformação dos compostos gerados anteriormente em metano propriamente dito e dióxido de carbono (MCCARTY, 1982; STAMS et al., 2009; LOVATO et al, 2015).

A Figura 3.1 a seguir ilustra a digestão anaeróbia através de um esquema simplificado. 


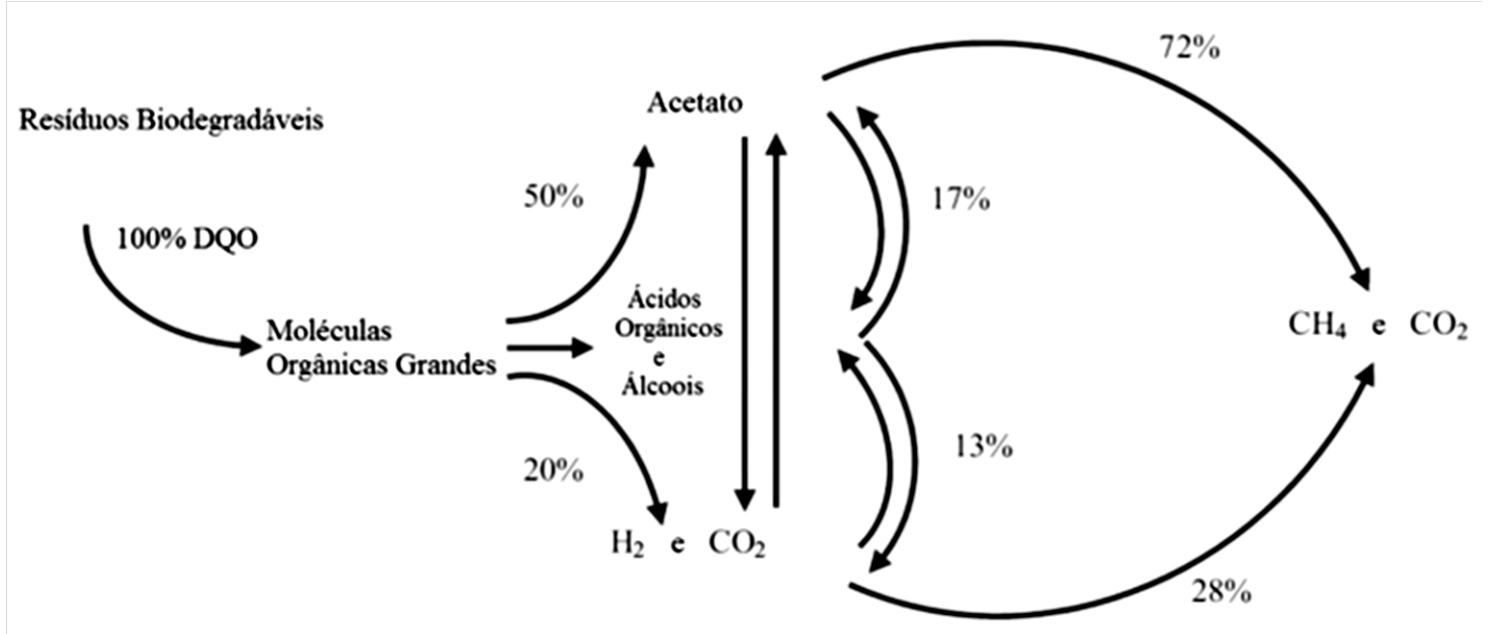

Figura 3.1 - Esquema simplificado da digestão anaeróbia

Fonte: Chandra et al. (2012), adaptado de MCCARTY (1964).

\subsubsection{Influências de variáveis de processo sobre o desempenho}

A atividade metanogênica é afetada por diversos fatores operacionais, podendo-se destacar: a configuração dos reatores, tipo de inóculo, o tipo de resíduo, a carga orgânica afluente, tempo de reação (tempo de residência para reatores contínuos e tempo de ciclo para reatores descontínuos), estratégia de alimentação, temperatura.

\subsubsection{Tipo de inóculo}

A comunidade responsável pela formação de metano é composta pelas chamadas arqueias metanogênicas, que já foram classificadas como bactérias. A diferença principal é a presença de membranas lipídicas e ausência de compostos presentes nas bactérias, como o peptidioglicano. Estritamente anaeróbias por não suportarem a presença de oxigênio, as arqueias metanogênicas são consideradas a espécie limitante da produção de metano, uma vez que a velocidade de crescimento da comunidade metanogênica é muito menor do que a da comunidade acidogênica. Os microrganismos metanogênicos são mais comumente encontrados em ambientes anaeróbios com 
grande disposição de matérias orgânica, como brejos, pântanos, lagoas e sedimentos marinhos e fluviais (LOVATO, ALBANEZ e FONTES LIMA et al, 2015).

Apesar de não haver necessidade de executar pré-tratamento do inóculo quando se deseja a produção de metano, diferentemente da produção de hidrogênio, há que se ter um cuidado maior durante a inoculação de um reator metanogênico, uma vez que a comunidade metanogênica é bastante sensível e possui tempo de duplicação grande. Deve-se atentar à inoculação de um reator anaeróbio, promovendo aumento gradual de carga e temperatura, tornando mais fácil a adaptação e o crescimento das arquéias metanogênicas ao longo do tempo, formando, assim, uma comunidade estável e eficiente.

Quando o objetivo do reator anaeróbio é a produção de hidrogênio, há a necessidade de promover o pré-tratamento do inóculo para selecionar uma comunidade específica, uma vez que, o hidrogênio é um produto intermediário da metanogênese. Sendo assim, se vê necessário interromper este processo para que o hidrogênio não seja consumido. Dentre as diversas alternativas de tratamento de inóculo, as mais comuns são: térmico, ácido, básico, químico ou com aeração sucessiva (GIOANNIS et al, 2013).

\subsubsection{Tipo de biomassa}

Dentre os diferentes tipos de reatores, o tipo de biomassa mais comum é a em suspensão, que pode ser granular ou floculenta. Nestes reatores, os fatores mais importantes sobre o desempenho do reator são a relação S/X (relação entre concentração de substrato e de biomassa), a configuração geométrica e a estratégia de alimentação (ZAIAT et al, 2001).

A relação S/X influencia fortemente a granulação da biomassa, tornando-a um fator de grande importância para os reatores com biomassa em suspensão. Relação baixa de S/X facilita a 
formação de grânulos, resultando em maior manutenção da biomassa no reator, uma vez que aumenta a sedimentabilidade da biomassa. Isso facilita a partida do reator, dificultando a sua lavagem no início de operação. Quando a relação $\mathrm{S} / \mathrm{X}$ é alta, há interferência sobre a remoção de matéria orgânica, já que pode ocorrer inibição da comunidade pelo excesso de substrato e também pela má sedimentação, processo muito importante para a remoção de matéria orgânica (ZAIAT et al., 2001; HAWKINS et al., 2001).

A configuração geométrica tem papel importante nas características da biomassa, influenciando a granulação e até a seleção de microrganismos (SUNG \& DAGUE, 1995). A relação do fator S/X com a retenção de sólidos e a estratégia de alimentação, afeta todo o desempenho do reator. Quando o reator opera em batelada convencional, há grande aumento de carga no início da operação do reator, diminuindo ao longo do tempo, devido ao consumo e ao fator de diluição. Isso favorece grande produção de biogás no início de operação, com baixa formação em seu período final, facilitando a sedimentação da biomassa no interior do reator.

Devido ao fator de diluição ao durante o longo período de enchimento, quando o reator opera em batelada alimentada, o fluxo contínuo de alimentação faz com que as concentrações sejam mantidas baixas durante todo o ciclo, o que favorece o tratamento biológico quando há a presença de compostos inibidores na água residuária, ou então quando a carga aplicada é muito grande. (RODRIGUES et al, 2011)

Uma mudança de grande importância na aplicação de reatores anaeróbios foi a imobilização da biomassa. Quando comparada com a configuração convencional (em suspensão), segundo Ratusznei et al. (2000), a imobilização melhora a retenção de sólidos e não requer a formação de grânulos nem a etapa de sedimentação, o que leva a um tempo de operação menor. Por outro lado, uma desvantagem dos sistemas com biomassa imobilizada é a dificuldade de transferência de 
massa, que pode ser remediada por meio de recirculação (RAMOS et al., 2003) ou agitação adequada, que facilita o contato entre substrato e biomassa (DAMASCENO et al., 2008).

Quanto ao material suporte da biomassa imobilizada, um estudo realizado por Garcia et al. (2008) testou quatro diferentes tipos de materiais suporte, sendo eles: espuma de poliuretano, carvão vegetal, pomes sintética e polietileno de baixa densidade reciclado em um reator AnSBBR. Os autores analisaram os materiais suportes através de testes relacionados à remoção de matéria orgânica, retenção de sólidos e diversidade microbiológica no material suporte. Os resultados indicaram a espuma de poliuretano como o material mais indicado, entretanto, os autores apontam que o polietileno de baixa densidade constitui de uma boa alternativa haja vista que apresentou maior aderência e diversidade da comunidade metanogênica.

Sarti et al. (2006) testaram dois reatores anaeróbios contendo diferentes tipos de biomassa. O reator contendo biomassa granular apresentou formação de metano mais rapidamente do que o reator que continha biomassa imibilizada. Os autores analisaram a comunidade microbiana contida no interior de ambos os reatores nos dias 35 e 70 de operação. Os autores observaram que a comunidade mudou no reator com biomassa imobilizada e atribuíram essa diferença à seleção da comunidade aderida ao meio suporte. A comunidade relacionada às arquéias metanogênicas foi similar em ambos os reatores, possivelmente pelo uso de substratos específicos no processo anaeróbio.

\subsubsection{Carga Orgânica}

De uma maneira geral, os estudos realizados entre o aumento da carga orgânica aplicada e a produtividade/produção de metano, indicam que há um aumento proporcional do biogás quanto maior a carga aplicada. A variação da carga aplicada pode ocorrer de duas formas, através do

\section{VERSÃO CORRIGIDA}


aumento da concentração afluente de DQO ou então por meio da mudança na estratégia de alimentação.

Bezerra et al. (2007) estudaram a produção de metano a partir da aplicação de 3, 6 e 12 g DQO $\mathrm{L}^{-1} \mathrm{~d}^{-1}$ em AnSBBR com recirculação tratando soro. Os resultados indicaram que, quanto maior a carga aplicada, maior foi a formação de metano. Segundo os autores, o aumento da carga resulta num aumento do substrato disponível e, portanto, aumento da produção de ácidos. Isto aumenta a disponibilidade de acetato para a comunidade metanogênica, aumentando a produção de metano.

Mockaitis et al. (2006) estudaram o aumento carga orgânica e a diminuição da suplementação de alcalinidade num reator ASBR agitado mecanicamente tratando soro. O reator operou em ciclos de 8 horas com concentração afluente de $0,5,1,2$ e 4 g DQO L ${ }^{-1}$ a $30^{\circ} \mathrm{C}$. Os resultados indicaram que, quanto maior a carga aplicada, maior foi a produção de biogás. Os resultados também indicaram que, houve um período em que a taxa de produção de biogás foi muito alta, com redução no período final. Além disso, os autores verificaram que, quanto maior a carga, menor foi o período com redução da taxa de produção de biogás, indicando a possibilidade de necessidade de aumento no tempo de ciclo do reator.

\subsubsection{Tempo de ciclo e estratégia de alimentação}

O tempo de ciclo tem grande influência em reatores produtores de metano uma vez que a comunidade metanogênica tem tempo de crescimento pequeno se comparado à comunidade acidogênica. (Lettinga e Haandel, 1993), sendo assim, ciclos mais curtos tendem a privilegiar as acidogênicas e, consequentemente, a produção de hidrogênio. Enquanto que ciclos maiores tendem a ajudar a metanogênese. Além disso, segundo Kumar (2008), outro fator que influencia na produção de metano e hidrogênio é o efeito da diluição da carga orgânica afluente. 
Em geral, reatores aplicados para a produção de metano operam com tempo de ciclo de 4, 6, 8, 12 e 24 horas, com maior tendência para o tempo de ciclo de 8 horas. Lullio et al. (2014), estudaram, em um reator AnSBBR, a influência do tempo de ciclo tratando sacarose. Os testes envolveram a aplicação de 8 e 12 horas de ciclo. A maior produção molar de metano foi alcançada quando o tempo de ciclo menor foi empregado. Os autores também alimentaram o reator com efluente de um reator acidogênico alimentado com sacarose, aplicando ciclos de 6 e 8 horas. Novamente, os melhores resultados foram obtidos com o ciclo de 8 horas. Oliveira et al. (2009), tratando efluente da indústria de higiene pessoal e Silva et al. (2013) tratando glicerina de uma indústria de biodiesel, ambos utilizando reator ASBR, também alcançaram melhores resultados quando aplicaram tempo de ciclo de 8 horas.

Damasceno et al. (2007), testaram a aplicação de 2, 4, 8 e 12 g DQO L ${ }^{-1}$ a $30{ }^{\circ} \mathrm{C}$ com 500 rpm de rotação. Os autores estudaram, além da carga, a aplicação de diferentes estratégias de alimentação em um reator AnSBBR tratando soro. Os resultados mostraram que um ciclo de 2 horas de batelada alimentada, seguindo de 6 horas de reação, foi positivo na aplicação nas cargas de 2 e 4 g DQO L ${ }^{-1}$. Para as duas maiores cargas avaliadas, a mesma estratégia de alimentação apresentou resultados um pouco piores, enquanto que a alimentação por 4 horas, seguida de 4 horas de reação alcançou melhores resultados para as cargas de 8 e $12 \mathrm{~g} \mathrm{DQO} \mathrm{L}^{-1}$.

Bezerra. et al. (2009) estudaram o comportamento de um reator AnSBBR tratando soro com cargas orgânicas aplicadas de 3, 6 e $12 \mathrm{~g} \mathrm{DQO} \mathrm{L}^{-1}$ e com tempo de alimentação de 2, 4 e 6 horas e tempo de ciclo de 8 horas para todas as condições. Os resultados obtidos indicaram que, para a menor carga aplicada, o tempo de alimentação pouco influenciou na eficiência do reator. Já para a carga de $6 \mathrm{~g}$ DQO L ${ }^{-1}$, o reator mostrou desempenho melhor do que na carga anteriormente testada, porém, quanto maior o tempo de alimentação do reator, menor foi sua eficiência. Para a maior carga

\section{VERSÃO CORRIGIDA}


testada, houve menor eficiência quando o tempo de alimentação utilizado foi maior. Os autores também analisaram a influência do choque de carga orgânica no desempenho do reator, aplicando uma carga única de $24 \mathrm{~g}$ DQO L ${ }^{-1}$ em cada uma das condições. Os resultados mostraram um grande acúmulo de ácidos em todas as condições, mas o choque não foi o suficiente para desestabilizar a operação do reator, que reganhou estabilidade durante a operação normal.

\subsubsection{Temperatura}

Os processos anaeróbios são altamente influenciados pela temperatura. Dentro das possibilidades de geração de metano na natureza destacam-se três diferentes faixas ótimas de temperatura. A psicrofílica, que tem sua máxima eficiência entre 5 e $15^{\circ} \mathrm{C}$; mesofílica com temperatura ótima entre 35 e $40{ }^{\circ} \mathrm{C}$ e a termofílica, com temperatura ótima próxima de $55{ }^{\circ} \mathrm{C}$, podendo chegar a $60{ }^{\circ} \mathrm{C}$. Quando atuando fora dessas faixas, há um decréscimo significativo na produção de metano (POHLAND, 1992; LETTINGA \& HAANDEL 1993).

Apesar de o soro ser gerado em uma temperatura intermediária entre a mesofílica e a termofílica (próximo a $40^{\circ} \mathrm{C}$ ), a aplicação de um reator operado na faixa termofílica pode ser uma vantagem uma vez que o resfriamento necessário para a aplicação de um processo biológico mesofílico convencional, pode ser custoso, além de ser um processo de difícil aplicação (RIBAS et al., 2009). Além disso, estudos com vinhaça, outra água residuária de grande impacto ambiental, apontam que a geração de biogás pelo tratamento anaeróbio deste efluente em condições termofílicas se mostra uma escolha viável de opção tecnológica uma vez que apresenta potencial melhoria da produtividade de metano e fator de rendimento (entre metano gerado e substrato consumido), além de se aproveitar do fato de que a vinhaça é retirada da etapa de destilação no processo de produção de etanol em temperatura elevada (SONG et al., 2004; TATARA et al., 2005; UENO et al., 2007; YANG et al., 2008; FERRAZ JÚNIOR et al., 2016). 
Em reator UASB tratando efluente da indústria de café solúvel, Dinsdale et al. (1996) estudaram o comportamento de um mesmo lodo adaptado as condições mesofílica e termofílicas. Os autores testaram diferentes tempos de detenção hidráulica e carga orgânica aplicada para cada um dos reatores. Os resultados indicaram que os reatores obtiveram eficiências similares em relação à remoção de DQO, concentração total de ácidos voláteis, produção e concentração de biogás. Entretanto, quando aplicada a maior carga orgânica de teste $\left(11.4 \mathrm{kgDQO} \cdot \mathrm{m}^{3} \cdot \mathrm{d}^{-1}\right)$ houve falha irreversível do reator mesofílico. Outro fator notável foi a maior concentração de ácidos totais voláteis no interior do reator termofílico em todas as condições, provavelmente pela tendência do reator termofílico possuir a tendência de acumular ácido propiônico.

\subsubsection{Tipo de resíduo}

O tipo de resíduo utilizado como substrato para um reator biológico é de crucial importância uma vez que micro e macronutrientes são essenciais para a vida microbiológica. Dentre os nutrientes essenciais, carbono, nitrogênio e fósforo são considerados os mais importantes. Estes nutrientes são muitas vezes analisados através de sua relação, como $\mathrm{C} / \mathrm{N}$ ou $\mathrm{C} / \mathrm{P}$ ou até DQO:N:P.

Diversas águas residuárias são estudadas na produção biológica de metano, cada uma delas possui uma composição diferente e, portanto, relação de micro e macronutrientes diferentes. Além disso, há ainda a relação de biodegradabilidade de uma água residuária. Quanto à matéria orgânica, uma água residuária pode ser considerada facilmente biodegradável, como o soro ou esgoto sanitário. Outro exemplo é o lixiviado de aterro sanitário, o qual pode ser constituído de matéria orgânica facilmente biodegradável quando seu tempo de operação for pequeno, enquanto que aterros sanitários maduros, ou seja, com longo tempo de operação, possuem maior quantidade de matéria orgânica recalcitrante (TANG et al., 2013; CHAMCHOI et al., 2008).

\section{VERSÃO CORRIGIDA}


Apesar de existirem diversos estudos com diferentes águas residuárias, é possível notar que os resultados são mais dependentes de todas as outras condições de operação para alcançar resultados mais satisfatórios (LOVATO et al, 2015).

\subsection{Considerações finais}

O soro é um efluente de grande potencial poluidor com boas alternativas técnicas de disposição que, apesar de possíveis, se tornam de difícil aplicação pois são custosas financeiramente aos pequenos e médios produtores de laticínios, maioria no Brasil.

Dentre as alternativas técnicas de baixo custo, a aplicação no solo não tem sido aplicada devido ao alto risco de poluição de corpos hídricos próximos ao local. Outra alternativa é o tratamento biológico com geração de energia através do biogás formado pelo metabolismo anaeróbio. Essa alternativa se mostra viável devido ao seu baixo custo e facilidade de aplicação. Além disso, considerando que o soro é um subproduto gerado de maneira intermitente, o estudo de reatores anaeróbios que operem em bateladas sequenciais se torna um diferencial interessante no tratamento dessa água residuária.

Estes reatores têm apresentados resultado bastante satisfatórios em escala de laboratório, mas seu uso em escala real ainda está um pouco distante. Estudos sobre o desempenho dessa configuração de reator, com ênfase em condição termofílica continuam sendo necessários como alternativa tecnológica para que se possa alternar entre a escala de laboratório para a real.

Assim, o estudo de um reator AnSBBR em condição termofílica se torna importante para se obter conhecimento e ferramentas para alcançar maior controle do processo anaeróbio sob uma condição que ainda é pouco estudada, mas que se apresenta como uma alternativa de grande 
eficiência tanto na recuperação energética quanto da adequação ambiental de um resíduo bastante poluidor.

VERSÃO CORRIGIDA 


\section{MATERIAIS E MÉTODOS}

\subsection{Configuração do reator}

O reator utilizado no projeto foi um AnSBBR com agitação mecânica. As Figuras 4.1 e 4.2 apresentam a representação esquemática e a fotografia do reator, respectivamente.

Figura 4.1 - Representação esquemática do reator anaeróbio com agitação operado em batelada sequencial contendo biomassa imobilizada - AnSBBR

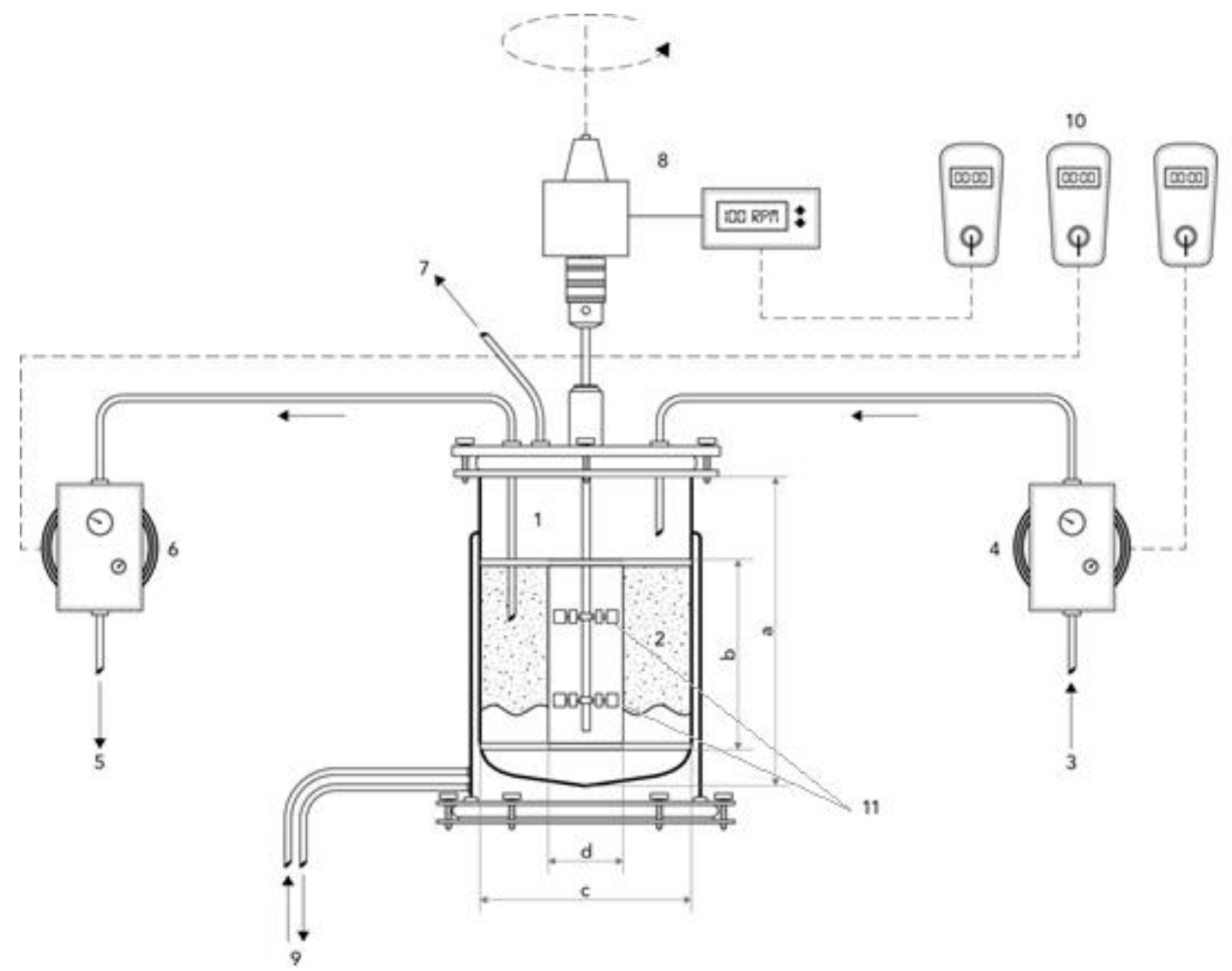

Dimensões: (a) Reator: 1 - Bioreator BIOFLO 110 (New Brunswick Scientific Co.) com capacidade de 6 L $(\mathrm{a}=29,5 \mathrm{~cm} ; \mathrm{b}=18 \mathrm{~cm} ; \mathrm{c}=18 \mathrm{~cm}) ; 2$ - Cesto de retenção e material suporte da biomassa $(\mathrm{b}=18 \mathrm{~cm} ; \mathrm{d}=7$ cm); 3 - Afluente; 4 - Bomba de alimentação; 5 - Efluente; 6 - Bomba de descarga; 7 - Saída de biogás; 8 -

Sistema de agitação; 9 - Sistema de controle de temperatura (banho termostático); 10 - Sistema de automação; 11- impelidor do tipo turbina.

Fonte: Autor (2017) 
Figura 4.2 - Fotografia do aparato experimental (esq.) e reator AnSBBR (dir.).
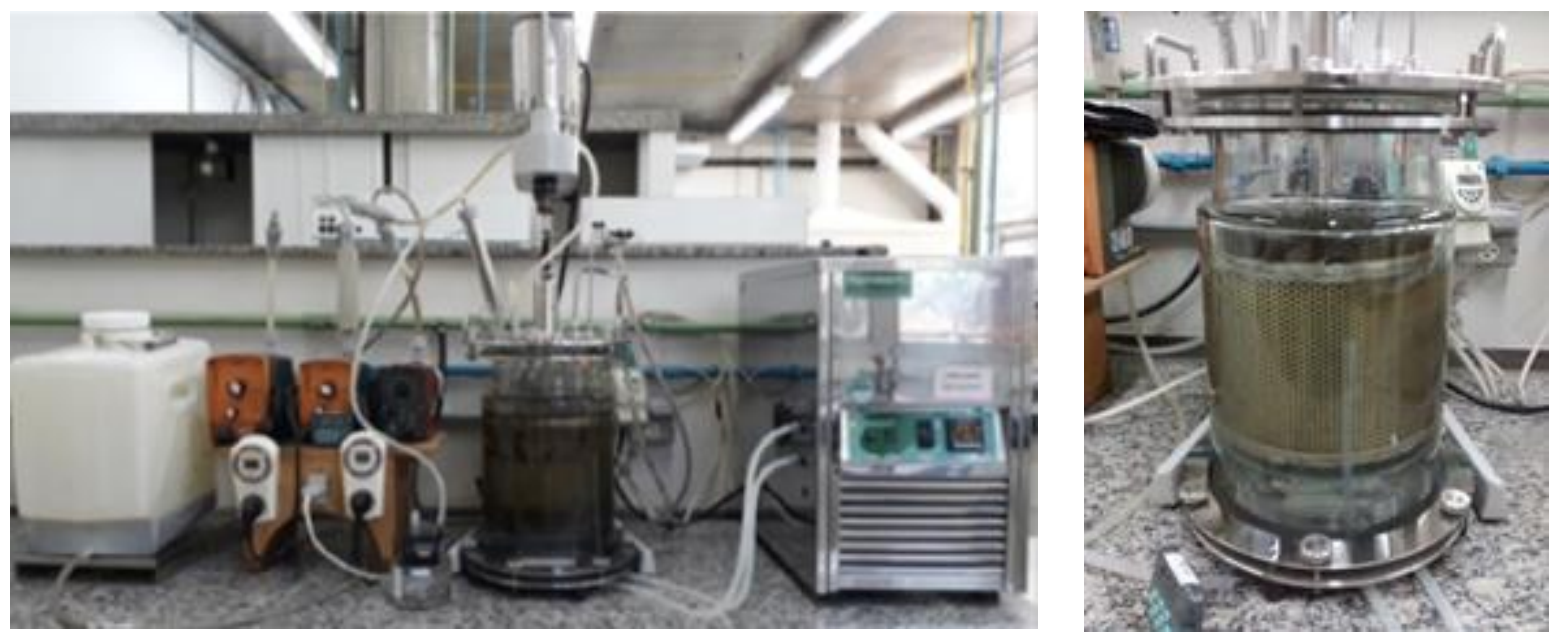

Fonte: Autor (2017)

O modelo de reator utilizado foi o Bioflo $110^{\circledR}$ (New Brunswick Scientific Co.), constituído por um frasco de vidro de $20 \mathrm{~cm}$ de diâmetro e $30 \mathrm{~cm}$ de altura, com capacidade total de 7,5 L e capacidade útil de 6,0 L. Para o confinamento da biomassa, foi empregado um cesto de aço Inox316 perfurado de $18,0 \mathrm{~cm}$ de altura, $7,0 \mathrm{~cm}$ e $17,5 \mathrm{~cm}$ de diâmetros interno e externo, respectivamente. As partes superior, inferior e lateral do cesto foram cobertas por uma tela de aço Inox 316 de malha fina $(5 \mathrm{~mm})$ para retenção da biomassa. A agitação de $100 \mathrm{rpm}$ foi realizada por motor acoplado aos impelidores tipo turbina de $6 \mathrm{~cm}$ de diâmetro constituído por seis lâminas planas (padrão Rushton) e instalados a 8 e $16 \mathrm{~cm}$ do fundo do tanque, em destaque na Figura 4.1 (MICHELAN et al., 2009).

O controle operacional do reator foi realizado por temporizadores para acionamento ou desligamento da agitação mecânica e do conjunto de bombas para alimentação ou descarte (tipo diafragma Prominent modelos $\beta$ e Concept). A temperatura termofílica foi controlada pela circulação de água aquecida na dupla parede externa do reator. O controle da mesma foi realizado por meio de banho ultratermostatizado (Marconi modelo MA-184).

\section{VERSÃO CORRIGIDA}




\subsection{Inóculo e suporte para a biomassa}

O inóculo utilizado foi o de um reator UASB termofílico aplicado ao tratamento de vinhaça na Usina de São Martinho (Pradópolis, SP).

Na imobilização da biomassa com o inóculo citado, foi utilizada espuma de poliuretano (densidade aparente de $23 \mathrm{~kg} \mathrm{~m}^{-3}$ e porosidade próxima a 95\%), cortada em cubos de 1,0 $\mathrm{cm}$ de aresta, é isenta de corantes e aditivos. A metodologia seguida para a fixação do lodo anaeróbio na espuma de poliuretano foi a proposta por Zaiat et al. (1994). Toda a espuma foi disposta em um recipiente e, posteriormente, coberta com o lodo anaeróbio até que este estivesse em contato com todo o material suporte. O contato foi de 2 horas. Para melhor fixação do lodo no interior das espumas, foi aplicado uma pequena compressão nas espumas para que essas absorvessem ainda mais o inóculo. Após o período de contato, foi realizada uma lavagem dos sólidos fracamente aderidos através da inserção do material suporte com biomassa aderida no meio utilizado nos experimentos. Após este procedimento, o material suporte inoculado foi introduzido no cesto do reator, completando todo o seu volume sem promover compactação das espumas. A Figura 4.3 apresenta o meio suporte antes e depois da inoculação.

Figura 4.3 - Fotografia da espuma de poliuretano antes (esquerda) e depois (centro) da inoculação além do método de inoculação (direita)

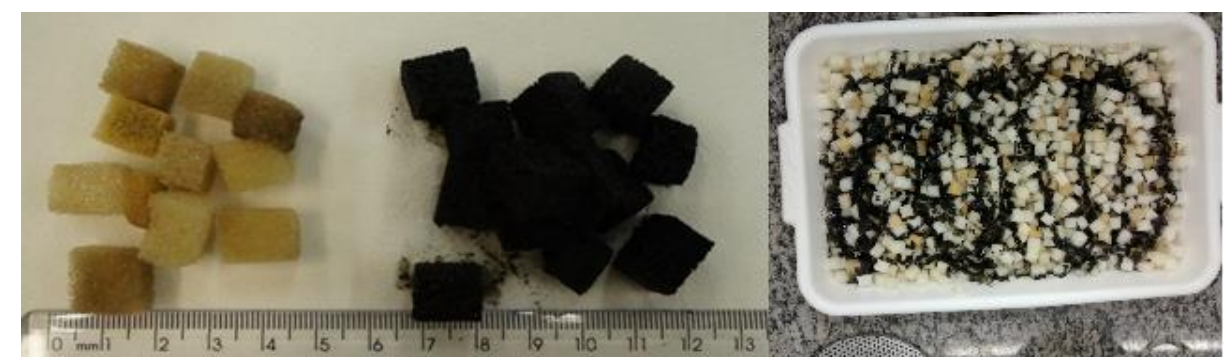

Fonte: Autor (2017)) 


\section{3 Água residuária}

A água residuária utilizada no projeto foi preparada a partir de soro comercial, o qual é obtido como efluente do processo de produção de queijos. Optou-se pela utilização da forma desidratada em pó (composição: 73\% carboidratos, $11 \%$ proteínas, 2\% gordura, minerais 9\%, umidade 5\%), cuja água residuária é obtida a partir da dissolução do composto em pó com água de torneira. Para a composição da água residuária, considerou-se, após testes no laboratório, que aproximadamente $970 \mathrm{mg}$ de soro equivalia a $1000 \mathrm{mgDQO} \mathrm{\textrm {L } ^ { - 1 }}$.

Conforme a etapa experimental, esta água residuária foi suplementada com concentração de bicarbonato de sódio relativa à carga orgânica aplicada.

\subsection{Análises físico-químicas e exame microbiológico}

O monitoramento do reator foi efetuado medindo-se, em amostras do afluente e do efluente, as concentrações de matéria orgânica nas formas não filtrada $\left(\mathrm{C}_{\mathrm{ST}}\right.$ e $\left.\mathrm{C}_{\mathrm{CT}}\right)$ e filtrada $\left(\mathrm{C}_{\mathrm{SF}}\right.$ e $\left.\mathrm{C}_{\mathrm{CF}}\right)$ como demanda química de oxigênio (DQO) e carboidratos (DUBOIS, 1956), alcalinidade a bicarbonato $(\mathrm{AB})$, ácidos voláteis totais (AVT), série de sólidos, $\mathrm{pH}$ e volume de meio alimentado/descarregado (APHA, 1995; DILALLO e ALBERTSON, 1961; RIPLEY et al., 1986).

Os compostos intermediários do metabolismo anaeróbio (acetona, metanol, etanol, nbutanol, ácidos: acético, propiônico, butírico, iso-butírico, valérico, iso-valérico e capróico) foram analisados por cromatografia em fase gasosa com padrão externo (iso-butanol e ácido crotônico) utilizando-se um cromatógrafo Hewlett Packard ${ }^{\circledR}$ modelo 7890 equipado com detector de ionização de chama e coluna HP-Innowax. 
A composição do biogás formado pelo metabolismo anaeróbio (hidrogênio, metano e dióxido de carbono foi analisada por cromatografia em fase gasosa utilizando-se um cromatógrafo Agilent ${ }^{\circledR}$ modelo 7890 equipado com detector de condutividade térmica e coluna GS-Carbonplot.

A produção do biogás formado $\left(\mathrm{V}_{\mathrm{G}}\right)$ foi contabilizada por medidor de gás Rittter modelo MilligasCounter. Esta quantificação foi realizada através da medição do volume de gás acumulado durante um ciclo do reator.

É importante citar que, quando o reator operou em batelada alimentada, há a necessidade de se descontar o volume alimentado, uma vez que este é contabilizado através da aparelhagem de medição de volume de gás. Este procedimento é realizado através da Equação (4.1, sendo $\mathrm{V}_{\mathrm{Gi}-\mathrm{BA}} \mathrm{O}$ volume acumulado de biogás obtido em determinado ponto do período em batelada alimentada, $\mathrm{V}_{\mathrm{M} \text { - }}$ i $\mathrm{O}$ volume obtido pelo medidor de biogás, $\mathrm{N}_{\mathrm{i}} \mathrm{O}$ número do ponto do perfil do biogás, $\mathrm{N}_{\mathrm{t}-\mathrm{BA}} \mathrm{O}$ número total de pontos do perfil durante a batelada alimentada, $\mathrm{V}_{\mathrm{A}} \mathrm{O}$ volume de afluente alimentado durante o ciclo. a seguir:

$$
V_{G i-B A}=V_{M-i}-\frac{N_{i}}{N_{t-B A}} V_{A}
$$

Este cálculo Equação 4.1 não foi necessário quando o reator operou em batelada, uma vez que a alimentação e a descarga eram travadas e o medidor de gás era zerado após o período de alimentação, sendo assim, o volume contabilizado era o volume real de gás produzido durante o ciclo.

Entretanto, para ambas as estratégias de alimentação, foi necessário realizar o procedimento para corrigir o volume gerado para as condições normais de temperatura e pressão (CNTP), uma 
vez que as condições do reator são diferentes da mesma. A conversão foi feita de acordo com a lei geral dos gases através da Equação 4.2, que se encontra no manual do equipamento, sendo $\mathrm{V}_{\mathrm{N}} \mathrm{O}$ volume nas CNTP, $\mathrm{V}_{\mathrm{i}}$ o volume de biogás a ser convertido (ou seja, $\mathrm{V}_{\mathrm{Gi}-\mathrm{BA}}$ ou $\mathrm{V}_{\mathrm{Gi}-\mathrm{B}}$ ), $\mathrm{P}_{\mathrm{A}}$ a pressão do ar no local da medição, $\mathrm{P}_{\mathrm{V}}$ a pressão parcial de vapor d'água, $\mathrm{P}_{\mathrm{L}}$ a pressão da coluna líquida acima da câmara de medição (2 mbar), $\mathrm{P}_{\mathrm{N}}$ a pressão normal (1013,25 mbar), $\mathrm{T}_{\mathrm{N}}$ a temperatura normal $(273,15 \mathrm{~K})$ e $\mathrm{T}_{\mathrm{a}}$ a temperatura no local da medição.

$$
V_{N}=V_{i} \frac{\left(P_{a}-P_{V}+P_{L}\right)}{P_{N}} \frac{T_{N}}{T_{a}}
$$

Após o cálculo do volume de gás nas CNPT, foi possível calcular o número de mmols de metano gerado através da Equação 4.3, em que $\mathrm{n}_{\mathrm{CH} 4}$ é a quantidade em mmol de metano gerado, $\mathrm{P}$ a pressão (1 atm), $\mathrm{V}_{\mathrm{N}}$ o volume nas CNTP, R a constante de Clapeyron $\left(0.082 \mathrm{~L} \cdot \mathrm{atm} \cdot \mathrm{K}^{-1} \cdot \mathrm{mol}^{-1}\right)$ e $\mathrm{T}_{\mathrm{N}} \mathrm{a}$ temperatura normal $(273,15 \mathrm{~K})$.

$$
n_{C H_{4}}=\frac{P \cdot V_{N}}{R \cdot T_{N}}
$$

A Tabela 4.1 a seguir apresenta um resumo das análises realizadas no projeto. 
Tabela 4.1 - Resumo das análises realizadas

\begin{tabular}{cccc}
\hline Parâmetro & Amostra & Frequência & Método \\
\hline Carboidrato $\left(\mathrm{C}_{\mathrm{CT}}\right.$ e $\left.\mathrm{C}_{\mathrm{CF}}\right)$ & Afluente e efluente & 5 vezes por semana & Dubois et. al., 1995 \\
$\mathrm{DQO}\left(\mathrm{C}_{\mathrm{ST}}\right.$ e $\left.\mathrm{C}_{\mathrm{SF}}\right)$ & Afluente e efluente & 5 vezes por semana & Standard Methods, 1995 \\
$\mathrm{pH}$ & Afluente e efluente & 5 vezes por semana & Standard Methods, 1995 \\
Alcalinidade/AVT & Afluente e efluente & 5 vezes por semana & $\begin{array}{c}\text { Standard Methods, } 1995 \\
\text { Ripley } \text { et al,.1986 }\end{array}$ \\
Série de sólidos & Afluente e efluente & 2 vezes por semana & Standard Methods, 1995 \\
Volume do biogás & Saída de gás & 5 vezes por semana & Medidor de gás Ritter \\
Ácidos e álcoois & Efluente & Ao final da condição & Cromatografia Gasosa \\
Composição do biogás & Saída de gás & 5 vezes por semana & Cromatografia Gasosa \\
Microbiológico & Biomassa & Ao final da condição & Microscopia Óptica \\
Volume alimentado & Efluente & 5 vezes por semana & Volumétrico \\
\hline
\end{tabular}

Ao final de cada condição foram retiradas amostras de biomassa do reator para análise de sólidos e realização exame microbiológico, com o objetivo de avaliar a morfologia dos microrganismos nas condições operacionais em estudo e a concentração de biomassa no interior do reator. Foi utilizado microscópio Olympus® modelo BX41, com sistema de câmera digital Optronics e aquisição de imagens feita pelo software Image Pro-Plus® versão 4.5.0.

Esse processo iniciou-se com a drenagem completa do meio do reator para a quantificação do volume residual $\left(\mathrm{V}_{\mathrm{R}}\right.$ - somente do volume do líquido residual) em seu interior. Feito isso, toda a espuma contendo a biomassa, foi retirada do interior do cesto de aço inox e quantificada $\left(\mathrm{M}_{\mathrm{T}-\mathrm{SI}+\mathrm{B}}\right)$. Feito isso, homogeneizou-se o material suporte contendo biomassa e retirou-se uma pequena amostra $\left(\mathrm{M}_{\mathrm{A}-\mathrm{SI}+\mathrm{B}}\right)$ para quantificação dos sólidos no interior do reator. A partir dessa amostragem, realizou-se a lavagem das espumas para remoção completa da biomassa de seu interior. Deste procedimento foram obtidas duas fases. Em uma delas, a amostra líquida contendo água destilada mais a biomassa e na outra, somente as espumas, sem biomassa. Na primeira, realizou-se a quantificação dos sólidos voláteis totais e totais (SVT e ST), pela segunda amostra obteve-se a 
quantificação dos sólidos totais (ST). Este procedimento permitiu estimar a quantidade de biomassa presente no material inerte e com isso, a concentração de biomassa no interior do reator. Tal informação é útil em três diferentes formas:

(i) Quantidade total de biomassa do reator $\left(\mathrm{M}_{\mathrm{SVT}}\right)$, que avalia a capacidade do reator na retenção da biomassa, sendo essa variável importante também devido à sua utilização em outros indicadores utilizados na análise do reator, como a carga orgânica específica aplicada (COEA), a carga orgânica específica removida (COER) e a produtividade molar específica (PrME) (Equação 4.4).

$$
M_{S V T}=\frac{M_{A-S V T} \cdot M_{T-S I+B}}{M_{A-S I+B}}
$$

(ii) Relação entre a quantidade de biomassa e o volume de meio líquido do reator $\left(\mathrm{C}_{\mathrm{X}}\right)$, que permite medir a relação entre a quantidade de meio líquido disponível ao tratamento e a biomassa envolvida nas biotransformações inerentes ao processo em estudo (Equação 4.5).

$$
C_{X}=\frac{M_{S V T}}{V_{R}}
$$

(iii) Relação entre a quantidade de biomassa e a quantidade de suporte inerte presente no reator $\left(\mathrm{C}_{\mathrm{X}}{ }^{\prime}\right)$, que permite medir a relação entre a quantidade de suporte inerte disponível para a imobilização/retenção da biomassa e a biomassa envolvida no biológico em estudo (Equação 4.6).

$$
C_{X}{ }^{\prime}=\frac{M_{A-S V T}}{M_{A-S I}}
$$


Para a execução das análises de microbiologia, uma ou duas espumas foram retiradas do interior do cesto inox e lavadas com água destilada, para remoção da biomassa contida no meio suporte. Primeiramente utilizou pouca água para obtenção de biomassa mais concentrada. Uma segunda amostra, agora mais diluída, também foi obtida. Com as amostras, concentrada e diluída, preparou-se uma placa de vidro com ágar para fixação da biomassa. As placas foram deixadas em local seguro para a secagem do ágar. Após a solidificação do material, as amostras foram levadas a um microscópio e analisadas com e sem fluorescência.

\subsection{Fundamentos teóricos dos indicadores de desempenho do reator}

A eficiência de remoção de matéria orgânica total $\left(\varepsilon_{\mathrm{ST}}\right)$ no sistema foi calculada pela Equação 4.7, na qual $\mathrm{C}_{\mathrm{SAFL}}$ é a concentração de matéria orgânica total no afluente e $\mathrm{C}_{\mathrm{ST}}$ é a concentração de matéria orgânica total no efluente. A eficiência de remoção de matéria orgânica filtrada $\left(\varepsilon_{\mathrm{SF}}\right)$ foi calculada pela Equação 4.8, na qual $\mathrm{C}_{\mathrm{SF}}$ é a concentração de matéria orgânica filtrada no efluente.

$$
\begin{aligned}
& \varepsilon_{\mathrm{ST}}(\%)=\frac{\mathrm{C}_{\mathrm{SAFL}}-\mathrm{C}_{\mathrm{ST}}}{\mathrm{C}_{\mathrm{SAFL}}} \cdot 100 \\
& \varepsilon_{\mathrm{SF}}(\%)=\frac{\mathrm{C}_{\mathrm{SAFL}}-\mathrm{C}_{\mathrm{SF}}}{\mathrm{C}_{\mathrm{SAFL}}} \cdot 100
\end{aligned}
$$

A carga orgânica aplicada volumétrica (COAV) é definida como sendo a quantidade de matéria orgânica aplicada ao reator por unidade de tempo e por volume de meio do reator (gDQO.L ${ }^{1} \cdot \mathrm{d}^{-1}$ ) e foi calculada pela Equação 4.9 , na qual $\mathrm{V}_{\mathrm{A}}$ é o volume de água residuária alimentada no ciclo, $\mathrm{N}$ é o número de ciclos por dia, $\mathrm{C}_{\mathrm{SAFL}}$ é a concentração de matéria orgânica no afluente e $\mathrm{V}_{\mathrm{R}}$ é o volume de água residuária no reator. A carga orgânica aplicada específica (COAE) é definida 
como sendo a quantidade de matéria orgânica aplicada ao reator por unidade de tempo e por massa de sólidos totais voláteis no reator $\left(\mathrm{gDQO} \mathrm{gSVT}^{-1} \cdot \mathrm{d}^{-1}\right)$ e foi calculada pela Equação 4.10, na qual $\mathrm{M}_{\mathrm{SvT}}$ é a massa de sólidos voláteis totais no interior do reator.

$$
\begin{aligned}
\mathrm{COAV} & =\frac{\left(\mathrm{V}_{\mathrm{A}} \cdot \mathrm{N}\right) \cdot \mathrm{C}_{\mathrm{SAFL}}}{\mathrm{V}_{\mathrm{R}}} \\
\mathrm{COAE} & =\frac{\left(\mathrm{V}_{\mathrm{A}} \cdot \mathrm{N}\right) \cdot \mathrm{C}_{\mathrm{SAFL}}}{\mathrm{M}_{\mathrm{SVT}}}
\end{aligned}
$$

A carga orgânica removida volumétrica $\left(\mathrm{CORV}_{\mathrm{SF}}\right)$, para amostras filtradas, é definida como sendo a quantidade de matéria orgânica removida pelo reator por unidade de tempo e por volume de meio do reator $\left(\mathrm{gDQO} . \mathrm{L}^{-1} \cdot \mathrm{d}^{-1}\right)$ e foi calculada pela Equação 4.11. A carga orgânica removida específica $\left(\mathrm{CORE}_{\mathrm{SF}}\right)$, para amostras filtradas, é definida como sendo a quantidade de matéria orgânica removida pelo reator por unidade de tempo e por massa de sólidos totais voláteis no reator $\left(\mathrm{gDQO} \mathrm{gSVT}^{-1} \cdot \mathrm{d}^{-1}\right)$ e foi calculada pela Equação 4.12 .

$$
\begin{gathered}
\operatorname{CORV}_{\mathrm{SF}}=\frac{\left(\mathrm{V}_{\mathrm{A}} \cdot \mathrm{N}\right) \cdot\left(\mathrm{C}_{\mathrm{SAFL}}-\mathrm{C}_{\mathrm{SF}}\right)}{\mathrm{V}_{\mathrm{R}}} \\
\operatorname{CORE}_{\mathrm{SF}}=\frac{\left(\mathrm{V}_{\mathrm{A}} \cdot \mathrm{N}\right) \cdot\left(\mathrm{C}_{\mathrm{SAFL}}-\mathrm{C}_{\mathrm{SF}}\right)}{\mathrm{M}_{\mathrm{SVT}}}
\end{gathered}
$$

O fator de rendimento entre o metano produzido (mL-CNTP) e matéria orgânica na forma de DQO (gDQO), consumidos permite analisar a produção específica de metano em relação ao consumo total de DQO. Para reatores operados em batelada ou batelada alimentada pode ser calculado pela Equação 4.13. 


$$
R M C R_{S}=\frac{V_{C H_{4}-C N T P}}{\left(V_{A} \cdot N\right) \cdot\left(C_{M O A F L}-C_{M O F}\right)}
$$

Destaca-se que os parâmetros relacionados à matéria orgânica na forma de DQO citados anteriormente, também foram todos quantificados de forma análoga em relação à matéria orgânica na forma de carboidratos.

\subsection{Fundamentos teóricos do modelo cinético do reator}

O modelo da rota metabólica foi proposto considerando a simplificação das etapas de tratamento anaeróbio (LOVATO et al., 2016), sendo mostrado nas Equações 4.14 a 4.23. As três etapas iniciais em paralelo constam da hidrólise e acidogênese, sendo o substrato ( $\mathrm{S}$ - sacarose ou lactose, ou seja, obtido através da análise de Dubois), convertido em ácido acético (HAc), ácido propiônico (HPr) e ácido butírico (HBu). Então, considerou-se o consumo dos ácidos propiônico e butírico para formar ácido acético e hidrogênio (acetogênese). Finalmente, considerou-se a metanogênese acetoclástica e hidrogenotrófica para a formar metano (metanogêse) (ALBANEZ et al., 2016a; ALBANEZ et al., 2016b; LOVATO et al., 2016).

Hidrólise e Acidogênese

$$
\begin{aligned}
& \mathrm{C}_{12} \mathrm{H}_{22} \mathrm{O}_{11}+5 \mathrm{H}_{2} \mathrm{O} \stackrel{k_{1}}{\rightarrow} 4 \mathrm{CH}_{3} \mathrm{COOH}+4 \mathrm{CO}_{2}+8 \mathrm{H}_{2} \\
& \mathrm{C}_{12} \mathrm{H}_{22} \mathrm{O}_{11}+4 \mathrm{H}_{2} \stackrel{k_{2}}{\rightarrow} 4 \mathrm{CH}_{3} \mathrm{CH}_{2} \mathrm{COOH}+3 \mathrm{H}_{2} \mathrm{O} \\
& \mathrm{C}_{12} \mathrm{H}_{22} \mathrm{O}_{11}+1 \mathrm{H}_{2} \mathrm{O} \stackrel{k_{3}}{\rightarrow} 2 \mathrm{CH}_{3} \mathrm{CH}_{2} \mathrm{CH}_{2} \mathrm{COOH}+4 \mathrm{CO}_{2}+4 \mathrm{H}_{2} \\
& 8 \mathrm{C}_{12} \mathrm{H}_{22} \mathrm{O}_{11} \stackrel{k_{4}}{\rightarrow} 13 \mathrm{CH}_{3} \mathrm{CH}_{2} \mathrm{CH}_{2} \mathrm{CH}_{2} \mathrm{COOH}+31 \mathrm{CO}_{2}+23 \mathrm{H}_{2} \\
& \mathrm{C}_{12} \mathrm{H}_{22} \mathrm{O}_{11}+1 \mathrm{H}_{2} \mathrm{O} \stackrel{k_{5}}{\rightarrow} 4 \mathrm{CH}_{3} \mathrm{CH}_{2} \mathrm{OH}+4 \mathrm{CO}_{2}
\end{aligned}
$$




$$
\begin{aligned}
& \mathrm{CH}_{3} \mathrm{CH}_{2} \mathrm{COOH}+2 \mathrm{H}_{2} \mathrm{O} \stackrel{k_{6}}{\rightarrow} \mathrm{CH}_{3} \mathrm{COOH}+\mathrm{CO}_{2}+3 \mathrm{H}_{2} \\
& \mathrm{CH}_{3} \mathrm{CH}_{2} \mathrm{CH}_{2} \mathrm{COOH}+2 \mathrm{H}_{2} \mathrm{O} \stackrel{k_{7}}{\rightarrow} \mathrm{CH}_{3} \mathrm{CH}_{2} \mathrm{COOH}+\mathrm{CO}_{2}+3 \mathrm{H}_{2} \\
& \mathrm{CH}_{3} \mathrm{CH}_{2} \mathrm{CH}_{2} \mathrm{CH}_{2} \mathrm{COOH}+2 \mathrm{H}_{2} \mathrm{O} \stackrel{k_{8}}{\rightarrow} \mathrm{CH}_{3} \mathrm{CH}_{2} \mathrm{CH}_{2} \mathrm{COOH}+\mathrm{CO}_{2}+3 \mathrm{H}_{2} \\
& \mathrm{CH}_{3} \mathrm{CH}_{2} \mathrm{OH}+\mathrm{H}_{2} \mathrm{O} \stackrel{k_{9}}{\rightarrow} \mathrm{CH}_{3} \mathrm{COOH}+2 \mathrm{H}_{2}
\end{aligned}
$$

Metanogênese

$$
\begin{aligned}
& \mathrm{CH}_{3} \mathrm{COOH} \stackrel{k_{10}}{\longrightarrow} \mathrm{CH}_{4}+\mathrm{CO}_{2} \\
& 4 \mathrm{H}_{2}+\mathrm{CO}_{2} \stackrel{k_{11}}{\longrightarrow} \mathrm{CH}_{4}+2 \mathrm{H}_{2} \mathrm{O}
\end{aligned}
$$

As Equações 4.25 a 4.32 apresentam os modelos cinéticos de primeira ordem de consumo de substrato $\left(\mathrm{r}_{\mathrm{S}}\right)$, formação e consumo dos ácidos acético $\left(\mathrm{r}_{\mathrm{HAc}}\right)$, propiônico $\left(\mathrm{r}_{\mathrm{HPr}}\right)$ e butírico, hidrogênio $\left(r_{H}\right)$ e metano $\left(r_{M}\right)$, respectivamente.

$$
\begin{aligned}
& \mathrm{r}_{\mathrm{S}}=-\left(\mathrm{k}_{1 \mathrm{~S}}+\mathrm{k}_{2 \mathrm{~S}}+\mathrm{k}_{3 \mathrm{~S}}+\mathrm{k}_{4 \mathrm{~S}}+\mathrm{k}_{5 \mathrm{~S}}\right) \cdot \mathrm{C}_{\mathrm{S}}=-\mathrm{k}_{1 \mathrm{~S}} \cdot \mathrm{C}_{\mathrm{S}} \\
& \mathrm{r}_{\mathrm{HAc}}=\mathrm{k}_{1 \mathrm{HAc}} \cdot \mathrm{C}_{\mathrm{S}}+\mathrm{k}_{6 \mathrm{HAc}} \cdot \mathrm{C}_{\mathrm{HPr}}+\mathrm{k}_{9 \mathrm{HAc}} \cdot \mathrm{C}_{\mathrm{EtOH}}-\mathrm{k}_{10 \mathrm{HAc}} \cdot \mathrm{C}_{\mathrm{HAc}} \\
& \mathrm{r}_{\mathrm{HPr}}=\mathrm{k}_{2 \mathrm{HPr}} \cdot \mathrm{C}_{\mathrm{S}}-\mathrm{k}_{6 \mathrm{HPr}} \cdot \mathrm{C}_{\mathrm{HPr}}+\mathrm{k}_{7 \mathrm{HPr}} \cdot \mathrm{C}_{\mathrm{HBu}} \\
& \mathrm{r}_{\mathrm{HBu}}=\mathrm{k}_{3 \mathrm{HBu}} \cdot \mathrm{C}_{\mathrm{S}}-\mathrm{k}_{7 \mathrm{HBu}} \cdot \mathrm{C}_{\mathrm{HBu}}+\mathrm{k}_{8 \mathrm{HBu}} \cdot \mathrm{C}_{\mathrm{HVa}} \\
& \mathrm{r}_{\mathrm{HVa}}=\mathrm{k}_{4 \mathrm{HVa}} \cdot \mathrm{C}_{\mathrm{S}}-\mathrm{k}_{8 \mathrm{HVa}} \cdot \mathrm{C}_{\mathrm{HVa}} \\
& \mathrm{r}_{\mathrm{EtOH}}=\mathrm{k}_{5 \mathrm{EtOH}} \cdot \mathrm{C}_{\mathrm{S}}-\mathrm{k}_{9 \mathrm{HAc}} \cdot \mathrm{C}_{\mathrm{EtOH}} \\
& \mathrm{r}_{\mathrm{H}}=\mathrm{k}_{1 \mathrm{H}} \cdot \mathrm{C}_{\mathrm{S}}-\mathrm{k}_{2 \mathrm{H}} \cdot \mathrm{C}_{\mathrm{S}}+\mathrm{k}_{3 \mathrm{H}} \cdot \mathrm{C}_{\mathrm{S}}+\mathrm{k}_{4 \mathrm{H}} \cdot \mathrm{C}_{\mathrm{S}}+\mathrm{k}_{6 \mathrm{H}} \cdot \mathrm{C}_{\mathrm{HPr}}+\mathrm{k}_{7 \mathrm{H}} \cdot \mathrm{C}_{\mathrm{HBu}}+\mathrm{k}_{8 \mathrm{H}} \cdot \mathrm{C}_{\mathrm{HVa}}+\mathrm{k}_{9 \mathrm{H}} \cdot \mathrm{C}_{\mathrm{EtOH}}-\mathrm{k}_{11 \mathrm{H}} \cdot \mathrm{C}_{\mathrm{H}}(4.31) \\
& \mathrm{r}_{\mathrm{M}}=\mathrm{k}_{10 \mathrm{M}} \cdot \mathrm{C}_{\mathrm{HAc}}+\mathrm{k}_{11 \mathrm{M}} \cdot \mathrm{C}_{\mathrm{H}}
\end{aligned}
$$

As Equações 4.33 a 4.41 apresentam os balanços de massa do reator em batelada $(\mathrm{F}=0) \mathrm{e}$ batelada alimentada $(\mathrm{F} \neq 0)$ para os compostos envolvidos no tratamento anaeróbio (substrato, ácidos, hidrogênio e metano). Essas equações foram usadas para determinar os parâmetros cinéticos 
relacionados à rota metabólica proposta ("INF" refere-se a concentração dos compostos no afluente).

$$
\begin{aligned}
& \frac{d V}{d t}=F \\
& \frac{d C_{S}}{d t}=\frac{F}{V} \cdot\left(C_{S I N F}-C_{S F}\right)+r_{S} \\
& \frac{d C_{H A C}}{d t}=\frac{F}{V} \cdot\left(C_{H A C I N F}-C_{H A C}\right)+r_{H A C} \\
& \frac{d C_{H P r}}{d t}=\frac{F}{V} \cdot\left(C_{H P r I N F}-C_{H P r}\right)+r_{H P r} \\
& \frac{d C_{H B u}}{d t}=\frac{F}{V} \cdot\left(C_{H B u I N F}-C_{H B u}\right)+r_{H B u} \\
& \frac{d C_{H V a}}{d t}=\frac{F}{V} \cdot\left(C_{H V a I N F}-C_{H V a}\right)+r_{H V a} \\
& \frac{d C_{E t O H}}{d t}=\frac{F}{V} \cdot\left(C_{E t O H I N F}-C_{E t O H}\right)+r_{E t O H} \\
& \frac{d C_{H}}{d t}=\frac{F}{V} \cdot\left(C_{H I N F}-C_{H}\right)+r_{H} \\
& \frac{d C_{M}}{d t}=-\frac{F}{V} \cdot\left(C_{M}\right)+r_{M}
\end{aligned}
$$

A resolução das equações diferenciais foi feita pelo método numérico de Euler (Equação 4.42) (implementado em Excel), neste método o intervalo de tempo foi de 0,001s. Os parâmetros cinéticos foram calculados, através da equação 4.43. Executou-se um chute inicial dos valores de todos os parâmetros e executou-se a função Solver do Excel® de modo a se minimizar os erros quadráticos entre a diferença dos valores experimentais (obtidos nos perfis ao longo do tempo) e os resultados obtidos no modelo cinético (LOVATO et al., 2016).

$$
\begin{aligned}
& t_{i+1}=t+\Delta t \\
& C_{i+1}=C_{i}+\left(\frac{d C_{i}}{d t}\right)_{i} \cdot \Delta t
\end{aligned}
$$

Para a execução do modelo cinético, inicialmente executou-se o modelo de forma a adaptar a curva de consumo de substrato (na forma de carboidratos), variando somente a constante 
pertinente a esta etapa. Após isso, executou-se o solver novamente, variando todas as constantes ligadas à acidogênese e acetogênese. Logo após a obtenção destas constantes, executou-se o modelo variando somente as variáveis que influenciam na metanogênese. Por fim, foi executada uma última etapa, uma ou duas vezes (de modo a melhorar a precisão), variando-se todas as constantes e etapas de estudo, de modo a finalizar o modelo cinético.

Mesmo o etanol não fazendo parte do modelo teórico de degradação do soro, foram implementadas as reações envolvendo este composto. Uma vez que não foram detectadas concentrações deste componente e nenhuma das condições, o cálculo do modelo resultou numa constante igual a zero para este componente em todas as condições.

\subsection{Fundamentos teóricos para estimativa de aumento de escala}

O procedimento para estimativa do potencial de produção de metano foi realizado conforme metodologia descrita por Albanez et al. (2016b), utilizando informações de usinas de produção de etanol e de laticínios. Para tal, foram utilizados dados das condições experimentais do projeto em conjunto com dados reais da indústria de laticínios.

A produção de metano e o poder de combustão do metano foram utilizados como parâmetro de projeto, com isso foi possível calcular a energia gerada $\left(\mathrm{E}_{\mathrm{CH} 4}\right)$ a partir da produção molar diária de metano $\left(\operatorname{Prod}_{\mathrm{CH} 4}\right)$ e da entalpia de combustão de metano $\left(\Delta \mathrm{H}_{\mathrm{C}-\mathrm{CH} 4}\right)$ pela Equações 4.44 e 4.45 , onde $\mathrm{VR}_{\mathrm{IND} 3}$ é o volume de líquido, ou de reação, no interior do reator em escala industrial.

$$
\begin{aligned}
& \operatorname{Prod}_{C H 4}=V R_{I N D 3} \cdot \operatorname{COVR}_{M O} \cdot \operatorname{RMCR}_{S, M} \\
& E_{C H 4}=\operatorname{Prod}_{C H 4} \cdot \Delta H_{C-C H 4}
\end{aligned}
$$




\subsection{Procedimento experimental}

O procedimento operacional do reator em batelada e/ou batelada alimentada sequenciais (após a inoculação, ou seja, contendo a biomassa imobilizada em suporte inerte), para todas as condições experimentais, está descrito a seguir.

O primeiro ciclo foi realizado de maneira distinta de outras etapas de estudo. Neste ciclo inicial foram alimentados 2,5 litros de meio no reator durante 20 minutos. Após a alimentação, a agitação mecânica foi iniciada até que se completasse o tempo total de ciclo. Após o final desse tempo, a agitação foi desligada e 1,0 litro de meio foi descarregado em 10 minutos, mantendo-se assim 1,5 litros no reator (denominado de volume residual). Imediatamente após o final do primeiro ciclo, um novo ciclo tem início, caracterizando, assim, as bateladas sequencias. A estratégia de alimentação foi variável de acordo com a condição de estudo. Caso seja em batelada, o tempo de enchimento foi de 10 minutos, sendo que a agitação foi ligada assim que se finalizou o período de alimentação. Caso fosse em batelada alimentada, o tempo de enchimento foi de $50 \%$ do tempo de ciclo, sendo que a agitação foi ligada assim que se iniciou a alimentação.

O protocolo experimental, iniciado por uma etapa de adaptação do lodo ao soro, visou estudar o comportamento do reator em diferentes condições de carga orgânica e tempo de alimentação, seja pelo aumento da concentração de soro afluente (carga orgânica) ou alterando a estratégia de alimentação (batelada ou batelada alimentada), cada mudança implicou no início de uma nova condição. A transição de uma etapa para outra foi realizada apenas aumentando-se a concentração afluente ao reator ou a estratégia de alimentação, sem necessidade de um tempo de adaptação extra ou drenagem completa do meio residual, que permaneceu no interior do reator durante a troca de uma condição para outra, para facilitar a adaptação à nova condição.

A etapa de adaptação do inóculo às condições do reator teve 3 semanas de duração, 
elevando-se gradualmente a temperatura e a concentração de soro afluente até os valores desejados. A cada dois ou três dias, aumentou-se em $1000 \mathrm{mgDQOL}^{-1}$ a concentração afluente e $5^{\circ} \mathrm{C}$ a temperatura de operação, iniciando o reator em $1000 \mathrm{mgDQOL}^{-1}$ e $30^{\circ} \mathrm{C}$ e finalizando a etapa de adaptação em $5000 \mathrm{mgDQOL}^{-1}$ e $55^{\circ} \mathrm{C}$. Durante todo o período de adaptação, a água residuária foi suplementada com 50\% de Bicarbonato de Sódio $\left(\mathrm{NaHCO}_{3}\right)$.

Os ensaios (em batelada - tempo de enchimento de 10 minutos e tempo de ciclo de 8 horas) foram realizados aumentando-se a carga orgânica volumétrica em função da concentração afluente, que variou de 5000 à $20000 \mathrm{mgDQOL}^{-1}$. Além disso, foi realizado um estudo do reator à mudança da estratégia de alimentação, ou seja, de batelada (tempo de enchimento de 10 minutos e tempo de ciclo de 8 horas) para batelada alimentada (tempo de enchimento de 4 horas e tempo de ciclo de 8 horas). As etapas experimentais realizadas estão apresentadas na Tabela 4.2.

Tabela 4.2 - Ensaios realizados

\begin{tabular}{ccccc}
\hline $\begin{array}{c}\text { Condição/Et } \\
\text { apa }\end{array}$ & $\begin{array}{c}\mathrm{C}_{\text {afluente }} \\
\left(\mathrm{mgDQOL}^{-1}\right)\end{array}$ & $\begin{array}{c}\text { Tempo de ciclo } \\
(\mathrm{h})\end{array}$ & $\begin{array}{c}\text { Estratégia de } \\
\text { Alimentação }\end{array}$ & $\begin{array}{c}\text { Concentração de } \mathrm{NaHCO}_{3} \\
\left(\% \text { NaHCO }_{3}: \text { Soro }\right)\end{array}$ \\
\hline Adaptação & 1.000 até 5.000 & 8 & Batelada & 50 \\
1 & 5.000 & 8 & Batelada & 50 \\
2 & 6.000 & 8 & Batelada & 50 \\
3 & 7.000 & 8 & Batelada & 50 até 33 \\
4 & 8.500 & 8 & Batelada & 33 até 25 \\
5 & 10.000 & 8 & Batelada & 25 até 20 \\
6 & 12.000 & 8 & Batelada & 20 \\
7 & 14.000 & 8 & Batelada & 50 \\
8 & 16.000 & 8 & Batelada & 50 \\
9 & 18.000 & 8 & Batelada & 50 \\
10 & 20.000 & 8 & Batelada & 50 \\
11 & 20.000 & 8 & Batelada Alimentada & 50 \\
\hline
\end{tabular}

Em todos dos casos, assim que a estabilidade operacional foi atingida (o tempo para alcançála variou entre 2-3 semanas, sendo o reator considerado estável quando houve variação de aproximadamente $5 \%$ dos valores monitorados), foram obtidos os perfis do longo do tempo de ciclo para as concentrações de matéria orgânica na forma filtrada (DQO e de carboidratos), de VERSÃO CORRIGIDA 
alcalinidade à bicarbonato, de ácidos voláteis totais, de metabólitos intermediários (ácidos voláteis), de biogás (composição e produção) e pH. O intervalo de retirada das amostras foi de 30-60 minutos, sendo o volume total retirado inferior à $10 \%$ do volume do reator.

Vale destacar que durante a operação do reator, a quantidade de bicarbonato de sódio adicionada foi reduzida de forma gradual quando se percebeu que a concentração efluente de alcalinidade a bicarbonato $(\mathrm{AB})$ estava superior à do afluente. Primeiramente reduziu-se a suplementação de $50 \%$ para $33 \%$ e verificou-se a estabilidade do reator. Depois, houve nova redução para $25 \%$ e, finalmente, para $20 \%$, ressaltando-se que o valor citado é uma fração (\%) do valor da concentração afluente em termos de DQO. Assim, apesar da possibilidade de se operar o sistema com o valor de $50 \%$ de suplementação implementados do início da operação, é interessante diminuir o custo de operação do reator, visando a sua aplicação para escala plena.

Após o fim do perfil do reator em cada condição, este foi desmontado e uma amostra dos suportes inertes foi removida para análise de sólidos e também microbiológica, como explicado anteriormente. 


\section{RESULTADOS E DISCUSSÃO}

Neste capítulo são apresentados e discutidos os resultados referentes aos experimentos realizados. Para estruturação do texto, os dados foram divididos em relação à etapa correspondente, como adaptação, otimização e comparação entre as diferentes estratégias de alimentação. Por fim, foram realizadas análises comparativas entre as condições do trabalho e também com a literatura. Os dados foram discutidos em relação à estabilidade operacional (compostos intermediários do metabolismo anaeróbio), produtividade e composição do biogás (geração de metano), e do rendimento entre metano gerado e matéria orgânica consumida, conforme objetivo do projeto.

\subsection{Etapa I - Ativação da biomassa}

Nesta etapa, visou-se a adaptação e reativação do lodo anaeróbio proveniente de um reator UASB termofílico aplicado ao tratamento de vinhaça, uma vez que o lodo esteve guardado em câmara fria. O reator foi operado durante 29 dias, realizando aumento gradual da concentração afluente de soro bem como a temperatura. Durante o processo, o tempo de enchimento, descarga e de ciclo permaneceram os mesmos, bem como a relação de bicarbonato/DQO afluente (50\%). Durante esse período não se quantificou a produção e composição do biogás. Também não foram feitas análises dos sólidos, compostos intermediários do metabolismo anaeróbio e o perfil ao longo do tempo da etapa.

A Figura 5.1 mostra a variação do pH (a), da alcalinidade a bicarbonato (b) e dos ácidos voláteis totais (c). As Figuras 5.2 e 5.3 mostram a variação das concentrações de DQO e carboidratos, respectivamente, filtrados e não-filtrados e suas eficiências de remoção. 
Figura 5.1 - Variação dos parâmetros nas amostras de afluente e efluente durante a etapa I: (a) pH; (b) alcalinidade a bicarbonato; (c) ácidos voláteis totais.
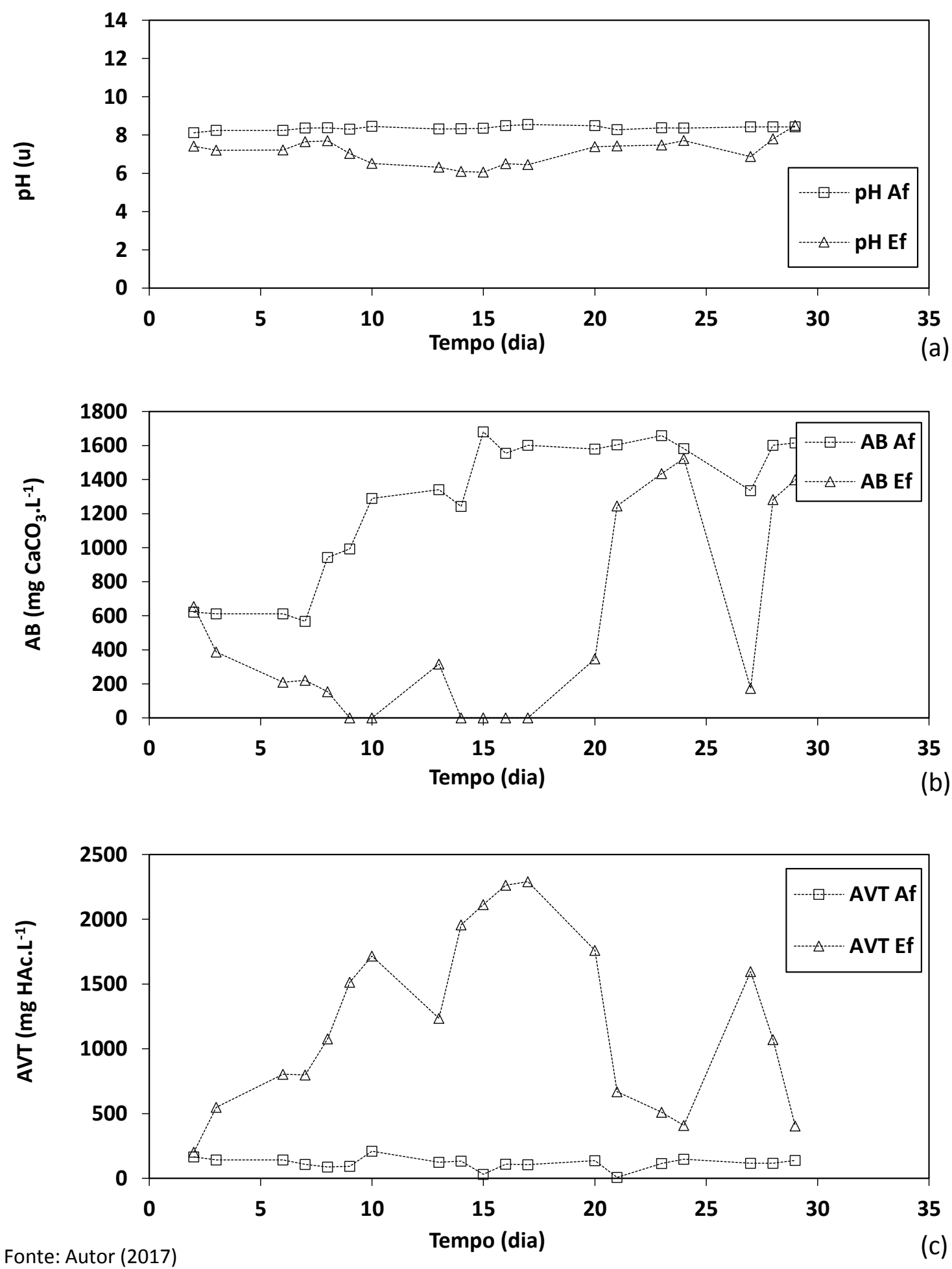
Figura 5.2- Concentração da matéria orgânica na forma de DQO (a) e eficiência de remoção da DQO (b) durante a etapa I
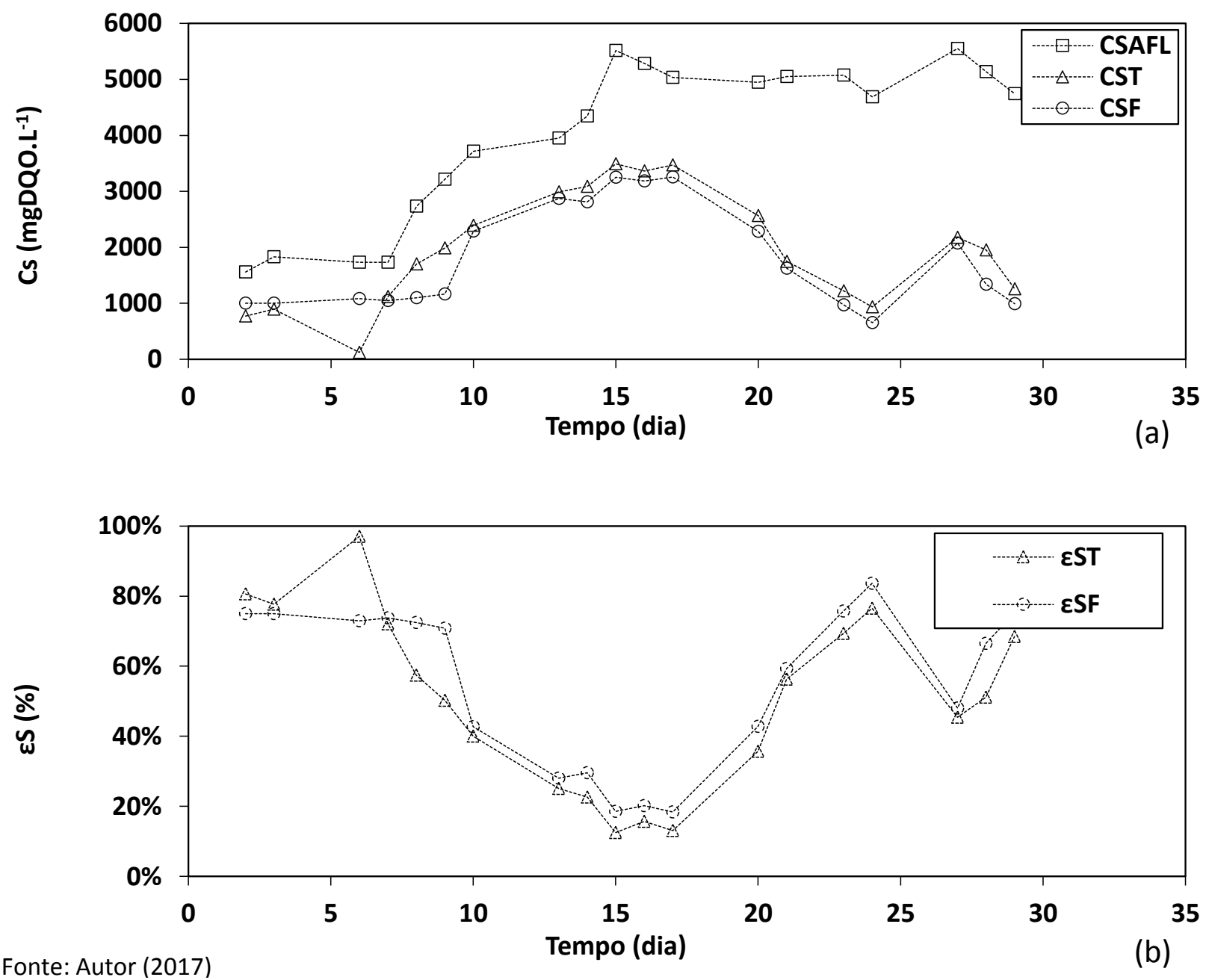
Figura 5.3 - Concentração da matéria orgânica na forma de Carboidratos (a) e eficiência de remoção de Carboidratos (b) durante a Etapa I
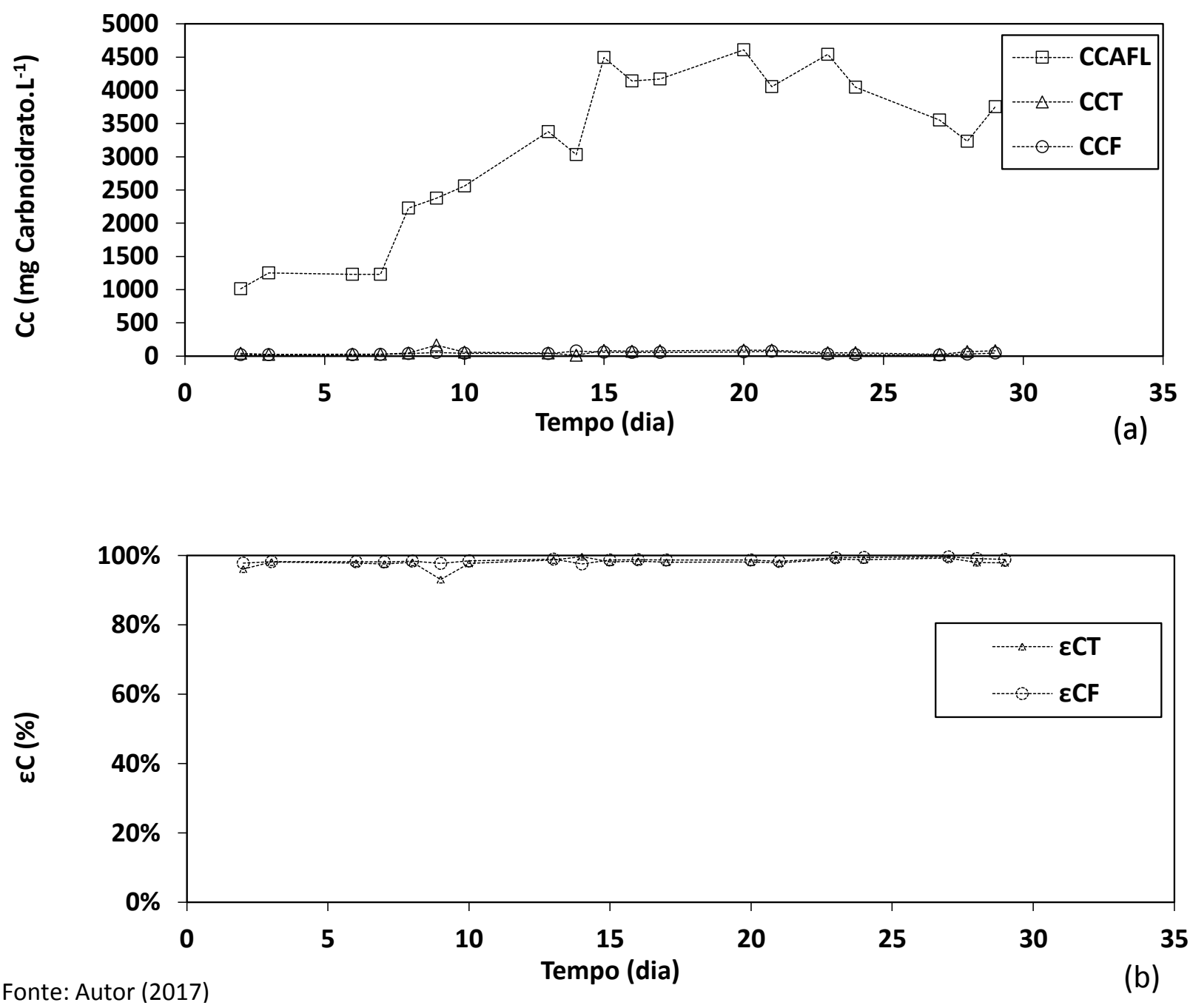

Os resultados do monitoramento não demonstram que o reator atingiu a estabilidade plena durante a Etapa I, apesar de mostrar pouca variação nos últimos dias de adaptação. Entretanto, os resultados mostram que as conversões de DQO e carboidratos aumentaram consideravelmente ao longo do tempo, indicando ativação da biomassa, objetivo da primeira etapa. Verifica-se também que as amostras filtradas e não-filtradas pouco variam entre si, indicativo da retenção dos sólidos no interior do reator. Concluiu-se então que o reator estava apto a iniciar a fase de otimização. 


\subsection{Etapa II - Otimização}

Neste item estão apresentados todos os dados referentes a cada uma das condições, bem como os gráficos relacionados aos perfis e ajuste do modelo cinético de cada uma. O item 5.4 apresenta a comparação entre todas as condições estudadas na etapa II.

\subsubsection{Condição I - 5.000 mg DQO L ${ }^{-1} ; 100 \%$ Soro; $50 \%$ de bicarbonato; $55^{\circ}$ C; Batelada}

Nesta condição de operação, o valor nominal de concentração de DQO no afluente do reator foi de $5000 \mathrm{mg} \mathrm{L}^{-1}$ com carga orgânica aplicada teórica de $6,00 \mathrm{~g} \mathrm{DQO} \mathrm{L}^{-1} \mathrm{dia}^{-1}$.

\subsubsection{Monitoramento}

O reator foi operado por 8 dias, em que a concentração média da matéria orgânica afluente

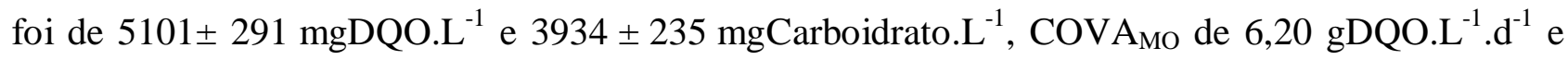
COVA $_{C}$ de 4,78 gCarboidrato. $\mathrm{L}^{-1} \cdot \mathrm{d}^{-1}$. A quantidade de biomassa contida no reator foi de $28,3 \mathrm{~g}$. O número reduzido de amostras desta condição se deve ao fato de que a mesma pode ser considerada uma etapa transitória entre a adaptação e a otimização da biomassa. Por isto, foi considerado um período menor de tempo em que o reator se apresentou estável. O reator operou, no total, por 20 dias com concentração afluente de $5000 \mathrm{mg}$ DQO L ${ }^{-1}$ e $55^{\circ} \mathrm{C}$.

Os valores referentes ao monitoramento e aos indicadores desempenho encontram-se apresentados na Tabela 5.1 a seguir. A eficiência de remoção de matéria orgânica na forma de DQO da primeira condição, para amostras não-filtradas e filtradas, respectivamente, foi de $88 \pm 03 \%$ e $92 \pm 03 \%$. Para a matéria orgânica na forma de Carboidratos (lactose) a remoção foi de $99 \pm 00 \%$ e $99 \pm 00 \%$, respectivamente para não-filtradas e filtradas. $\mathrm{O} \mathrm{pH}$ afluente foi de $8,45 \pm 0,06$ e o efluente 8,08 $\pm 0,27$. A alcalinidade a bicarbonato do afluente e efluente foram VERSÃO CORRIGIDA 
$1575 \pm 76 \mathrm{mgCaCO}_{3} \cdot \mathrm{L}^{-1}$ e $1795 \pm 66 \mathrm{mgCaCO}_{3} \cdot \mathrm{L}^{-1}$. Os ácidos voláteis do afluente e efluente foram $127 \pm 17$ mgHAc. $\mathrm{L}^{-1}$ e $97 \pm 62 \mathrm{mgHac} . \mathrm{L}^{-1}$. Pelos resultados referentes à alcalinidade a bicarbonato e ácidos voláteis pode ser notar que houve produção de alcalinidade a bicarbonato e consumo dos ácidos voláteis produzidos durante a operação do reator, indicando bom desempenho.

A concentração de sólidos suspensos voláteis (SSV) no efluente indica que houve pouca perda de biomassa mesmo numa condição de transição entre a adaptação, onde se espera perda de biomassa, e a otimização do reator, em que se deseja a menor perda possível de biomassa. Isto indica boa capacidade de fixação da biomassa nas espumas de poliuretano utilizadas no AnSBBR de estudo.

O rendimento de metano gerado por matéria orgânica consumida foi de 15,57 $\mathrm{mmolCH}_{4} \cdot \mathrm{gDQO}^{-1}$ e 20,19 $\mathrm{mmolCH}_{4} \cdot \mathrm{gCarboidrato}^{-1}$. A produção de biogás foi de $2504 \pm 109 \mathrm{~mL}-$ CNTP.ciclo $^{-1}$, sendo a fração molar de metano equivalente a $72,72 \pm 0,15 \%$ e a produtividade molar de metano de $96,6 \mathrm{molCH}_{4} \cdot \mathrm{m}^{-3} \cdot \mathrm{d}^{-1}$. 
Tabela 5.1 - Resumo dos valores médios obtidos no monitoramento do reator com concentração afluente de $5000 \mathrm{mgDQO} . \mathrm{L}^{-1}$ na condição I

\begin{tabular}{|c|c|c|c|c|c|c|c|c|c|}
\hline \multicolumn{2}{|r|}{ Parâmetro } & \multicolumn{4}{|c|}{ Afluente } & \multicolumn{4}{|c|}{ Efluente } \\
\hline $\mathrm{C}_{\mathrm{ST}}$ & $\left(\mathrm{mgDQO} \cdot \mathrm{L}^{-1}\right)$ & 5101 & \pm & 291 & $(7)$ & 595 & \pm & 174 & $(7)$ \\
\hline $\mathrm{C}_{\mathrm{SF}}$ & $\left(\operatorname{mgDQO} \cdot \mathrm{L}^{-1}\right)$ & - & & - & & 425 & \pm & 128 & ( 7 ) \\
\hline$\varepsilon_{\mathrm{ST}}$ & $(\%)$ & - & & - & & $88 \%$ & \pm & $3 \%$ & $\left(\begin{array}{l}7 \\
7\end{array}\right)$ \\
\hline$\varepsilon_{\mathrm{SF}}$ & $(\%)$ & - & & - & & $92 \%$ & \pm & $3 \%$ & $\left(\begin{array}{l}7 \\
7\end{array}\right)$ \\
\hline $\mathrm{C}_{\mathrm{CT}}$ & (mgCarboidrato. $\mathrm{L}^{-1}$ ) & 3934 & \pm & 235 & $\left(\begin{array}{ll}7 \\
\text { ) }\end{array}\right.$ & 46 & \pm & 11 & $(7)$ \\
\hline $\mathrm{C}_{\mathrm{CF}}$ & (mgCarboidrato. $\mathrm{L}^{-1}$ ) & - & & - & & 24 & \pm & 5 & $\left(\begin{array}{l}7 \\
)\end{array}\right.$ \\
\hline$\varepsilon_{\mathrm{CT}}$ & $(\%)$ & - & & - & & $99 \%$ & \pm & $0 \%$ & \\
\hline$\varepsilon_{\mathrm{CF}}$ & $(\%)$ & - & & - & & $99 \%$ & \pm & $0 \%$ & \\
\hline $\mathrm{pH}$ & (u) & 8,45 & \pm & 0,06 & $\left(\begin{array}{ll}7 \\
7\end{array}\right)$ & 8,08 & \pm & 0,27 & ( 7 ) \\
\hline AVT & $\left(\mathrm{mgHAc} . \mathrm{L}^{-1}\right)$ & 127 & \pm & 17 & $(7)$ & 97 & \pm & 62 & $(7)$ \\
\hline AT & $\left(\mathrm{mgCaCO}_{3} \cdot \mathrm{L}^{-1}\right)$ & 1575 & \pm & 62 & $(7)$ & 1864 & \pm & 35 & $\left(\begin{array}{l}7 \\
7\end{array}\right)$ \\
\hline $\mathrm{AP}$ & $\left(\mathrm{mgCaCO}_{3} \cdot \mathrm{L}^{-1}\right)$ & 337 & \pm & 23 & $(7)$ & 1504 & \pm & 74 & $(7)$ \\
\hline $\mathrm{AI}$ & $\left(\mathrm{mgCaCO}_{3} \cdot \mathrm{L}^{-1}\right)$ & 1327 & \pm & 69 & $(7)$ & 360 & \pm & 51 & $(7)$ \\
\hline $\mathrm{AB}$ & $\left(\mathrm{mgCaCO}_{3} \cdot \mathrm{L}^{-1}\right)$ & 1575 & \pm & 56 & $\left(\begin{array}{ll}7 \\
7\end{array}\right)$ & 1795 & \pm & 66 & $(7)$ \\
\hline ST & $\left(\mathrm{mg} . \mathrm{L}^{-1}\right)$ & 5577 & \pm & 370 & $\left(\begin{array}{l}3 \\
3\end{array}\right)$ & 2893 & \pm & 256 & $\left(\begin{array}{l}3 \\
3\end{array}\right)$ \\
\hline SVT & $\left(\mathrm{mg} \cdot \mathrm{L}^{-1}\right)$ & 3559 & \pm & 225 & $(3)$ & 971 & \pm & 153 & $\left(\begin{array}{ll}3 \\
)\end{array}\right)$ \\
\hline SST & $\left(\mathrm{mg} \cdot \mathrm{L}^{-1}\right)$ & 138 & \pm & 43 & $(3)$ & 225 & \pm & 121 & $(3)$ \\
\hline SSV & $\left(\mathrm{mg} \cdot \mathrm{L}^{-1}\right)$ & 101 & \pm & 33 & $\left(\begin{array}{l}3 \\
3\end{array}\right)$ & 173 & \pm & 111 & $\left(\begin{array}{ll}3 \\
)\end{array}\right)$ \\
\hline SDF & $\left(\mathrm{mg} \cdot \mathrm{L}^{-1}\right)$ & 1779 & & - & & 1524 & & - & \\
\hline $\mathrm{M}_{\mathrm{SVT}}$ & (g) & 28,3 & & - & & - & & - & \\
\hline $\mathrm{C}_{\mathrm{X}}$ & $\left(\mathrm{gSVT} . \mathrm{L}^{-1}\right)$ & 11,2 & & - & & - & & - & \\
\hline $\mathrm{C}_{\mathrm{X}}^{\prime}$ & $\left(\right.$ gSVT.gsuporte ${ }^{-1}$ ) & 0,8 & & - & & - & & - & \\
\hline $\mathrm{V}_{\mathrm{G}}$ & $\left(\mathrm{mL}-\mathrm{CNTP} . \mathrm{Ciclo}^{-1}\right)$ & - & & - & & 2504 & \pm & 109 & $(6)$ \\
\hline $\mathrm{V}_{\mathrm{CH} 4}$ & $\left(\mathrm{~mL}-\mathrm{CNTPCH}_{4} \cdot \mathrm{Ciclo}^{-1}\right)$ & - & & - & & 1821 & & - & \\
\hline $\mathrm{COVA}_{\mathrm{S}}$ & $\left(\mathrm{gDQO} \cdot \mathrm{L}^{-1} \cdot \mathrm{d}^{-1}\right)$ & 6,20 & & - & & - & & - & \\
\hline $\mathrm{COVR}_{\mathrm{S}}$ & $\left(\mathrm{gDQO} \cdot \mathrm{L}^{-1} \cdot \mathrm{d}^{-1}\right)$ & - & & - & & 5,48 & & - & \\
\hline $\mathrm{COEA}_{\mathrm{S}}$ & $\left(\right.$ gDQO.gSVT $\left.{ }^{-1} \cdot \mathrm{d}^{-1}\right)$ & 0,55 & & - & & - & & - & \\
\hline $\mathrm{COER}_{\mathrm{S}}$ & $\left(\right.$ gDQO.gSVT $\left.{ }^{-1} \cdot d^{-1}\right)$ & - & & - & & 0,24 & & - & \\
\hline $\mathrm{COVA}_{\mathrm{c}}$ & (gCarboidrato. $\left.\mathrm{L}^{-1} \cdot \mathrm{d}^{-1}\right)$ & 4,78 & & - & & & & - & \\
\hline $\mathrm{COVR}_{\mathrm{c}}$ & (gCarboidrato. $\mathrm{L}^{-1} \cdot \mathrm{d}^{-1}$ ) & & & - & & 4,73 & & - & \\
\hline $\mathrm{COEA}_{\mathrm{C}}$ & $\left(\mathrm{gCarboidrato.gSVT}^{-1} \cdot \mathrm{d}^{-1}\right)$ & 0,43 & & - & & & & - & \\
\hline $\mathrm{COER}_{\mathrm{c}}$ & $\left(\right.$ gCarboidrato.gSVT $\left.{ }^{-1} \cdot \mathrm{d}^{-1}\right)$ & & & & & 0,21 & & - & \\
\hline $\mathrm{n}_{\mathrm{CH} 4}$ & $\left(\mathrm{molCH}_{4} \cdot \mathrm{d}^{-1}\right)$ & - & & - & & 0,2438 & & - & \\
\hline $\mathrm{X}_{\mathrm{CH} 4}$ & $(\%)$ & & & & & 72,72 & \pm & 0,15 & \\
\hline PrM & $\left(\mathrm{molCH}_{4} \cdot \mathrm{m}^{-3} \cdot \mathrm{d}^{-1}\right)$ & - & & - & & 96,6 & & - & \\
\hline PrME & $\left(\mathrm{molCH}_{4} \cdot \mathrm{kgSVT}^{-1} \cdot \mathrm{d}^{-1}\right)$ & - & & - & & 8,61 & & - & \\
\hline $\operatorname{PrV}$ & $\left(\mathrm{mL}-\mathrm{CNTPCH}_{4} \cdot \mathrm{L}^{-1} \cdot \mathrm{d}^{-1}\right)$ & - & & - & & 2166 & & - & \\
\hline PrVE & 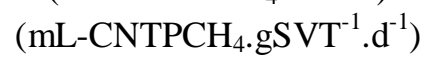 & - & & - & & 192,96 & & - & \\
\hline $\mathrm{RMCA}_{s}$ & $\left(\mathrm{mmolCH}_{4} \cdot \mathrm{gDQO}^{-1}\right)$ & 15,57 & & - & & - & & - & \\
\hline $\mathrm{RMCR}_{\mathbf{s}}$ & $\left(\mathrm{mmolCH}_{4} \cdot \mathrm{gDQO}^{-1}\right)$ & - & & - & & 17,63 & & - & \\
\hline $\mathrm{RMCA}_{\mathrm{c}}$ & $\left(\mathrm{mmolCH}_{4} \cdot \mathrm{gCarboidrato}^{-1}\right)$ & 20,19 & & - & & - & & - & \\
\hline $\mathrm{RMCR}_{\mathrm{c}}$ & $\left(\mathrm{mmolCH}_{4} \cdot \mathrm{gCarboidrato}^{-1}\right)$ & - & & - & & 20,43 & & - & \\
\hline $\mathrm{V}_{\mathrm{A}}$ & $\left(\mathrm{mL} . \mathrm{Ciclo}^{-1}\right)$ & 1023 & \pm & 18 & $(7)$ & - & & - & \\
\hline$V_{\text {RES }}$ & $(\mathrm{mL})$ & 1500 & & - & & - & & - & \\
\hline
\end{tabular}

*Os valores entre parêntesis representam o número de amostras consideradas para o cálculo da média 
Fonte: Autor (2017)

\subsubsection{Perfil ao longo do ciclo}

Durante o perfil, a concentração de matéria orgânica afluente na forma de DQO e de

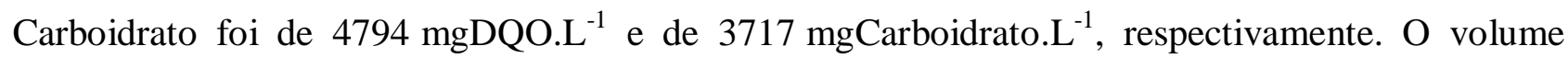
afluente foi diluído no volume residual que permanece no reator após a descarga, por isso no início do ciclo essas concentrações foram de $1731 \mathrm{mgDQO} . \mathrm{L}^{-1}$ e $925 \mathrm{mgCarboidrato.L^{-1 }}$.

Observa-se na Figura 5.4 a variação do pH ao longo do ciclo, com valor de 8,12 no afluente, mínimo durante o perfil de 7,46 e saindo com 7,77 no efluente. Também é possível acompanhar a variação da alcalinidade a bicarbonato e ácidos voláteis totais durante o ciclo. Os ácidos voláteis totais têm o pico de produção $\left(529 \mathrm{mgHAc} . \mathrm{L}^{-1}\right)$ em 1,5 horas de ciclo. O acúmulo de ácidos voláteis totais no reator não comprometeu a capacidade tampão do reator, resultando num valor mínimo de alcalinidade a bicarbonato de $1490 \mathrm{mg} \mathrm{CaCO}_{3} \cdot \mathrm{L}^{-1}$. Não houve grande excedente de ácidos voláteis nesta condição, indicando bom desempenho quanto à produção de alcalinidade a bicarbonato e de biogás. 
Figura 5.4 - Perfis de pH (a), alcalinidade a bicarbonato e a ácidos voláteis totais (b) na condição I
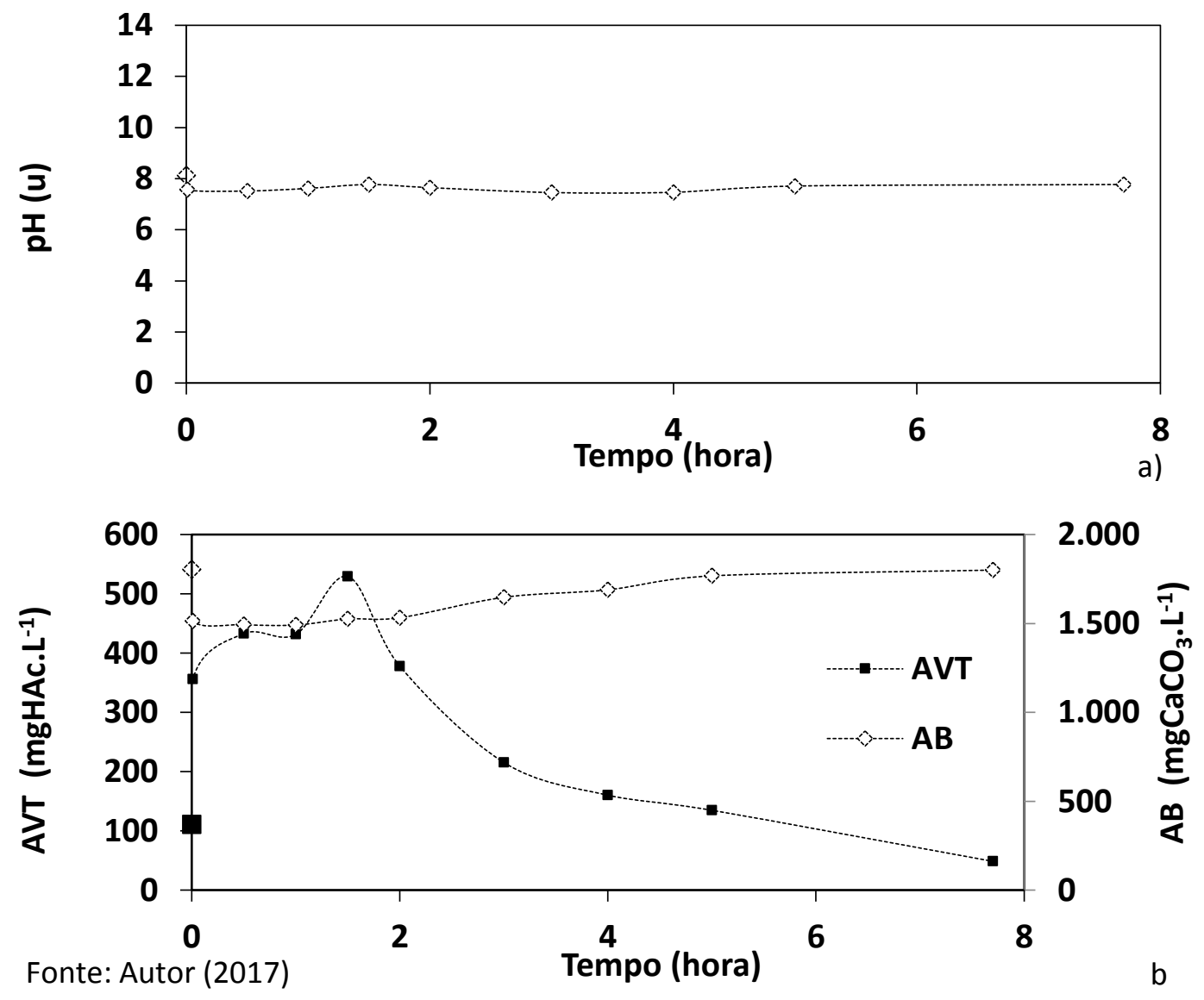

O consumo da matéria orgânica nas formas de DQO e Carboidrato ao longo do ciclo pode ser analisado através da Figura 5.5. Pode-se observar um rápido consumo da matéria orgânica na forma de carboidrato, resultando em $99 \%$ de consumo em 1 hora de ciclo. No mesmo período, a eficiência de remoção de DQO foi de $81 \%$. Com isso, se confirma a fácil biodegradabilidade do soro de leite. Apesar disso, este fator faz com que a produção de ácidos tenha seu pico logo após este período (1,5 horas), o que pode oferecer riscos ao reator caso a capacidade tamponante não seja suficiente, o que não ocorreu nesta condição. 
Figura 5.5 - Perfis de concentração e eficiência de remoção de DQO (a) e carboidratos (b) na condição I
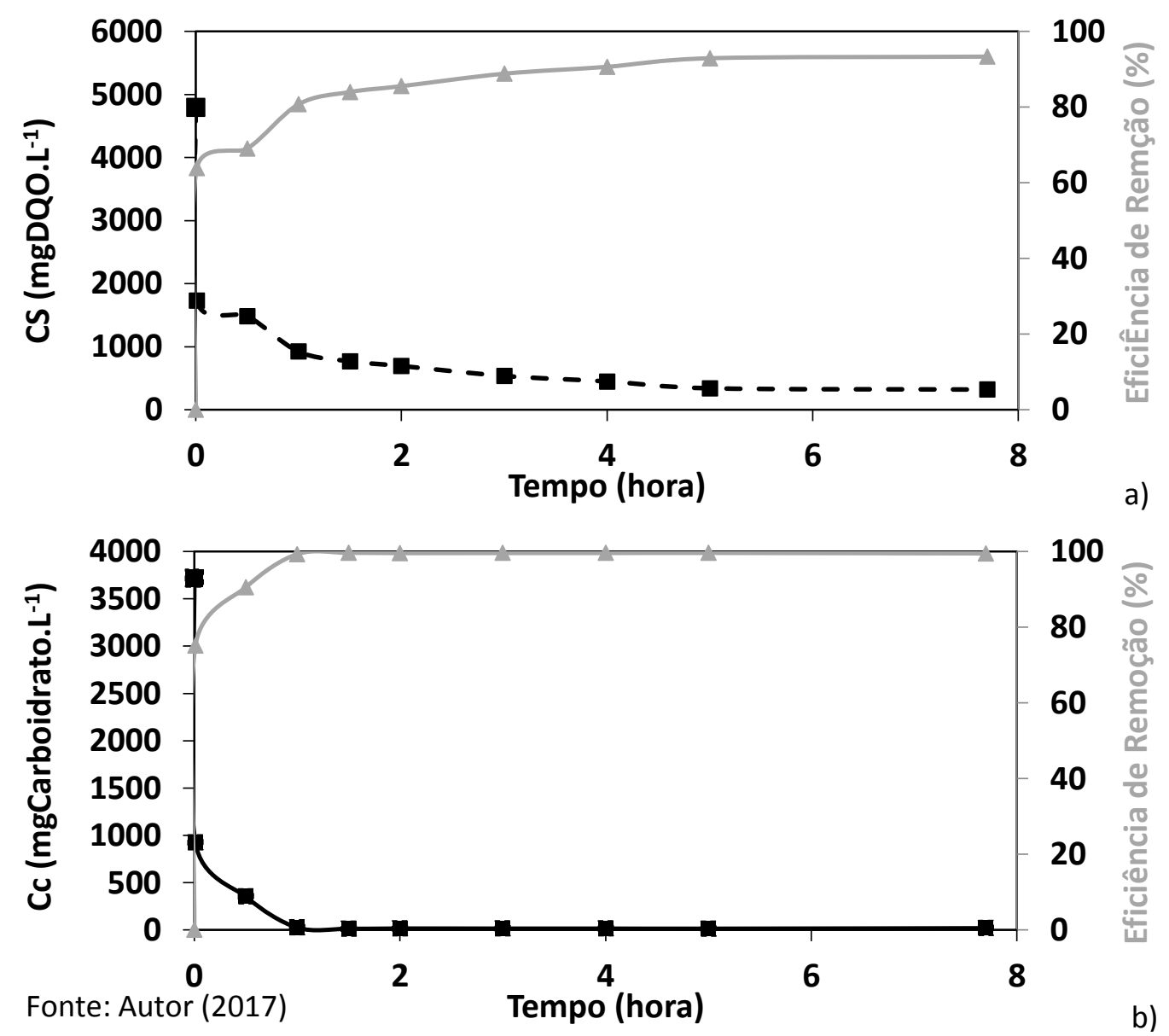

A variação da produção e consumo dos compostos metabólicos intermediários ao longo do ciclo pode ser observada pela Figura 5.6. Analisando o resultado, verifica-se que há certo acúmulo de ácido propiônico, o que pode ser um fator de risco caso este acúmulo seja mantido por maior período de tempo. Nesta condição, o ácido propiônico tem seu pico em 2 horas de ciclo, mas é quase totalmente consumido até o final da operação do reator, o que também acontece com os ácidos butírico e valérico. 
Figura 5.6 - Perfil das concentrações dos compostos intermediários ao longo do ciclo na Condição I

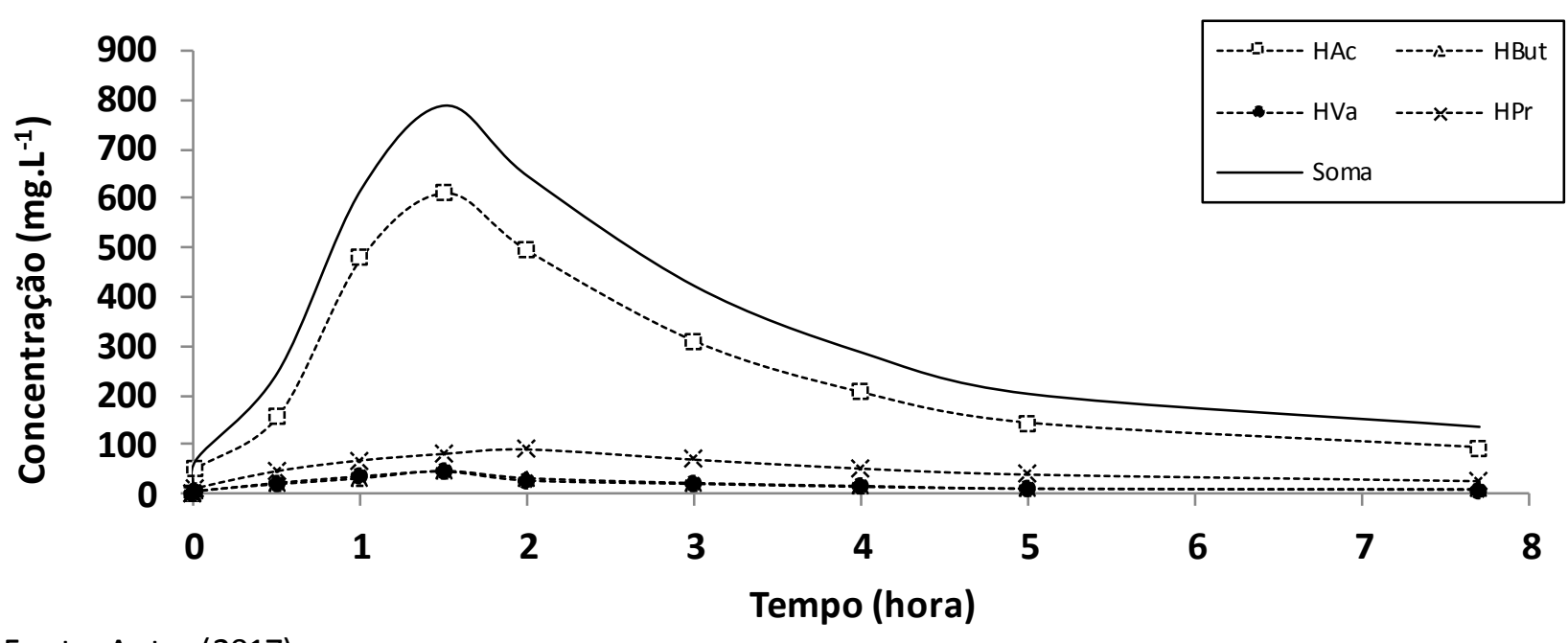

Fonte: Autor(2017)

A produção volumétrica de metano $\left(\mathrm{CH}_{4}\right)$ e dióxido de carbono $\left(\mathrm{CO}_{2}\right)$ ao longo do ciclo pode ser observada através da Figura 5.7. Nota-se que a produção volumétrica de metano foi predominante por todo o ciclo. Também se verifica a evolução das concentrações de metano e dióxido de carbono presente no biogás e a vazão molar de metano ao longo do ciclo além do volume total de biogás gerado durante o período. Durante os primeiros 30min de ciclo o biogás gerado apresentava pouca diferença nas concentrações de metano $\left(2,9\right.$ mmol. $\left.\mathrm{L}^{-1}\right)$ e dióxido de carbono $\left(1,9\right.$ mmol. $\left.\mathrm{L}^{-1}\right)$. A produção de metano é maior do que a de dióxido de carbono durante todo o período, resultando numa concentração final de $73 \%$ dos 2484 mL-CNTP.ciclo ${ }^{-1}$ de biogás gerados durante o ciclo. 
Figura 5.7 - Perfis de volume nas CNTP de metano e $\mathrm{CO}_{2}$ (a), concentração dos gases e vazão molar (b) e volume e concentração ao longo do ciclo (c) na condição I
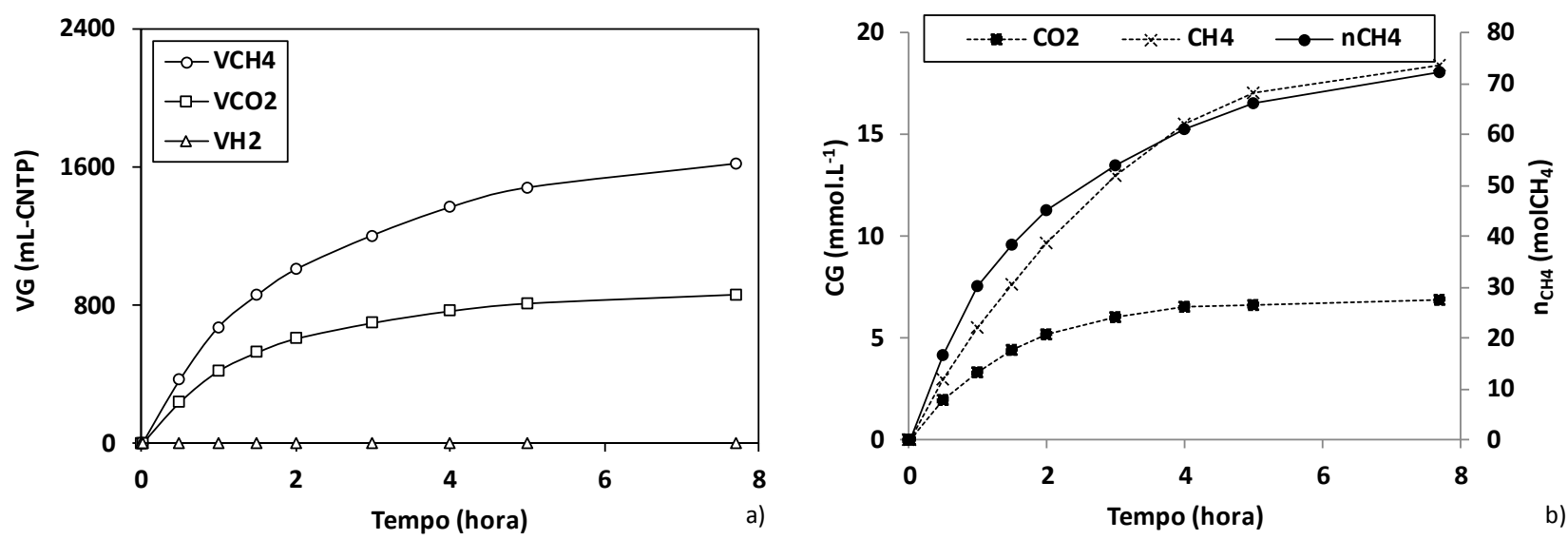

Produção e Composição do Biogás

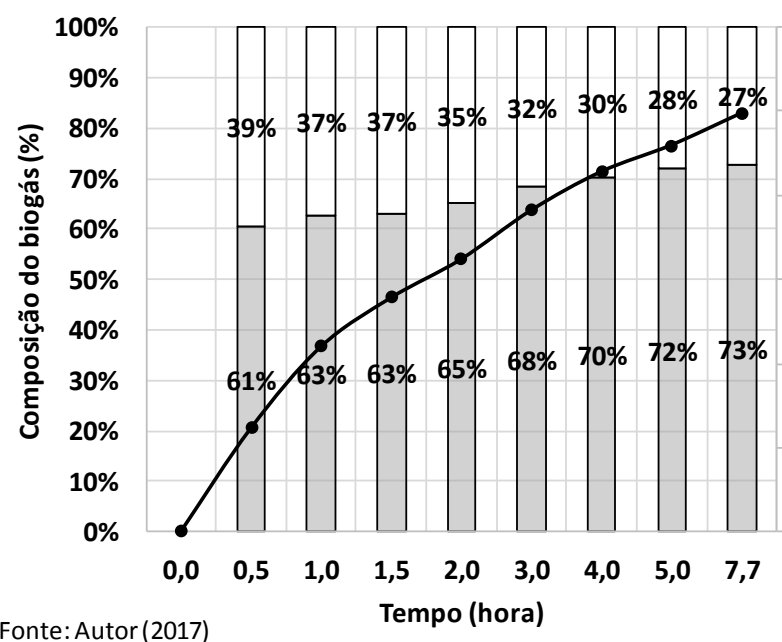

3000,0

2500,0

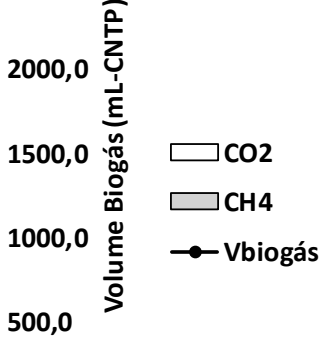

0,0

c)

Os dados do perfil indicam que o reator poderia ser operado eficientemente num ciclo de 5 horas. Os resultados indicam que houve remoção de 93\% de matéria orgânica na forma de DQO e 99,9\% de carboidratos, ambos na forma filtrada. Houve consumo de $75 \%$ da concentração máxima de ácidos voláteis. Além disso, houve a produção de 2294,8 mL-ciclo de biogás, contendo $72 \%$ de metano. 
5.2.1.3 Ajuste do modelo cinético

Os parâmetros cinéticos aparentes foram calculados (Tabela 5.2) e indicam maior produção de ácido acético através do substrato $\left(\mathrm{k}_{1 \mathrm{HAC}}\right)$ e também da conversão do ácido proprônico ( $\left.\mathrm{K}_{6 \mathrm{HAC}}\right)$. A produção de metano foi maior na rota metanogênica hidrogenotrófica $\left(\mathrm{K}_{11 \mathrm{M}}\right)$. Portanto, o modelo cinético foi ajustado de modo adequado pelos dados experimentais (Figura 5.8).

Tabela 5.2 - Parâmetros cinéticos da rota metabólica ao longo do ciclo na Condição I

\begin{tabular}{|c|c|c|}
\hline Condição & Parâmetro & Condição I \\
\hline \multirow{10}{*}{$\begin{array}{l}\text { Hidrólise e } \\
\text { Acidogênese }\end{array}$} & $\mathrm{k}_{1 \mathrm{~S}}^{\prime}\left(\mathrm{h}^{-1}\right)$ & 1,54 \\
\hline & $\mathrm{k}_{1 \mathrm{HAc}}\left(\mathrm{h}^{-1}\right)$ & 11,65 \\
\hline & $\mathrm{k}_{1 \mathrm{H}}\left(\mathrm{h}^{-1}\right)$ & 0,03 \\
\hline & $\mathrm{k}_{2 \mathrm{HPr}}\left(\mathrm{h}^{-1}\right)$ & 0,01 \\
\hline & $\mathrm{k}_{2 \mathrm{H}}\left(\mathrm{h}^{-1}\right)$ & 0,21 \\
\hline & $\mathrm{k}_{3 \mathrm{HBu}}\left(\mathrm{h}^{-1}\right)$ & 0,75 \\
\hline & $\mathrm{k}_{3 \mathrm{H}}\left(\mathrm{h}^{-1}\right)$ & 0,02 \\
\hline & $\mathrm{k}_{4 \mathrm{HVa}}\left(\mathrm{h}^{-1}\right)$ & 0,08 \\
\hline & $\mathrm{k}_{4 \mathrm{H}}\left(\mathrm{h}^{-1}\right)$ & 0,00 \\
\hline & $\mathrm{k}_{\text {5ЕTOH }}\left(\mathrm{h}^{-1}\right)$ & 0,00 \\
\hline \multirow{10}{*}{ Acetogênese } & $\mathrm{k}_{6 \mathrm{HPr}}\left(\mathrm{h}^{-1}\right)$ & 1,20 \\
\hline & $\mathrm{k}_{6 \mathrm{HAc}}\left(\mathrm{h}^{-1}\right)$ & 124,04 \\
\hline & $\mathrm{k}_{6 \mathrm{H}}\left(\mathrm{h}^{-1}\right)$ & 0,00 \\
\hline & $\mathrm{k}_{7 \mathrm{HPr}}\left(\mathrm{h}^{-1}\right)$ & 2,95 \\
\hline & $\mathrm{k}_{7 \mathrm{HBu}}\left(\mathrm{h}^{-1}\right)$ & 5,98 \\
\hline & $\mathrm{k}_{7 \mathrm{H}}\left(\mathrm{h}^{-1}\right)$ & 0,06 \\
\hline & $\mathrm{k}_{8 \mathrm{HBu}}\left(\mathrm{h}^{-1}\right)$ & 7,24 \\
\hline & $\mathrm{k}_{8 \mathrm{HVa}}\left(\mathrm{h}^{-1}\right)$ & 0,35 \\
\hline & $\mathrm{k}_{8 \mathrm{H}}\left(\mathrm{h}^{-1}\right)$ & 0,20 \\
\hline & $\mathrm{k}_{9 \mathrm{HAc}}\left(\mathrm{h}^{-1}\right)$ & 0,00 \\
\hline \multirow{4}{*}{ Metanogênese } & $\mathrm{k}_{10 \mathrm{HAc}}\left(\mathrm{h}^{-1}\right)$ & 13,83 \\
\hline & $\mathrm{k}_{10 \mathrm{H}}\left(\mathrm{h}^{-1}\right)$ & 7,87 \\
\hline & $\mathrm{k}_{11 \mathrm{H}}\left(\mathrm{h}^{-1}\right)$ & 0,20 \\
\hline & $\mathrm{k}_{11 \mathrm{M}}\left(\mathrm{h}^{-1}\right)$ & 178,08 \\
\hline
\end{tabular}


Figura 5.8 - Dados experimentais (marcadores) e modelo (linha) do metano (a), substrato (b) e ácidos intermediários (c) na Condição I
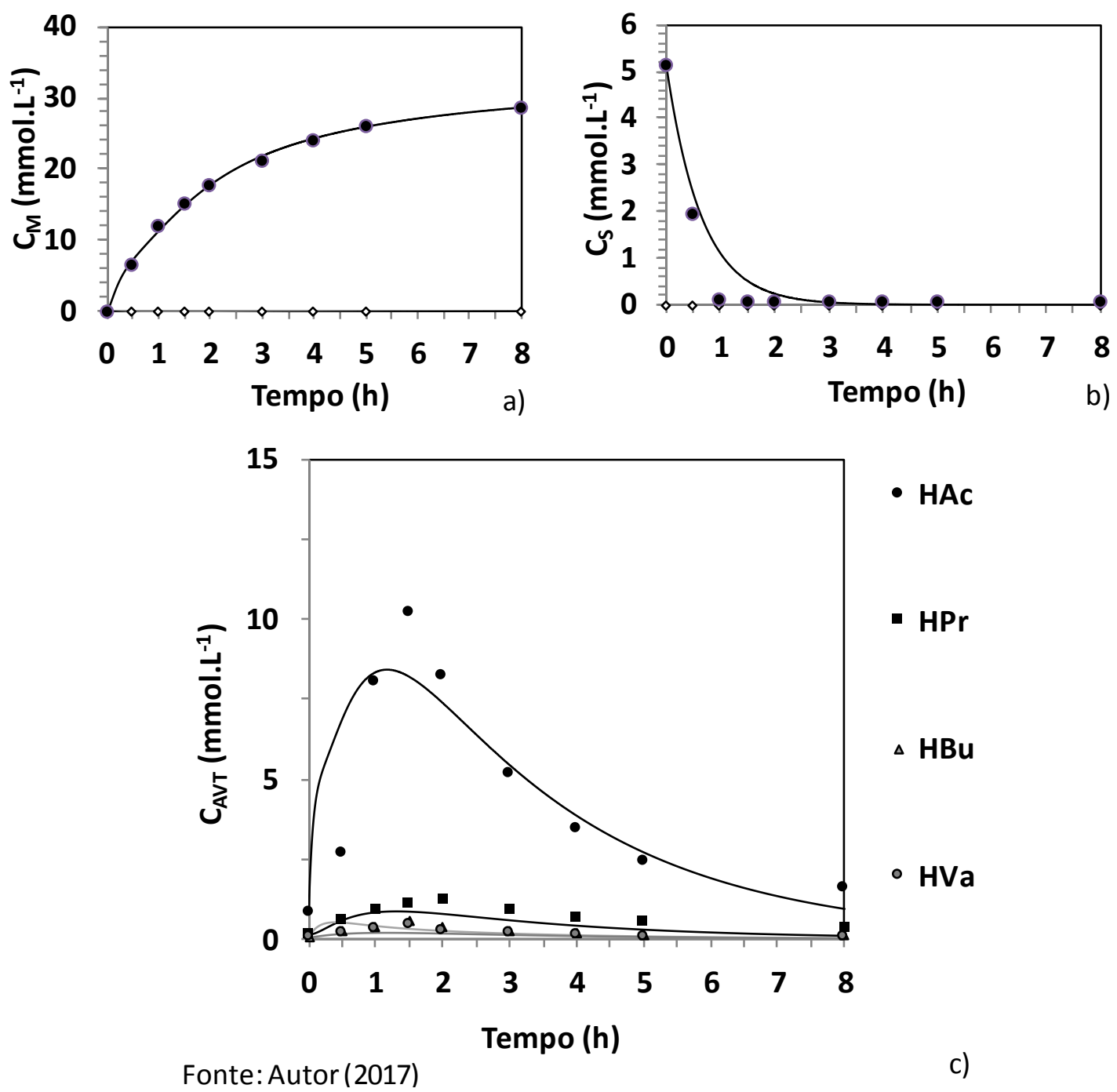

5.2.2 Condição II - $6.000 \mathrm{mg}$ DQO L ${ }^{-1} ; 100 \%$ Soro; 50 a $33 \%$ de bicarbonato; $55^{\circ} \mathrm{C}$; Batelada

Nesta condição de operação, o valor nominal de DQO alimentado ao reator foi de $6000 \mathrm{mg}$ $\mathrm{L}^{-1}$ com carga orgânica aplicada teórica de 7,20 g DQO $\mathrm{L}^{-1} \mathrm{dia}^{-1}$. 


\subsubsection{Monitoramento}

O reator foi operado por 11 dias, em que a concentração média da matéria orgânica afluente

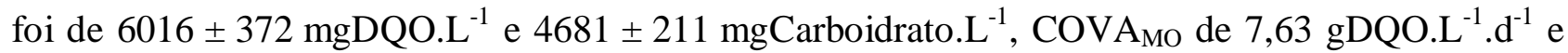
$\operatorname{COVA}_{\mathrm{C}}$ de 5,94 gCarboidrato. $\mathrm{L}^{-1} \cdot \mathrm{d}^{-1}$. A quantidade de biomassa contida no reator foi de $36,7 \mathrm{~g}$.

Os valores referentes ao monitoramento e aos indicadores desempenho encontram-se apresentados na Tabela 5.3 a seguir. A eficiência de remoção de matéria orgânica na forma de DQO desta condição, para amostras não-filtradas e filtradas, respectivamente, foi de $93 \pm 02 \%$ e $95 \pm 02 \%$. Para a matéria orgânica na forma de Carboidratos (lactose) a remoção foi de $99 \pm 00 \%$ e $100 \pm 00 \%$, respectivamente para não-filtradas e filtradas. $\mathrm{O} \mathrm{pH}$ afluente foi de $8,43 \pm 0,03$ e o efluente 8,24 $\pm 0,19$. A alcalinidade a bicarbonato do afluente $\mathrm{e}$ efluente foram $1904 \pm 79 \mathrm{mgCaCO} \cdot \mathrm{L}^{-1}$ e $2170 \pm 38 \mathrm{mgCaCO}_{3} \cdot \mathrm{L}^{-1}$. A alcalinidade referente aos ácidos voláteis do afluente e efluente foram $162 \pm 05 \mathrm{mgHAc} . \mathrm{L}^{-1}$ e $87 \pm 55 \mathrm{mgHac} . \mathrm{L}^{-1}$. Nota-se que o reator apresentou grande capacidade produtiva de alcalinidade a bicarbonato, resultando em concentrações maiores no efluente do que no afluente. Devido à isso, optou-se pela redução da fração afluente de bicarbonato na condição seguinte.

A concentração de sólidos suspensos voláteis (SSV) no efluente indica que houve pouca perda de biomassa no reator.

O rendimento de metano gerado por matéria orgânica consumida foi de 16,52 $\mathrm{mmolCH}_{4} \cdot \mathrm{gDQO}^{-1}$ e 21,23 $\mathrm{mmolCH}_{4} \cdot \mathrm{gCarboidrato}^{-1}$. A produção de biogás foi de $3343 \pm 364 \mathrm{~mL}-$ CNTP.ciclo $^{-1}$, sendo a fração molar de metano equivalente a 73,22 $\pm 0,23 \%$ e a produtividade molar de metano de $126,1 \mathrm{molCH}_{4} \cdot \mathrm{m}^{-3} \cdot \mathrm{d}^{-1}$. 
Tabela 5.3 - Resumo dos valores médios obtidos no monitoramento do reator com concentração afluente de $6000 \mathrm{mgDQO}^{-1}$ na condição II

\begin{tabular}{|c|c|c|c|c|c|c|c|c|c|}
\hline \multicolumn{2}{|r|}{ Parâmetro } & \multicolumn{4}{|c|}{ Afluente } & \multicolumn{4}{|c|}{ Efluente } \\
\hline $\mathrm{C}_{\mathrm{ST}}$ & $\left(\mathrm{mgDQO} . \mathrm{L}^{-1}\right)$ & 6016 & \pm & 372 & $(8)$ & 451 & \pm & 141 & $(8)$ \\
\hline $\mathrm{C}_{\mathrm{SF}}$ & (mgDQO.L $\left.{ }^{-1}\right)$ & - & & - & & 317 & \pm & 113 & $\left(\begin{array}{l}8 \\
8\end{array}\right)$ \\
\hline$\varepsilon_{\mathrm{ST}}$ & $(\%)$ & - & & - & & $93 \%$ & \pm & $2 \%$ & $\left(\begin{array}{l}8 \\
8\end{array}\right)$ \\
\hline$\varepsilon_{\mathrm{SF}}$ & $(\%)$ & - & & - & & $95 \%$ & \pm & $2 \%$ & $\left(\begin{array}{l}8 \\
8\end{array}\right)$ \\
\hline $\mathrm{C}_{\mathrm{CT}}$ & $\left(\right.$ mgCarboidrato. $\left.\mathrm{L}^{-1}\right)$ & 4681 & \pm & 211 & $\left(\begin{array}{ll}8 & )\end{array}\right.$ & 34 & \pm & 14 & $\left(\begin{array}{l}8 \\
(8)\end{array}\right.$ \\
\hline $\mathrm{C}_{\mathrm{CF}}$ & (mgCarboidrato. $\mathrm{L}^{-1}$ ) & - & & - & & 21 & \pm & 12 & $\left(\begin{array}{ll}8\end{array}\right)$ \\
\hline$\varepsilon_{\mathrm{CT}}$ & $(\%)$ & - & & - & & $99 \%$ & \pm & $0 \%$ & \\
\hline$\varepsilon_{\mathrm{CF}}$ & $(\%)$ & - & & - & & $100 \%$ & \pm & $0 \%$ & \\
\hline $\mathrm{pH}$ & (u) & 8,43 & \pm & 0,03 & $\left(\begin{array}{ll}9 & )\end{array}\right.$ & 8,24 & \pm & 0,19 & $\left(\begin{array}{ll}9 & )\end{array}\right.$ \\
\hline AVT & $\left(\operatorname{mgHAc} . \mathrm{L}^{-1}\right)$ & 162 & \pm & 5 & $\left(\begin{array}{ll}9\end{array}\right)$ & 87 & \pm & 55 & $\left(\begin{array}{l}9 \\
)\end{array}\right)$ \\
\hline AT & $\left(\mathrm{mgCaCO}{ }_{3} \cdot \mathrm{L}^{-1}\right)$ & 1904 & \pm & 80 & $\left(\begin{array}{ll}9 & )\end{array}\right.$ & 2232 & \pm & 103 & $\left(\begin{array}{l}9 \\
)\end{array}\right)$ \\
\hline $\mathrm{AP}$ & $\left(\mathrm{mgCaCO}_{3} \cdot \mathrm{L}^{-1}\right)$ & 397 & \pm & 38 & $\left(\begin{array}{ll}9\end{array}\right)$ & 1790 & \pm & 110 & $\left(\begin{array}{l}9 \\
)\end{array}\right.$ \\
\hline AI & $\left(\mathrm{mgCaCO}_{3} \cdot \mathrm{L}^{-1}\right)$ & 1622 & \pm & 63 & $\left(\begin{array}{ll}9 \\
)\end{array}\right.$ & 441 & \pm & 57 & $(9)$ \\
\hline $\mathrm{AB}$ & $\left(\mathrm{mgCaCO}_{3} \cdot \mathrm{L}^{-1}\right)$ & 1904 & \pm & 79 & $\left(\begin{array}{ll}9 & )\end{array}\right.$ & 2170 & \pm & 138 & $\left(\begin{array}{ll}9 & )\end{array}\right.$ \\
\hline ST & $\left(\mathrm{mg} . \mathrm{L}^{-1}\right)$ & 6551 & \pm & 326 & $\left(\begin{array}{l}3 \\
3\end{array}\right)$ & 3090 & \pm & 198 & $\left(\begin{array}{l}3 \\
3\end{array}\right)$ \\
\hline SVT & $\left(\mathrm{mg} \cdot \mathrm{L}^{-1}\right)$ & 3996 & \pm & 280 & $(3)$ & 813 & \pm & 145 & $\left(\begin{array}{ll}3 \\
)\end{array}\right)$ \\
\hline SST & $\left(\mathrm{mg} \cdot \mathrm{L}^{-1}\right)$ & 205 & \pm & 41 & $(3)$ & 183 & \pm & 67 & $\left(\begin{array}{ll}3 \\
)\end{array}\right)$ \\
\hline SSV & $\left(\mathrm{mg} \cdot \mathrm{L}^{-1}\right)$ & 143 & \pm & 20 & $(3)$ & 127 & \pm & 50 & $(3)$ \\
\hline SDF & $\left(\mathrm{mg} \cdot \mathrm{L}^{-1}\right)$ & 2208 & & - & & 1967 & & - & \\
\hline $\mathrm{M}_{\mathrm{SVT}}$ & (g) & 36,7 & & - & & - & & - & \\
\hline $\mathrm{C}_{\mathrm{X}}$ & $\left(\mathrm{gSVT} . \mathrm{L}^{-1}\right)$ & 14,1 & & - & & - & & - & \\
\hline $\mathrm{C}_{\mathrm{X}}^{\prime}$ & $\left(\right.$ gSVT.gsuporte $^{-1}$ ) & 0,9 & & - & & - & & - & \\
\hline $\mathrm{V}_{\mathrm{G}}$ & $\left(\mathrm{mL}-\mathrm{CNTP} . \mathrm{Ciclo}^{-1}\right)$ & - & & - & & 3343 & \pm & 364 & $(5)$ \\
\hline $\mathrm{V}_{\mathrm{CH} 4}$ & $\left(\mathrm{~mL}-\mathrm{CNTPCH}_{4} \cdot \mathrm{Ciclo}^{-1}\right)$ & - & & - & & 2448 & & - & \\
\hline $\mathrm{COVA}_{\mathrm{S}}$ & $\left(\mathrm{gDQO} \cdot \mathrm{L}^{-1} \cdot \mathrm{d}^{-1}\right)$ & 7,63 & & - & & - & & - & \\
\hline $\mathrm{COVR}_{\mathrm{S}}$ & $\left(\mathrm{gDQO} \cdot \mathrm{L}^{-1} \cdot \mathrm{d}^{-1}\right)$ & - & & - & & 7,06 & & - & \\
\hline $\mathrm{COEA}_{\mathrm{S}}$ & $\left(\right.$ gDQO.gSVT $\left.{ }^{-1} \cdot \mathrm{d}^{-1}\right)$ & 0,54 & & - & & - & & - & \\
\hline $\mathrm{COER}_{\mathrm{S}}$ & $\left(\mathrm{gDQO} \cdot \mathrm{gSVT}^{-1} \cdot \mathrm{d}^{-1}\right)$ & - & & - & & 0,25 & & - & \\
\hline $\mathrm{COVA}_{\mathrm{c}}$ & (gCarboidrato. $\left.\mathrm{L}^{-1} \cdot \mathrm{d}^{-1}\right)$ & 5,94 & & - & & & & - & \\
\hline $\mathrm{COVR}_{\mathrm{c}}$ & (gCarboidrato. $\left.\mathrm{L}^{-1} \cdot \mathrm{d}^{-1}\right)$ & & & - & & 5,89 & & - & \\
\hline $\mathrm{COEA}_{c}$ & $\left(\mathrm{gCarboidrato.gSVT}^{-1} \cdot \mathrm{d}^{-1}\right)$ & 0,42 & & - & & & & - & \\
\hline $\mathrm{COER}_{\mathrm{c}}$ & (gCarboidrato.gSVT ${ }^{-1} \cdot \mathrm{d}^{-1}$ ) & & & & & 0,21 & & - & \\
\hline $\mathrm{n}_{\mathrm{CH} 4}$ & $\left(\mathrm{molCH}_{4} \cdot \mathrm{d}^{-1}\right)$ & - & & - & & 0,3277 & & - & \\
\hline $\mathrm{X}_{\mathrm{CH} 4}$ & $(\%)$ & & & & & 73,22 & \pm & 0,23 & \\
\hline PrM & $\left(\mathrm{molCH}_{4} \cdot \mathrm{m}^{-3} \cdot \mathrm{d}^{-1}\right)$ & - & & - & & 126,1 & & - & \\
\hline PrME & $\left(\mathrm{molCH}_{4} \cdot \mathrm{kgSVT}^{-1} \cdot \mathrm{d}^{-1}\right)$ & - & & - & & 8,93 & & - & \\
\hline $\operatorname{PrV}$ & $\left(\mathrm{mL}-\mathrm{CNTPCH} 4 \cdot \mathrm{L}^{-1} \cdot \mathrm{d}^{-1}\right)$ & - & & - & & 2826 & & - & \\
\hline PrVE & 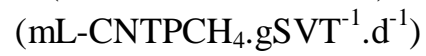 & - & & - & & 200,12 & & - & \\
\hline $\mathrm{RMCA}_{s}$ & $\left(\mathrm{mmolCH}_{4} \cdot \mathrm{gDQO}^{-1}\right)$ & 16,52 & & - & & - & & - & \\
\hline $\mathrm{RMCR}_{\mathbf{s}}$ & $\left(\mathrm{mmolCH}_{4} \cdot \mathrm{gDQO}^{-1}\right)$ & - & & - & & 17,86 & & - & \\
\hline $\mathrm{RMCA}_{\mathrm{c}}$ & $\left(\mathrm{mmolCH}_{4} \cdot \mathrm{gCarboidrato}^{-1}\right)$ & 21,23 & & - & & - & & - & \\
\hline $\mathrm{RMCR}_{\mathrm{c}}$ & $\left(\mathrm{mmolCH}_{4} \cdot\right.$ gCarboidrato $\left.^{-1}\right)$ & - & & - & & 21,39 & & - & \\
\hline $\mathrm{V}_{\mathrm{A}}$ & $\left(\mathrm{mL} . \mathrm{Ciclo}^{-1}\right)$ & 1099 & \pm & 305 & 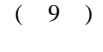 & - & & - & \\
\hline$V_{\text {RES }}$ & $(\mathrm{mL})$ & 1500 & & - & & - & & - & \\
\hline
\end{tabular}

*Os valores entre parêntesis representam o número de amostras consideradas para o cálculo da média Fonte: Autor (2017) 


\subsubsection{Perfil ao longo do ciclo}

Durante o perfil, a concentração de matéria orgânica afluente na forma de DQO e de

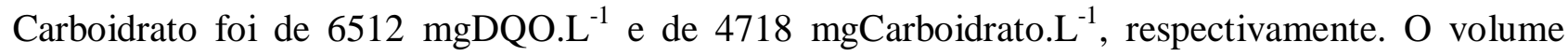
afluente foi diluído no volume residual que permanece no reator após a descarga, resultando em concentrações de 2736 mgDQO.L ${ }^{-1}$ e 1097 mgCarboidrato. $\mathrm{L}^{-1}$ no início de operação.

Observa-se na Figura 5.9 a variação do pH ao longo do ciclo, com valor de 8,45 no afluente, mínimo de 7,60 e com 8,20 no efluente. Também é possível acompanhar a variação da alcalinidade a bicarbonato e ácidos voláteis totais durante o ciclo. Os ácidos voláteis totais têm o pico de produção $\left(879 \mathrm{mgHAc} . \mathrm{L}^{-1}\right)$ em 1,0 hora de ciclo. O acúmulo de ácidos voláteis totais no reator não comprometeu a capacidade tampão do reator, resultando num valor mínimo de alcalinidade a bicarbonato de $1467 \mathrm{mg} \mathrm{CaCO} 3 \cdot \mathrm{L}^{-1}$. Não houve grande excedente de ácidos voláteis nesta condição, indicando bom desempenho quanto à produção de bicarbonato e de biogás. 
Figura 5.9 - Perfis de pH (a), alcalinidade a bicarbonato e a ácidos voláteis totais (b) na condição II
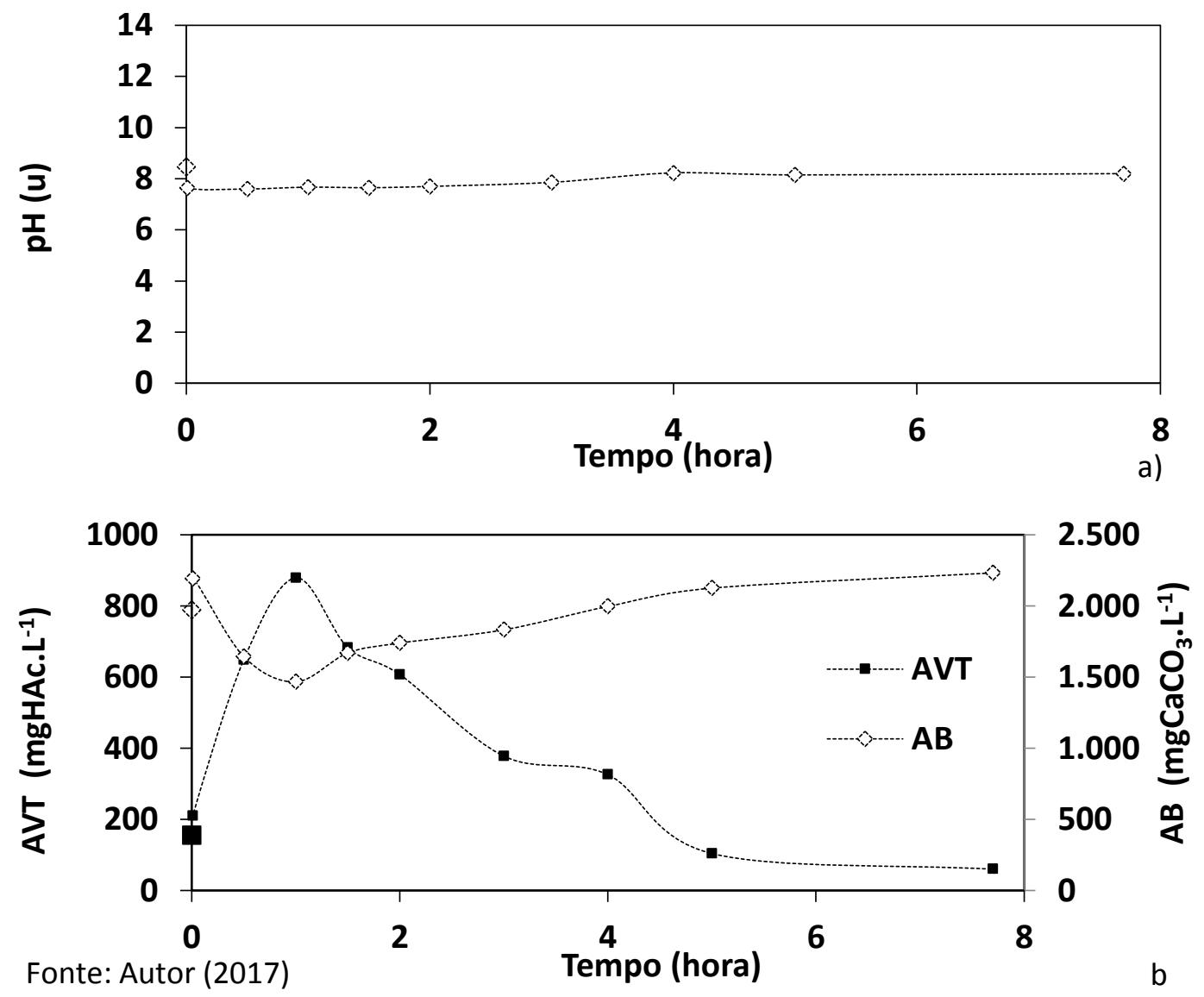

O consumo da matéria orgânica nas formas de DQO e Carboidrato ao longo do ciclo pode ser analisado através da Figura 5.10. Pode-se observar um rápido consumo da matéria orgânica na forma de carboidrato, resultando em $97 \%$ de consumo em 0,5 hora de ciclo. No mesmo período, a eficiência de remoção de DQO foi de $81 \%$, atingindo $97 \%$ após 8 horas. 
Figura 5.10 - Perfis de concentração e eficiência de remoção de DQO (a) e carboidratos (b) na condição II
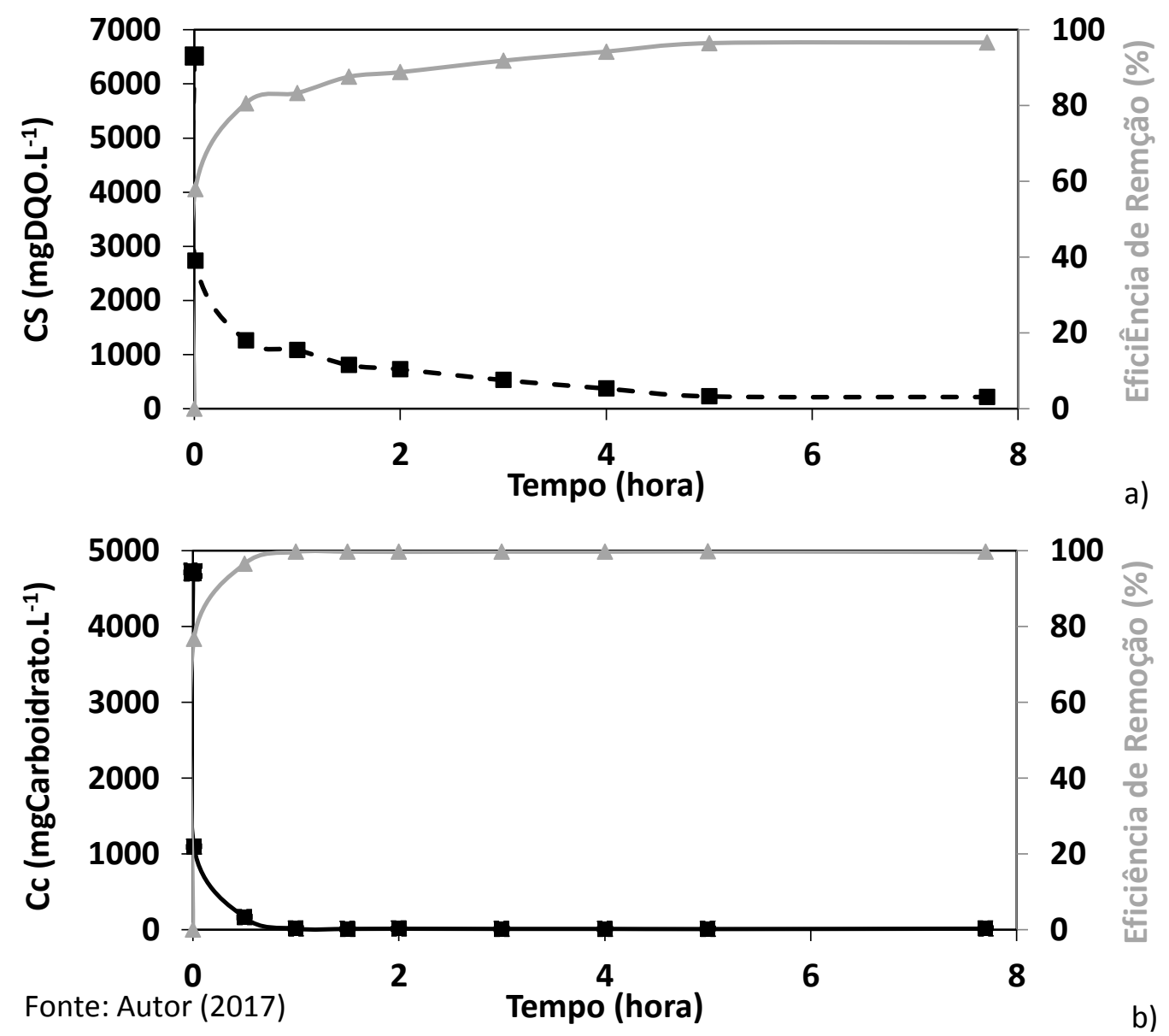

A variação da produção e consumo dos compostos metabólicos intermediários ao longo do ciclo pode ser observada pela Figura 5.11. Nesta condição, não houve acúmulo de ácido propiônico, o qual manteve sua concentração sempre abaixo de 125 mg.L- ${ }^{1}$. 
Figura 5.11 - Perfil das concentrações dos compostos intermediários ao longo do ciclo na condição II

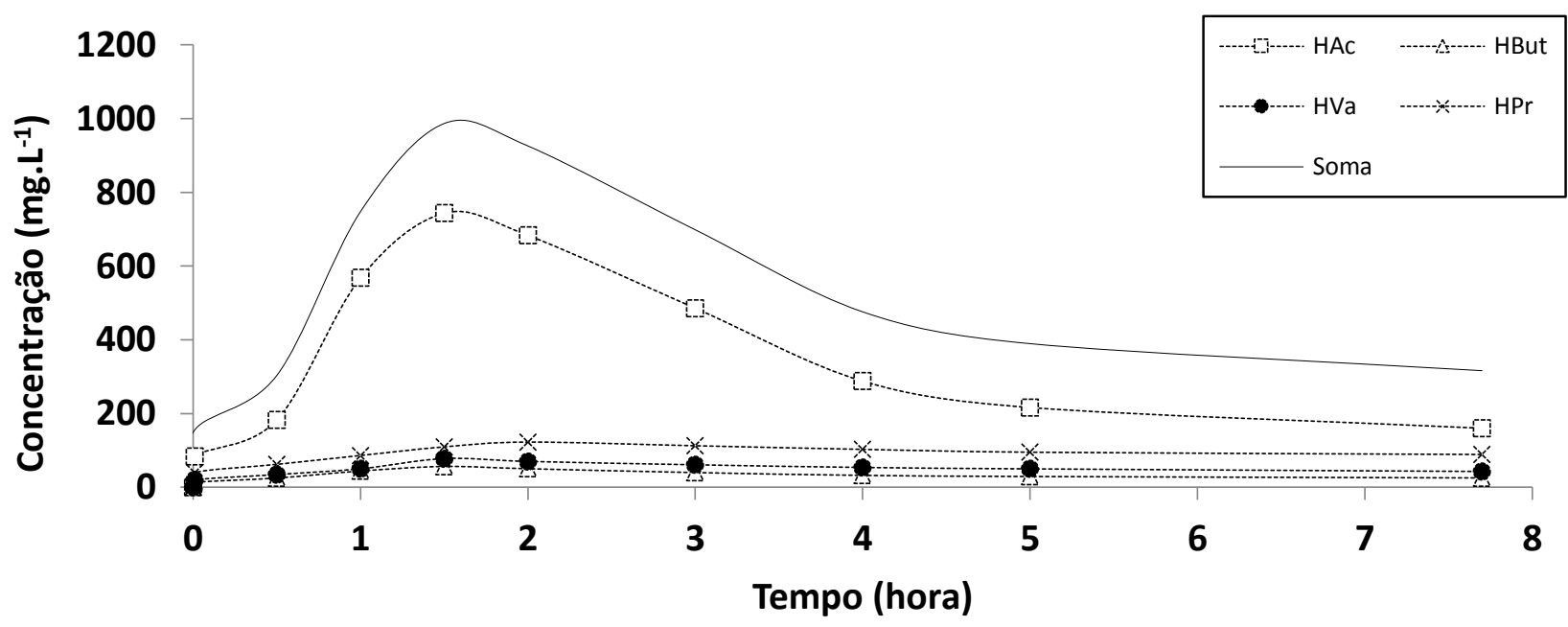

Fonte: Autor (2017)

A produção volumétrica de metano $\left(\mathrm{CH}_{4}\right)$ e dióxido de carbono $\left(\mathrm{CO}_{2}\right)$ ao longo do ciclo pode ser observada através da Figura 5.12. Nota-se que a produção volumétrica de metano foi predominante por todo o ciclo. Também se verifica a evolução das concentrações de metano e dióxido de carbono presente no biogás e a vazão molar de metano ao longo do ciclo além do volume total de biogás gerado durante o período. A produção de metano é maior do que a de dióxido de carbono durante todo o período, resultando numa concentração final de $73 \%$ dos 3343 mL-CNTP.ciclo ${ }^{-1}$ de biogás gerados durante o ciclo. 
Figura 5.12 - Perfis de volume nas CNTP de metano e $\mathrm{CO}_{2}$ (a), concentração dos gases e vazão molar (b) e volume e concentração ao longo do ciclo (c) na condição II
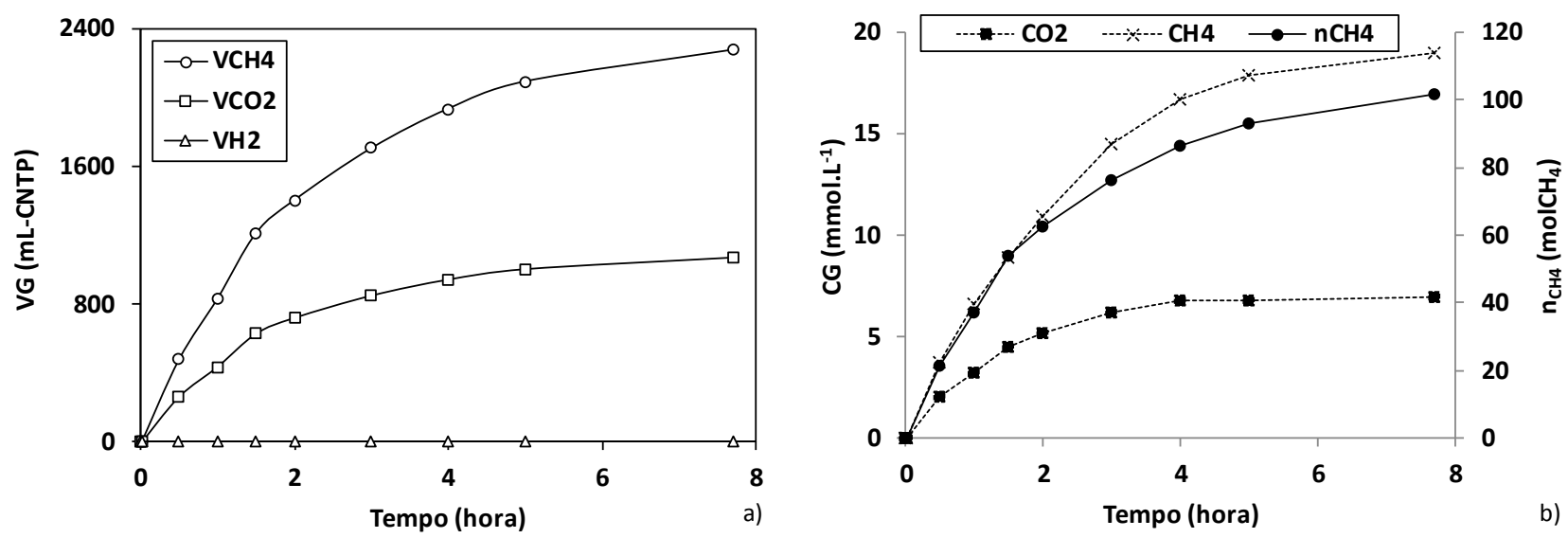

Produção e Composição do Biogás
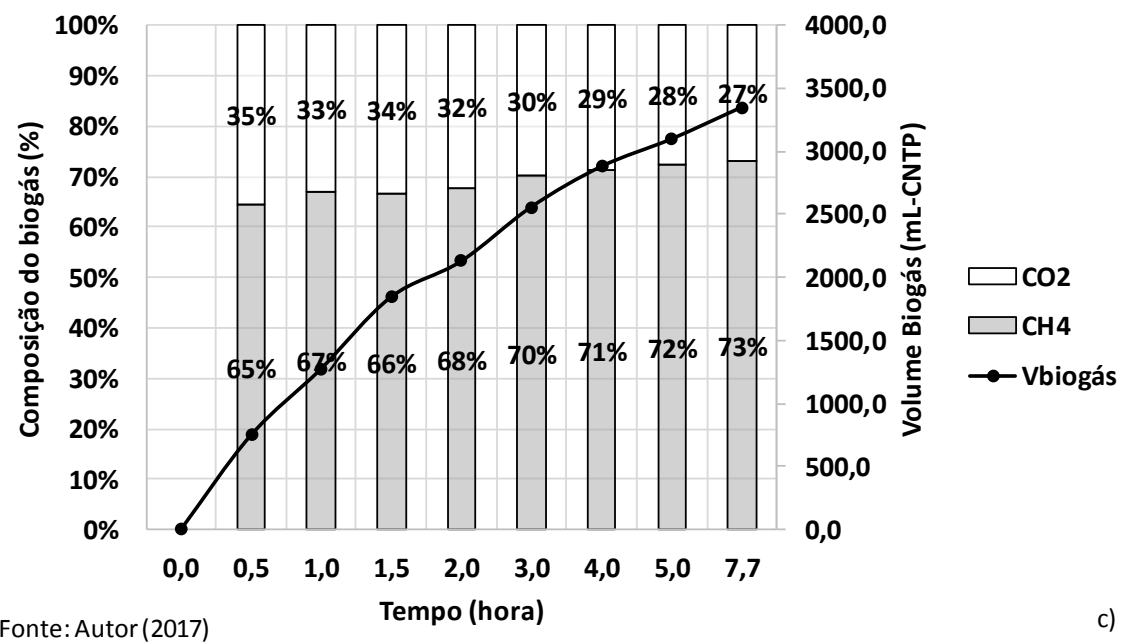

c)

Os dados do perfil indicam que o reator poderia ser operado eficientemente num ciclo de 5 horas. Os resultados indicam que houve remoção de 96\% de matéria orgânica na forma de DQO e 99,9\% de carboidratos, ambos na forma filtrada. Houve consumo de $88 \%$ da concentração máxima de ácidos voláteis. Além disso, houve a produção de 3093,1 mL-ciclo de biogás, contendo 72\% de metano. 
5.2.2.3 Ajuste do modelo cinético

Os parâmetros cinéticos aparentes foram calculados (Tabela 5.4) e indicam maior produção de ácido acético através do substrato $\left(\mathrm{k}_{1 \mathrm{HAC}}\right)$ e também da conversão do ácido proprônico ( $\left.\mathrm{K}_{6 \mathrm{HAC}}\right)$. A produção de metano foi maior na rota metanogênica hidrogenotrófica $\left(\mathrm{K}_{11 \mathrm{M}}\right)$. Portanto, o modelo cinético foi ajustado de modo adequado pelos dados experimentais (Figura 5.13).

Tabela 5.4 - Parâmetros cinéticos da rota metabólica ao longo do ciclo na condição II

\begin{tabular}{ccc}
\hline Condição & Parâmetro & Condição II \\
\hline & $\mathrm{k}_{1 \mathrm{~S}}^{\prime}\left(\mathrm{h}^{-1}\right)$ & 1,54 \\
& $\mathrm{k}_{1 \mathrm{HAc}}\left(\mathrm{h}^{-1}\right)$ & 3,00 \\
& $\mathrm{k}_{1 \mathrm{H}}\left(\mathrm{h}^{-1}\right)$ & 0,00 \\
& $\mathrm{k}_{2 \mathrm{HPr}}\left(\mathrm{h}^{-1}\right)$ & 0,00 \\
Hidrólise e & $\mathrm{k}_{2 \mathrm{H}}\left(\mathrm{h}^{-1}\right)$ & 0,03 \\
Acidogênese & $\mathrm{k}_{3 \mathrm{HBu}}\left(\mathrm{h}^{-1}\right)$ & 0,24 \\
& $\mathrm{k}_{3 \mathrm{H}}\left(\mathrm{h}^{-1}\right)$ & 0,00 \\
& $\mathrm{k}_{4 \mathrm{HVa}}\left(\mathrm{h}^{-1}\right)$ & 0,07 \\
& $\mathrm{k}_{4 \mathrm{H}}\left(\mathrm{h}^{-1}\right)$ & 0,00 \\
& $\mathrm{k}_{5 \mathrm{ETOH}}\left(\mathrm{h}^{-}\right.$ & 0,00 \\
$\left.\mathrm{H}^{1}\right)$ & 0,49 \\
& $\mathrm{k}_{6 \mathrm{HPr}}\left(\mathrm{h}^{-1}\right)$ & 2,21 \\
& $\mathrm{k}_{6 \mathrm{HAc}}\left(\mathrm{h}^{-1}\right)$ & 0,00 \\
& $\mathrm{k}_{6 \mathrm{H}}\left(\mathrm{h}^{-1}\right)$ & 2,94 \\
& $\mathrm{k}_{7 \mathrm{HPr}}\left(\mathrm{h}^{-1}\right)$ & 1,11 \\
& $\mathrm{k}_{7 \mathrm{HBu}}\left(\mathrm{h}^{-1}\right)$ & 0,00 \\
& $\mathrm{k}_{7 \mathrm{H}}\left(\mathrm{h}^{-1}\right)$ & 0,08 \\
& $\mathrm{k}_{8 \mathrm{HBu}}\left(\mathrm{h}^{-1}\right)$ & 0,00 \\
& $\mathrm{k}_{8 \mathrm{HVa}}\left(\mathrm{h}^{-1}\right)$ & 0,00 \\
$\mathrm{k}_{8 \mathrm{H}}\left(\mathrm{h}^{-1}\right)$ & 0,03 \\
$\mathrm{k}_{9 \mathrm{HAc}}\left(\mathrm{h}^{-1}\right)$ & 0,00 \\
\hline $\mathrm{k}_{10 \mathrm{HAc}}\left(\mathrm{h}^{-1}\right)$ & 0,56 \\
$\mathrm{k}_{10 \mathrm{H}}\left(\mathrm{h}^{-1}\right)$ & 9,23 \\
$\mathrm{k}_{11 \mathrm{H}}\left(\mathrm{h}^{-1}\right)$ & 0,01 \\
$\mathrm{k}_{11 \mathrm{M}}\left(\mathrm{h}^{-1}\right)$ & 767,56 \\
\hline Metanogêêenes &
\end{tabular}


Figura 5.13 - Dados experimentais (marcadores) e modelo (linha) do metano (a), substrato (b) e ácidos intermediários (c) na condição II
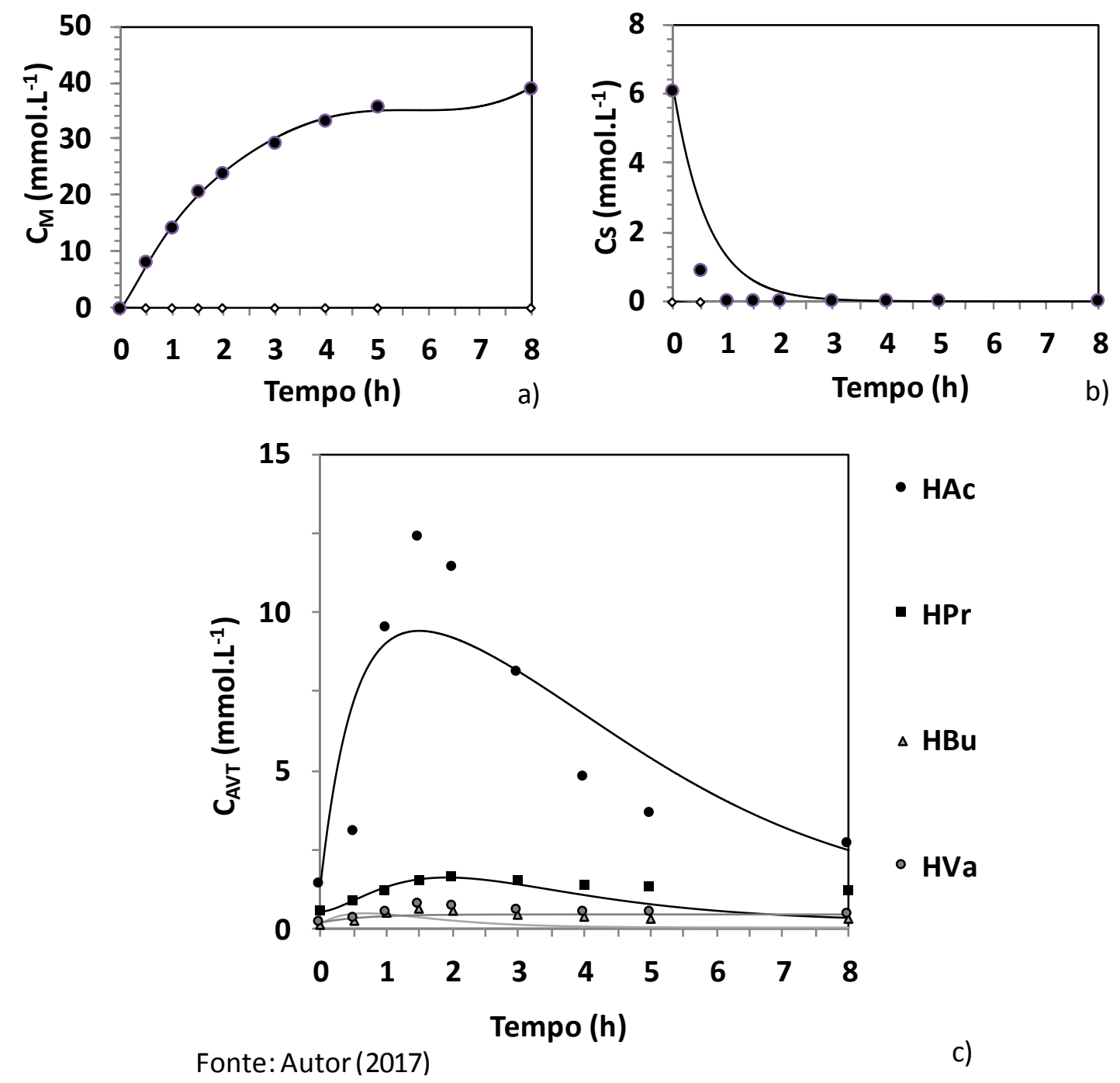

5.2.3 Condição III - $7.000 \mathrm{mg}$ DQO L L $; 100 \%$ Soro; 50 a $25 \%$ de bicarbonato; $55^{\circ} \mathrm{C}$; Batelada

Nesta condição de operação, o valor nominal de DQO alimentado ao reator foi de $7000 \mathrm{mg}$ $\mathrm{L}^{-1}$ com carga orgânica aplicada teórica de 9,00 g DQO $\mathrm{L}^{-1} \mathrm{dia}^{-1}$. 


\subsubsection{Monitoramento}

O reator foi operado por 11 dias, em que a concentração média da matéria orgânica afluente

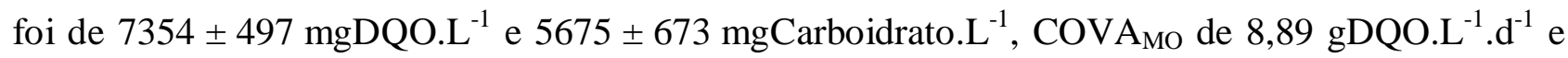
$\operatorname{COVA}_{C}$ de 6,86 gCarboidrato. $\mathrm{L}^{-1} \cdot \mathrm{d}^{-1}$. A quantidade de biomassa contida no reator foi de $37,3 \mathrm{~g}$. Neta condição, o reator operou os três primeiros dias com $50 \%$ de bicarbonato, relação que foi diminuída, inicialmente, para 33\% e, posteriormente, para $25 \%$ após mais cinco dias.

Os valores referentes ao monitoramento e aos indicadores desempenho encontram-se apresentados na Tabela 5.5 a seguir. A eficiência de remoção de matéria orgânica na forma de DQO desta condição, para amostras não-filtradas e filtradas, respectivamente, foi de $94 \pm 01 \%$ e $95 \pm 01 \%$. Para a matéria orgânica na forma de Carboidratos (lactose) a remoção foi de $99 \pm 00 \%$ e $100 \pm 00 \%$, respectivamente para não-filtradas e filtradas. $\mathrm{O} \mathrm{pH}$ afluente foi de $8,40 \pm 0,21$ e o efluente 8,29 $\pm 0,28$. A alcalinidade a bicarbonato do afluente e efluente foram $1515 \pm 434 \mathrm{mgCaCO} 3 \cdot \mathrm{L}^{-1}$ e $1852 \pm 355 \mathrm{mgCaCO}_{3} \cdot \mathrm{L}^{-1}$. A alcalinidade referente aos ácidos voláteis do afluente e efluente foram $183 \pm 26 \mathrm{mgHAc} . \mathrm{L}^{-1}$ e $55 \pm 18 \mathrm{mgHac} . \mathrm{L}^{-1}$. A grande variação que se vê nos valores de alcalinidade a bicarbonato, tanto do afluente quanto do efluente, se deve às variações na fração de bicarbonato aplicada no reator. Nota-se, também, que o reator seguiu apresentando grande capacidade produtiva de bicarbonato, resultando em concentrações maiores no efluente do que no afluente.

A concentração de sólidos suspensos voláteis (SSV) no efluente indica que houve pouca perda de biomassa no reator.

O rendimento de metano gerado por matéria orgânica consumida foi de 16,28 $\mathrm{mmolCH}_{4} \cdot \mathrm{gDQO}^{-1}$ e 21,10 $\mathrm{mmolCH}_{4} \cdot \mathrm{gCarboidrato}^{-1}$. A produção de biogás foi de $3635 \pm 437 \mathrm{~mL}-$ 
CNTP.ciclo ${ }^{-1}$, sendo a fração molar de metano equivalente a $74,83 \pm 0,28 \%$ e a produtividade molar de metano de $144,8 \mathrm{molCH}_{4} \cdot \mathrm{m}^{-3} \cdot \mathrm{d}^{-1}$. 
Tabela 5.5 - Resumo dos valores médios obtidos no monitoramento do reator com concentração afluente de $7000 \mathrm{mgDQO} . \mathrm{L}^{-1}$ na condição III

\begin{tabular}{|c|c|c|c|c|c|c|c|c|c|}
\hline \multicolumn{2}{|r|}{ Parâmetro } & \multicolumn{4}{|c|}{ Afluente } & \multicolumn{4}{|c|}{ Efluente } \\
\hline $\mathrm{C}_{\mathrm{ST}}$ & $\left(\mathrm{mgDQO} . \mathrm{L}^{-1}\right)$ & 7354 & \pm & 497 & $(8)$ & 471 & \pm & 88 & $(8)$ \\
\hline $\mathrm{C}_{\mathrm{SF}}$ & (mgDQO.L $\left.{ }^{-1}\right)$ & - & & - & & 339 & \pm & 72 & $\left(\begin{array}{l}8 \\
8\end{array}\right)$ \\
\hline$\varepsilon_{\mathrm{ST}}$ & $(\%)$ & - & & - & & $94 \%$ & \pm & $1 \%$ & $\left(\begin{array}{l}8 \\
8\end{array}\right)$ \\
\hline$\varepsilon_{\mathrm{SF}}$ & $(\%)$ & - & & - & & $95 \%$ & \pm & $1 \%$ & $\left(\begin{array}{l}8 \\
8\end{array}\right)$ \\
\hline $\mathrm{C}_{\mathrm{CT}}$ & $\left(\right.$ mgCarboidrato. $\left.\mathrm{L}^{-1}\right)$ & 5675 & \pm & 673 & $\left(\begin{array}{ll}8 & )\end{array}\right.$ & 39 & \pm & 14 & $\left(\begin{array}{l}8 \\
(8)\end{array}\right.$ \\
\hline $\mathrm{C}_{\mathrm{CF}}$ & (mgCarboidrato. $\mathrm{L}^{-1}$ ) & - & & - & & 24 & \pm & 10 & $\left(\begin{array}{ll}8\end{array}\right)$ \\
\hline$\varepsilon_{\mathrm{CT}}$ & $(\%)$ & - & & - & & $99 \%$ & \pm & $0 \%$ & \\
\hline$\varepsilon_{\mathrm{CF}}$ & $(\%)$ & - & & - & & $100 \%$ & \pm & $0 \%$ & \\
\hline $\mathrm{pH}$ & (u) & 8,40 & \pm & 0,21 & $\left(\begin{array}{ll}9 & )\end{array}\right.$ & 8,29 & \pm & 0,28 & $\left(\begin{array}{ll}9 & )\end{array}\right.$ \\
\hline AVT & $\left(\operatorname{mgHAc} . \mathrm{L}^{-1}\right)$ & 183 & \pm & 26 & $\left(\begin{array}{ll}9\end{array}\right)$ & 55 & \pm & 18 & $\left(\begin{array}{l}9 \\
)\end{array}\right)$ \\
\hline AT & $\left(\mathrm{mgCaCO}{ }_{3} \cdot \mathrm{L}^{-1}\right)$ & 1515 & \pm & 449 & $\left(\begin{array}{ll}9 & )\end{array}\right.$ & 1891 & \pm & 365 & $\left(\begin{array}{l}9 \\
)\end{array}\right)$ \\
\hline $\mathrm{AP}$ & $\left(\mathrm{mgCaCO}_{3} \cdot \mathrm{L}^{-1}\right)$ & 295 & \pm & 126 & $\left(\begin{array}{ll}9\end{array}\right)$ & 1558 & \pm & 324 & $\left(\begin{array}{l}9 \\
)\end{array}\right.$ \\
\hline AI & $\left(\mathrm{mgCaCO}_{3} \cdot \mathrm{L}^{-1}\right)$ & 1350 & \pm & 365 & $\left(\begin{array}{ll}9 \\
)\end{array}\right.$ & 333 & \pm & 134 & $\left(\begin{array}{l}9 \\
)\end{array}\right.$ \\
\hline $\mathrm{AB}$ & $\left(\mathrm{mgCaCO}_{3} \cdot \mathrm{L}^{-1}\right)$ & 1515 & \pm & 434 & $\left(\begin{array}{ll}9 & )\end{array}\right.$ & 1852 & \pm & 355 & $\left(\begin{array}{ll}9 & )\end{array}\right.$ \\
\hline ST & $\left(\mathrm{mg} . \mathrm{L}^{-1}\right)$ & 6427 & \pm & 929 & $\left(\begin{array}{ll}4 & )\end{array}\right.$ & 2922 & \pm & 148 & ( 4 ) \\
\hline SVT & $\left(\mathrm{mg} \cdot \mathrm{L}^{-1}\right)$ & 4695 & \pm & 884 & $\left(\begin{array}{ll}4 & )\end{array}\right.$ & 827 & \pm & 98 & ( 4 ) \\
\hline SST & $\left(\mathrm{mg} \cdot \mathrm{L}^{-1}\right)$ & 258 & \pm & 80 & $\left(\begin{array}{ll}4 & )\end{array}\right.$ & 134 & \pm & 67 & ( 4 ) \\
\hline SSV & $\left(\mathrm{mg} \cdot \mathrm{L}^{-1}\right)$ & 179 & \pm & 95 & $(4)$ & 103 & \pm & 29 & $(4)$ \\
\hline SDF & $\left(\mathrm{mg} \cdot \mathrm{L}^{-1}\right)$ & 1296 & & - & & 1858 & & - & \\
\hline $\mathrm{M}_{\mathrm{SVT}}$ & (g) & 37,3 & & - & & - & & - & \\
\hline $\mathrm{C}_{\mathrm{X}}$ & $\left(\mathrm{gSVT} . \mathrm{L}^{-1}\right)$ & 14,8 & & - & & - & & - & \\
\hline $\mathrm{C}_{\mathrm{X}}^{\prime}$ & $\left(\right.$ gSVT.gsuporte $^{-1}$ ) & 1,0 & & - & & - & & - & \\
\hline $\mathrm{V}_{\mathrm{G}}$ & $\left(\mathrm{mL}-\mathrm{CNTP} . \mathrm{Ciclo}^{-1}\right)$ & - & & - & & 3635 & \pm & 437 & $(5)$ \\
\hline $\mathrm{V}_{\mathrm{CH} 4}$ & $\left(\mathrm{~mL}-\mathrm{CNTPCH}_{4} \cdot \mathrm{Ciclo}^{-1}\right)$ & - & & - & & 2720 & & - & \\
\hline $\mathrm{COVA}_{\mathrm{S}}$ & $\left(\mathrm{gDQO} \cdot \mathrm{L}^{-1} \cdot \mathrm{d}^{-1}\right)$ & 8,89 & & - & & - & & - & \\
\hline $\mathrm{COVR}_{\mathrm{S}}$ & $\left(\mathrm{gDQO} \cdot \mathrm{L}^{-1} \cdot \mathrm{d}^{-1}\right)$ & - & & - & & 8,33 & & - & \\
\hline $\mathrm{COEA}_{\mathrm{S}}$ & $\left(\right.$ gDQO.gSVT $\left.{ }^{-1} \cdot \mathrm{d}^{-1}\right)$ & 0,60 & & - & & - & & - & \\
\hline $\mathrm{COER}_{\mathrm{S}}$ & $\left(\mathrm{gDQO} \cdot \mathrm{gSVT}^{-1} \cdot \mathrm{d}^{-1}\right)$ & - & & - & & 0,28 & & - & \\
\hline $\mathrm{COVA}_{\mathrm{c}}$ & (gCarboidrato. $\left.\mathrm{L}^{-1} \cdot \mathrm{d}^{-1}\right)$ & 6,86 & & - & & & & - & \\
\hline $\mathrm{COVR}_{\mathrm{c}}$ & (gCarboidrato. $\left.\mathrm{L}^{-1} \cdot \mathrm{d}^{-1}\right)$ & & & - & & 6,82 & & - & \\
\hline $\mathrm{COEA}_{c}$ & $\left(\mathrm{gCarboidrato.gSVT}^{-1} \cdot \mathrm{d}^{-1}\right)$ & 0,46 & & - & & & & - & \\
\hline $\mathrm{COER}_{\mathrm{c}}$ & (gCarboidrato.gSVT ${ }^{-1} \cdot \mathrm{d}^{-1}$ ) & & & & & 0,23 & & - & \\
\hline $\mathrm{n}_{\mathrm{CH} 4}$ & $\left(\mathrm{molCH}_{4} \cdot \mathrm{d}^{-1}\right)$ & - & & - & & 0,3640 & & - & \\
\hline $\mathrm{X}_{\mathrm{CH} 4}$ & $(\%)$ & & & & & 74,83 & \pm & 0,28 & \\
\hline PrM & $\left(\mathrm{molCH}_{4} \cdot \mathrm{m}^{-3} \cdot \mathrm{d}^{-1}\right)$ & - & & - & & 144,8 & & - & \\
\hline PrME & $\left(\mathrm{molCH}_{4} \cdot \mathrm{kgSVT}^{-1} \cdot \mathrm{d}^{-1}\right)$ & - & & - & & 9,75 & & - & \\
\hline $\operatorname{PrV}$ & $\left(\mathrm{mL}-\mathrm{CNTPCH} 4 \cdot \mathrm{L}^{-1} \cdot \mathrm{d}^{-1}\right)$ & - & & - & & 3247 & & - & \\
\hline PrVE & 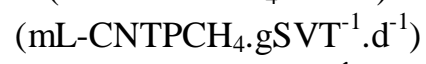 & - & & - & & 218,65 & & - & \\
\hline $\mathrm{RMCA}_{\mathbf{s}}$ & $\left(\mathrm{mmolCH}_{4} \cdot \mathrm{gDQO}^{-1}\right)$ & 16,28 & & - & & - & & - & \\
\hline $\mathrm{RMCR}_{S}$ & $\left(\mathrm{mmolCH}_{4} \cdot \mathrm{gDQO}^{-1}\right)$ & - & & - & & 17,40 & & - & \\
\hline $\mathrm{RMCA}_{\mathrm{c}}$ & $\left(\mathrm{mmolCH}_{4} \cdot \mathrm{gCarboidrato}^{-1}\right)$ & 21,10 & & - & & - & & - & \\
\hline $\mathrm{RMCR}_{\mathrm{c}}$ & $\left(\mathrm{mmolCH}_{4} \cdot \mathrm{gCarboidrato}^{-1}\right)$ & - & & - & & 21,25 & & - & \\
\hline $\mathrm{V}_{\mathrm{A}}$ & $\left(\mathrm{mL} . \mathrm{Ciclo}^{-1}\right)$ & 1013 & \pm & 85 & 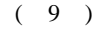 & - & & - & \\
\hline$V_{\text {RES }}$ & $(\mathrm{mL})$ & 1500 & & - & & - & & - & \\
\hline
\end{tabular}

*Os valores entre parêntesis representam o número de amostras consideradas para o cálculo da média Fonte: Autor (2017) 


\subsubsection{Perfil ao longo do ciclo}

Durante o perfil, a concentração de matéria orgânica afluente na forma de DQO e de Carboidrato foi de $6983 \mathrm{mgDQO} . \mathrm{L}^{-1}$ e de $6149 \mathrm{mgCarboidrato} . \mathrm{L}^{-1}$, respectivamente. O valor das concentrações após a diluição foram de $2741 \mathrm{mgDQO}^{-1}$ e $1239 \mathrm{mgCarboidrato.L}^{-1}$ no início de operação.

Observa-se na Figura 5.14 a variação do $\mathrm{pH}$ ao longo do ciclo, com valor de 8,28 no afluente, mínimo de 7,21, resultado bem abaixo do restante, o que pode indicar acúmulo de ácidos, porém, sem representar um valor de risco. Por fim, o pH do efluente foi 8,13. Também é possível acompanhar a variação da alcalinidade a bicarbonato e ácidos voláteis totais durante o ciclo. Os ácidos voláteis totais têm o pico de produção (969 mgHAc. $\left.\mathrm{L}^{-1}\right)$ em 1,0 hora de ciclo. O acúmulo de ácidos voláteis totais no reator não comprometeu a capacidade tampão do reator, mas comprometeu significativamente o valor mínimo de alcalinidade a bicarbonato, resultando em $549 \mathrm{mg} \mathrm{CaCO} \cdot \mathrm{L}^{-1}$. É importante ressaltar que nesta condição, houve redução da concentração afluente de bicarbonato de 50 para $25 \%$. Não houve grande excedente de ácidos voláteis nesta condição, indicando bom desempenho. Quanto à produção de bicarbonato, o qual demonstrou grande recuperação, o resultado indica concentração de $1681 \mathrm{CaCO}_{3} \cdot \mathrm{L}^{-1}$ no efluente, valor maior do que o afluente. Além disso, os resultados referentes ao biogás também indicam bom desempenho. 
Figura 5.14 - Perfis de pH (a), alcalinidade a bicarbonato e a ácidos voláteis totais (b) na condição III
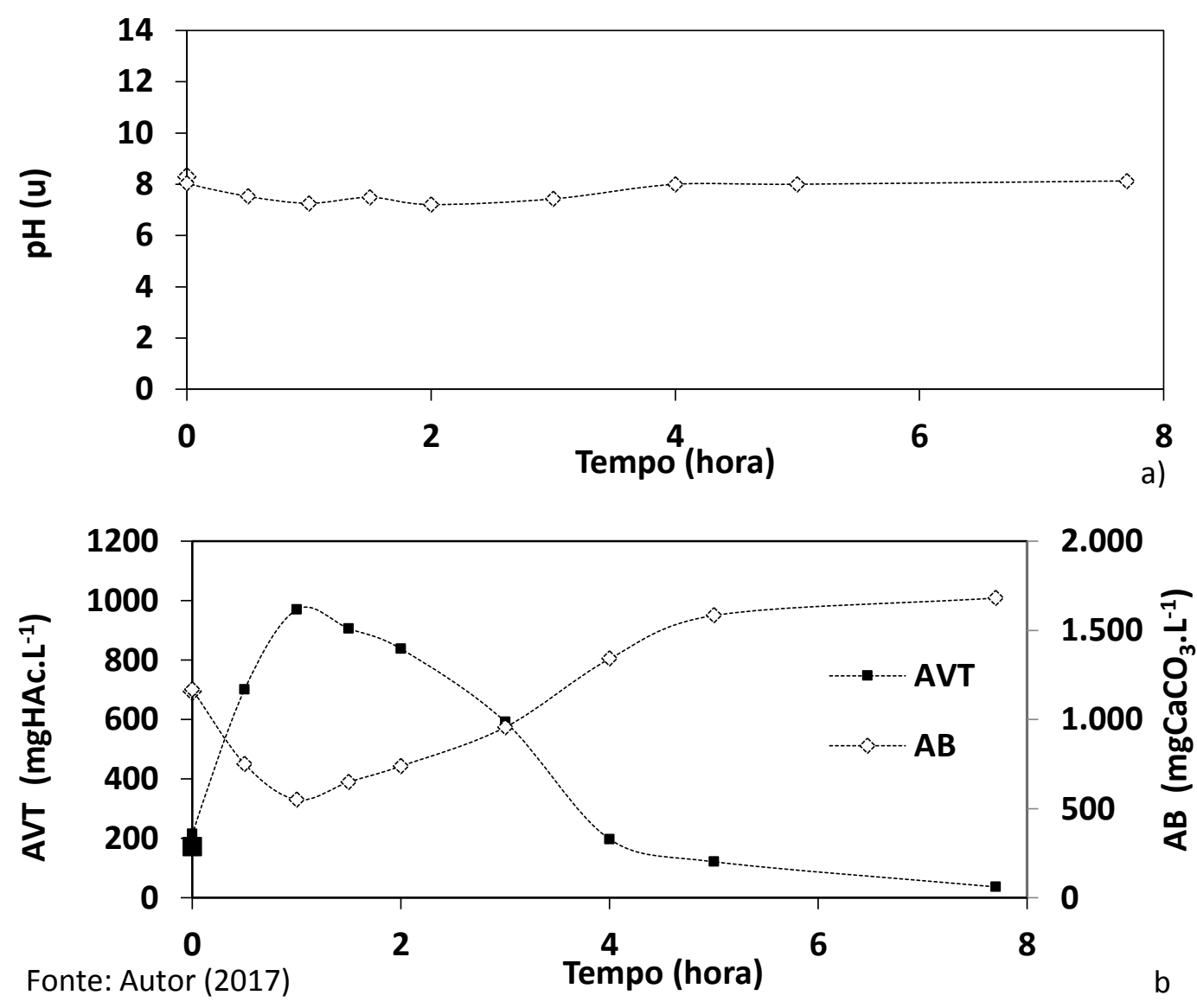

O consumo da matéria orgânica nas formas de DQO e Carboidrato ao longo do ciclo pode ser analisado através da Figura 5.15. Novamente, pôde-se observar um rápido consumo da matéria orgânica na forma de carboidrato, resultando em $99 \%$ de consumo em 1,0 hora de ciclo. No mesmo período, a eficiência de remoção de DQO foi de $78 \%$, atingindo $96 \%$ no final do ciclo. 
Figura 5.15 - Perfis de concentração e eficiência de remoção de DQO (a) e carboidratos (b) na condição III
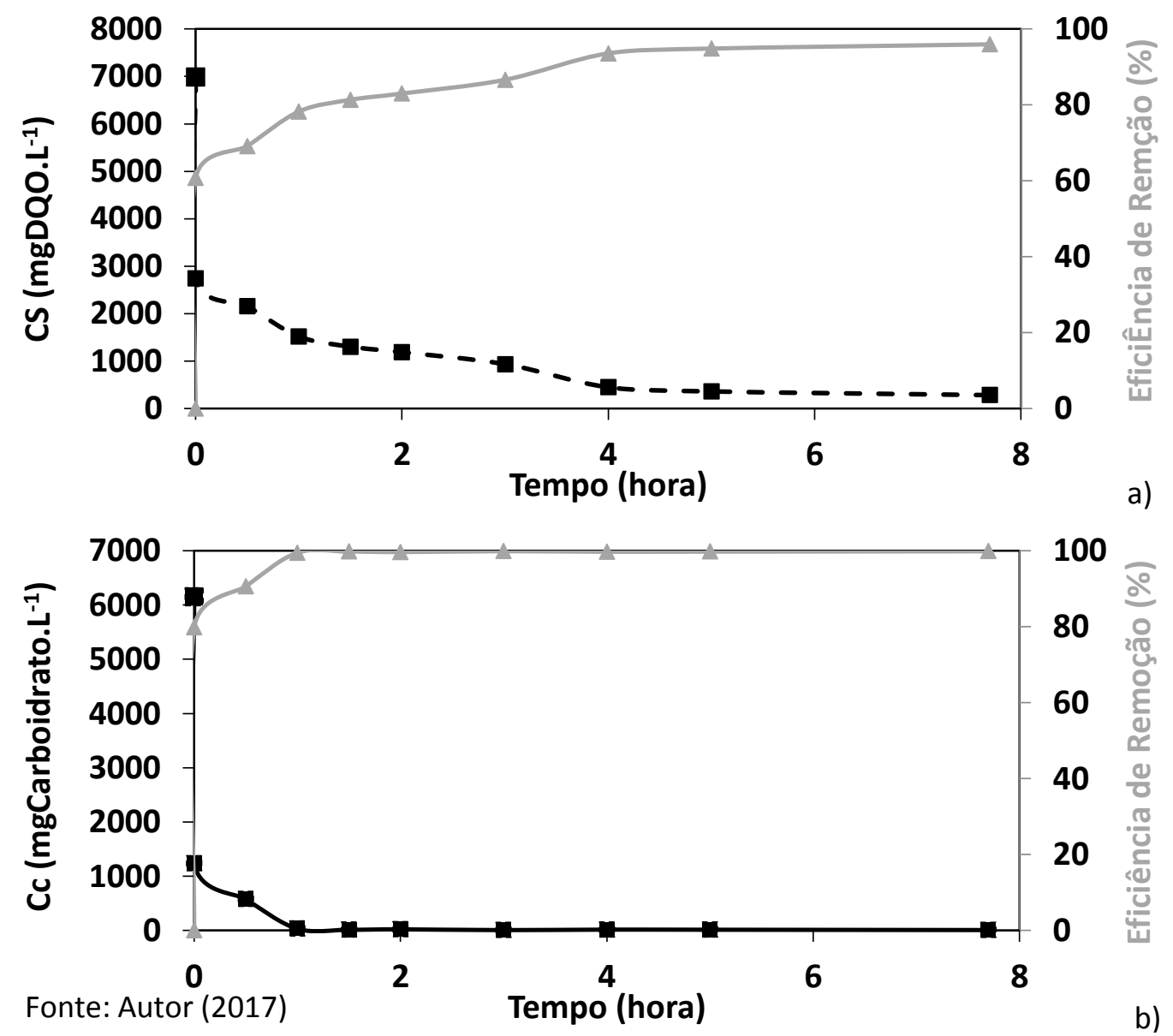

A variação da produção e consumo dos compostos metabólicos intermediários ao longo do ciclo pode ser observada pela Figura 5.16. Nesta condição, não houve acúmulo significativo de ácido propiônico, o qual manteve sua concentração sempre abaixo de 175 mg.L- ${ }^{1}$. 
Figura 5.16 - Perfil das concentrações dos compostos intermediários ao longo do ciclo na condição III

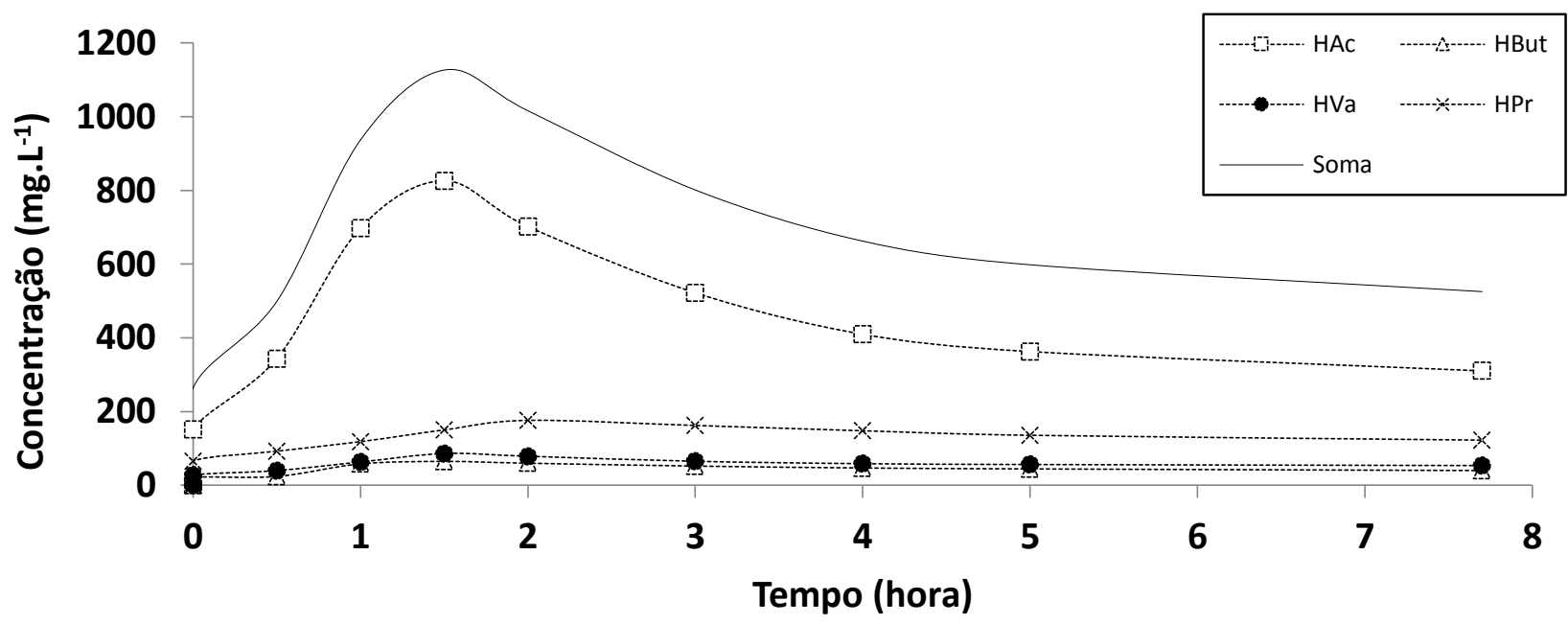

Fonte: Autor (2017)

A produção volumétrica de metano $\left(\mathrm{CH}_{4}\right)$ e dióxido de carbono $\left(\mathrm{CO}_{2}\right)$ ao longo do ciclo pode ser observada através da Figura 5.17. Nota-se que a produção volumétrica de metano foi predominante por todo o ciclo. Também se verifica a evolução das concentrações de metano e dióxido de carbono presente no biogás e a vazão molar de metano ao longo do ciclo além do volume total de biogás gerado durante o período. A produção de metano é maior do que a de dióxido de carbono durante todo o período, resultando numa concentração final de $75 \%$ dos 3634 mL-CNTP.ciclo ${ }^{-1}$ de biogás gerados durante o ciclo. 
Figura 5.17 - Perfis de volume nas CNTP de metano e $\mathrm{CO}_{2}$ (a), concentração dos gases e vazão molar (b) e volume e concentração ao longo do ciclo (c) na condição III
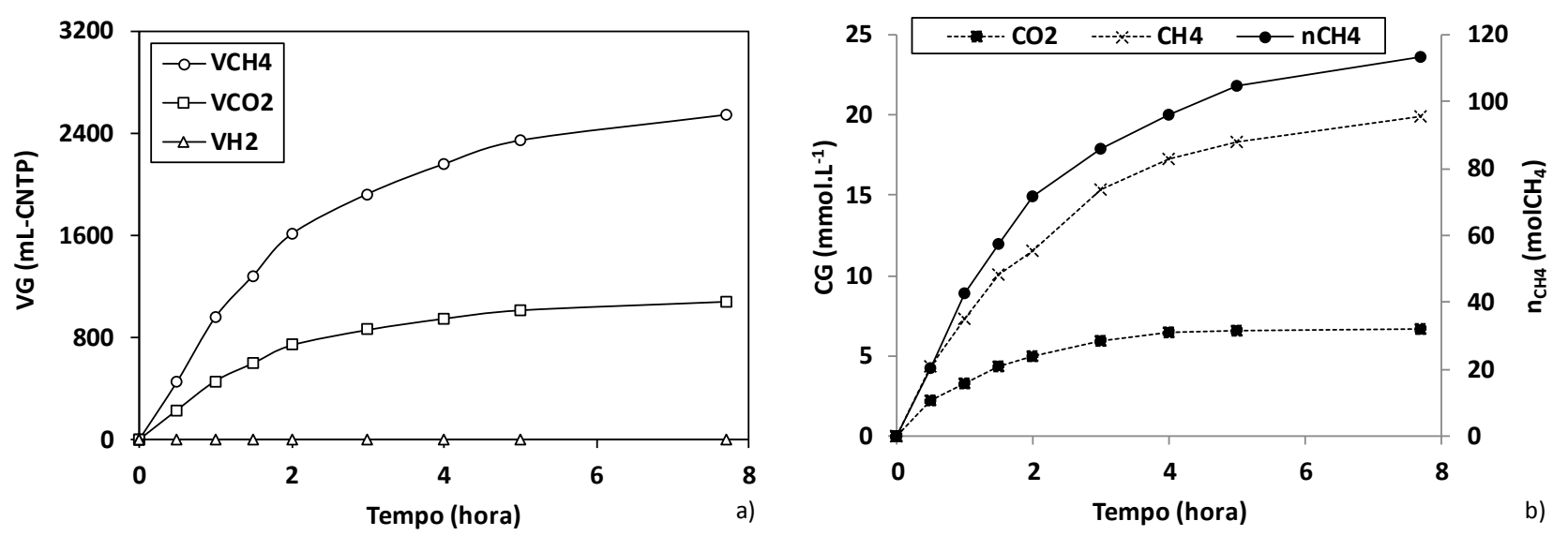

Produção e Composição do Biogás
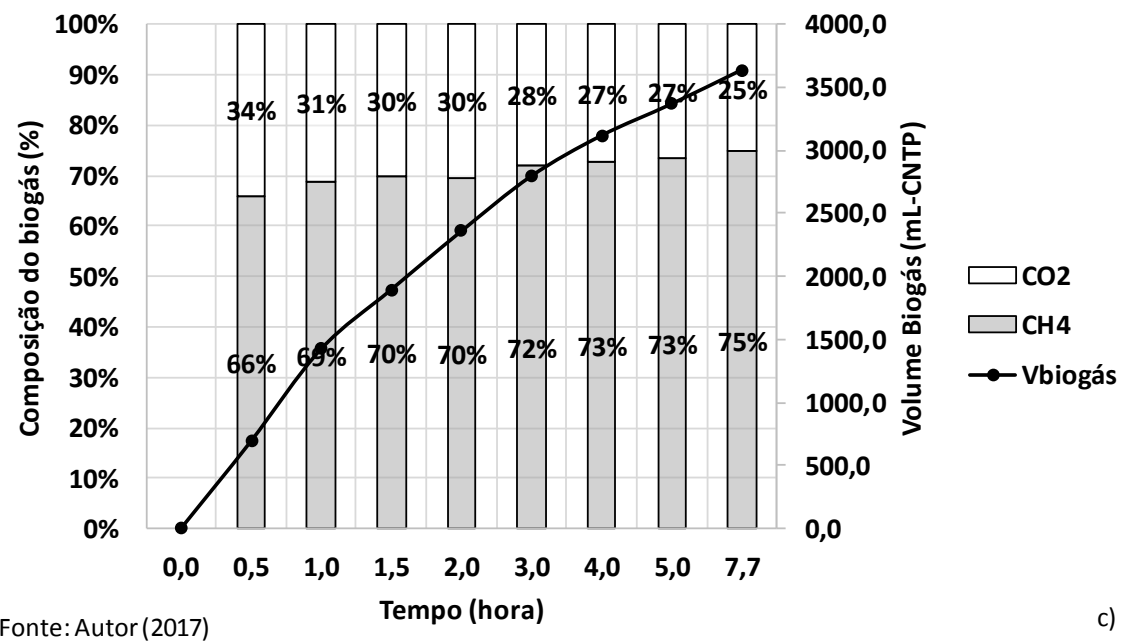

c)

Os dados do perfil indicam que o reator poderia ser operado eficientemente num ciclo de 5 horas. Os resultados indicam que houve remoção de 95\% de matéria orgânica na forma de DQO e 99,9\% de carboidratos, ambos na forma filtrada. Houve consumo de $87 \%$ da concentração máxima de ácidos voláteis. Além disso, houve a produção de 3365,4 mL-ciclo de biogás, contendo 73\% de metano. 
5.2.3.3 Ajuste do modelo cinético

Os parâmetros cinéticos aparentes foram calculados (Tabela 5.6) e indicam maior produção de ácido acético através do substrato $\left(\mathrm{k}_{1 \mathrm{HAC}}\right)$ e também da conversão do ácido proprônico ( $\left.\mathrm{K}_{6 \mathrm{HAC}}\right)$. A produção de metano foi maior na rota metanogênica hidrogenotrófica $\left(\mathrm{K}_{11 \mathrm{M}}\right)$. Portanto, o modelo cinético foi ajustado de modo adequado pelos dados experimentais (Figura 5.18).

Tabela 5.6 - Parâmetros cinéticos da rota metabólica ao longo do ciclo na condição III

\begin{tabular}{|c|c|c|}
\hline Condição & Parâmetro & Condição III \\
\hline \multirow{10}{*}{$\begin{array}{l}\text { Hidrólise e } \\
\text { Acidogênese }\end{array}$} & $\mathrm{k}_{1 \mathrm{~S}}^{\prime}\left(\mathrm{h}^{-1}\right)$ & 1,55 \\
\hline & $\mathrm{k}_{1 \mathrm{HAc}}\left(\mathrm{h}^{-1}\right)$ & 3,03 \\
\hline & $\mathrm{k}_{1 \mathrm{H}}\left(\mathrm{h}^{-1}\right)$ & 0,00 \\
\hline & $\mathrm{k}_{2 \mathrm{HPr}}\left(\mathrm{h}^{-1}\right)$ & 0,00 \\
\hline & $\mathrm{k}_{2 \mathrm{H}}\left(\mathrm{h}^{-1}\right)$ & 0,12 \\
\hline & $\mathrm{k}_{3 \mathrm{HBu}}\left(\mathrm{h}^{-1}\right)$ & 0,28 \\
\hline & $\mathrm{k}_{3 \mathrm{H}}\left(\mathrm{h}^{-1}\right)$ & 0,00 \\
\hline & $\mathrm{k}_{4 \mathrm{HVa}}\left(\mathrm{h}^{-1}\right)$ & 0,15 \\
\hline & $\mathrm{k}_{4 \mathrm{H}}\left(\mathrm{h}^{-1}\right)$ & 0,00 \\
\hline & $\mathrm{k}_{\text {5ЕTOH }}\left(\mathrm{h}^{-1}\right)$ & 0,00 \\
\hline \multirow{10}{*}{ Acetogênese } & $\mathrm{k}_{6 \mathrm{HPr}}\left(\mathrm{h}^{-1}\right)$ & 3,67 \\
\hline & $\mathrm{k}_{6 \mathrm{HAc}}\left(\mathrm{h}^{-1}\right)$ & 20,58 \\
\hline & $\mathrm{k}_{6 \mathrm{H}}\left(\mathrm{h}^{-1}\right)$ & 0,00 \\
\hline & $\mathrm{k}_{7 \mathrm{HPr}}\left(\mathrm{h}^{-1}\right)$ & 10,97 \\
\hline & $\mathrm{k}_{7 \mathrm{HBu}}\left(\mathrm{h}^{-1}\right)$ & 2,39 \\
\hline & $\mathrm{k}_{7 \mathrm{H}}\left(\mathrm{h}^{-1}\right)$ & 0,00 \\
\hline & $\mathrm{k}_{8 \mathrm{HBu}}\left(\mathrm{h}^{-1}\right)$ & 2,06 \\
\hline & $\mathrm{k}_{8 \mathrm{HVa}}\left(\mathrm{h}^{-1}\right)$ & 0,14 \\
\hline & $\mathrm{k}_{8 \mathrm{H}}\left(\mathrm{h}^{-1}\right)$ & 0,03 \\
\hline & $\mathrm{k}_{9 \mathrm{HAc}}\left(\mathrm{h}^{-1}\right)$ & 0,00 \\
\hline \multirow{4}{*}{ Metanogênese } & $\mathrm{k}_{10 \mathrm{HAc}}\left(\mathrm{h}^{-1}\right)$ & 4,27 \\
\hline & $\mathrm{k}_{10 \mathrm{H}}\left(\mathrm{h}^{-1}\right)$ & 6,26 \\
\hline & $\mathrm{k}_{11 \mathrm{H}}\left(\mathrm{h}^{-1}\right)$ & 0,09 \\
\hline & $\mathrm{k}_{11 \mathrm{M}}\left(\mathrm{h}^{-1}\right)$ & 143,88 \\
\hline
\end{tabular}


Figura 5.18 - Dados experimentais (marcadores) e modelo (linha) do metano (a), substrato (b) e ácidos intermediários (c) na condição III
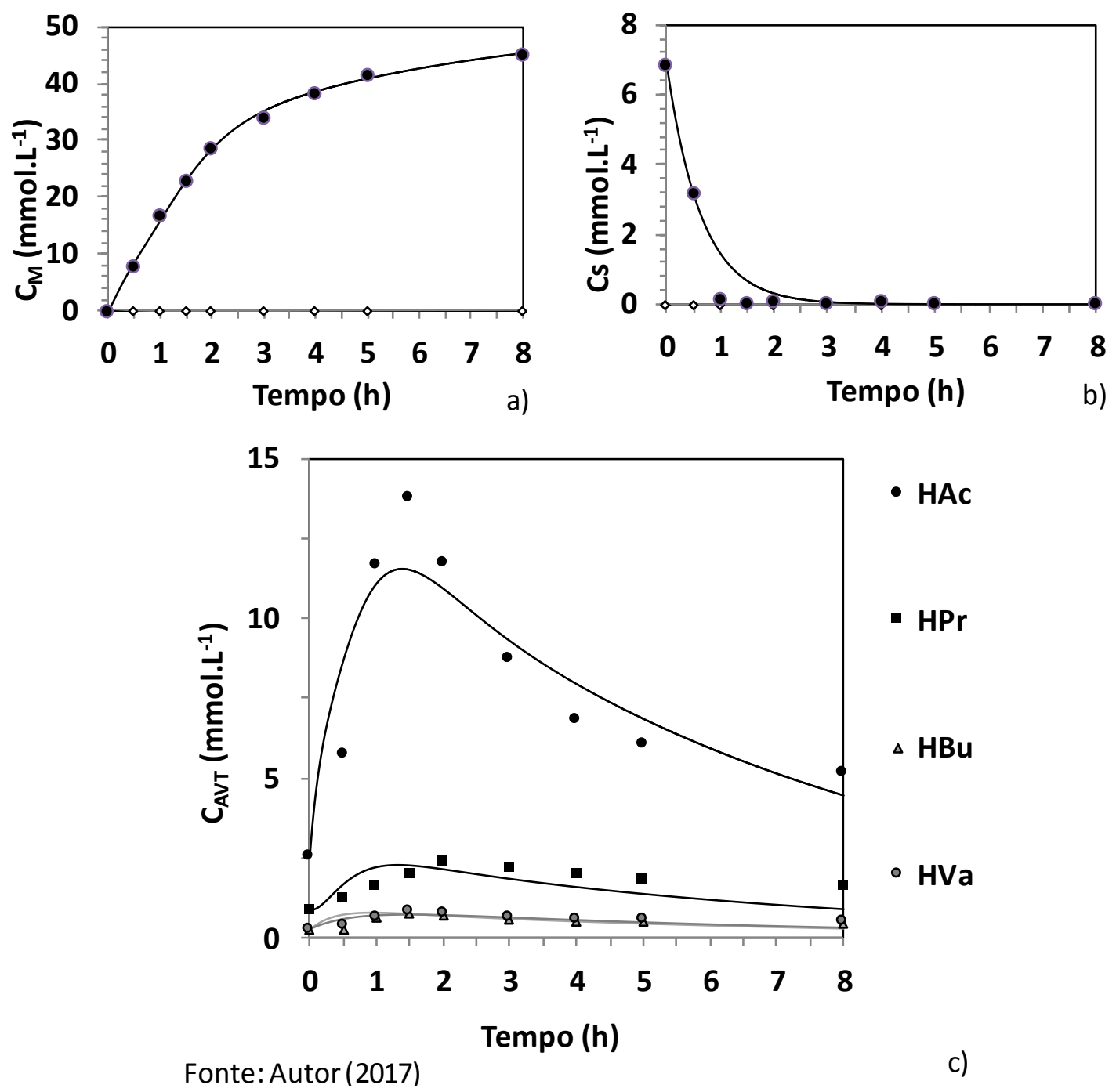

5.2.4 Condição IV - 8.500 mg DQO L ${ }^{-1} ; 100 \%$ Soro; 25 a $20 \%$ de bicarbonato; $55^{\circ}$ C; Batelada

Nesta condição de operação, o valor nominal de DQO alimentado ao reator foi de $8500 \mathrm{mg}$ $\mathrm{L}^{-1}$ com carga orgânica aplicada teórica de 9,60 g DQO $\mathrm{L}^{-1} \mathrm{dia}^{-1}$. 


\subsubsection{Monitoramento}

O reator foi operado por 10 dias, em que a concentração média da matéria orgânica afluente foi de $8519 \pm 357 \mathrm{mgDQO} . \mathrm{L}^{-1}$ e $6443 \pm 1120 \mathrm{mgCarboidrato.L^{-1 }}$, COVAMO de 10,25 gDQO.L ${ }^{-1} \cdot \mathrm{d}^{-1}$ e COVA $A_{C}$ de 7,75 gCarboidrato. $\mathrm{L}^{-1} \cdot \mathrm{d}^{-1}$. A quantidade de biomassa contida no reator foi de 52,8 $\mathrm{g}$. Nesta condição, o reator operou os todos os dias com $25 \%$ de bicarbonato afluente. A carga aplicada no reator foi consideravelmente maior do que a nominal pois, como a água residuária é preparada a partir do soro de queijo industrializado em pó, qualquer variação na composição ou homogeneização do produto ou então na armazenagem, pode interferir no resultado. Ainda assim, a variação significa menos de $10 \%$ do valor teórico, o que é aceitável.

Os valores referentes ao monitoramento e aos indicadores desempenho encontram-se apresentados na Tabela 5.7 a seguir. A eficiência de remoção de matéria orgânica na forma de DQO desta condição, para amostras não-filtradas e filtradas, respectivamente, foi de $94 \pm 01 \%$ e $96 \pm 01 \%$. Para a matéria orgânica na forma de Carboidratos (lactose) a remoção foi de $99 \pm 00 \%$ e $100 \pm 00 \%$, respectivamente para não-filtradas e filtradas. $\mathrm{O} \mathrm{pH}$ afluente foi de $8,32 \pm 0,09$ e o efluente $8,24 \pm 0,17$. A alcalinidade a bicarbonato do afluente e efluente foram $1297 \pm 47 \mathrm{mgCaCO} 3 \cdot \mathrm{L}^{-1}$ e $1753 \pm 53 \mathrm{mgCaCO}_{3} \cdot \mathrm{L}^{-1}$. A alcalinidade referente aos ácidos voláteis do afluente e efluente foram $291 \pm 71 \mathrm{mgHAc} . \mathrm{L}^{-1}$ e $47 \pm 13 \mathrm{mgHac} . \mathrm{L}^{-1}$. Observa-se que o reator seguiu apresentando grande capacidade produtiva de bicarbonato, resultando em concentrações maiores no efluente do que no afluente. Devido à isso, optou-se novamente pela redução da fração afluente de bicarbonato na condição seguinte.

A concentração de sólidos suspensos voláteis (SSV) no efluente indica que houve pouca perda de biomassa no reator. 
O rendimento de metano gerado por matéria orgânica consumida foi de 19,36 $\mathrm{mmolCH}_{4} \cdot \mathrm{gDQO}^{-1}$ e 25,59 $\mathrm{mmolCH}_{4} \cdot \mathrm{gCarboidrato}^{-1}$. A produção de biogás foi de $4931 \pm 655 \mathrm{~mL}-$ CNTP.ciclo ${ }^{-1}$, sendo a fração molar de metano equivalente a 75,29 $\pm 0,16 \%$ e a produtividade molar de metano de $198,4 \mathrm{molCH}_{4} \cdot \mathrm{m}^{-3} \cdot \mathrm{d}^{-1}$. 
Tabela 5.7 - Resumo dos valores médios obtidos no monitoramento do reator com concentração afluente de $8500 \mathrm{mgDQO} . \mathrm{L}^{-1}$ na condição IV

\begin{tabular}{|c|c|c|c|c|c|c|c|c|c|c|}
\hline \multicolumn{2}{|r|}{ Parâmetro } & \multicolumn{5}{|c|}{ Afluente } & \multicolumn{4}{|c|}{ Efluente } \\
\hline $\mathrm{C}_{\mathrm{ST}}$ & $\left(\mathrm{mgDQO} \cdot \mathrm{L}^{-1}\right)$ & 8519 & \pm & 377 & $(9$ & 1 & 523 & \pm & 57 & $(9)$ \\
\hline $\mathrm{C}_{\mathrm{SF}}$ & $\left(\operatorname{mgDQO} \cdot L^{-1}\right)$ & - & & - & & & 353 & \pm & 73 & $\left(\begin{array}{ll}9 \\
9\end{array}\right)$ \\
\hline$\varepsilon_{\mathrm{ST}}$ & $(\%)$ & - & & - & & & $94 \%$ & \pm & $1 \%$ & $\left(\begin{array}{ll}9 & )\end{array}\right.$ \\
\hline$\varepsilon_{\mathrm{SF}}$ & $(\%)$ & - & & - & & & $96 \%$ & \pm & $1 \%$ & $(9)$ \\
\hline $\mathrm{C}_{\mathrm{CT}}$ & $\left(\right.$ mgCarboidrato. $\left.\mathrm{L}^{-1}\right)$ & 6443 & \pm & 1120 & ( 9 & 9 ) & 47 & \pm & 8 & $(9)$ \\
\hline $\mathrm{C}_{\mathrm{CF}}$ & $\left(\right.$ mgCarboidrato. $\left.L^{-1}\right)$ & - & & - & & & 22 & \pm & 8 & $\left(\begin{array}{ll}9\end{array}\right)$ \\
\hline$\varepsilon_{\mathrm{CT}}$ & $(\%)$ & - & & - & & & $99 \%$ & \pm & $0 \%$ & \\
\hline$\varepsilon_{\mathrm{CF}}$ & $(\%)$ & - & & - & & & $100 \%$ & \pm & $0 \%$ & \\
\hline $\mathrm{pH}$ & (u) & 8,32 & \pm & 0,09 & ( 9 & 9 ) & 8,24 & \pm & 0,17 & $\left(\begin{array}{ll}9 & )\end{array}\right.$ \\
\hline AVT & $\left(\mathrm{mgHAc} . \mathrm{L}^{-1}\right)$ & 291 & \pm & 71 & ( 9 & 9 ) & 47 & \pm & 13 & $(9)$ \\
\hline AT & $\left(\mathrm{mgCaCO}{ }_{3} \cdot \mathrm{L}^{-1}\right)$ & 1297 & \pm & 63 & ( 9 & 9 ) & 1786 & \pm & 64 & $\left(\begin{array}{ll}9 & )\end{array}\right.$ \\
\hline AP & $\left(\mathrm{mgCaCO}_{3} \cdot \mathrm{L}^{-1}\right)$ & 249 & \pm & 67 & ( 9 & 9 ) & 1653 & \pm & 151 & $\left(\begin{array}{ll}9\end{array}\right)$ \\
\hline AI & $\left(\mathrm{mgCaCO}_{3} \cdot \mathrm{L}^{-1}\right)$ & 1254 & \pm & 68 & ( 9 & $9 \quad$ & 133 & \pm & 95 & $(9)$ \\
\hline $\mathrm{AB}$ & $\left(\mathrm{mgCaCO}_{3} \cdot \mathrm{L}^{-1}\right)$ & 1297 & \pm & 47 & ( 9 & $9 \quad$ & 1753 & \pm & 63 & $\left(\begin{array}{ll}9\end{array}\right)$ \\
\hline ST & $\left(\mathrm{mg} . \mathrm{L}^{-1}\right)$ & 8501 & \pm & 813 & ( 4 & $4 \quad$ & 2733 & \pm & 199 & $\left(\begin{array}{ll}4 & )\end{array}\right.$ \\
\hline SVT & $\left(\mathrm{mg} \cdot \mathrm{L}^{-1}\right)$ & 6585 & \pm & 826 & ( 4 & $4 \quad)$ & 949 & \pm & 138 & $(4)$ \\
\hline SST & $\left(\mathrm{mg} \cdot \mathrm{L}^{-1}\right)$ & 168 & \pm & 46 & ( 4 & $4 \quad$ & 172 & \pm & 54 & $\left(\begin{array}{ll}4 \\
)\end{array}\right)$ \\
\hline SSV & $\left(\mathrm{mg} \cdot \mathrm{L}^{-1}\right)$ & 149 & \pm & 46 & $(4$ & $4)$ & 160 & \pm & 52 & $\left(\begin{array}{ll}4 & )\end{array}\right.$ \\
\hline SDF & $\left(\mathrm{mg} \cdot \mathrm{L}^{-1}\right)$ & 1600 & & - & & & 1452 & & - & \\
\hline $\mathrm{M}_{\mathrm{SVT}}$ & (g) & 52,8 & & - & & & - & & - & \\
\hline $\mathrm{C}_{\mathrm{X}}$ & $\left(\mathrm{gSVT} . \mathrm{L}^{-1}\right)$ & 21,1 & & - & & & - & & - & \\
\hline $\mathrm{C}_{\mathrm{X}}^{\prime}$ & $\left(\right.$ gSVT.gsuporte ${ }^{-1}$ ) & 1,2 & & 一 & & & - & & - & \\
\hline $\mathrm{V}_{\mathrm{G}}$ & $\left(\mathrm{mL}-\mathrm{CNTP} . \mathrm{Ciclo}^{-1}\right)$ & - & & - & & & 4931 & \pm & 655 & $(6)$ \\
\hline $\mathrm{V}_{\mathrm{CH} 4}$ & $\left(\mathrm{~mL}-\mathrm{CNTPCH}_{4} \cdot \mathrm{Ciclo}^{-1}\right)$ & - & & - & & & 3712 & & - & \\
\hline $\mathrm{COVA}_{\mathrm{S}}$ & $\left(\mathrm{gDQO} \cdot \mathrm{L}^{-1} \cdot \mathrm{d}^{-1}\right)$ & 10,25 & & - & & & - & & - & \\
\hline $\mathrm{COVR}_{\mathrm{S}}$ & $\left(\mathrm{gDQO} \cdot \mathrm{L}^{-1} \cdot \mathrm{d}^{-1}\right)$ & - & & - & & & 9,62 & & - & \\
\hline COEA $_{S}$ & $\left(\right.$ gDQO.gSVT $\left.{ }^{-1} \cdot d^{-1}\right)$ & 0,49 & & - & & & - & & - & \\
\hline $\mathrm{COER}_{\mathrm{S}}$ & $\left(\right.$ gDQO.gSVT $\left.{ }^{-1} \cdot \mathrm{d}^{-1}\right)$ & - & & - & & & 0,23 & & - & \\
\hline $\mathrm{COVA}_{\mathrm{c}}$ & (gCarboidrato. $\left.\mathrm{L}^{-1} \cdot \mathrm{d}^{-1}\right)$ & 7,75 & & - & & & & & - & \\
\hline $\mathrm{COVR}_{\mathrm{c}}$ & (gCarboidrato. $\mathrm{L}^{-1} \cdot \mathrm{d}^{-1}$ ) & & & - & & & 7,70 & & - & \\
\hline $\mathrm{COEA}_{c}$ & (gCarboidrato.gSVT ${ }^{-1} \cdot \mathrm{d}^{-1}$ ) & 0,37 & & - & & & & & - & \\
\hline $\mathrm{COER}_{\mathrm{c}}$ & (gCarboidrato.gSVT ${ }^{-1} \cdot \mathrm{d}^{-1}$ ) & & & & & & 0,18 & & - & \\
\hline $\mathrm{n}_{\mathrm{CH} 4}$ & $\left(\mathrm{molCH}_{4} \cdot \mathrm{d}^{-1}\right)$ & - & & - & & & 0,4969 & & - & \\
\hline $\mathrm{X}_{\mathrm{CH} 4}$ & $(\%)$ & & & & & & 75,29 & \pm & 0,16 & \\
\hline PrM & $\left(\mathrm{molCH}_{4} \cdot \mathrm{m}^{-3} \cdot \mathrm{d}^{-1}\right)$ & - & & - & & & 198,4 & & - & \\
\hline PrME & $\left(\mathrm{molCH}_{4} \cdot \mathrm{kgSVT}^{-1} \cdot \mathrm{d}^{-1}\right)$ & - & & - & & & 9,42 & & - & \\
\hline $\operatorname{PrV}$ & $\left(\mathrm{mL}-\mathrm{CNTPCH} 4 \cdot \mathrm{L}^{-1} \cdot \mathrm{d}^{-1}\right)$ & - & & - & & & 4447 & & - & \\
\hline PrVE & 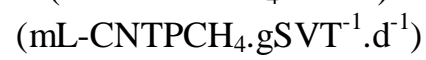 & - & & - & & & 211,07 & & - & \\
\hline $\mathrm{RMCA}_{\mathbf{s}}$ & $\left(\mathrm{mmolCH}_{4} \cdot \mathrm{gDQO}^{-1}\right)$ & 19,36 & & - & & & - & & - & \\
\hline $\mathrm{RMCR}_{\mathbf{s}}$ & $\left(\mathrm{mmolCH}_{4} \cdot \mathrm{gDQO}^{-1}\right)$ & - & & - & & & 20,62 & & - & \\
\hline $\mathrm{RMCA}_{\mathrm{C}}$ & $\left(\mathrm{mmolCH}_{4} \cdot \mathrm{gCarboidrato}^{-1}\right)$ & 25,59 & & - & & & - & & - & \\
\hline $\mathrm{RMCR}_{\mathrm{c}}$ & $\left(\mathrm{mmolCH}_{4} \cdot\right.$ gCarboidrato $\left.^{-1}\right)$ & - & & - & & & 25,78 & & - & \\
\hline $\mathrm{V}_{\mathrm{A}}$ & $\left(\mathrm{mL} . \mathrm{Ciclo}^{-1}\right)$ & 1004 & \pm & 9 & $(9$ & & - & & - & \\
\hline$V_{\text {RES }}$ & $(\mathrm{mL})$ & 1500 & & - & & & - & & - & \\
\hline
\end{tabular}

*Os valores entre parêntesis representam o número de amostras consideradas para o cálculo da média Fonte: Autor (2017) 


\subsubsection{Perfil ao longo do ciclo}

Durante o perfil, a concentração de matéria orgânica afluente na forma de DQO e de

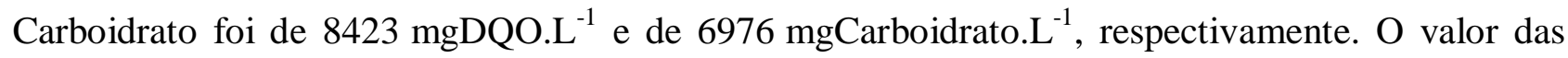
concentrações após a diluição foram de $2764 \mathrm{mgDQO}^{-1}$ e $1800 \mathrm{mgCarboidrato.L}^{-1}$ no início de operação.

Observa-se na Figura 5.19 a variação do $\mathrm{pH}$ ao longo do ciclo, com valor de 8,39 no afluente, mínimo de 7,05, resultado bem abaixo do restante, indicativo do acúmulo de ácidos, porém, sem representar um valor de risco. Por fim, o pH do efluente foi 8,18. Também é possível acompanhar a variação da alcalinidade a bicarbonato e ácidos voláteis totais durante o ciclo. Os ácidos voláteis totais têm o pico de produção (1192 mgHAc. $\left.\mathrm{L}^{-1}\right)$ em 1,0 hora de ciclo. O acúmulo de ácidos voláteis totais no reator não comprometeu a capacidade tampão do reator, mas comprometeu significativamente o valor mínimo de alcalinidade a bicarbonato, resultando em 703

$\mathrm{mg} \mathrm{CaCO}_{3} \cdot \mathrm{L}^{-1}$. É importante ressaltar que nesta condição, houve redução da concentração afluente de bicarbonato de 25 para $20 \%$. Não houve grande excedente de ácidos voláteis ao final do ciclo nesta condição, indicando bom desempenho. Quanto à produção de bicarbonato, houve grande recuperação, resultando em concentração de $1827 \mathrm{CaCO}_{3} \cdot \mathrm{L}^{-1}$ no efluente, valor maior do que o afluente. 
Figura 5.19 - Perfis de pH (a), alcalinidade a bicarbonato e a ácidos voláteis totais (b) na condição IV
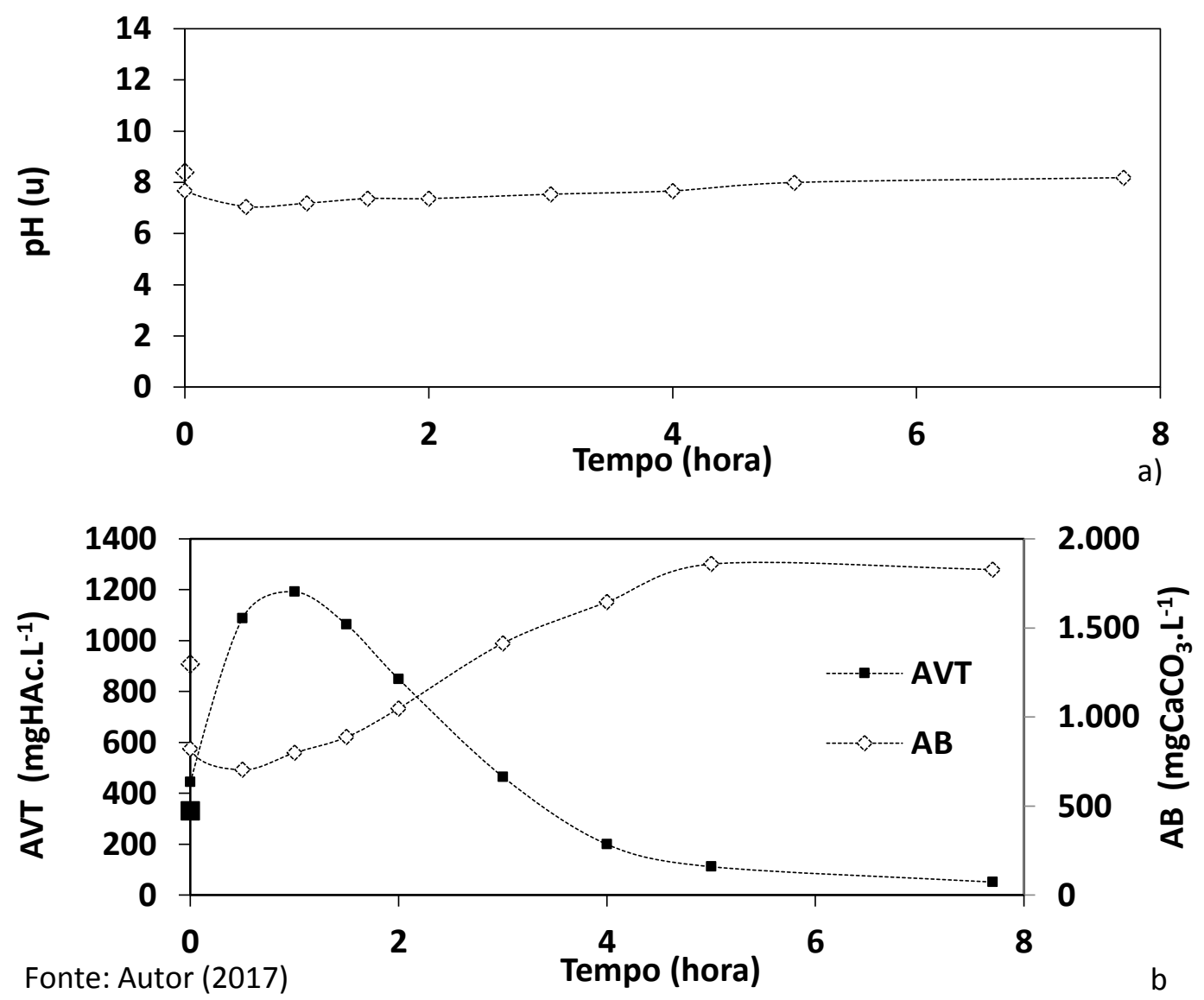

O consumo da matéria orgânica nas formas de DQO e Carboidrato ao longo do ciclo pode ser analisado através da Figura 5.20. Novamente, pôde-se observar um rápido consumo da matéria orgânica na forma de carboidrato, resultando em 99,8\% de consumo em 1,0 hora de ciclo. No mesmo período, a eficiência de remoção de DQO foi de $82 \%$, atingindo $95 \%$ ao final do ciclo. 
Figura 5.20 - Perfis de concentração e eficiência de remoção de DQO (a) e carboidratos (b) na condição IV
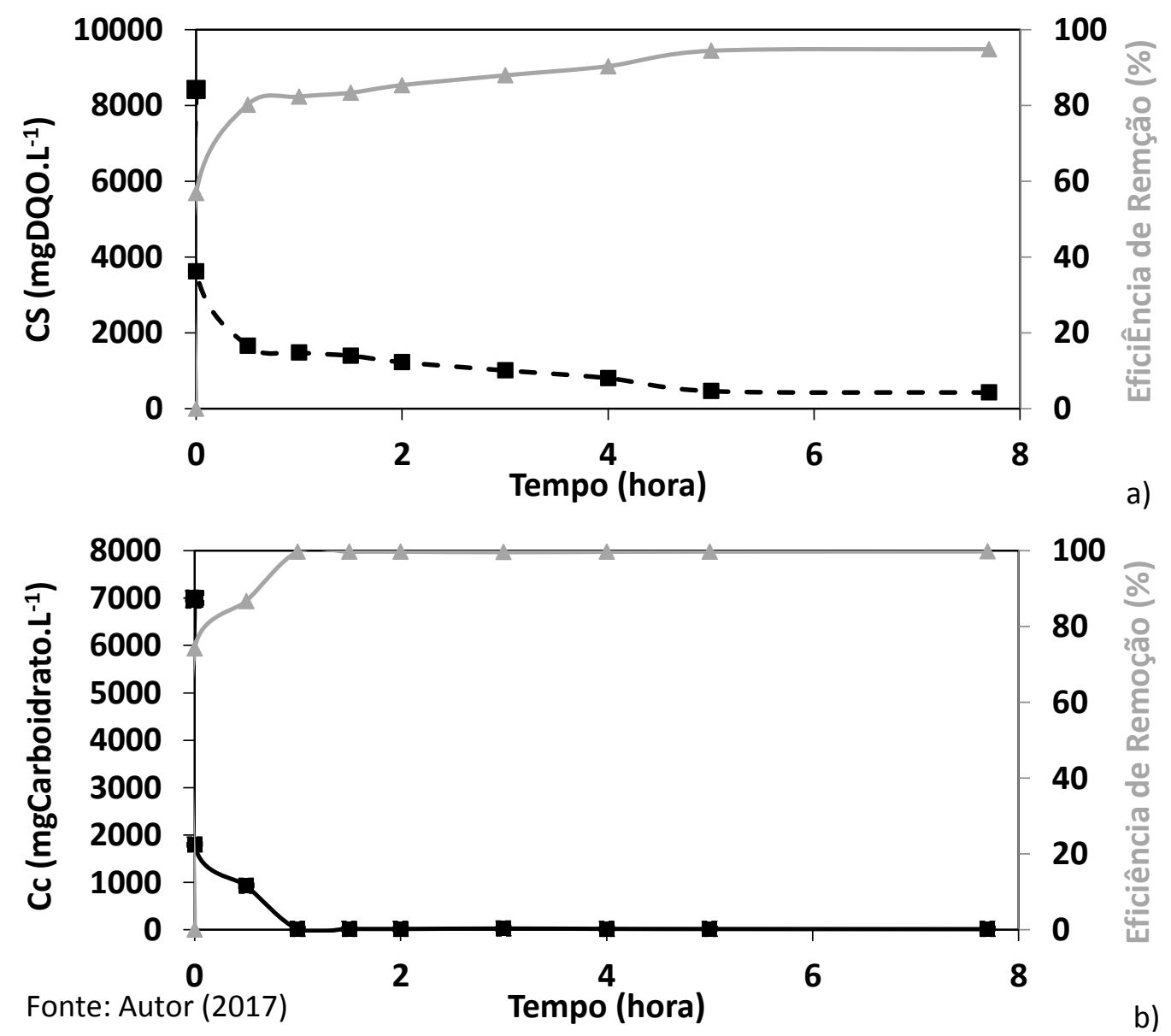

A variação da produção e consumo dos compostos metabólicos intermediários ao longo do ciclo pode ser observada pela Figura 5.21. Nesta condição, não houve acúmulo significativo de ácido propiônico, o qual manteve sua concentração sempre abaixo de 203 mg.L- ${ }^{1}$. 
Figura 5.21 - Perfil das concentrações dos compostos intermediários ao longo do ciclo na condição IV

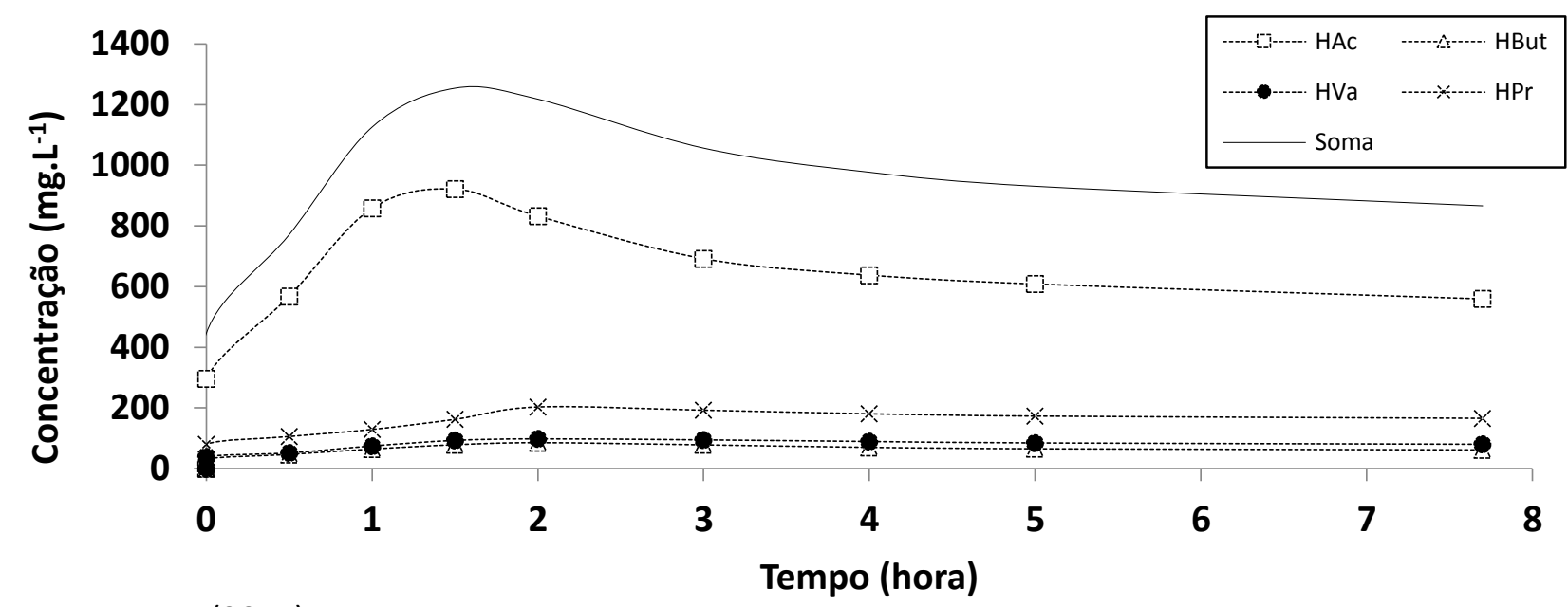

Fonte: Autor (2017)

A produção volumétrica de metano $\left(\mathrm{CH}_{4}\right)$ e dióxido de carbono $\left(\mathrm{CO}_{2}\right)$ ao longo do ciclo pode ser observada através da Figura 5.22. Nota-se que a produção volumétrica de metano foi predominante por todo o ciclo. Também se verifica a evolução das concentrações de metano e dióxido de carbono presente no biogás e a vazão molar de metano ao longo do ciclo além do volume total de biogás gerado durante o período. A produção de metano é maior do que a de dióxido de carbono durante todo o período, resultando numa concentração final de $75 \%$ dos 4931 mL-CNTP.ciclo ${ }^{-1}$ de biogás gerados durante o ciclo. 
Figura 5.22 - Perfis de volume nas CNTP de metano e $\mathrm{CO}_{2}$ (a), concentração dos gases e vazão molar (b) e volume e concentração ao longo do ciclo (c) na condição IV
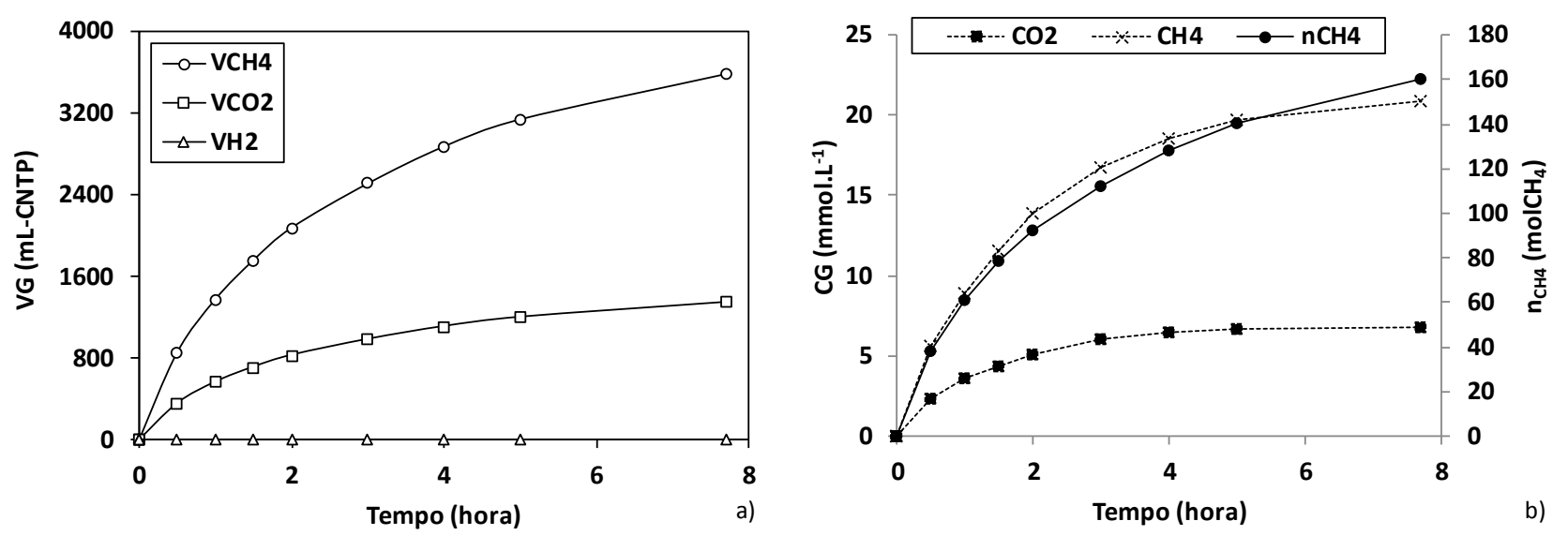

Produção e Composição do Biogás

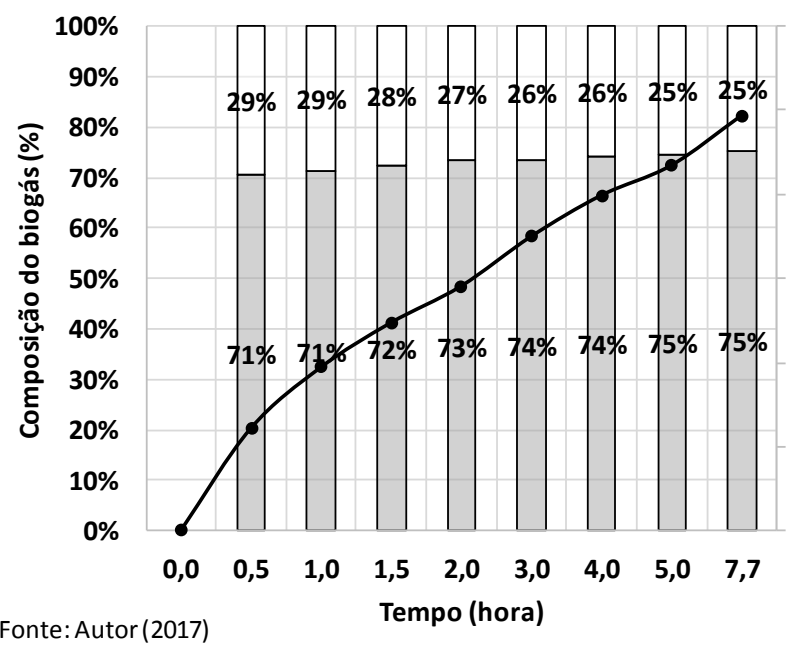

6000,0

5000,0

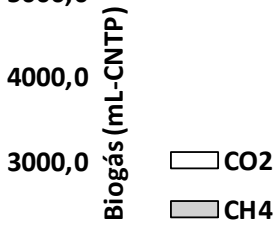

2000,0 $\stackrel{0}{\frac{\Xi}{5}} \rightarrow$ Vbiogás

0,0

c)

Os dados do perfil indicam que o reator poderia ser operado eficientemente num ciclo de 5 horas. Os resultados indicam que houve remoção de 94\% de matéria orgânica na forma de DQO e 99,9\% de carboidratos, ambos na forma filtrada. Houve consumo de $91 \%$ da concentração máxima de ácidos voláteis. Além disso, houve a produção de 4340,8 mL-ciclo de biogás, contendo 75\% de metano. 
5.2.4.3 Ajuste do modelo cinético

Os parâmetros cinéticos aparentes foram calculados (Tabela 5.8) e indicam maior produção de ácido acético através do substrato $\left(\mathrm{k}_{1 \mathrm{HAC}}\right)$ e também da conversão do ácido proprônico ( $\left.\mathrm{K}_{6 \mathrm{HAC}}\right)$. A produção de metano foi maior na rota metanogênica hidrogenotrófica $\left(\mathrm{K}_{11 \mathrm{M}}\right)$. Portanto, o modelo cinético foi ajustado de modo adequado pelos dados experimentais (Figura 5.23).

Tabela 5.8 - Parâmetros cinéticos da rota metabólica ao longo do ciclo na condição IV

\begin{tabular}{|c|c|c|}
\hline Condição & Parâmetro & Condição IV \\
\hline \multirow{10}{*}{$\begin{array}{l}\text { Hidrólise e } \\
\text { Acidogênese }\end{array}$} & $\mathrm{k}_{1 \mathrm{~S}}^{\prime}\left(\mathrm{h}^{-1}\right)$ & 2,29 \\
\hline & $\mathrm{k}_{1 \mathrm{HAc}}\left(\mathrm{h}^{-1}\right)$ & 2,67 \\
\hline & $\mathrm{k}_{1 \mathrm{H}}\left(\mathrm{h}^{-1}\right)$ & 0,00 \\
\hline & $\mathrm{k}_{2 \mathrm{HPr}}\left(\mathrm{h}^{-1}\right)$ & 0,30 \\
\hline & $\mathrm{k}_{2 \mathrm{H}}\left(\mathrm{h}^{-1}\right)$ & 0,05 \\
\hline & $\mathrm{k}_{3 \mathrm{HBu}}\left(\mathrm{h}^{-1}\right)$ & 0,26 \\
\hline & $\mathrm{k}_{3 \mathrm{H}}\left(\mathrm{h}^{-1}\right)$ & 0,00 \\
\hline & $\mathrm{k}_{4 \mathrm{HVa}}\left(\mathrm{h}^{-1}\right)$ & 0,16 \\
\hline & $\mathrm{k}_{4 \mathrm{H}}\left(\mathrm{h}^{-1}\right)$ & 0,00 \\
\hline & $\mathrm{k}_{\text {5ЕTOH }}\left(\mathrm{h}^{-1}\right)$ & 0,00 \\
\hline \multirow{10}{*}{ Acetogênese } & $\mathrm{k}_{6 \mathrm{HPr}}\left(\mathrm{h}^{-1}\right)$ & 0,63 \\
\hline & $\mathrm{k}_{6 \mathrm{HAc}}\left(\mathrm{h}^{-1}\right)$ & 12,03 \\
\hline & $\mathrm{k}_{6 \mathrm{H}}\left(\mathrm{h}^{-1}\right)$ & 0,00 \\
\hline & $\mathrm{k}_{7 \mathrm{HPr}}\left(\mathrm{h}^{-1}\right)$ & 2,85 \\
\hline & $\mathrm{k}_{7 \mathrm{HBu}}\left(\mathrm{h}^{-1}\right)$ & 2,33 \\
\hline & $\mathrm{k}_{7 \mathrm{H}}\left(\mathrm{h}^{-1}\right)$ & 0,00 \\
\hline & $\mathrm{k}_{8 \mathrm{HBu}}\left(\mathrm{h}^{-1}\right)$ & 1,28 \\
\hline & $\mathrm{k}_{8 \mathrm{HVa}}\left(\mathrm{h}^{-1}\right)$ & 0,00 \\
\hline & $\mathrm{k}_{8 \mathrm{H}}\left(\mathrm{h}^{-1}\right)$ & 0,00 \\
\hline & $\mathrm{k}_{9 \mathrm{HAc}}\left(\mathrm{h}^{-1}\right)$ & 0,00 \\
\hline \multirow{4}{*}{ Metanogênese } & $\mathrm{k}_{10 \mathrm{HAc}}\left(\mathrm{h}^{-1}\right)$ & 2,91 \\
\hline & $\mathrm{k}_{10 \mathrm{H}}\left(\mathrm{h}^{-1}\right)$ & 7,16 \\
\hline & $\mathrm{k}_{11 \mathrm{H}}\left(\mathrm{h}^{-1}\right)$ & 0,01 \\
\hline & $\mathrm{k}_{11 \mathrm{M}}\left(\mathrm{h}^{-1}\right)$ & 357,76 \\
\hline
\end{tabular}


Figura 5.23 - Dados experimentais (marcadores) e modelo (linha) do metano (a), substrato (b) e ácidos intermediários (c) na condição IV
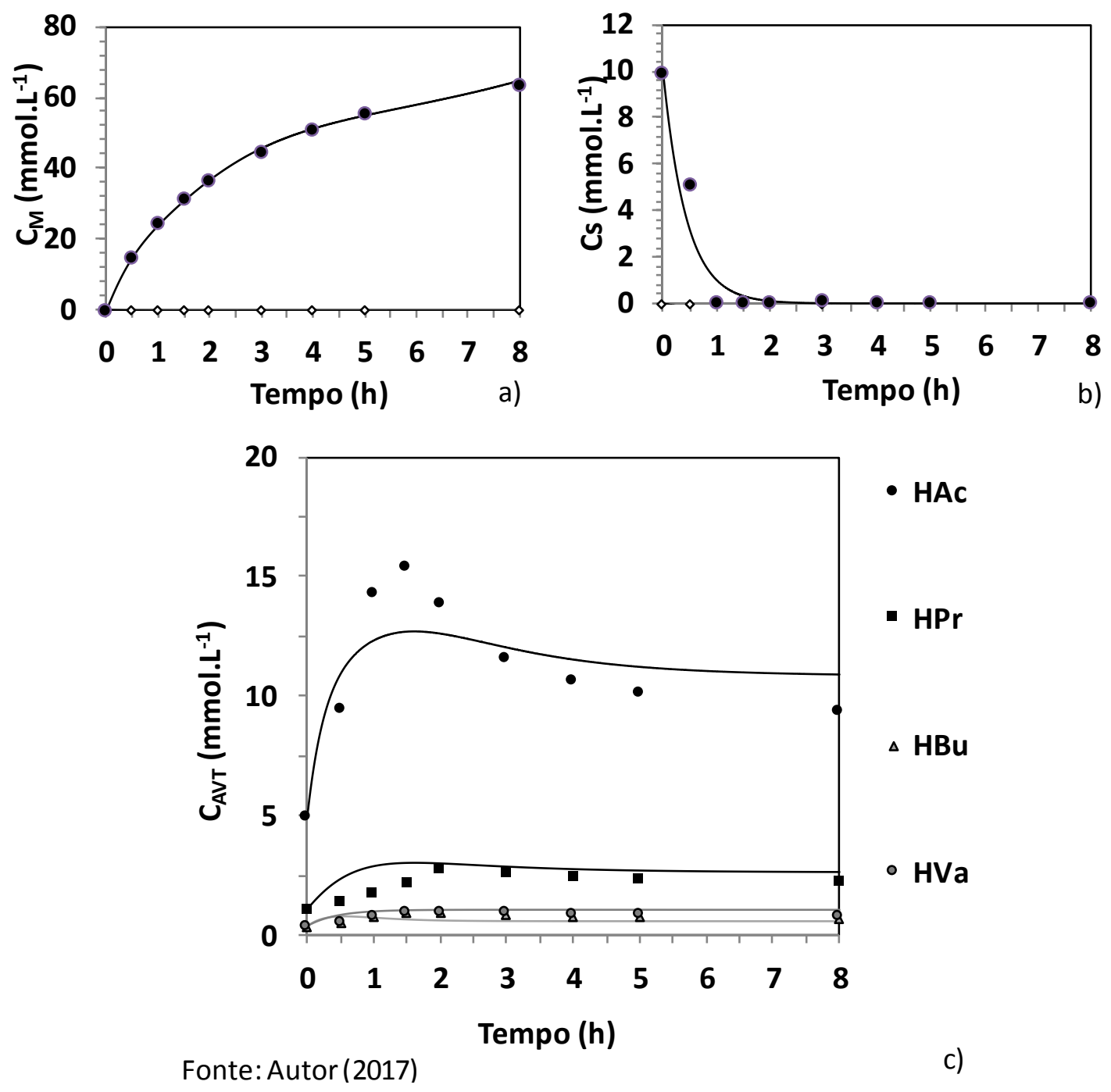

5.2.5 Condição V - 10.000 mg DQO L ${ }^{-1} ; 100 \%$ Soro; $20 \%$ de bicarbonato; $55^{\circ} \mathrm{C}$; Batelada

Nesta condição de operação, o valor nominal de DQO alimentado ao reator foi de 10000 mg $\mathrm{L}^{-1}$ com carga orgânica aplicada teórica de $12,00 \mathrm{~g} \mathrm{DQO} \mathrm{L}^{-1} \mathrm{dia}^{-1}$. 


\subsubsection{Monitoramento}

O reator foi operado por 10 dias, em que a concentração média da matéria orgânica afluente

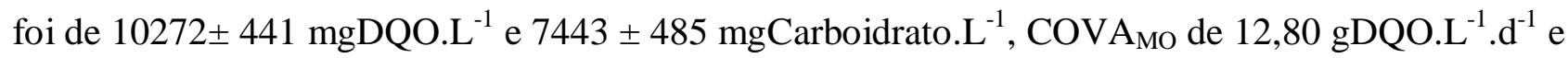
$\operatorname{COVA}_{C}$ de 9,27 gCarboidrato. $\mathrm{L}^{-1} \cdot \mathrm{d}^{-1}$. A quantidade de biomassa contida no reator foi de 51,2 $\mathrm{g}$. Nesta condição, o reator operou um dia com $25 \%$ de bicarbonato afluente, reduzindo a relação para $20 \%$ durante o restante da condição.

Os valores referentes ao monitoramento e aos indicadores desempenho encontram-se apresentados na Tabela 5.9 a seguir. A eficiência de remoção de matéria orgânica na forma de DQO desta condição, para amostras não-filtradas e filtradas, respectivamente, foi de $93 \pm 01 \%$ e $95 \pm 02 \%$. Para a matéria orgânica na forma de Carboidratos (lactose) a remoção foi de $99 \pm 01 \%$ e $100 \pm 01 \%$, respectivamente para não-filtradas e filtradas. $\mathrm{O} \mathrm{pH}$ afluente foi de $8,43 \pm 0,06$ e o efluente 8,29 $\pm 0,12$. A alcalinidade a bicarbonato do afluente e efluente foram $1337 \pm 122 \mathrm{mgCaCO} 3 \cdot \mathrm{L}^{-1}$ e $1881 \pm 161 \mathrm{mgCaCO}_{3} \cdot \mathrm{L}^{-1}$. A alcalinidade referente aos ácidos voláteis do afluente e efluente foram $411 \pm 43$ mgHAc. $\mathrm{L}^{-1}$ e $110 \pm 109 \mathrm{mgHac} . \mathrm{L}^{-1}$. Observa-se que o reator seguiu apresentando grande capacidade produtiva de alcalinidade a bicarbonato, resultando em concentrações maiores no efluente do que no afluente. Apesar disso, optou-se por não diminuir mais a relação para evitar problemas com a capacidade tampão do reator durante o pico de produção de ácidos voláteis, como pode ser visto nos resultados dos perfis do reator.

A concentração de sólidos suspensos voláteis (SSV) no efluente indica que houve pouca perda de biomassa no reator.

O rendimento de metano gerado por matéria orgânica consumida foi de 19,56 $\mathrm{mmolCH}_{4} \cdot \mathrm{gDQO}^{-1}$ e 26,99 $\mathrm{mmolCH}_{4} \cdot \mathrm{gCarboidrato}^{-1}$. A produção de biogás foi de $6311 \pm 829 \mathrm{~mL}-$ 
CNTP.ciclo ${ }^{-1}$, sendo a fração molar de metano equivalente a $76,03 \pm 0,14 \%$ e a produtividade molar de metano de 250,3 $\mathrm{molCH}_{4} \cdot \mathrm{m}^{-3} \cdot \mathrm{d}^{-1}$. 
Tabela 5.9 - Resumo dos valores médios obtidos no monitoramento do reator com concentração afluente de $10000 \mathrm{mgDQO} . \mathrm{L}^{-1}$ na condição V

\begin{tabular}{|c|c|c|c|c|c|c|c|c|c|c|}
\hline \multicolumn{2}{|r|}{ Parâmetro } & \multicolumn{5}{|c|}{ Afluente } & \multicolumn{4}{|c|}{ Efluente } \\
\hline $\mathrm{C}_{\mathrm{ST}}$ & $\left(\mathrm{mgDQO} . \mathrm{L}^{-1}\right)$ & 10272 & \pm & 441 & $(9$ & & 739 & \pm & 89 & $(9)$ \\
\hline $\mathrm{C}_{\mathrm{SF}}$ & $\left(\operatorname{mgDQO} \cdot L^{-1}\right)$ & - & & - & & & 470 & \pm & 154 & $\left(\begin{array}{ll}9 \\
9\end{array}\right)$ \\
\hline$\varepsilon_{\mathrm{ST}}$ & $(\%)$ & - & & - & & & $93 \%$ & \pm & $1 \%$ & $\left(\begin{array}{ll}9 & )\end{array}\right.$ \\
\hline$\varepsilon_{\mathrm{SF}}$ & $(\%)$ & - & & - & & & $95 \%$ & \pm & $2 \%$ & $(9)$ \\
\hline $\mathrm{C}_{\mathrm{CT}}$ & $\left(\right.$ mgCarboidrato. $\left.\mathrm{L}^{-1}\right)$ & 7443 & \pm & 485 & ( 9 & & 69 & \pm & 15 & $(9)$ \\
\hline $\mathrm{C}_{\mathrm{CF}}$ & $\left(\right.$ mgCarboidrato. $\left.L^{-1}\right)$ & - & & - & & & 33 & \pm & 15 & $\left(\begin{array}{ll}9\end{array}\right)$ \\
\hline$\varepsilon_{\mathrm{CT}}$ & $(\%)$ & - & & - & & & $99 \%$ & \pm & $0 \%$ & \\
\hline$\varepsilon_{\mathrm{CF}}$ & $(\%)$ & - & & - & & & $100 \%$ & \pm & $0 \%$ & \\
\hline $\mathrm{pH}$ & (u) & 8,43 & \pm & 0,06 & ( 9 & & 8,29 & \pm & 0,12 & $\left(\begin{array}{ll}9 & )\end{array}\right.$ \\
\hline AVT & $\left(\mathrm{mgHAc} . \mathrm{L}^{-1}\right)$ & 411 & \pm & 43 & ( 9 & ) & 110 & \pm & 109 & $(9)$ \\
\hline AT & $\left(\mathrm{mgCaCO}{ }_{3} \cdot \mathrm{L}^{-1}\right)$ & 1337 & \pm & 107 & ( 9 & ) & 1959 & \pm & 151 & $\left(\begin{array}{ll}9 & )\end{array}\right.$ \\
\hline AP & $\left(\mathrm{mgCaCO}_{3} \cdot \mathrm{L}^{-1}\right)$ & 196 & \pm & 63 & ( 9 & ) & 1847 & \pm & 104 & $\left(\begin{array}{ll}9\end{array}\right)$ \\
\hline AI & $\left(\mathrm{mgCaCO}_{3} \cdot \mathrm{L}^{-1}\right)$ & 1433 & \pm & 85 & ( 9 & ) & 113 & \pm & 77 & $(9)$ \\
\hline $\mathrm{AB}$ & $\left(\mathrm{mgCaCO}_{3} \cdot \mathrm{L}^{-1}\right)$ & 1337 & \pm & 122 & ( 9 & ) & 1881 & \pm & 161 & $\left(\begin{array}{ll}9\end{array}\right)$ \\
\hline ST & $\left(\mathrm{mg} . \mathrm{L}^{-1}\right)$ & 9855 & \pm & 906 & $(3$ & ) & 3206 & \pm & 529 & $(3)$ \\
\hline SVT & $\left(\mathrm{mg} \cdot \mathrm{L}^{-1}\right)$ & 7952 & \pm & 930 & $(3$ & ) & 1409 & \pm & 369 & $(3)$ \\
\hline SST & $\left(\mathrm{mg} \cdot \mathrm{L}^{-1}\right)$ & 277 & \pm & 11 & $(3$ & ) & 230 & \pm & 33 & $(3)$ \\
\hline SSV & $\left(\mathrm{mg} \cdot \mathrm{L}^{-1}\right)$ & 227 & \pm & 26 & $(3$ & ) & 225 & \pm & 29 & $(3)$ \\
\hline SDF & $\left(\mathrm{mg} \cdot \mathrm{L}^{-1}\right)$ & 1399 & & - & & & 1342 & & - & \\
\hline $\mathrm{M}_{\mathrm{SVT}}$ & (g) & 51,2 & & - & & & - & & - & \\
\hline $\mathrm{C}_{\mathrm{X}}$ & $\left(\mathrm{gSVT} . \mathrm{L}^{-1}\right)$ & 20,0 & & - & & & - & & - & \\
\hline $\mathrm{C}_{\mathrm{X}}^{\prime}$ & $\left(\right.$ gSVT.gsuporte ${ }^{-1}$ ) & 1,2 & & - & & & - & & - & \\
\hline $\mathrm{V}_{\mathrm{G}}$ & $\left(\mathrm{mL}-\mathrm{CNTP} . \mathrm{Ciclo}^{-1}\right)$ & - & & - & & & 6311 & \pm & 829 & $(4)$ \\
\hline $\mathrm{V}_{\mathrm{CH} 4}$ & $\left(\mathrm{~mL}-\mathrm{CNTPCH}_{4} \cdot \mathrm{Ciclo}^{-1}\right)$ & - & & - & & & 4798 & & - & \\
\hline $\mathrm{COVA}_{\mathrm{S}}$ & $\left(\mathrm{gDQO} \cdot \mathrm{L}^{-1} \cdot \mathrm{d}^{-1}\right)$ & 12,80 & & - & & & - & & - & \\
\hline $\mathrm{COVR}_{\mathrm{S}}$ & $\left(\mathrm{gDQO} \cdot \mathrm{L}^{-1} \cdot \mathrm{d}^{-1}\right)$ & - & & - & & & 11,88 & & - & \\
\hline COEA $_{S}$ & $\left(\right.$ gDQO.gSVT $\left.{ }^{-1} \cdot d^{-1}\right)$ & 0,64 & & - & & & - & & - & \\
\hline $\mathrm{COER}_{\mathrm{S}}$ & $\left(\right.$ gDQO.gSVT $\left.{ }^{-1} \cdot \mathrm{d}^{-1}\right)$ & - & & - & & & 0,30 & & - & \\
\hline $\mathrm{COVA}_{\mathrm{c}}$ & (gCarboidrato. $\left.\mathrm{L}^{-1} \cdot \mathrm{d}^{-1}\right)$ & 9,27 & & - & & & & & - & \\
\hline $\mathrm{COVR}_{\mathrm{c}}$ & (gCarboidrato. $\left.\mathrm{L}^{-1} \cdot \mathrm{d}^{-1}\right)$ & & & - & & & 9,19 & & - & \\
\hline $\mathrm{COEA}_{c}$ & (gCarboidrato.gSVT ${ }^{-1} \cdot \mathrm{d}^{-1}$ ) & 0,46 & & - & & & & & - & \\
\hline $\mathrm{COER}_{\mathrm{c}}$ & (gCarboidrato.gSVT ${ }^{-1} \cdot \mathrm{d}^{-1}$ ) & & & & & & 0,23 & & - & \\
\hline $\mathrm{n}_{\mathrm{CH} 4}$ & $\left(\mathrm{molCH}_{4} \cdot \mathrm{d}^{-1}\right)$ & - & & - & & & 0,6422 & & - & \\
\hline $\mathrm{X}_{\mathrm{CH} 4}$ & $(\%)$ & & & & & & 76,03 & \pm & 0,14 & \\
\hline PrM & $\left(\mathrm{molCH}_{4} \cdot \mathrm{m}^{-3} \cdot \mathrm{d}^{-1}\right)$ & - & & - & & & 250,3 & & - & \\
\hline PrME & $\left(\mathrm{molCH}_{4} \cdot \mathrm{kgSVT}^{-1} \cdot \mathrm{d}^{-1}\right)$ & - & & - & & & 12,54 & & - & \\
\hline $\operatorname{PrV}$ & $\left(\mathrm{mL}-\mathrm{CNTPCH} 4 \cdot \mathrm{L}^{-1} \cdot \mathrm{d}^{-1}\right)$ & - & & - & & & 5611 & & - & \\
\hline PrVE & 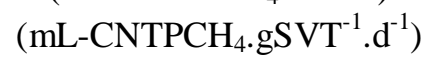 & - & & - & & & 281,01 & & - & \\
\hline $\mathrm{RMCA}_{\mathbf{s}}$ & $\left(\mathrm{mmolCH}_{4} \cdot \mathrm{gDQO}^{-1}\right)$ & 19,56 & & - & & & - & & - & \\
\hline $\mathrm{RMCR}_{\mathbf{s}}$ & $\left(\mathrm{mmolCH}_{4} \cdot \mathrm{gDQO}^{-1}\right)$ & - & & - & & & 21,07 & & - & \\
\hline $\mathrm{RMCA}_{\mathrm{C}}$ & $\left(\mathrm{mmolCH}_{4} \cdot \mathrm{gCarboidrato}^{-1}\right)$ & 26,99 & & - & & & - & & - & \\
\hline $\mathrm{RMCR}_{\mathrm{c}}$ & $\left(\mathrm{mmolCH}_{4} \cdot\right.$ gCarboidrato $\left.^{-1}\right)$ & - & & - & & & 27,24 & & - & \\
\hline $\mathrm{V}_{\mathrm{A}}$ & $\left(\mathrm{mL} . \mathrm{Ciclo}^{-1}\right)$ & 1066 & \pm & 84 & $(9$ & ) & - & & - & \\
\hline$V_{\text {RES }}$ & $(\mathrm{mL})$ & 1500 & & - & & & - & & - & \\
\hline
\end{tabular}

*Os valores entre parêntesis representam o número de amostras consideradas para o cálculo da média Fonte: Autor (2017) 


\subsubsection{Perfil ao longo do ciclo}

Durante o perfil, a concentração de matéria orgânica afluente na forma de DQO e de Carboidrato foi de $9888 \mathrm{mgDQO} . \mathrm{L}^{-1}$ e de $72437 \mathrm{mgCarboidrato.L^{-1 }}$, respectivamente. Após a diluição, os valores se alteraram para $4910 \mathrm{mgDQO} . \mathrm{L}^{-1}$ e $2813 \mathrm{mgCarboidrato.L^{-1 }}$ no início do ciclo.

Observa-se na Figura 5.24 a variação do $\mathrm{pH}$ ao longo do ciclo, com valor de 8,51 no afluente, mínimo de 7,12 e 8,38 no efluente. Também é possível acompanhar a variação da alcalinidade a bicarbonato e ácidos voláteis totais durante o ciclo. Os ácidos voláteis totais têm o pico de produção (1808 mgHAc. $\mathrm{L}^{-1}$ ) em 1,0 horas de ciclo. Houve grande acúmulo de ácidos no reator, comprometendo a alcalinidade a bicarbonato, reduzindo seu valor a um mínimo de 139 mg $\mathrm{CaCO}_{3} \cdot \mathrm{L}^{-1}$. Apesar disso, ainda houve valor excedente de bicarbonato, logo, a capacidade tampão ainda se manteve visto que o pH não esteve em nenhum momento abaixo de 7,0. 
Figura 5.24 - Perfis de pH (a), alcalinidade a bicarbonato e a ácidos voláteis totais (b) na condição $\mathrm{V}$
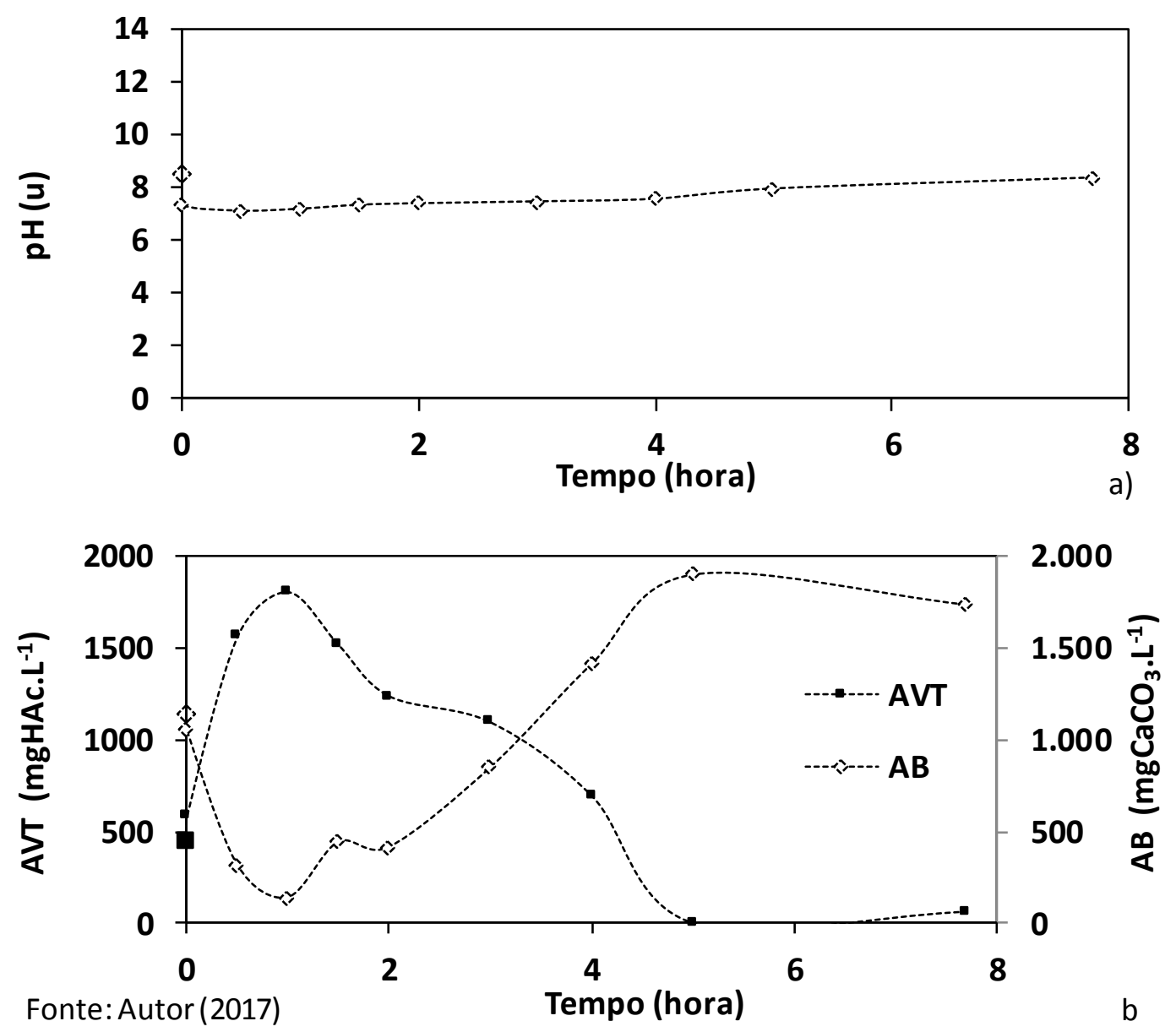

O consumo da matéria orgânica nas formas de DQO e Carboidrato ao longo do ciclo pode ser analisado através da Figura 5.25. Pode-se observar um consumo de matéria orgânica reduzida nesta condição em comparação com as anteriores, ainda assim, houve rápido consumo da matéria orgânica na forma de carboidrato, resultando em $96 \%$ de consumo em 0,5 hora de ciclo. No mesmo período, a eficiência de remoção de DQO foi de 73\%. A maior quantidade de matéria orgânica presente no efluente diminui a sua taxa de consumo, resultando num consumo mais lento a cada vez que se aumenta a sua concentração. Mesmo assim, a eficiência final do reator se manteve boa, resultando em $92 \%$ de remoção de DQO ao final das 8 horas de ciclo. 
Figura 5.25 - Perfis de concentração e eficiência de remoção de DQO (a) e carboidratos (b) na condição V
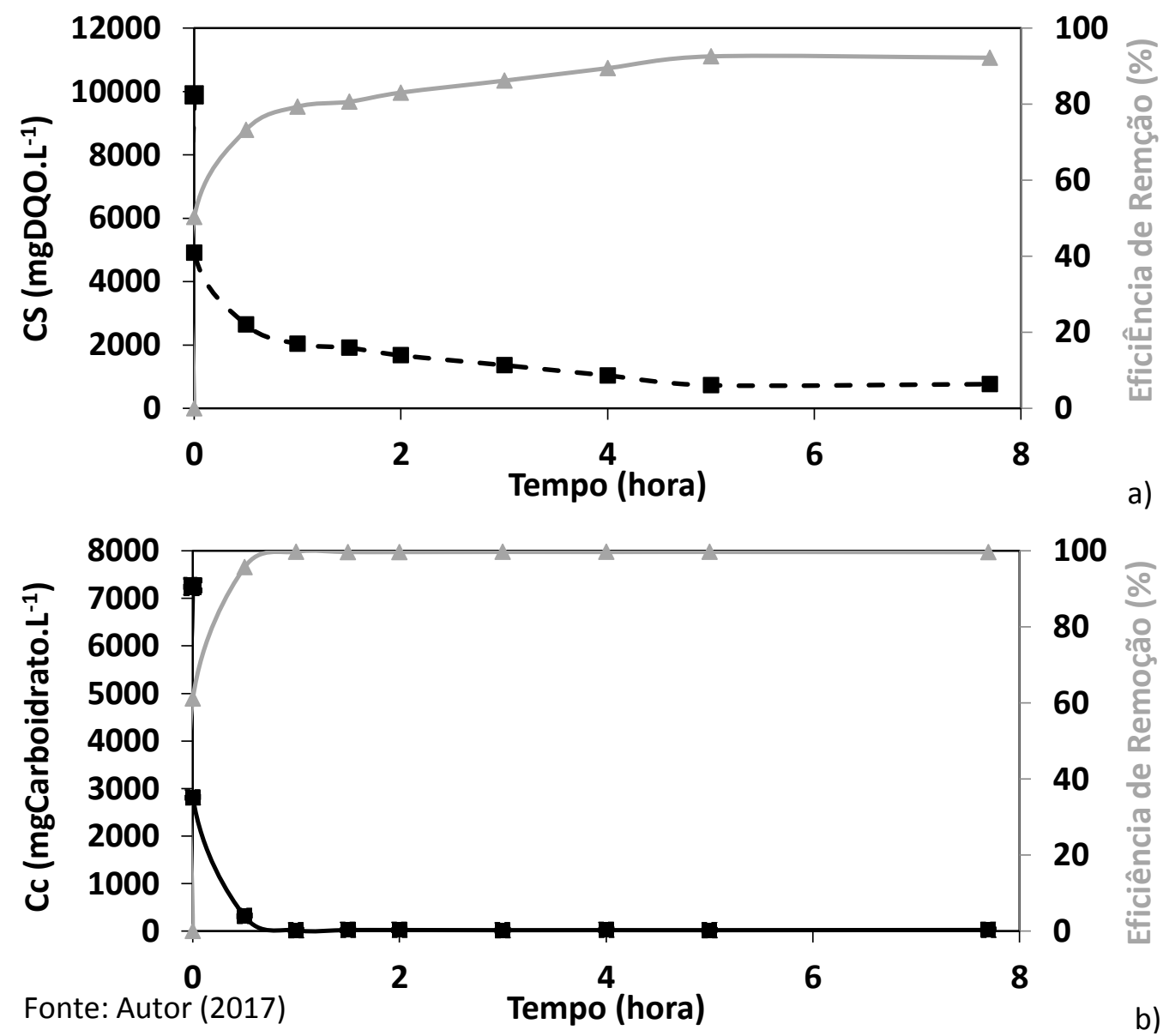

A variação da produção e consumo dos compostos metabólicos intermediários ao longo do ciclo pode ser observada pela Figura 5.26. O maior valor de ácido propiônico nesta condição foi de 244,5 mg.L-1, num pico que se deu após 2 horas de ciclo. Nesta condição, houve excedente de ácidos voláteis ao final do ciclo, indicando que houve alguma diminuição do potencial do reator, também observável por uma remoção de matéria orgânica pouco menor do que nas condições anteriores. 
Figura 5.26 - Perfil das concentrações dos compostos intermediários ao longo do ciclo na condição $\mathrm{V}$

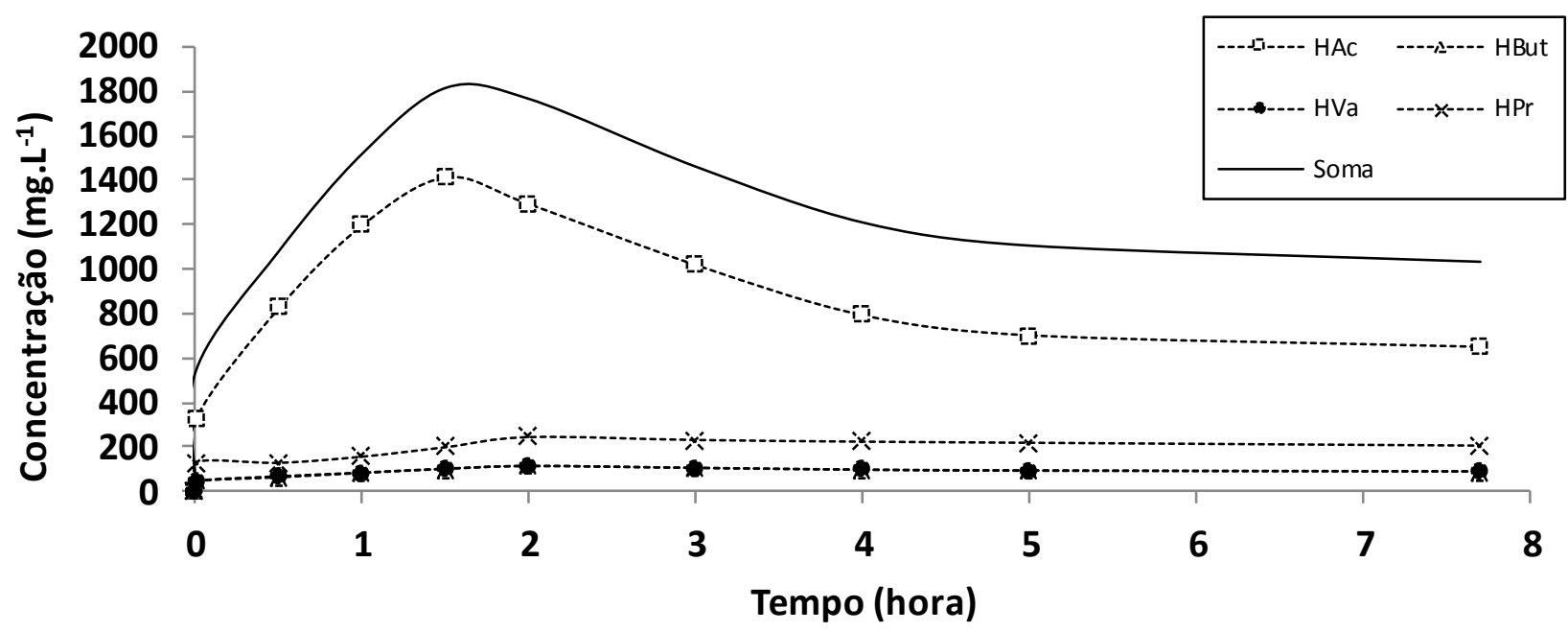

Fonte: Autor (2017)

A produção volumétrica de metano $\left(\mathrm{CH}_{4}\right)$ e dióxido de carbono $\left(\mathrm{CO}_{2}\right)$ ao longo do ciclo pode ser observada através da Figura 5.27. Nota-se que a produção volumétrica de metano foi predominante por todo o ciclo. Também se verifica a evolução das concentrações de metano e dióxido de carbono presente no biogás e a vazão molar de metano ao longo do ciclo além do volume total de biogás gerado durante o período. Durante os primeiros 30min de ciclo o biogás gerado apresentava, diferentemente das outras condições anteriores, grande diferença nas concentrações de metano $\left(6,46 \mathrm{mmol} \cdot \mathrm{L}^{-1}\right)$ e dióxido de carbono $\left(2,46 \mathrm{mmol} \cdot \mathrm{L}^{-1}\right)$. A produção de metano é maior do que a de dióxido de carbono durante todo o período, resultando numa concentração final de $76 \%$ dos 6311 mL-CNTP.ciclo ${ }^{-1}$ de biogás gerados durante o ciclo. 
Figura 5.27 - Perfis de volume nas CNTP de metano e $\mathrm{CO}_{2}$ (a), concentração dos gases e vazão molar (b) e volume e concentração ao longo do ciclo (c) na condição V
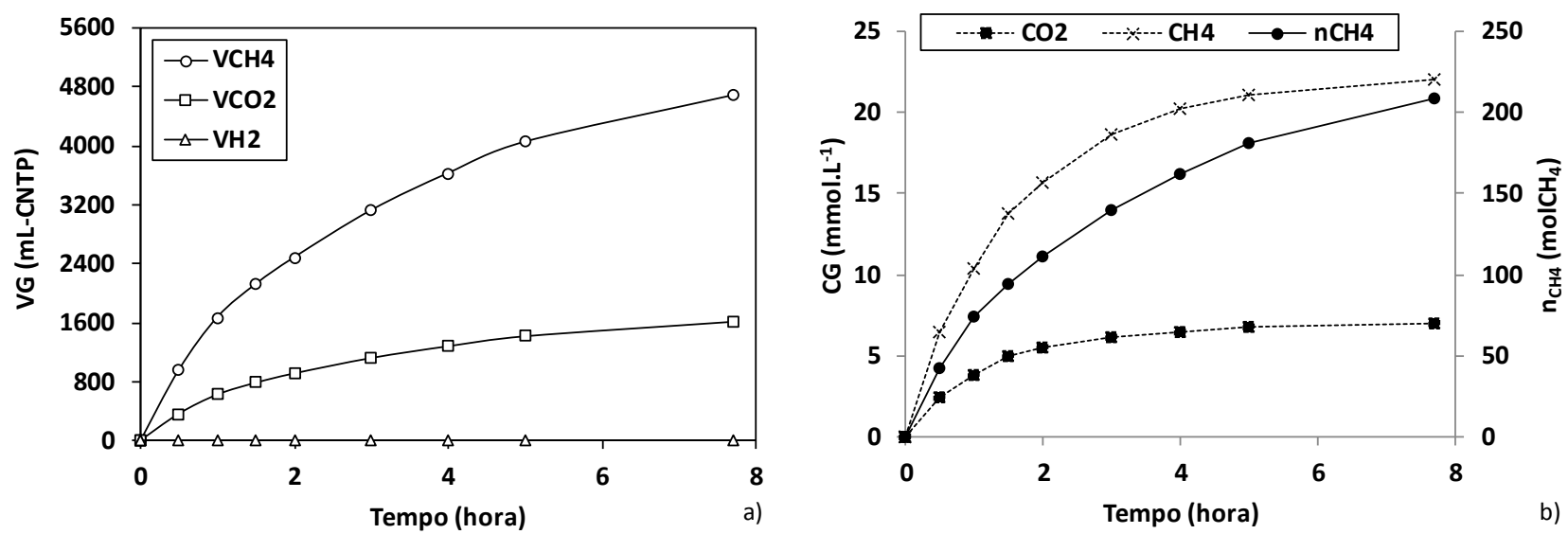

Produção e Composição do Biogás

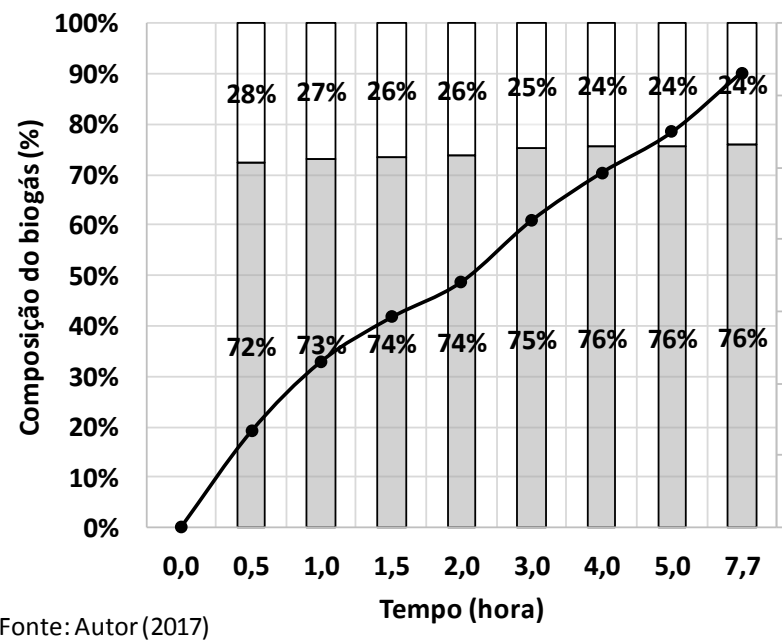

7000,0

6000,0

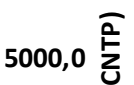

$4000,0 \frac{\vec{\varepsilon}}{y}$

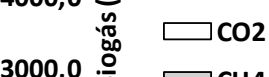

$\square \mathrm{CH} 4$

2000,0 $\frac{\stackrel{\mathrm{E}}{5}}{\frac{3}{\rho}} \rightarrow$ Vbiogás

1000,0

0,0

c)

Os dados do perfil indicam que o reator poderia ser operado eficientemente num ciclo de 5 horas. Os resultados indicam que houve remoção de 93\% de matéria orgânica na forma de DQO e 99,9\% de carboidratos, ambos na forma filtrada. Houve consumo de $100 \%$ da concentração máxima de ácidos voláteis. Além disso, houve a produção de 5481,0 mL-ciclo de biogás, contendo 76\% de metano. 
5.2.5.3 Ajuste do modelo cinético

Os parâmetros cinéticos aparentes foram calculados (Tabela 5.10) e indicam maior produção de ácido acético através do substrato $\left(\mathrm{k}_{1 \mathrm{HAC}}\right)$ e também da conversão do ácido proprônico ( $\left.\mathrm{K}_{6 \mathrm{HAC}}\right)$. A produção de metano foi maior na rota metanogênica hidrogenotrófica $\left(\mathrm{K}_{11 \mathrm{M}}\right)$. Portanto, o modelo cinético foi ajustado de modo adequado pelos dados experimentais (Figura 5.28).

Tabela 5.10 - Parâmetros cinéticos da rota metabólica ao longo do ciclo na condição V

\begin{tabular}{|c|c|c|}
\hline Condição & Parâmetro & Condição V \\
\hline \multirow{10}{*}{$\begin{array}{l}\text { Hidrólise e } \\
\text { Acidogênese }\end{array}$} & $\mathrm{k}_{1 \mathrm{~S}}^{\prime}\left(\mathrm{h}^{-1}\right)$ & 2,29 \\
\hline & $\mathrm{k}_{1 \mathrm{HAc}}\left(\mathrm{h}^{-1}\right)$ & 2,59 \\
\hline & $\mathrm{k}_{1 \mathrm{H}}\left(\mathrm{h}^{-1}\right)$ & 0,00 \\
\hline & $\mathrm{k}_{2 \mathrm{HPr}}\left(\mathrm{h}^{-1}\right)$ & 0,21 \\
\hline & $\mathrm{k}_{2 \mathrm{H}}\left(\mathrm{h}^{-1}\right)$ & 0,02 \\
\hline & $\mathrm{k}_{3 \mathrm{HBu}}\left(\mathrm{h}^{-1}\right)$ & 0,15 \\
\hline & $\mathrm{k}_{3 \mathrm{H}}\left(\mathrm{h}^{-1}\right)$ & 0,00 \\
\hline & $\mathrm{k}_{4 \mathrm{HVa}}\left(\mathrm{h}^{-1}\right)$ & 0,00 \\
\hline & $\mathrm{k}_{4 \mathrm{H}}\left(\mathrm{h}^{-1}\right)$ & 0,00 \\
\hline & $\mathrm{k}_{\text {5ЕTOH }}\left(\mathrm{h}^{-1}\right)$ & 0,00 \\
\hline \multirow{10}{*}{ Acetogênese } & $\mathrm{k}_{6 \mathrm{HPr}}\left(\mathrm{h}^{-1}\right)$ & 5,81 \\
\hline & $\mathrm{k}_{6 \mathrm{HAc}}\left(\mathrm{h}^{-1}\right)$ & 17,56 \\
\hline & $\mathrm{k}_{6 \mathrm{H}}\left(\mathrm{h}^{-1}\right)$ & 0,00 \\
\hline & $\mathrm{k}_{7 \mathrm{HPr}}\left(\mathrm{h}^{-1}\right)$ & 11,79 \\
\hline & $\mathrm{k}_{7 \mathrm{HBu}}\left(\mathrm{h}^{-1}\right)$ & 0,11 \\
\hline & $\mathrm{k}_{7 \mathrm{H}}\left(\mathrm{h}^{-1}\right)$ & 0,00 \\
\hline & $\mathrm{k}_{8 \mathrm{HBu}}\left(\mathrm{h}^{-1}\right)$ & 0,08 \\
\hline & $\mathrm{k}_{8 \mathrm{HVa}}\left(\mathrm{h}^{-1}\right)$ & 2,34 \\
\hline & $\mathrm{k}_{8 \mathrm{H}}\left(\mathrm{h}^{-1}\right)$ & 0,00 \\
\hline & $\mathrm{k}_{9 \mathrm{HAc}}\left(\mathrm{h}^{-1}\right)$ & 0,00 \\
\hline \multirow{4}{*}{ Metanogênese } & $\mathrm{k}_{10 \mathrm{HAc}}\left(\mathrm{h}^{-1}\right)$ & 2,52 \\
\hline & $\mathrm{k}_{10 \mathrm{H}}\left(\mathrm{h}^{-1}\right)$ & 6,27 \\
\hline & $\mathrm{k}_{11 \mathrm{H}}\left(\mathrm{h}^{-1}\right)$ & 0,09 \\
\hline & $\mathrm{k}_{11 \mathrm{M}}\left(\mathrm{h}^{-1}\right)$ & 1197,51 \\
\hline
\end{tabular}


Figura 5.28 - Dados experimentais (marcadores) e modelo (linha) do metano (a), substrato (b) e ácidos intermediários (c) na condição $\mathrm{V}$
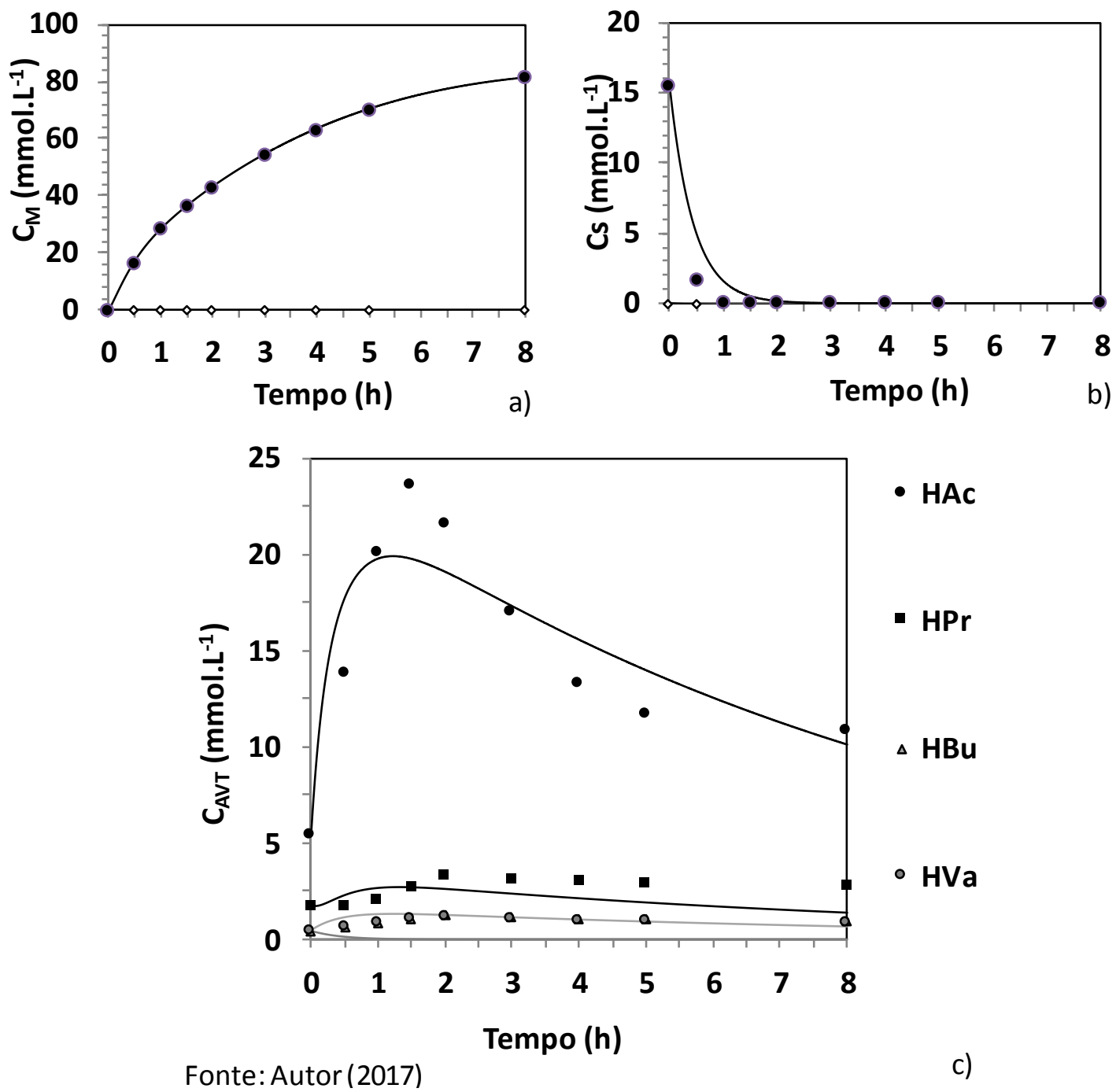

5.2.6 Condição VI - $12.000 \mathrm{mg}$ DQO L ${ }^{-1} ; 100 \%$ Soro; $20 \%$ de bicarbonato; $55^{\circ}$ C; Batelada

Nesta condição de operação, o valor nominal de DQO alimentado ao reator foi de $12000 \mathrm{mg}$ $\mathrm{L}^{-1}$ com carga orgânica aplicada teórica de $14,40 \mathrm{~g} \mathrm{DQO} \mathrm{L}^{-1}$ dia $^{-1}$. 


\subsubsection{Monitoramento}

O reator foi operado por 17 dias, em que a concentração média da matéria orgânica afluente foi de $12404 \pm 829 \mathrm{mgDQO} . \mathrm{L}^{-1}$ e $9526 \pm 2736 \mathrm{mgCarboidrato.L^{-1 }}$, COVA $\mathrm{MO}$ de $16,91 \mathrm{gDQO} . \mathrm{L}^{-1} \cdot \mathrm{d}^{-1}$ e COVA $\mathrm{C}_{\mathrm{C}}$ de $12,99 \mathrm{gCarboidrato} \cdot \mathrm{L}^{-1} \cdot \mathrm{d}^{-1}$. A quantidade de biomassa contida no reator foi de $61,3 \mathrm{~g}$. Nesta condição, o reator operou com $20 \%$ de bicarbonato afluente.

Os valores referentes ao monitoramento e aos indicadores desempenho encontram-se apresentados na Tabela 5.11 a seguir. A eficiência de remoção de matéria orgânica na forma de DQO desta condição, para amostras não-filtradas e filtradas, respectivamente, foi de 93,4 0,5\% e 95,7 $\pm 1,2 \%$. Para a matéria orgânica na forma de Carboidratos (lactose) a remoção foi de $98,9 \pm 1,6 \%$ e $99,4 \pm 0,8 \%$, respectivamente para não-filtradas e filtradas. $\mathrm{O} \mathrm{pH}$ afluente foi de $8,42 \pm 0,11$ e o efluente $8,26 \pm 0,18$. A alcalinidade a bicarbonato do afluente e efluente foram $1439 \pm 121 \mathrm{mgCaCO} 3 \cdot \mathrm{L}^{-1}$ e $2226 \pm 87 \mathrm{mgCaCO}_{3} \cdot \mathrm{L}^{-1}$. Os ácidos voláteis do afluente e efluente foram $463 \pm 44 \mathrm{mgHAc} . \mathrm{L}^{-1}$ e $78 \pm 39 \mathrm{mgHac} . \mathrm{L}^{-1}$. Observa-se que o reator seguiu apresentando grande capacidade produtiva de alcalinidade a bicarbonato, resultando em concentrações maiores no efluente do que no afluente. Apesar disso, optou-se pelo aumento da concentração de bicarbonato na etapa seguinte para evitar problema durante o período de pico de formação de ácidos, que se percebe durante a análise do perfil do reator.

A concentração de sólidos suspensos voláteis (SSV) no efluente indica que houve pouca perda de biomassa no reator. Nesta condição, nota-se aumento na concentração de sólidos totais do efluente. Isso aconteceu devido ao fato de que os reatores anaeróbios que tratam soro de leite tendem a formar uma espécie de polímero, que aumenta a concentração de sólidos no reator, o que é favorecido em maiores concentrações, como foi relatado por Mockaitis et al. (2006). Ademais, a presença destes sólidos diminui o volume útil no interior do reator, notável pela redução do volume residual. 
O rendimento de metano gerado por matéria orgânica consumida foi de 17,38 $\mathrm{mmolCH}_{4} \cdot \mathrm{gDQO}^{-1}$ e 22,62 $\mathrm{mmolCH}_{4} \cdot \mathrm{gCarboidrato}^{-1}$. A produção de biogás foi de $6403 \pm 508$ mL-CNTP.ciclo ${ }^{-1}$, sendo a fração molar de metano equivalente a 75,44 $\pm 0,14 \%$ e a produtividade molar de metano de $293,9 \mathrm{molCH}_{4} \cdot \mathrm{m}^{-3} \cdot \mathrm{d}^{-1}$. 
Tabela 5.11- Resumo dos valores médios obtidos no monitoramento do reator com concentração afluente de $12000 \mathrm{mgDQO} . \mathrm{L}^{-1}$ na condição VI.

\begin{tabular}{|c|c|c|c|c|c|c|c|c|c|c|c|c|c|}
\hline \multicolumn{2}{|r|}{ Parâmetro } & \multicolumn{6}{|c|}{ Afluente } & \multicolumn{6}{|c|}{ Efluente } \\
\hline $\mathrm{C}_{\mathrm{ST}}$ & $\left(\mathrm{mgDQO} . \mathrm{L}^{-1}\right)$ & 12404 & \pm & 829 & & 13 & & 820 & \pm & 64 & ( & & \\
\hline $\mathrm{C}_{\mathrm{SF}}$ & (mgDQO.L (-1) $^{-1}$ & - & & - & & & & 529 & \pm & 146 & & 13 & \\
\hline$\varepsilon_{\mathrm{ST}}$ & $(\%)$ & - & & - & & & & $93,4 \%$ & \pm & $0,5 \%$ & ( & 13 & \\
\hline$\varepsilon_{\mathrm{SF}}$ & $(\%)$ & - & & - & & & & $95,7 \%$ & \pm & $1,2 \%$ & ( & 13 & \\
\hline $\mathrm{C}_{\mathrm{CT}}$ & (mgCarboidrato. $\mathrm{L}^{-1}$ ) & 9526 & \pm & 2736 & ( & 13 & ) & 68 & \pm & 8 & ( & 13 & ) \\
\hline $\mathrm{C}_{\mathrm{CF}}$ & $\left(\mathrm{mgCarboidrato} . \mathrm{L}^{-1}\right)$ & - & & - & & & & 34 & \pm & 12 & ( & 13 & ) \\
\hline$\varepsilon_{\mathrm{CT}}$ & $(\%)$ & - & & - & & & & $98,9 \%$ & \pm & $1,6 \%$ & & & \\
\hline$\varepsilon_{\mathrm{CF}}$ & $(\%)$ & - & & - & & & & $99,4 \%$ & \pm & $0,8 \%$ & & & \\
\hline $\mathrm{pH}$ & (u) & 8,42 & \pm & 0,11 & ( & 13 & & 8,26 & \pm & 0,18 & ( & 13 & ) \\
\hline AVT & $\left(\mathrm{mgHAc} . \mathrm{L}^{-1}\right)$ & 463 & \pm & 44 & ( & 13 & ) & 78 & \pm & 39 & ( & 13 & ) \\
\hline AT & $\left(\mathrm{mgCaCO}{ }_{3} \cdot \mathrm{L}^{-1}\right)$ & 1439 & \pm & 137 & ( & 13 & ) & 2281 & \pm & 85 & ( & 13 & ) \\
\hline AP & $\left(\mathrm{mgCaCO}_{3} \cdot \mathrm{L}^{-1}\right)$ & 367 & \pm & 83 & ( & 13 & ) & 1909 & \pm & 98 & ( & 13 & ) \\
\hline AI & $\left(\mathrm{mgCaCO}_{3} \cdot \mathrm{L}^{-1}\right)$ & 1401 & \pm & 132 & ( & 13 & ) & 372 & \pm & 61 & ( & 13 & ) \\
\hline $\mathrm{AB}$ & $\left(\mathrm{mgCaCO}_{3} \cdot \mathrm{L}^{-1}\right)$ & 1439 & \pm & 121 & ( & 13 & ) & 2226 & \pm & 87 & ( & 13 & ) \\
\hline ST & $\left(\mathrm{mg} . \mathrm{L}^{-1}\right)$ & 12027 & \pm & 936 & ( & 4 & ) & 3218 & \pm & 203 & ( & 4 & ) \\
\hline SVT & $\left(\mathrm{mg} \cdot \mathrm{L}^{-1}\right)$ & 9492 & \pm & 563 & ( & 4 & ) & 1131 & \pm & 177 & ( & 4 & ) \\
\hline SST & $\left(\mathrm{mg} \cdot \mathrm{L}^{-1}\right)$ & 286 & \pm & 66 & ( & 4 & ) & 214 & \pm & 75 & & 4 & ) \\
\hline SSV & $\left(\mathrm{mg} \cdot \mathrm{L}^{-1}\right)$ & 232 & \pm & 33 & ( & 4 & ) & 196 & \pm & 41 & & 4 & ) \\
\hline SDF & $\left(\mathrm{mg} \cdot \mathrm{L}^{-1}\right)$ & 2018 & & - & & & & 1677 & & - & & & \\
\hline $\mathrm{M}_{\mathrm{SVT}}$ & (g) & 61,3 & & - & & & & - & & 一 & & & \\
\hline $\mathrm{C}_{\mathrm{X}}$ & $\left(\mathrm{gSVT} . \mathrm{L}^{-1}\right)$ & 27,9 & & - & & & & - & & - & & & \\
\hline $\mathrm{C}_{\mathrm{X}}^{\prime}$ & (gSVT.gsuporte ${ }^{-1}$ ) & 1,6 & & - & & & & - & & - & & & \\
\hline $\mathrm{V}_{\mathrm{G}}$ & (mL-CNTP.Ciclo $\left.{ }^{-1}\right)$ & - & & - & & & & 6403 & \pm & 508 & & 7 & ) \\
\hline $\mathrm{V}_{\mathrm{CH} 4}$ & $\left(\mathrm{~mL}-\mathrm{CNTPCH}_{4} \cdot \mathrm{Ciclo}^{-1}\right)$ & - & & - & & & & 4831 & & - & & & \\
\hline $\mathrm{COVA}_{\mathrm{S}}$ & $\left(\mathrm{gDQO} . \mathrm{L}^{-1} \cdot \mathrm{d}^{-1}\right)$ & 16,91 & & - & & & & - & & 一 & & & \\
\hline $\mathrm{COVR}_{\mathrm{S}}$ & $\left(\mathrm{gDQO} \cdot \mathrm{L}^{-1} \cdot \mathrm{d}^{-1}\right)$ & - & & - & & & & 15,80 & & - & & & \\
\hline $\mathrm{COEA}_{\mathrm{S}}$ & $\left(\right.$ gDQO.gSVT $\left.{ }^{-1} \cdot \mathrm{d}^{-1}\right)$ & 0,61 & & - & & & & - & & 一 & & & \\
\hline $\mathrm{COER}_{S}$ & $\left(\right.$ gDQO.gSVT $\left.{ }^{-1} \cdot d^{-1}\right)$ & - & & - & & & & 0,23 & & 一 & & & \\
\hline $\mathrm{COVA}_{\mathrm{c}}$ & (gCarboidrato. $\mathrm{L}^{-1} \cdot \mathrm{d}^{-1}$ ) & 12,99 & & - & & & & & & 一 & & & \\
\hline $\mathrm{COVR}_{\mathrm{c}}$ & (gCarboidrato. $\left.\mathrm{L}^{-1} \cdot \mathrm{d}^{-1}\right)$ & & & - & & & & 12,90 & & 一 & & & \\
\hline $\mathrm{COEA}_{\mathrm{C}}$ & (gCarboidrato.gSVT ${ }^{-1} \cdot \mathrm{d}^{-1}$ ) & 0,47 & & - & & & & & & 一 & & & \\
\hline $\mathrm{COER}_{c}$ & (gCarboidrato.gSVT ${ }^{-1} \cdot \mathrm{d}^{-1}$ ) & & & & & & & 0,19 & & 一 & & & \\
\hline $\mathrm{n}_{\mathrm{CH} 4}$ & $\left(\mathrm{molCH}_{4} \cdot \mathrm{d}^{-1}\right)$ & - & & - & & & & 0,6466 & & - & & & \\
\hline $\mathrm{X}_{\mathrm{CH} 4}$ & $(\%)$ & & & & & & & 75,44 & \pm & 0,14 & & & \\
\hline PrM & $\left(\mathrm{molCH}_{4} \cdot \mathrm{m}^{-3} \cdot \mathrm{d}^{-1}\right)$ & - & & - & & & & 293,9 & & - & & & \\
\hline PrME & $\left(\mathrm{molCH}_{4} \cdot \mathrm{kgSVT}^{-1} \cdot \mathrm{d}^{-1}\right)$ & - & & - & & & & 10,55 & & - & & & \\
\hline $\operatorname{PrV}$ & $\left(\mathrm{mL}-\mathrm{CNTPCH}_{4} \cdot \mathrm{L}^{-1} \cdot \mathrm{d}^{-1}\right)$ & - & & - & & & & 6587 & & 一 & & & \\
\hline PrVE & $\left(\mathrm{mL} \mathrm{CNTPCH}_{4} \cdot \mathrm{gSVT}^{-1} \cdot \mathrm{d}^{-1}\right)$ & - & & 一 & & & & 236,52 & & - & & & \\
\hline $\mathrm{RMCA}_{s}$ & $\left(\mathrm{mmolCH}_{4} \cdot \mathrm{gDQO}^{-1}\right)$ & 17,38 & & - & & & & - & & - & & & \\
\hline $\mathrm{RMCR}_{s}$ & $\left(\mathrm{mmolCH}_{4} \cdot \mathrm{gDQO}^{-1}\right)$ & - & & - & & & & 18,61 & & - & & & \\
\hline $\mathrm{RMCA}_{\mathrm{c}}$ & $\left(\mathrm{mmolCH}_{4} \cdot \mathrm{g}\right.$ Carboidrato $\left.{ }^{-1}\right)$ & 22,62 & & - & & & & - & & - & & & \\
\hline $\mathrm{RMCR}_{\mathrm{c}}$ & $\left(\mathrm{mmolCH}_{4} \cdot \mathrm{gCarboidrato}^{-1}\right)$ & - & & - & & & & 22,79 & & - & & & \\
\hline $\mathrm{V}_{\mathrm{A}}$ & $\left(\mathrm{mL} . \mathrm{Ciclo}^{-1}\right)$ & 1000 & \pm & 11 & ( & 13 & ) & - & & - & & & \\
\hline $\mathrm{V}_{\mathrm{RES}}$ & $(\mathrm{mL})$ & 1200 & & - & & & & - & & - & & & \\
\hline
\end{tabular}

*Os valores entre parêntesis representam o número de amostras consideradas para o cálculo da média Fonte: Autor (2017) 


\subsubsection{Perfil ao longo do ciclo}

Durante o perfil, a concentração de matéria orgânica afluente na forma de DQO e de Carboidrato foi de $11043 \mathrm{mgDQO} . \mathrm{L}^{-1}$ e de $9275 \mathrm{mgCarboidrato.L^{-1 }}$, respectivamente. Após a diluição, os valores se alteraram para $4910 \mathrm{mgDQO}^{-1}$ e $3144 \mathrm{mgCarboidrato.L}^{-1}$ no início do ciclo.

Observa-se na Figura 5.29 a variação do $\mathrm{pH}$ ao longo do ciclo, com valor de 8,42 no afluente, mínimo de 6,75 e 7,95 no efluente. Também é possível acompanhar a variação da alcalinidade a bicarbonato e ácidos voláteis totais durante o ciclo. Os ácidos voláteis totais têm o pico de produção (1505 mgHAc. $\mathrm{L}^{-1}$ ) em 1,0 horas de ciclo, apresentando baixa taxa de consumo após 1,5 horas (1490 mgHAc. $\mathrm{L}^{-1}$ ), o que indica que ainda houve produção significativa de ácidos no reator. $\mathrm{O}$ acúmulo de ácidos fez com que a alcalinidade a bicarbonato tivesse redução de sua concentração, resultando num valor mínimo de $723 \mathrm{mg} \mathrm{CaCO} 3 \mathrm{mg} . \mathrm{L}^{-1}$ e um valor mínimo de pH abaixo de 7,0. Por este motivo, optou-se pelo aumento da concentração de bicarbonato para a próxima condição. 
Figura 5.29 - Perfis de pH (a), alcalinidade a bicarbonato e a ácidos voláteis totais (b) na condição VI
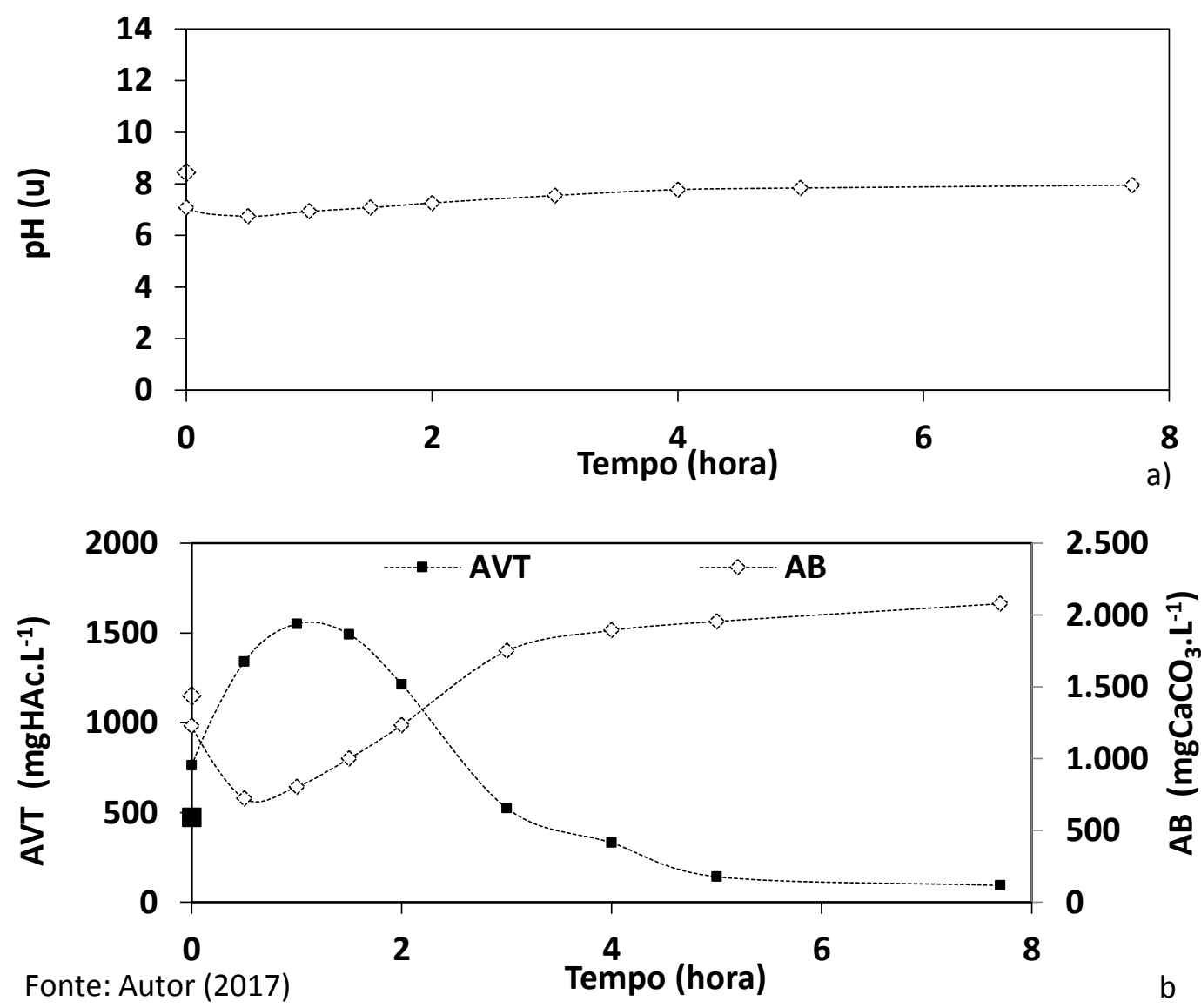

O consumo da matéria orgânica nas formas de DQO e Carboidrato ao longo do ciclo pode ser analisado através da Figura 5.30. Pode-se observar um consumo de matéria orgânica na forma de DQO um pouco lento nesta condição, mas ainda houve rápido consumo da matéria orgânica na forma de carboidrato, resultando em $95 \%$ de consumo em 0,5 horas de ciclo. No mesmo período, a eficiência de remoção de DQO foi de $72 \%$. A eficiência final do ciclo foi de $95 \%$ de remoção de DQO. 
Figura 5.30 - Perfis de concentração e eficiência de remoção de DQO (a) e carboidratos (b) na condição VI
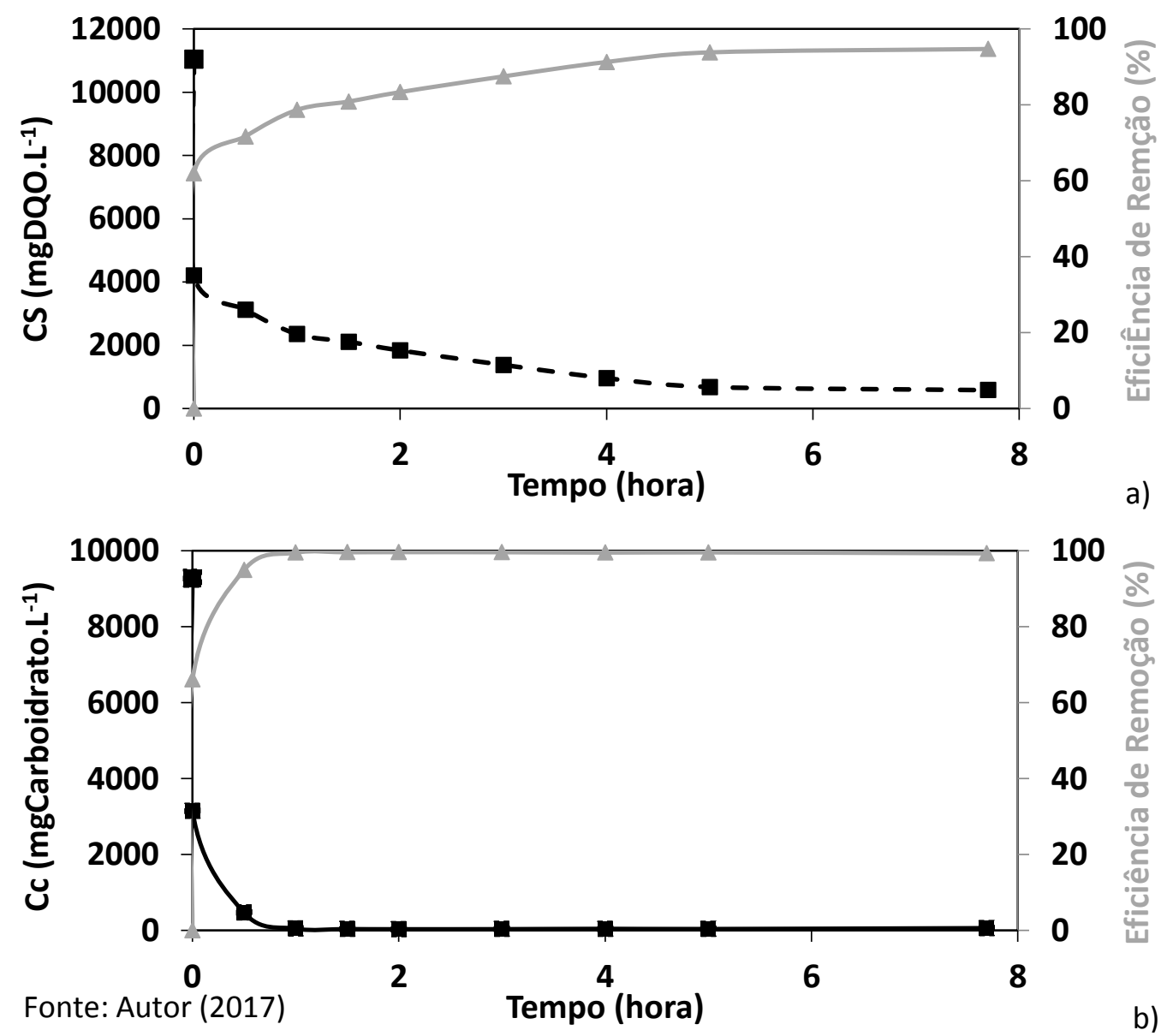

A variação da produção e consumo dos compostos metabólicos intermediários ao longo do ciclo pode ser observada pela Figura 5.31. O maior valor de ácido propiônico nesta condição foi de 270,1 mg. $\mathrm{L}^{-1}$, num pico que se deu após 2 horas de ciclo, o consumo deste ácido se manteve lento até o final do ciclo, resultando em concentração de $249,8 \mathrm{mg} . \mathrm{L}^{-1}$ no efluente. 
Figura 5.31 - Perfil das concentrações dos compostos intermediários ao longo do ciclo na condição VI

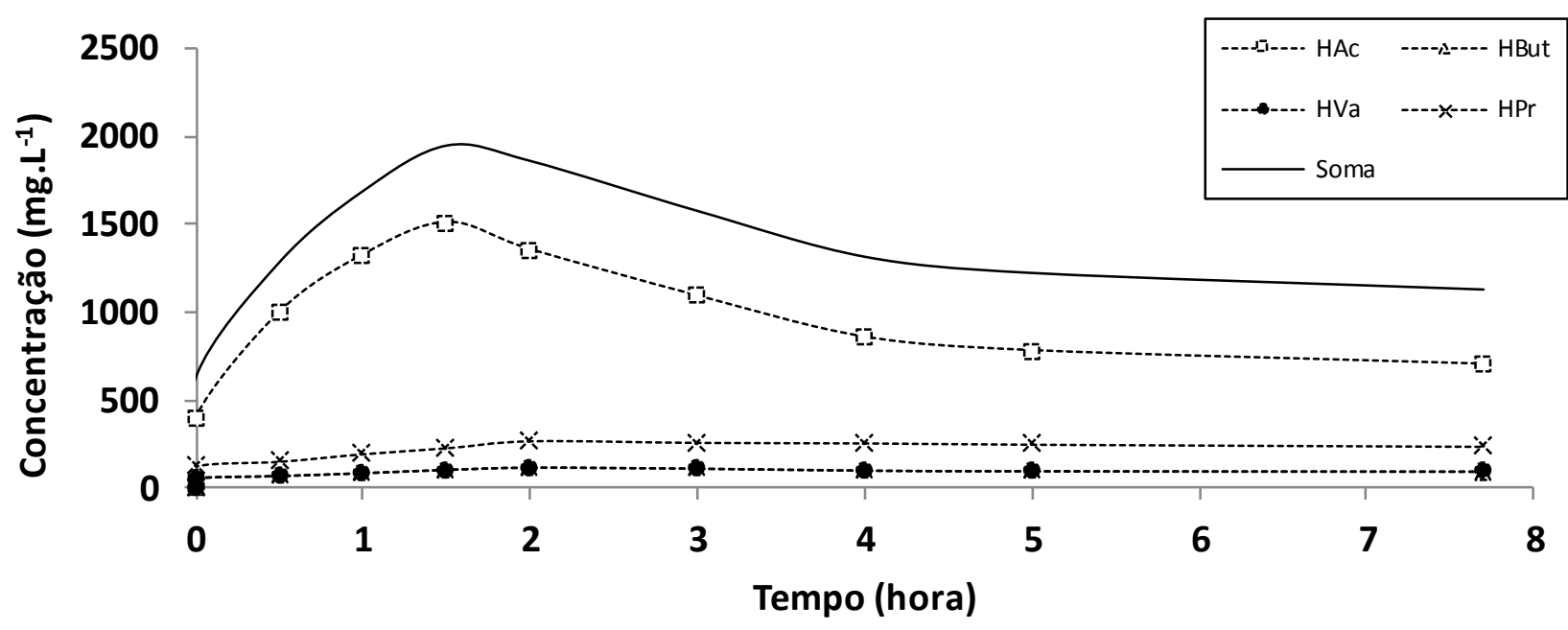

Fonte: Autor (2017)

A produção volumétrica de metano $\left(\mathrm{CH}_{4}\right)$ e dióxido de carbono $\left(\mathrm{CO}_{2}\right)$ ao longo do ciclo pode ser observada através da Figura 5.32. Nota-se que a produção volumétrica de metano foi predominante por todo o ciclo. Também se verifica a evolução das concentrações de metano e dióxido de carbono presente no biogás e a vazão molar de metano ao longo do ciclo além do volume total de biogás gerado durante o período. Durante os primeiros 30min de ciclo o biogás gerado apresentava diferença considerável nas concentrações de metano $\left(7,59\right.$ mmol. $\left.\mathrm{L}^{-1}\right)$ e dióxido de carbono $\left(2,95\right.$ mmol. $\left.\mathrm{L}^{-1}\right)$. A produção de metano é maior do que a de dióxido de carbono durante todo o período, resultando numa concentração final de $75 \%$ dos $6403 \mathrm{~mL}-\mathrm{CNTP}$.ciclo ${ }^{-1}$ de biogás gerados durante o ciclo. 
Figura 5.32 - Perfis de volume nas CNTP de metano e $\mathrm{CO}_{2}$ (a), concentração dos gases e vazão molar (b) e volume e concentração ao longo do ciclo (c) na condição VI
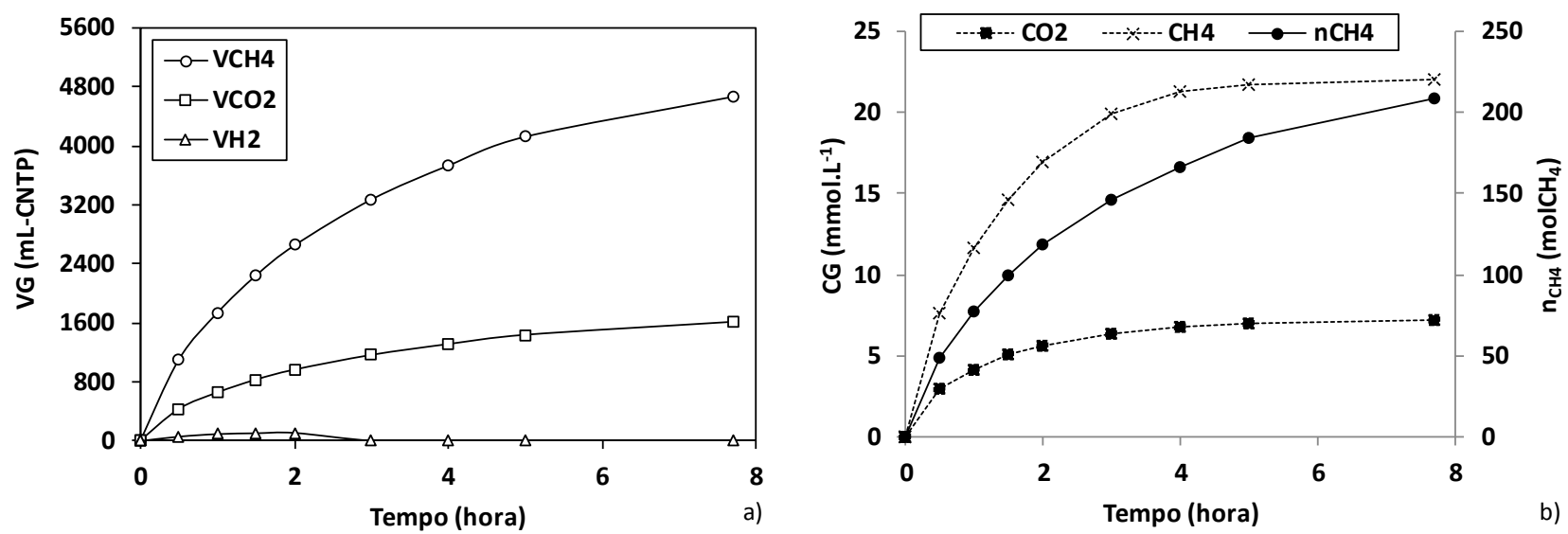

Produção e Composição do Biogás

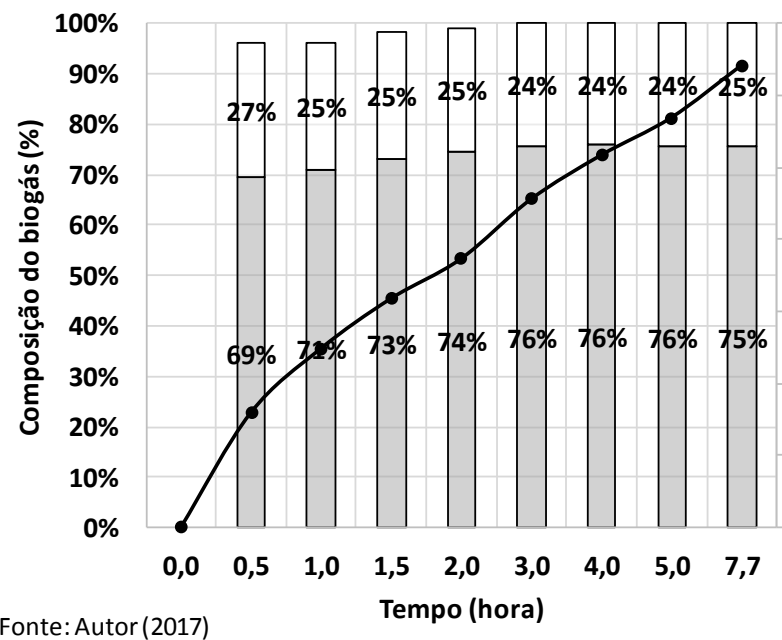

7000,0

6000,0

5000,0 玄

$4000,0 \frac{\vec{\varepsilon}}{4}$

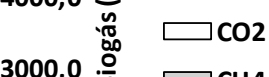

$2000,0 \frac{\text { है }}{\frac{2}{9}} \rightarrow \mathrm{CH} 4$

1000,0

0,0

c)

Os dados do perfil indicam que o reator poderia ser operado eficientemente num ciclo de 5 horas. Os resultados indicam que houve remoção de $94 \%$ de matéria orgânica na forma de DQO e 99,9\% de carboidratos, ambos na forma filtrada. Houve consumo de $91 \%$ da concentração máxima de ácidos voláteis. Além disso, houve a produção de 5680,9 mL-ciclo de biogás, contendo 76\% de metano. 
5.2.6.3 Ajuste do modelo cinético

Os parâmetros cinéticos aparentes foram calculados (Tabela 5.12) e indicam maior produção de ácido acético através do substrato $\left(\mathrm{k}_{1 \mathrm{HAC}}\right)$ e também da conversão do ácido proprônico ( $\left.\mathrm{K}_{6 \mathrm{HAC}}\right)$. A produção de metano foi maior na rota metanogênica hidrogenotrófica $\left(\mathrm{K}_{11 \mathrm{M}}\right)$. Portanto, o modelo cinético foi ajustado de modo adequado pelos dados experimentais (Figura 5.33).

Tabela 5.12 - Parâmetros cinéticos da rota metabólica ao longo do ciclo na condição VI

\begin{tabular}{|c|c|c|}
\hline Condição & Parâmetro & $\begin{array}{c}\text { Condição } \\
\text { VI }\end{array}$ \\
\hline \multirow{10}{*}{$\begin{array}{l}\text { Hidrólise e } \\
\text { Acidogênese }\end{array}$} & $\mathrm{k}_{1 \mathrm{~S}}^{\prime}\left(\mathrm{h}^{-1}\right)$ & 3,27 \\
\hline & $\mathrm{k}_{1 \mathrm{HAc}}\left(\mathrm{h}^{-1}\right)$ & 3,90 \\
\hline & $\mathrm{k}_{1 \mathrm{H}}\left(\mathrm{h}^{-1}\right)$ & 0,00 \\
\hline & $\mathrm{k}_{2 \mathrm{HPr}}\left(\mathrm{h}^{-1}\right)$ & 0,13 \\
\hline & $\mathrm{k}_{2 \mathrm{H}}\left(\mathrm{h}^{-1}\right)$ & 0,01 \\
\hline & $\mathrm{k}_{3 \mathrm{HBu}}\left(\mathrm{h}^{-1}\right)$ & 0,15 \\
\hline & $\mathrm{k}_{3 \mathrm{H}}\left(\mathrm{h}^{-1}\right)$ & 0,00 \\
\hline & $\mathrm{k}_{4 \mathrm{HVa}}\left(\mathrm{h}^{-1}\right)$ & 0,03 \\
\hline & $\mathrm{k}_{4 \mathrm{H}}\left(\mathrm{h}^{-1}\right)$ & 0,00 \\
\hline & $\underset{1}{\mathrm{k}_{5 \text { ETOH }}}\left(\mathrm{h}^{-}\right.$ & 0,00 \\
\hline \multirow{10}{*}{ Acetogênese } & $\mathrm{k}_{6 \mathrm{HPr}}\left(\mathrm{h}^{-1}\right)$ & 4,36 \\
\hline & $\mathrm{k}_{6 \mathrm{HAc}}\left(\mathrm{h}^{-1}\right)$ & 11,43 \\
\hline & $\mathrm{k}_{6 \mathrm{H}}\left(\mathrm{h}^{-1}\right)$ & 0,00 \\
\hline & $\mathrm{k}_{7 \mathrm{HPr}}\left(\mathrm{h}^{-1}\right)$ & 10,93 \\
\hline & $\mathrm{k}_{7 \mathrm{HBu}}\left(\mathrm{h}^{-1}\right)$ & 0,22 \\
\hline & $\mathrm{k}_{7 \mathrm{H}}\left(\mathrm{h}^{-1}\right)$ & 0,00 \\
\hline & $\mathrm{k}_{8 \mathrm{HBu}}\left(\mathrm{h}^{-1}\right)$ & 0,27 \\
\hline & $\mathrm{k}_{8 \mathrm{HVa}}\left(\mathrm{h}^{-1}\right)$ & 2,64 \\
\hline & $\mathrm{k}_{8 \mathrm{H}}\left(\mathrm{h}^{-1}\right)$ & 0,00 \\
\hline & $\mathrm{k}_{9 \mathrm{HAc}}\left(\mathrm{h}^{-1}\right)$ & 0,00 \\
\hline \multirow{4}{*}{ Metanogênse } & $\mathrm{k}_{10 \mathrm{HAc}}\left(\mathrm{h}^{-1}\right)$ & 2,91 \\
\hline & $\mathrm{k}_{10 \mathrm{H}}\left(\mathrm{h}^{-1}\right)$ & 2,64 \\
\hline & $\mathrm{k}_{11 \mathrm{H}}\left(\mathrm{h}^{-1}\right)$ & 0,18 \\
\hline & $\mathrm{k}_{11 \mathrm{M}}\left(\mathrm{h}^{-1}\right)$ & 828,11 \\
\hline
\end{tabular}


Figura 5.33 - Dados experimentais (marcadores) e modelo (linha) do metano (a), substrato (b) e ácidos intermediários (c) na condição VI
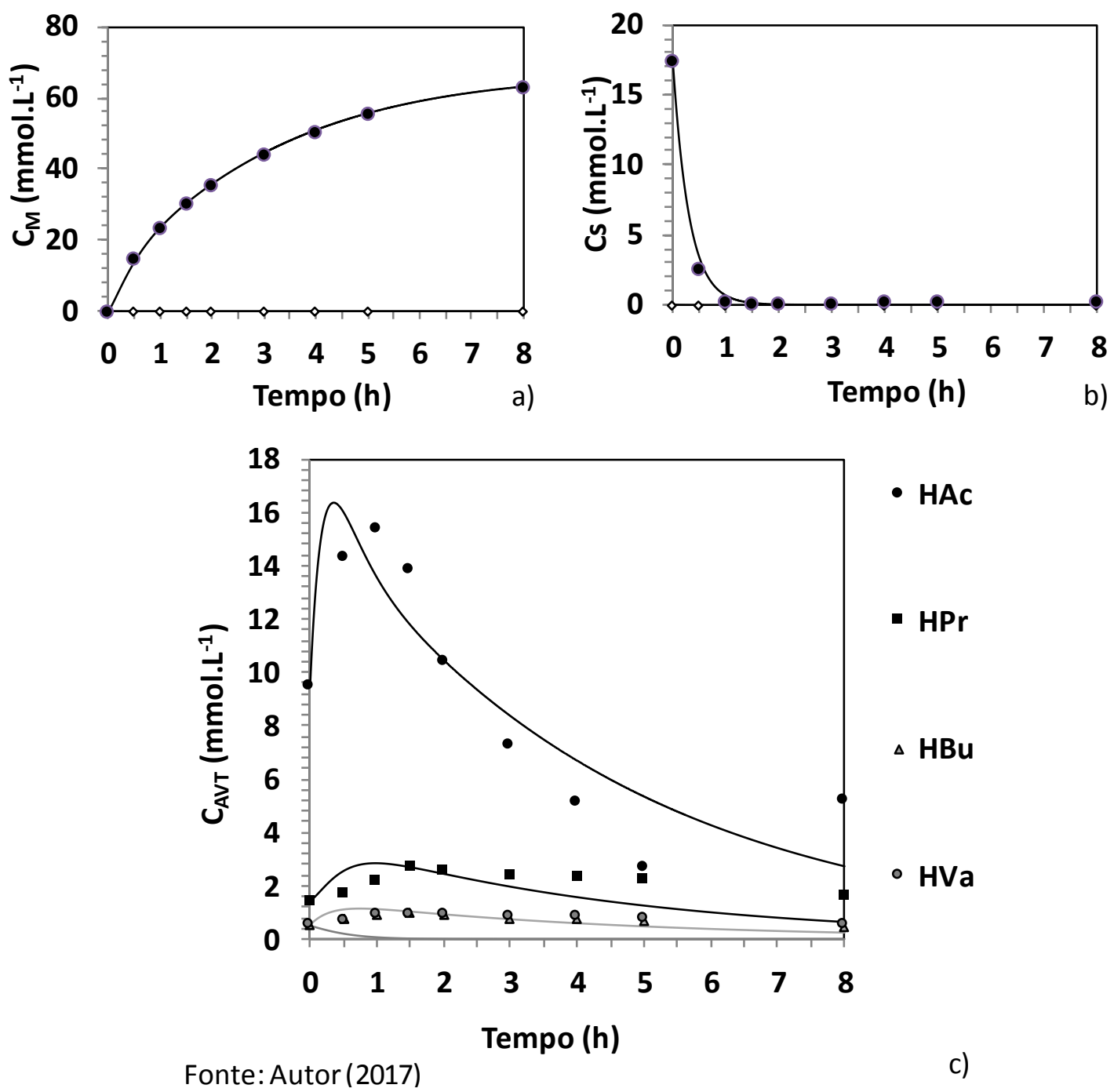

5.2.7 Condição VII - $14.000 \mathrm{mg}$ DQO L ${ }^{-1} ; 100 \%$ Soro; $50 \%$ de bicarbonato; $55^{\circ}$ C; Batelada

Nesta condição de operação, o valor nominal de DQO alimentado ao reator foi de $14000 \mathrm{mg}$ $\mathrm{L}^{-1}$ com carga orgânica aplicada teórica de 16,80 g DQO $\mathrm{L}^{-1} \mathrm{dia}^{-1}$. 


\subsubsection{Monitoramento}

O reator foi operado por 21 dias, em que a concentração média da matéria orgânica afluente foi de $14829 \pm 781 \mathrm{mgDQO} . \mathrm{L}^{-1}$ e $11595 \pm 853 \mathrm{mgCarboidrato.L^{-1 }}$, COVAMO de 19,34 gDQO.L ${ }^{-1} \cdot \mathrm{d}^{-1}$ e COVA $\mathrm{C}_{\mathrm{C}}$ de $15,12 \mathrm{gCarboidrato} \cdot \mathrm{L}^{-1} \cdot \mathrm{d}^{-1}$. A quantidade de biomassa contida no reator foi de $73,1 \mathrm{~g}$. A diferença notável entre a COVA nominal e a experimental se deve ao fato de que, com a grande produção de polímero, o volume útil do reator diminuiu dos teóricos 2,5 litros para 2,3 litros, resultando em valores mais altos de carga aplicada. Somando-se ao fato de que, nos afluentes de concentração maiores, as eventuais variações na concentração de matéria orgânica afluente tendem a resultar num efluente de maior concentração do que a teórica, como visto nos resultados. Este fato também ocorreu nas condições subsequentes. Nesta condição, o reator operou com $20 \%$ durante os dois primeiros dias, elevando a concentração para 50\% de bicarbonato afluente durante o resto do período. Essa concentração se manteve durante o restante da operação do reator. Esse aumento garantiu que a capacidade tampão do reator durante o período crítico de produção de ácidos, ou seja, consumo máximo de alcalinidade a bicarbonato, não colocasse a operação em risco.

Os valores referentes ao monitoramento e aos indicadores desempenho encontram-se apresentados na Tabela 5.13 a seguir. A eficiência de remoção de matéria orgânica na forma de DQO desta condição, para amostras não-filtradas e filtradas, respectivamente, foi de 90,0土 2,4 \% e $91,3 \pm 2,0 \%$. Para a matéria orgânica na forma de Carboidratos (lactose) a remoção foi de $99,4 \pm 0,3 \%$ e 99,6 $\pm 0,2 \%$, respectivamente para não-filtradas e filtradas. $\mathrm{O} \mathrm{pH}$ afluente foi de $8,36 \pm 0,08$ e o efluente $8,15 \pm 0,10$. A alcalinidade a bicarbonato do afluente e efluente foram $3868 \pm 719 \mathrm{mgCaCO}{ }_{3} \cdot \mathrm{L}^{-1}$ e $4327 \pm 356 \mathrm{mgCaCO}_{3} \cdot \mathrm{L}^{-1}$. A alcalinidade referente aos ácidos voláteis do afluente e efluente foram $587 \pm 99 \mathrm{mgHAc} . \mathrm{L}^{-1}$ e $632 \pm 187 \mathrm{mgHac} . \mathrm{L}^{-1}$. O reator seguiu apresentando grande capacidade produtiva de bicarbonato, resultando em excesso de bicarbonato no efluente. Mesmo assim, optou-se por manter a concentração de bicarbonato em $50 \%$ durante todo o 
restante do tempo de operação para evitar problema de concentração excessiva de ácidos durante o ciclo, diminuindo a capacidade tampão do reator.

A concentração de sólidos suspensos voláteis (SSV) no efluente indica que houve pouca perda de biomassa no reator. A análise dos sólidos totais indica que a produção de polímero seguiu em crescente.

O rendimento de metano gerado por matéria orgânica consumida foi de 14,69 $\mathrm{mmolCH}_{4} \cdot \mathrm{gDQO}^{-1}$ e $18,79 \mathrm{mmolCH}_{4} \cdot \mathrm{gCarboidrato}^{-1}$. A produção de biogás foi de $6453 \pm 325 \mathrm{~mL}-$ CNTP.ciclo $^{-1}$, sendo a fração molar de metano equivalente a 75,67 $\pm 0,13 \%$ e a produtividade molar de metano de $284,2 \cdot \mathrm{m}^{-3} \cdot \mathrm{d}^{-1}$. 
Tabela 5.13 - Resumo dos valores médios obtidos no monitoramento do reator com concentração afluente de $14000 \mathrm{mgDQO} . \mathrm{L}^{-1}$ na condição VII

\begin{tabular}{|c|c|c|c|c|c|c|c|c|c|c|c|c|}
\hline \multicolumn{2}{|r|}{ Parâmetro } & \multicolumn{5}{|c|}{ Afluente } & & \multicolumn{5}{|c|}{ Efluente } \\
\hline $\mathrm{C}_{\mathrm{ST}}$ & $\left(\mathrm{mgDQO} . \mathrm{L}^{-1}\right)$ & 14829 & \pm & 781 & ( & 13 & ) & 1477 & \pm & 349 & ( & $\overline{135}$ \\
\hline $\mathrm{C}_{\mathrm{SF}}$ & (mgDQO.L $\left.{ }^{-1}\right)$ & - & & - & & & & 1288 & \pm & 303 & ( & 13 \\
\hline$\varepsilon_{\mathrm{ST}}$ & $(\%)$ & - & & - & & & & $90,0 \%$ & \pm & $2,4 \%$ & ( & 13 \\
\hline$\varepsilon_{\mathrm{SF}}$ & $(\%)$ & - & & - & & & & $91,3 \%$ & \pm & $2,0 \%$ & ( & 13 \\
\hline $\mathrm{C}_{\mathrm{CT}}$ & (mgCarboidrato. $\left.\mathrm{L}^{-1}\right)$ & 11595 & \pm & 853 & ( & 15 & ) & 69 & \pm & 30 & ( & 15 \\
\hline $\mathrm{C}_{\mathrm{CF}}$ & (mgCarboidrato. $\mathrm{L}^{-1}$ ) & - & & - & & & & 45 & \pm & 21 & & $15)$ \\
\hline$\varepsilon_{\mathrm{CT}}$ & $(\%)$ & - & & - & & & & $99,4 \%$ & \pm & $0,3 \%$ & & \\
\hline$\varepsilon_{\mathrm{CF}}$ & $(\%)$ & - & & - & & & & $99,6 \%$ & \pm & $0,2 \%$ & & \\
\hline $\mathrm{pH}$ & (u) & 8,36 & \pm & 0,08 & ( & 14 & ) & 8,15 & \pm & 0,10 & ( & $14 \quad)$ \\
\hline AVT & $\left(\mathrm{mgHAc} . \mathrm{L}^{-1}\right)$ & 587 & \pm & 99 & ( & 14 & ) & 632 & \pm & 187 & ( & 14 \\
\hline AT & $\left(\mathrm{mgCaCO}_{3} \cdot \mathrm{L}^{-1}\right)$ & 3868 & \pm & 713 & ( & 14 & ) & 4776 & \pm & 349 & ( & 14 \\
\hline $\mathrm{AP}$ & $\left(\mathrm{mgCaCO}_{3} \cdot \mathrm{L}^{-1}\right)$ & 899 & \pm & 199 & ( & 14 & ) & 3649 & \pm & 323 & ( & 14 \\
\hline AI & $\left(\mathrm{mgCaCO}_{3} \cdot \mathrm{L}^{-1}\right)$ & 3386 & \pm & 667 & ( & 14 & ) & 1128 & \pm & 163 & ( & $14 \quad)$ \\
\hline $\mathrm{AB}$ & $\left(\mathrm{mgCaCO}_{3} \cdot \mathrm{L}^{-1}\right)$ & 3868 & \pm & 719 & ( & 14 & ) & 4327 & \pm & 356 & ( & 14 \\
\hline ST & $\left(\mathrm{mg} . \mathrm{L}^{-1}\right)$ & 15537 & \pm & 711 & ( & 6 & ) & 6279 & \pm & 320 & ( & 6 \\
\hline SVT & $\left(\mathrm{mg} \cdot \mathrm{L}^{-1}\right)$ & 9624 & \pm & 511 & ( & 6 & ) & 1488 & \pm & 239 & ( & 6 \\
\hline SST & $\left(\mathrm{mg} \cdot \mathrm{L}^{-1}\right)$ & 328 & \pm & 57 & ( & 6 & ) & 164 & \pm & 56 & ( & 6 \\
\hline SSV & $\left(\mathrm{mg} \cdot \mathrm{L}^{-1}\right)$ & 247 & \pm & 39 & ( & 6 & ) & 146 & \pm & 52 & & 6 \\
\hline SDF & $\left(\mathrm{mg} \cdot \mathrm{L}^{-1}\right)$ & 5337 & & 一 & & & & 4482 & & - & & \\
\hline $\mathrm{M}_{\mathrm{SVT}}$ & (g) & 73,1 & & - & & & & - & & - & & \\
\hline $\mathrm{C}_{\mathrm{X}}$ & $\left(\mathrm{gSVT} . \mathrm{L}^{-1}\right)$ & 31,8 & & - & & & & - & & - & & \\
\hline $\mathrm{C}_{\mathrm{X}}^{\prime}$ & $\left(\right.$ gSVT.gsuporte ${ }^{-1}$ ) & 1,9 & & - & & & & - & & - & & \\
\hline $\mathrm{V}_{\mathrm{G}}$ & $\left(\mathrm{mL}-\mathrm{CNTP} . \mathrm{Ciclo}^{-1}\right)$ & - & & - & & & & 6453 & \pm & 325 & & 9 \\
\hline $\mathrm{V}_{\mathrm{CH} 4}$ & $\left(\mathrm{~mL}-\mathrm{CNTPCH}{ }_{4} \cdot \mathrm{Ciclo}^{-1}\right)$ & - & & - & & & & 4883 & & - & & \\
\hline $\mathrm{COVA}_{\mathrm{S}}$ & $\left(\mathrm{gDQO} \cdot \mathrm{L}^{-1} \cdot \mathrm{d}^{-1}\right)$ & 19,34 & & - & & & & - & & - & & \\
\hline $\mathrm{COVR}_{\mathrm{S}}$ & $\left(\mathrm{gDQO} \cdot \mathrm{L}^{-1} \cdot \mathrm{d}^{-1}\right)$ & - & & - & & & & 17,42 & & - & & \\
\hline $\mathrm{COEA}_{\mathrm{S}}$ & $\left(\right.$ gDQO.gSVT $\left.{ }^{-1} \cdot \mathrm{d}^{-1}\right)$ & 0,61 & & - & & & & - & & - & & \\
\hline $\mathrm{COER}_{\mathrm{S}}$ & $\left(\mathrm{gDQO} . \mathrm{gSVT}^{-1} \cdot \mathrm{d}^{-1}\right)$ & - & & - & & & & 0,24 & & - & & \\
\hline $\mathrm{COVA}_{\mathrm{c}}$ & (gCarboidrato. $\left.\mathrm{L}^{-1} \cdot \mathrm{d}^{-1}\right)$ & 15,12 & & 一 & & & & & & - & & \\
\hline $\mathrm{COVR}_{\mathrm{c}}$ & (gCarboidrato. $\mathrm{L}^{-1} \cdot \mathrm{d}^{-1}$ ) & & & - & & & & 15,03 & & - & & \\
\hline $\mathrm{COEA}_{c}$ & $\left(\mathrm{gCarboidrato.gSVT}^{-1} \cdot \mathrm{d}^{-1}\right)$ & 0,48 & & - & & & & & & - & & \\
\hline $\mathrm{COER}_{\mathrm{c}}$ & (gCarboidrato.gSVT ${ }^{-1} \cdot \mathrm{d}^{-1}$ ) & & & & & & & 0,20 & & - & & \\
\hline $\mathrm{n}_{\mathrm{CH} 4}$ & $\left(\mathrm{molCH}_{4} \cdot \mathrm{d}^{-1}\right)$ & - & & - & & & & 0,6536 & & - & & \\
\hline $\mathrm{X}_{\mathrm{CH} 4}$ & $(\%)$ & & & & & & & 75,67 & \pm & 0,13 & & \\
\hline PrM & $\left(\mathrm{molCH}_{4} \cdot \mathrm{m}^{-3} \cdot \mathrm{d}^{-1}\right)$ & - & & - & & & & 284,2 & & - & & \\
\hline PrME & $\left(\mathrm{molCH}_{4} \cdot \mathrm{kgSVT}^{-1} \cdot \mathrm{d}^{-1}\right)$ & - & & - & & & & 8,94 & & - & & \\
\hline $\operatorname{PrV}$ & $\left(\mathrm{mL}-\mathrm{CNTPCH} 4 \cdot \mathrm{L}^{-1} \cdot \mathrm{d}^{-1}\right)$ & - & & 一 & & & & 6369 & & - & & \\
\hline PrVE & 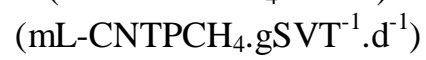 & - & & - & & & & 200,37 & & - & & \\
\hline $\mathrm{RMCA}_{\mathbf{s}}$ & $\left(\mathrm{mmolCH}_{4} \cdot \mathrm{gDQO}^{-1}\right)$ & 14,69 & & - & & & & - & & - & & \\
\hline $\mathrm{RMCR}_{\mathbf{s}}$ & $\left(\mathrm{mmolCH}_{4} \cdot \mathrm{gDQO}^{-1}\right)$ & - & & - & & & & 16,32 & & - & & \\
\hline $\mathrm{RMCA}_{\mathrm{c}}$ & $\left(\mathrm{mmolCH}_{4} \cdot \mathrm{gCarboidrato}^{-1}\right)$ & 18,79 & & - & & & & - & & - & & \\
\hline $\mathrm{RMCR}_{\mathrm{c}}$ & $\left(\mathrm{mmolCH}_{4} \cdot\right.$ gCarboidrato $\left.^{-1}\right)$ & - & & - & & & & 18,90 & & - & & \\
\hline $\mathrm{V}_{\mathrm{A}}$ & $\left(\mathrm{mL} . \mathrm{Ciclo}^{-1}\right)$ & 1000 & \pm & 16 & ( & 16 & ) & - & & - & & \\
\hline$V_{\text {RES }}$ & $(\mathrm{mL})$ & 1300 & & - & & & & - & & - & & \\
\hline
\end{tabular}

*Os valores entre parêntesis representam o número de amostras consideradas para o cálculo da média Fonte: Autor (2017) 


\subsubsection{Perfil ao longo do ciclo}

Durante o perfil, a concentração de matéria orgânica afluente na forma de DQO e de Carboidrato foi de $15181 \mathrm{mgDQO} . \mathrm{L}^{-1}$ e de $9981 \mathrm{mgCarboidrato.L^{-1 }}$, respectivamente. Após a diluição, os valores se alteraram para $6656 \mathrm{mgDQO} . \mathrm{L}^{-1}$ e $3622 \mathrm{mgCarboidrato.L^{-1 }}$ no início do ciclo.

Observa-se na Figura 5.34 a variação do $\mathrm{pH}$ ao longo do ciclo, com valor de 8,30 no afluente, mínimo de 7,26 e 8,10 no efluente. Também é possível acompanhar a variação da alcalinidade a bicarbonato e ácidos voláteis totais durante o ciclo. Os ácidos voláteis totais têm o pico de produção (2169 mgHAc. $\mathrm{L}^{-1}$ ) em 2,0 horas de ciclo, diferentemente das condições anteriores, significando que a produção de ácidos se estendeu por mais tempo nesta condição. O acúmulo de ácidos fez com que a alcalinidade a bicarbonato tivesse redução de sua concentração,

resultando num valor mínimo de $2706 \mathrm{mg} \mathrm{CaCO} 3 \mathrm{mg} . \mathrm{L}^{-1}$, representando grande excedente e capacidade tamponante. 
Figura 5.34 - Perfis de pH (a), alcalinidade a bicarbonato e a ácidos voláteis totais (b) na condição VII
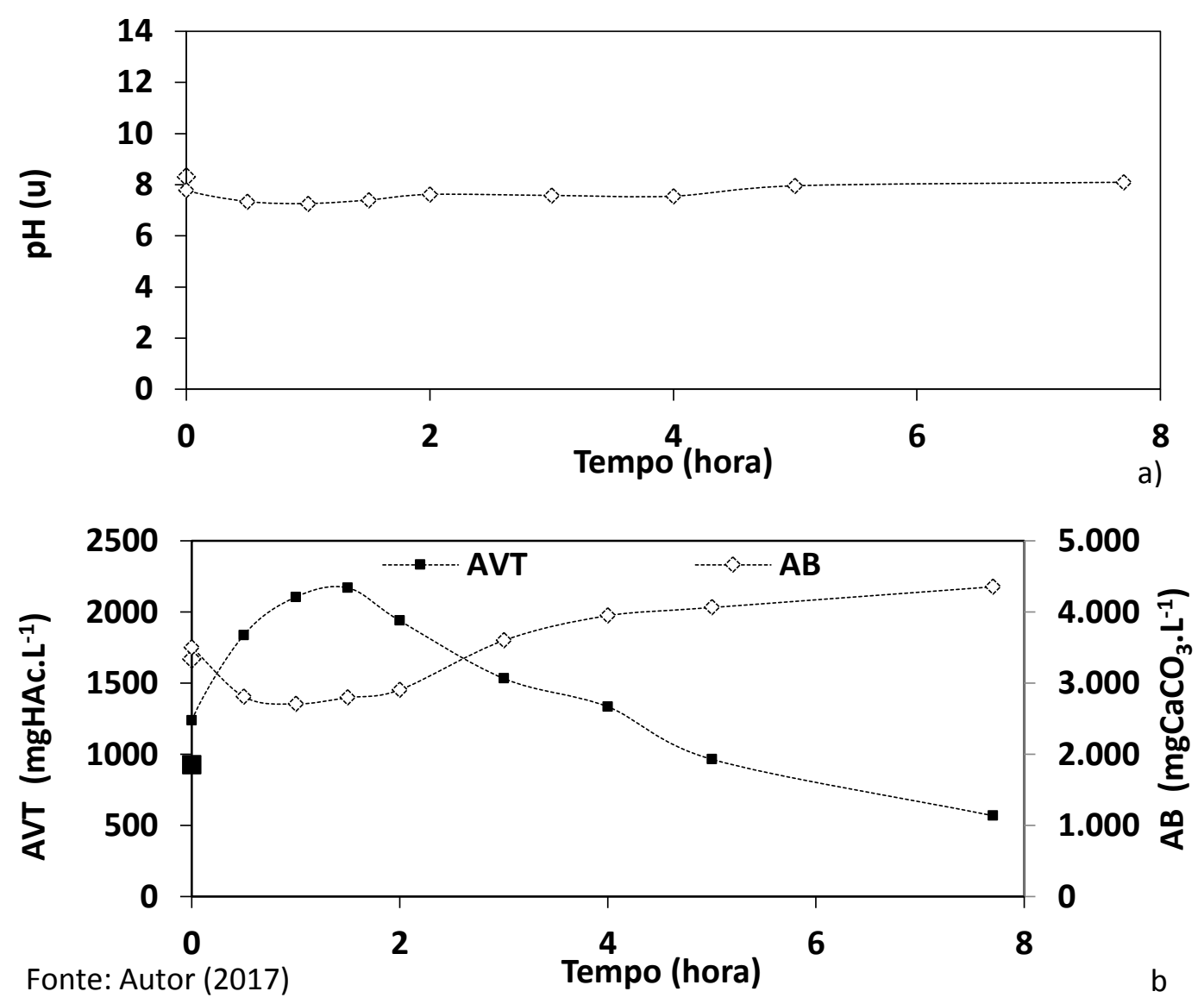

O consumo da matéria orgânica nas formas de DQO e Carboidrato ao longo do ciclo pode ser analisado através da Figura 5.35. Novamente, pôde-se observar um consumo de matéria orgânica na forma de DQO um pouco lento nesta condição. Apesar de rápido, o consumo de matéria orgânica na forma de carboidratos foi um pouco mais lento nesta condição, resultando em $94 \%$ de consumo em 1,0 hora de ciclo. No mesmo período, a eficiência de remoção de DQO foi de 79\%. A eficiência final do ciclo foi de $92 \%$ de remoção de DQO. 
Figura 5.35 - Perfis de concentração e eficiência de remoção de DQO (a) e carboidratos (b) na condição VII
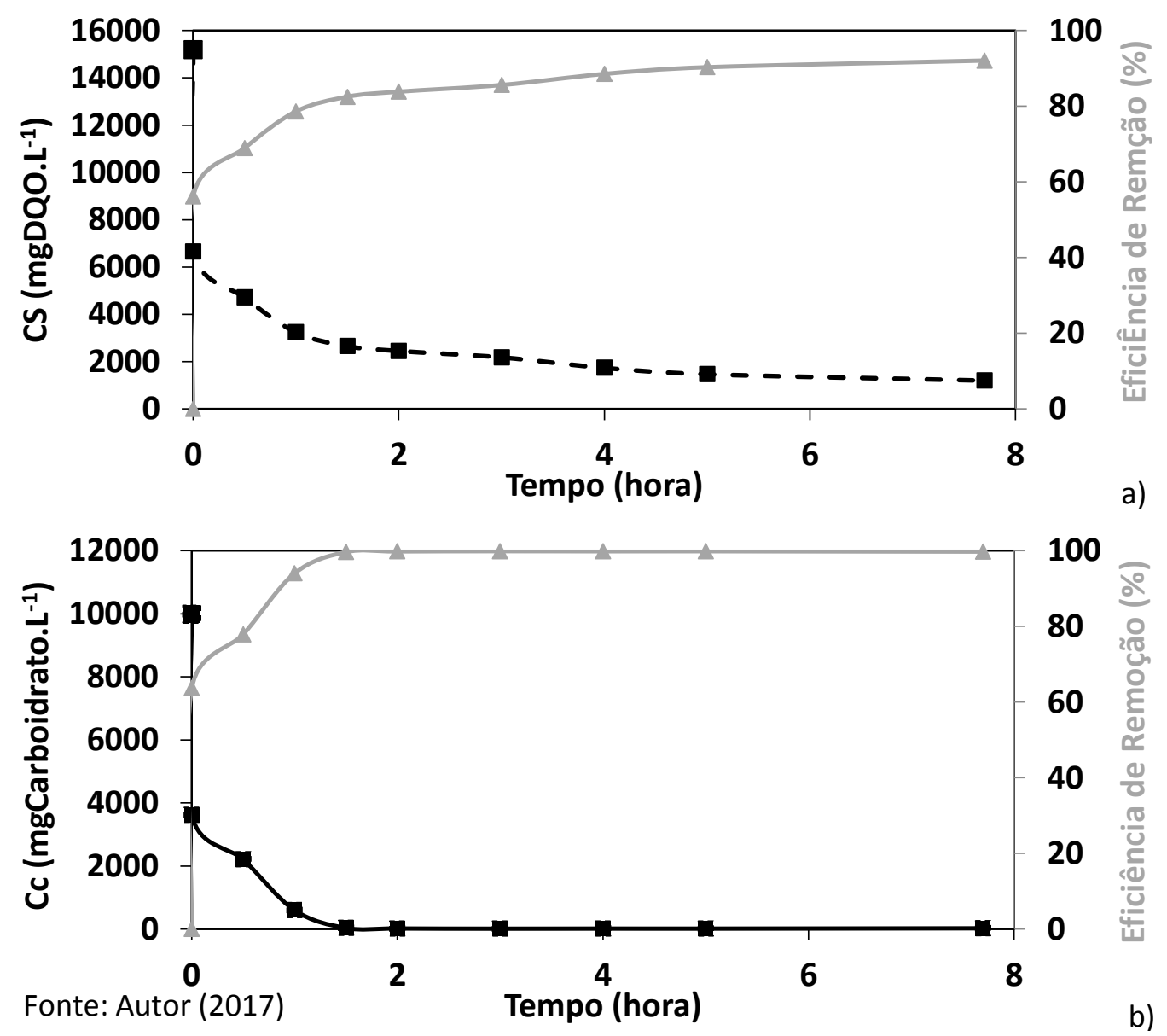

A variação da produção e consumo dos compostos metabólicos intermediários ao longo do ciclo pode ser observada pela Figura 5.36. O maior valor de ácido propiônico nesta condição foi de 302,1 mg. $\mathrm{L}^{-1}$, num pico que se deu após 2 horas de ciclo, o consumo deste ácido se manteve lento até o final do ciclo, resultando em concentração de $252,9 \mathrm{mg} . \mathrm{L}^{-1}$ no efluente. 
Figura 5.36 - Perfil das concentrações dos compostos intermediários ao longo do ciclo na condição VII

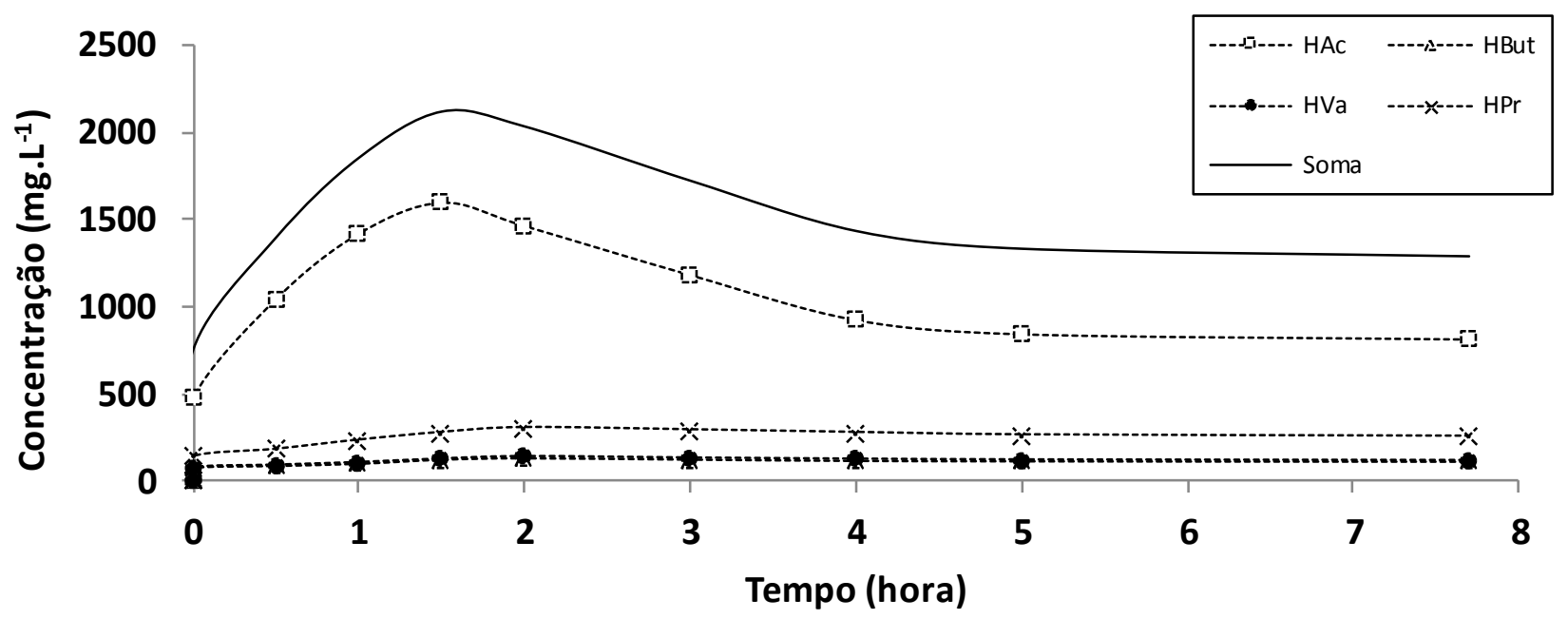

Fonte: Autor (2017)

A produção volumétrica de metano $\left(\mathrm{CH}_{4}\right)$ e dióxido de carbono $\left(\mathrm{CO}_{2}\right)$ ao longo do ciclo pode ser observada através da Figura 5.37. Nota-se que a produção volumétrica de metano foi predominante por todo o ciclo. Também se verifica a evolução das concentrações de metano e dióxido de carbono presente no biogás e a vazão molar de metano ao longo do ciclo além do volume total de biogás gerado durante o período. Durante os primeiros 30min de ciclo o biogás gerado apresentava diferença considerável nas concentrações de metano $\left(8,13\right.$ mmol. $\left.\mathrm{L}^{-1}\right)$ e dióxido de carbono $\left(3,10 \mathrm{mmol} \cdot \mathrm{L}^{-1}\right)$. A produção de metano é maior do que a de dióxido de carbono durante todo o período, resultando numa concentração final de $76 \%$ dos 6335 mL-CNTP.ciclo-1 de biogás $^{-1}$ gerados durante o ciclo. 
Figura 5.37 - Perfis de volume nas CNTP de metano e $\mathrm{CO}_{2}$ (a), concentração dos gases e vazão molar (b) e volume e concentração ao longo do ciclo (c) na condição VII
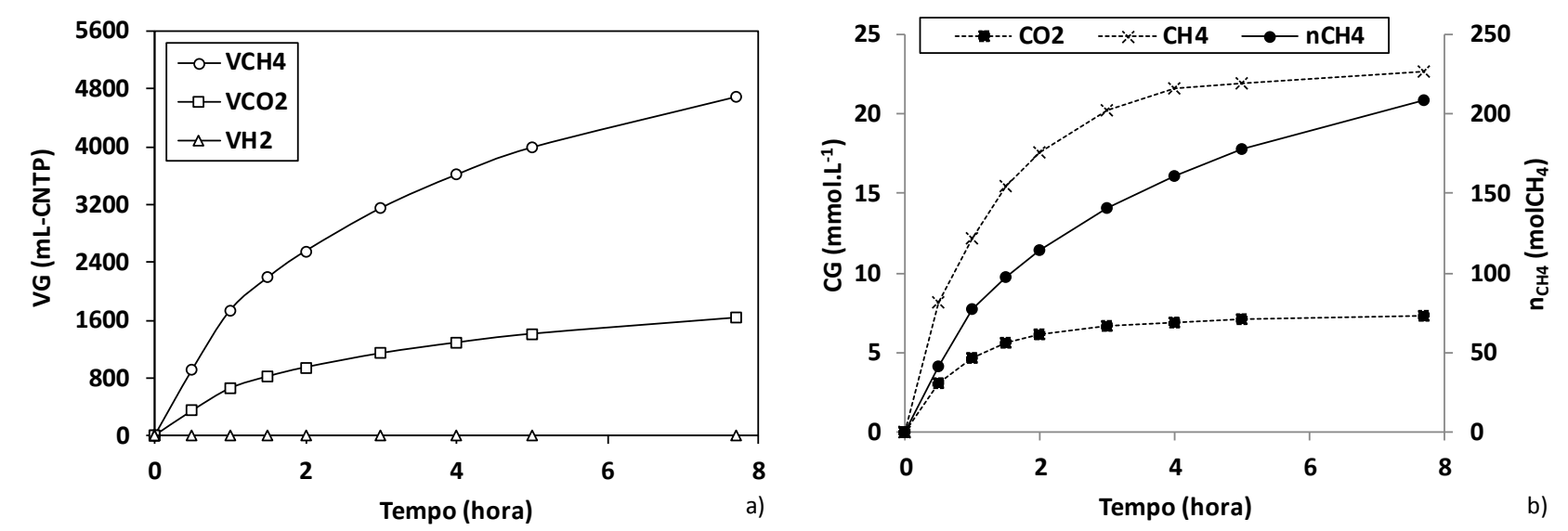

Produção e Composição do Biogás

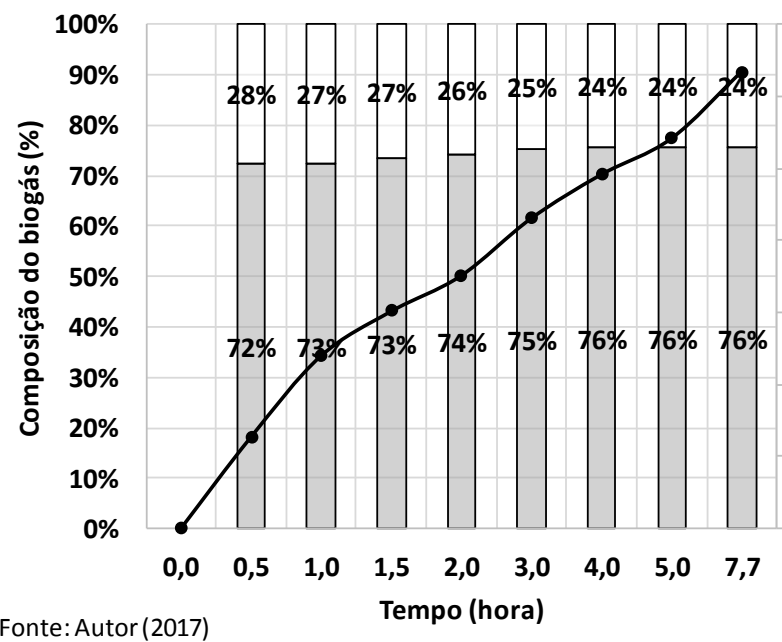

7000,0

6000,0

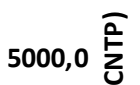

4000,0 $\frac{\vec{\xi}}{n}$

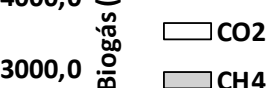

$2000,0 \underset{\frac{\Xi}{9}}{\frac{\Xi}{9}} \rightarrow$ Vbiogás

1000,0

0,0

c)

Os dados do perfil indicam que o reator poderia ser operado eficientemente num ciclo de 5 horas. Os resultados indicam que houve remoção de $90 \%$ de matéria orgânica na forma de DQO e 99,9\% de carboidratos, ambos na forma filtrada. Houve consumo de 56\% da concentração máxima de ácidos voláteis. Além disso, houve a produção de 5410,2 mL-ciclo de biogás, contendo $76 \%$ de metano. 
5.2.7.3 Ajuste do modelo cinético

Os parâmetros cinéticos aparentes foram calculados (Tabela 5.14) e indicam maior produção de ácido acético através do substrato $\left(\mathrm{k}_{1 \mathrm{HAC}}\right)$ e também da conversão do ácido proprônico ( $\left.\mathrm{K}_{6 \mathrm{HAC}}\right)$. A produção de metano foi maior na rota metanogênica hidrogenotrófica $\left(\mathrm{K}_{11 \mathrm{M}}\right)$. Portanto, o modelo cinético foi ajustado de modo adequado pelos dados experimentais (Figura 5.38).

Tabela 5.14 - Parâmetros cinéticos da rota metabólica ao longo do ciclo na condição VII

\begin{tabular}{|c|c|c|}
\hline Condição & Parâmetro & Condição VII \\
\hline \multirow{10}{*}{$\begin{array}{l}\text { Hidrólise e } \\
\text { Acidogênese }\end{array}$} & $\mathrm{k}_{1 \mathrm{~S}}^{\prime}\left(\mathrm{h}^{-1}\right)$ & 1,52 \\
\hline & $\mathrm{k}_{1 \mathrm{HAc}}\left(\mathrm{h}^{-1}\right)$ & 1,73 \\
\hline & $\mathrm{k}_{1 \mathrm{H}}\left(\mathrm{h}^{-1}\right)$ & 0,00 \\
\hline & $\mathrm{k}_{2 \mathrm{HPr}}\left(\mathrm{h}^{-1}\right)$ & 0,23 \\
\hline & $\mathrm{k}_{2 \mathrm{H}}\left(\mathrm{h}^{-1}\right)$ & 0,04 \\
\hline & $\mathrm{k}_{3 \mathrm{HBu}}\left(\mathrm{h}^{-1}\right)$ & 0,12 \\
\hline & $\mathrm{k}_{3 \mathrm{H}}\left(\mathrm{h}^{-1}\right)$ & 0,00 \\
\hline & $\mathrm{k}_{4 \mathrm{HVa}}\left(\mathrm{h}^{-1}\right)$ & 0,05 \\
\hline & $\mathrm{k}_{4 \mathrm{H}}\left(\mathrm{h}^{-1}\right)$ & 0,00 \\
\hline & $\mathrm{k}_{5 \mathrm{ETOH}}\left(\mathrm{h}^{-1}\right)$ & 0,00 \\
\hline \multirow{10}{*}{ Acetogênese } & $\mathrm{k}_{6 \mathrm{HPr}}\left(\mathrm{h}^{-1}\right)$ & 0,37 \\
\hline & $\mathrm{k}_{6 \mathrm{HAc}}\left(\mathrm{h}^{-1}\right)$ & 9,14 \\
\hline & $\mathrm{k}_{6 \mathrm{H}}\left(\mathrm{h}^{-1}\right)$ & 0,00 \\
\hline & $\mathrm{k}_{7 \mathrm{HPr}}\left(\mathrm{h}^{-1}\right)$ & 0,73 \\
\hline & $\mathrm{k}_{7 \mathrm{HBu}}\left(\mathrm{h}^{-1}\right)$ & 1,02 \\
\hline & $\mathrm{k}_{7 \mathrm{H}}\left(\mathrm{h}^{-1}\right)$ & 0,00 \\
\hline & $\mathrm{k}_{8 \mathrm{HBu}}\left(\mathrm{h}^{-1}\right)$ & 0,83 \\
\hline & $\mathrm{k}_{8 \mathrm{HVa}}\left(\mathrm{h}^{-1}\right)$ & 0,05 \\
\hline & $\mathrm{k}_{8 \mathrm{H}}\left(\mathrm{h}^{-1}\right)$ & 0,00 \\
\hline & $\mathrm{k}_{9 \mathrm{HAc}}\left(\mathrm{h}^{-1}\right)$ & 0,00 \\
\hline \multirow{4}{*}{ Metanogênese } & $\mathrm{k}_{10 \mathrm{HAc}}\left(\mathrm{h}^{-1}\right)$ & 1,76 \\
\hline & $\mathrm{k}_{10 \mathrm{H}}\left(\mathrm{h}^{-1}\right)$ & 4,96 \\
\hline & $\mathrm{k}_{11 \mathrm{H}}\left(\mathrm{h}^{-1}\right)$ & 0,12 \\
\hline & $\mathrm{k}_{11 \mathrm{M}}\left(\mathrm{h}^{-1}\right)$ & 217,12 \\
\hline
\end{tabular}


Figura 5.38 - Dados experimentais (marcadores) e modelo (linha) do metano (a), substrato (b) e ácidos intermediários (c) na condição VII
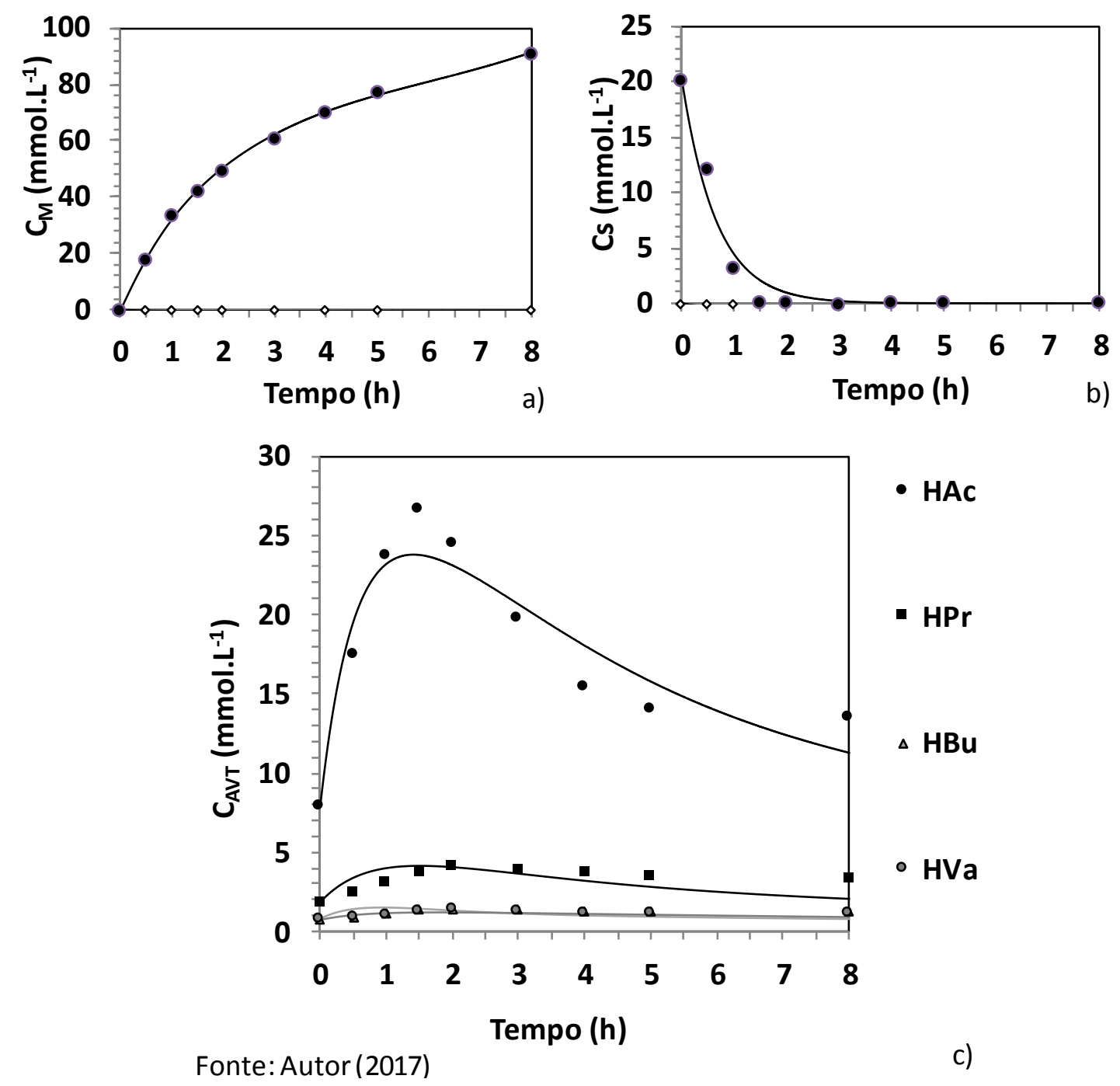

5.2.8 Condição VIII - $16.000 \mathrm{mg}$ DQO L ${ }^{-1} ; 100 \%$ Soro; $50 \%$ de bicarbonato; $55^{\circ}$ C; Batelada

Nesta condição de operação, o valor nominal de DQO alimentado ao reator foi de 16000 mg $\mathrm{L}^{-1}$ com carga orgânica aplicada teórica de 19,20 g DQO L $\mathrm{L}^{-1} \mathrm{dia}^{-1}$. 


\subsubsection{Monitoramento}

O reator foi operado por 17 dias, em que a concentração média da matéria orgânica afluente foi de $16692 \pm 889 \mathrm{mgDQO} . \mathrm{L}^{-1}$ e $12708 \pm 775 \mathrm{mgCarboidrato.L^{-1 }}$, COVAMO de $24,78 \mathrm{gDQO} . \mathrm{L}^{-1} \cdot \mathrm{d}^{-1}$ e COVA $\mathrm{C}_{\mathrm{C}}$ de 18,87 gCarboidrato. $\mathrm{L}^{-1} \cdot \mathrm{d}^{-1}$. A quantidade de biomassa contida no reator foi de 95,6 $\mathrm{g}$. Nesta condição, o reator operou com $50 \%$ de bicarbonato.

Os valores referentes ao monitoramento e aos indicadores desempenho encontram-se apresentados na Tabela 5.15 a seguir. A eficiência de remoção de matéria orgânica na forma de

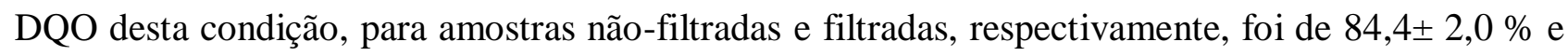
$85,8 \pm 2,0 \%$. Para a matéria orgânica na forma de Carboidratos (lactose) a remoção foi de $99,3 \pm 0,2 \%$ e $99,6 \pm 0,2 \%$, respectivamente para não-filtradas e filtradas. $\mathrm{O} \mathrm{pH}$ afluente foi de $8,40 \pm 0,08$ e o efluente $8,11 \pm 0,32$. A alcalinidade a bicarbonato do afluente e efluente foram $5054 \pm 640 \mathrm{mgCaCO} 3 \cdot \mathrm{L}^{-1}$ e $4355 \pm 1068 \mathrm{mgCaCO}_{3} \cdot \mathrm{L}^{-1}$. A alcalinidade referente aos ácidos voláteis do afluente e efluente foram $618 \pm 37 \mathrm{mgHAc} . \mathrm{L}^{-1}$ e $1585 \pm 409 \mathrm{mgHac} . \mathrm{L}^{-1}$.

A concentração de sólidos suspensos voláteis (SSV) no efluente indica que houve pouca perda de biomassa no reator. A análise dos sólidos totais indica que a produção de polímero seguiu em crescente, diminuindo o volume útil do reator para 1,98 litros.

O rendimento de metano gerado por matéria orgânica consumida foi de 13,07 $\mathrm{mmolCH}_{4} \cdot \mathrm{gDQO}^{-1}$ e $17,17 \mathrm{mmolCH}_{4} \cdot \mathrm{gCarboidrato}^{-1}$. A produção de biogás foi de $6506 \pm 185 \mathrm{~mL}-$ CNTP.ciclo $^{-1}$, sendo a fração molar de metano equivalente a 73,68 $\pm 0,43 \%$ e a produtividade molar de metano de $324,0 \mathrm{molCH}_{4} \cdot \mathrm{m}^{-3} \cdot \mathrm{d}^{-1}$.

Nesta condição, verificou-se os primeiros sinais de instabilidade do reator. Os resultados indicam maior produção de ácidos voláteis, resultando em maior concentração no efluente do que no afluente, assim como o consumo de alcalinidade a bicarbonato. A eficiência do reator na 
remoção de matéria orgânica na forma de DQO também diminuiu, possivelmente pela acumulação de ácidos e a não formação de metano, como indicado nos resultados de rendimento molar de metano e composição do biogás. Bezerra et al. (2009) relataram que um choque de carga orgânica de $24 \mathrm{mgDQO} \mathrm{L}{ }^{-1}$ fez com que o reator perdesse sua estabilidade, resultando em picos de ácidos voláteis no efluente do sistema. 
Tabela 5.15 - Resumo dos valores médios obtidos no monitoramento do reator com concentração afluente de $16000 \mathrm{mgDQO} . \mathrm{L}^{-1}$ na condição VIII

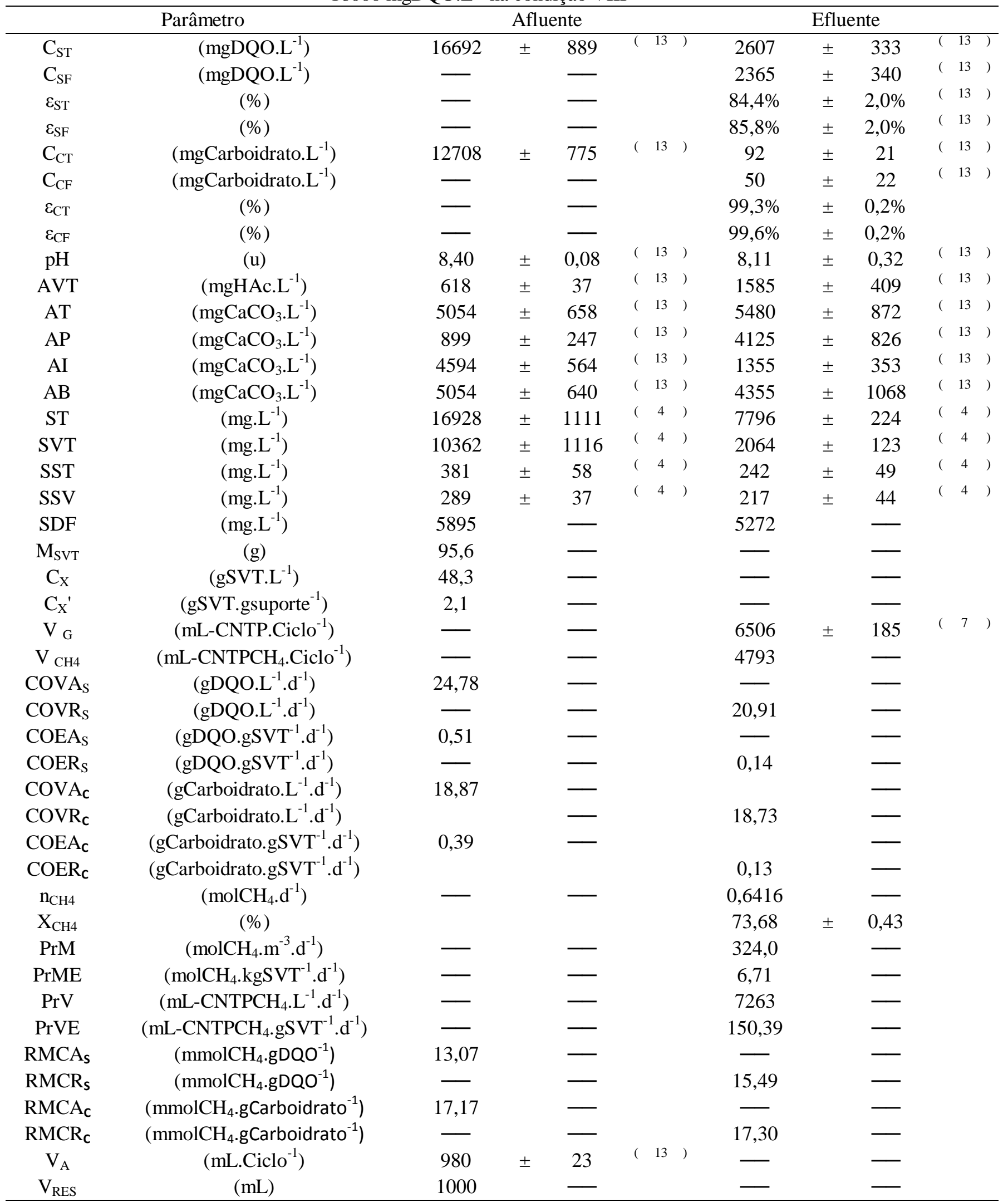

*Os valores entre parêntesis representam o número de amostras consideradas para o cálculo da média Fonte: Autor (2017) 


\subsubsection{Perfil ao longo do ciclo}

Durante o perfil, a concentração de matéria orgânica afluente na forma de DQO e de Carboidrato foi de $16216 \mathrm{mgDQO} . \mathrm{L}^{-1}$ e de $12271 \mathrm{mgCarboidrato.L^{-1 }}$, respectivamente. Após a diluição, os valores se alteraram para $7784 \mathrm{mgDQO}^{-1}$ e $3794 \mathrm{mgCarboidrato.L}^{-1}$ no início do ciclo.

Observa-se na Figura 5.39 a variação do $\mathrm{pH}$ ao longo do ciclo, com valor de 8,45 no afluente, mínimo de 7,35 e 7,95 no efluente. Também é possível acompanhar a variação da alcalinidade a bicarbonato e ácidos voláteis totais durante o ciclo. Os ácidos voláteis totais têm o pico de produção (2549 $\mathrm{mgHAc.} \mathrm{L}^{-1}$ ) em 3,0 horas de ciclo, um pouco mais tardio do que nas condições anteriores. Isto significa que a produção de ácidos se estendeu por mais tempo nesta condição, como se vê no gráfico abaixo. O acúmulo de ácidos fez com que a alcalinidade a bicarbonato tivesse redução de sua concentração, resultando num valor mínimo de 3127 $\mathrm{mg} \mathrm{CaCO} 3 \mathrm{mg} . \mathrm{L}^{-1}$, representando grande excedente e capacidade tamponante. 
Figura 5.39 - Perfis de pH (a), alcalinidade a bicarbonato e a ácidos voláteis totais (b) na condição VIII
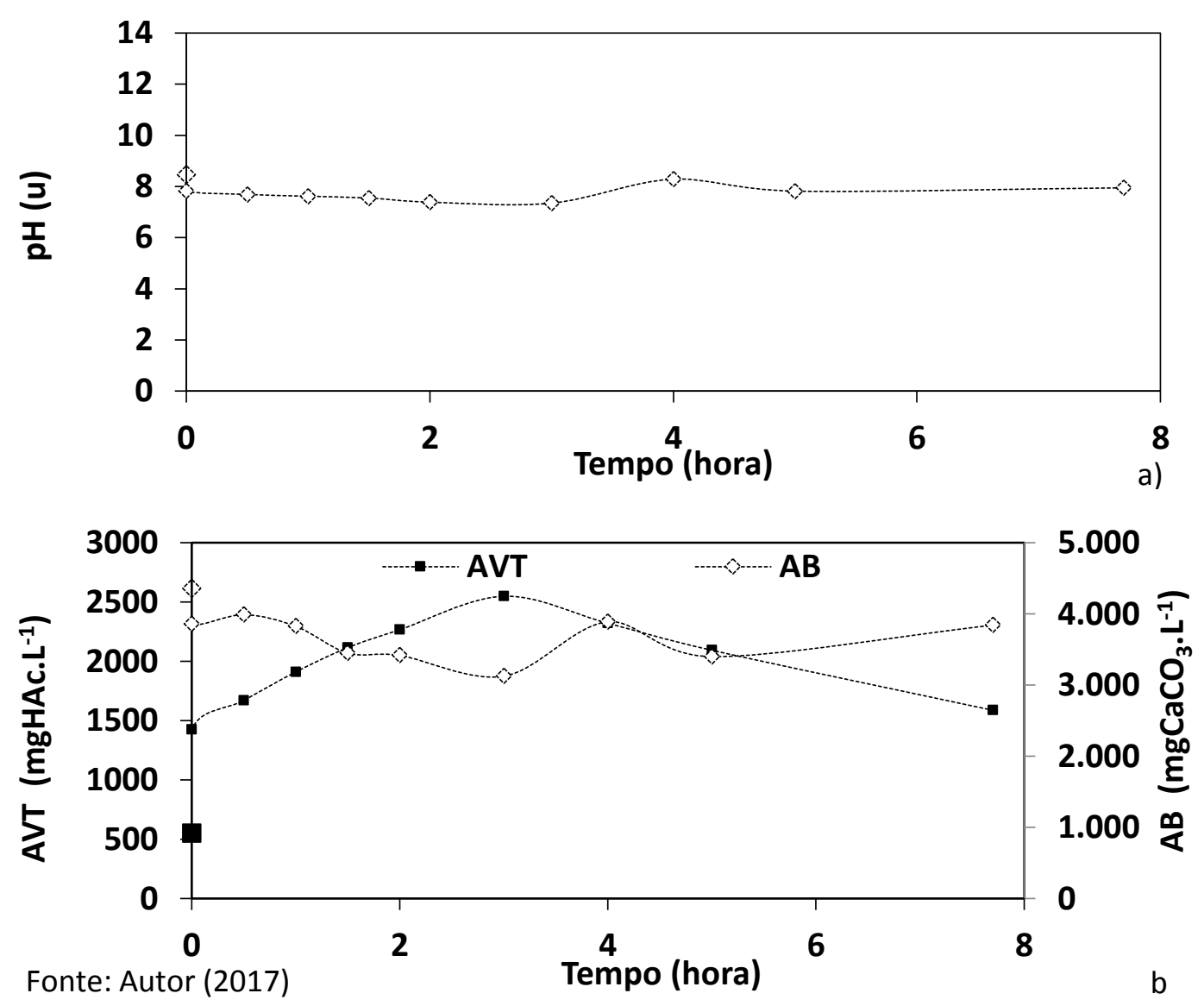

O consumo da matéria orgânica nas formas de DQO e Carboidrato ao longo do ciclo pode ser analisado através da Figura 5.40. Nesta condição, nota-se que a reação de consumo de carboidratos foi mais lenta do que nas condições anteriores. Isso é notado também na concentração da matéria orgânica na forma de DQO. Em 4 horas de ciclo houve consumo de $95 \%$ da fração de carboidratos, com $79 \%$ de consumo de DQO no mesmo período de tempo. 
Figura 5.40 - Perfis de concentração e eficiência de remoção de DQO (a) e carboidratos (b) na condição VIII
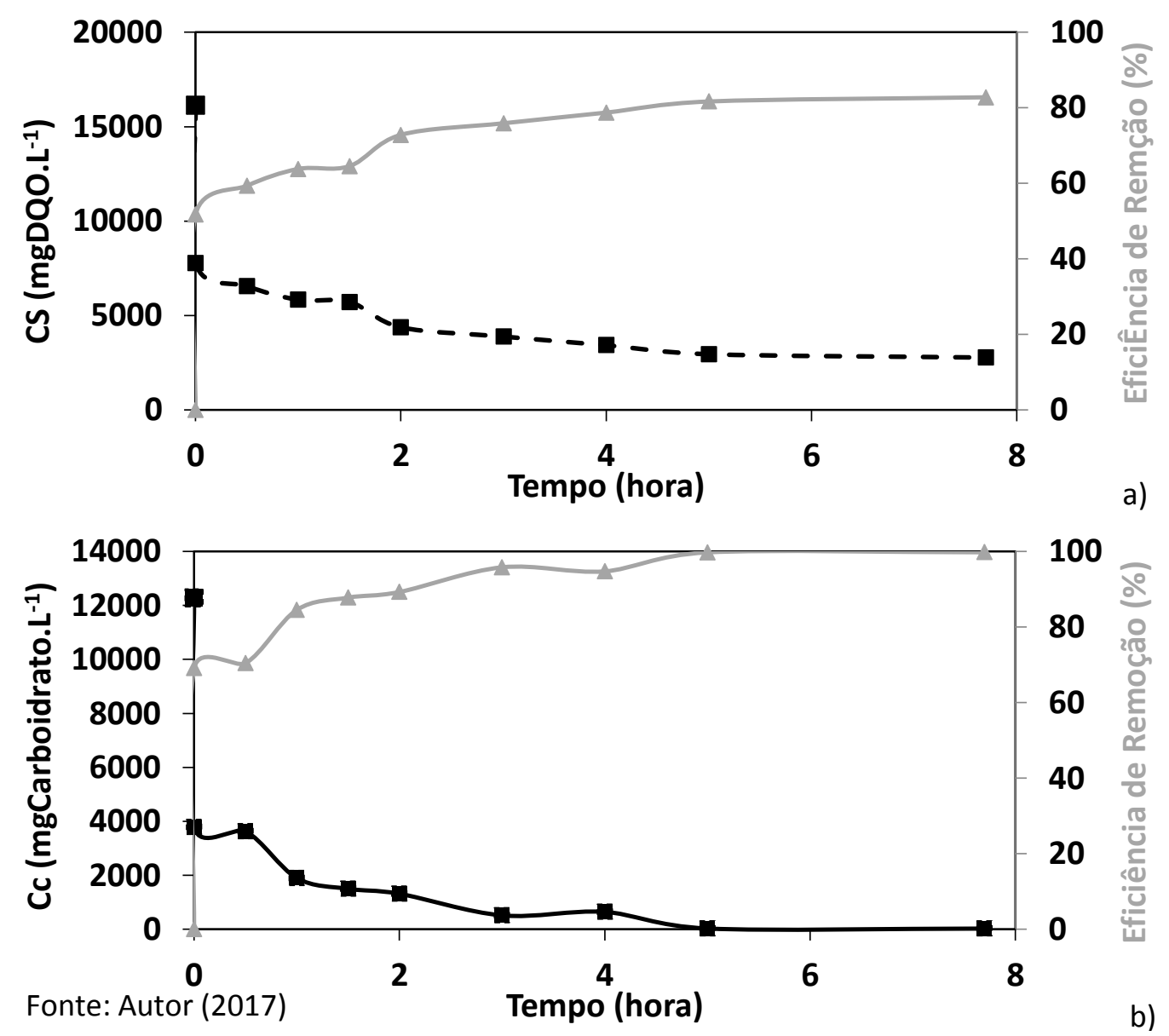

a)

A variação da produção e consumo dos compostos metabólicos intermediários ao longo do ciclo pode ser observada pela Figura 5.41. O maior valor de ácido propiônico nesta condição foi de 302,1 mg. $\mathrm{L}^{-1}$, num pico que se deu após 2 horas de ciclo, o consumo deste ácido se manteve lento até o final do ciclo, resultando em concentração de $252,9 \mathrm{mg} . \mathrm{L}^{-1}$ no efluente. A concentração remanescente de ácido acético representou $64 \%$ do valor do pico. 
Figura 5.41 - Perfil das concentrações dos compostos intermediários ao longo do ciclo na condição VIII

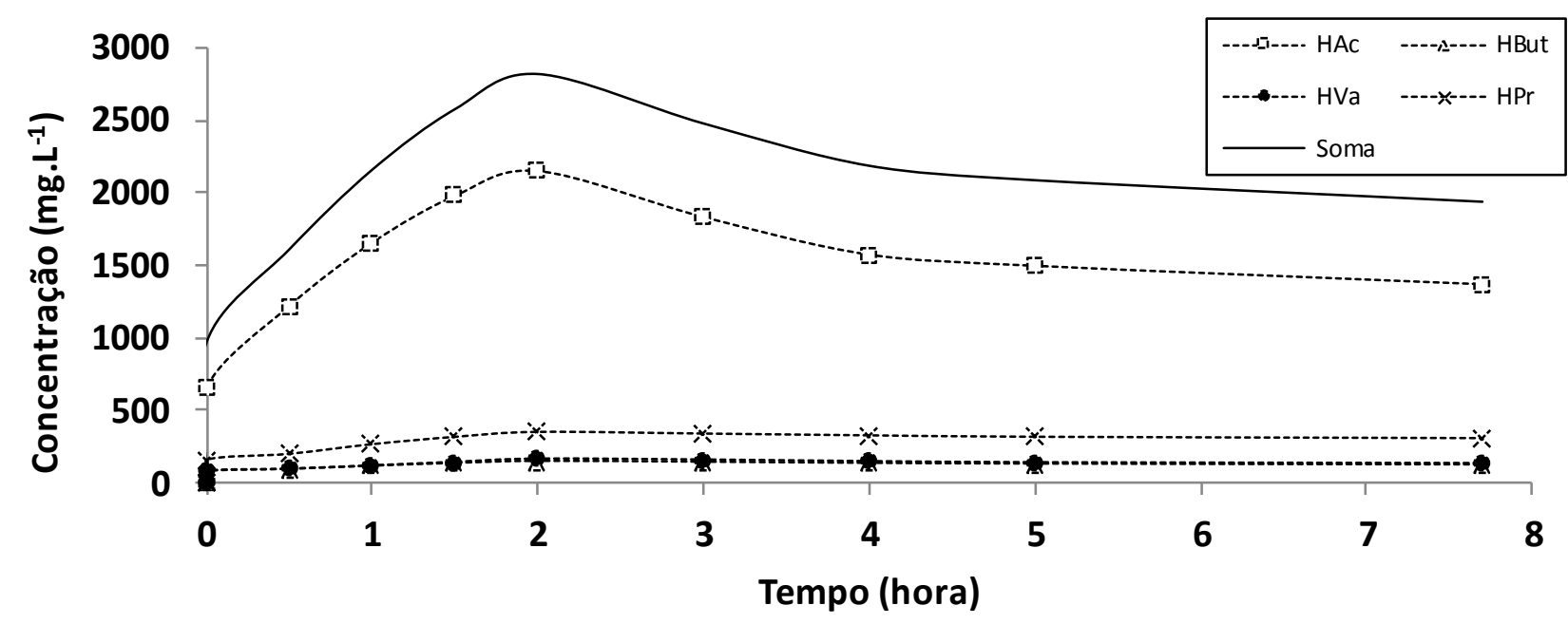

Fonte: Autor (2017)

A produção volumétrica de metano $\left(\mathrm{CH}_{4}\right)$ e dióxido de carbono $\left(\mathrm{CO}_{2}\right)$ ao longo do ciclo pode ser observada através da Figura 5.42. Nota-se que a produção volumétrica de metano foi predominante por todo o ciclo. Também se verifica a evolução das concentrações de metano e dióxido de carbono presente no biogás e a vazão molar de metano ao longo do ciclo além do volume total de biogás gerado durante o período. Durante os primeiros 30 minutos de ciclo o biogás gerado apresentava diferença considerável nas concentrações de metano $\left(7,94\right.$ mmol. $\left.\mathrm{L}^{-1}\right)$ e dióxido de carbono $\left(3,82 \mathrm{mmol} . \mathrm{L}^{-1}\right)$, entretanto, esta diferença é menor do que na última condição. A produção de metano é maior do que a de dióxido de carbono durante todo o período, resultando numa concentração final de $74 \%$ dos 6428 mL-CNTP.ciclo ${ }^{-1}$ de biogás gerados durante o ciclo, demonstrando piora em relação à condição antecessora. 
Figura 5.42 - Perfis de volume nas CNTP de metano e $\mathrm{CO}_{2}$ (a), concentração dos gases e vazão molar (b) e volume e concentração ao longo do ciclo (c) na condição VIII
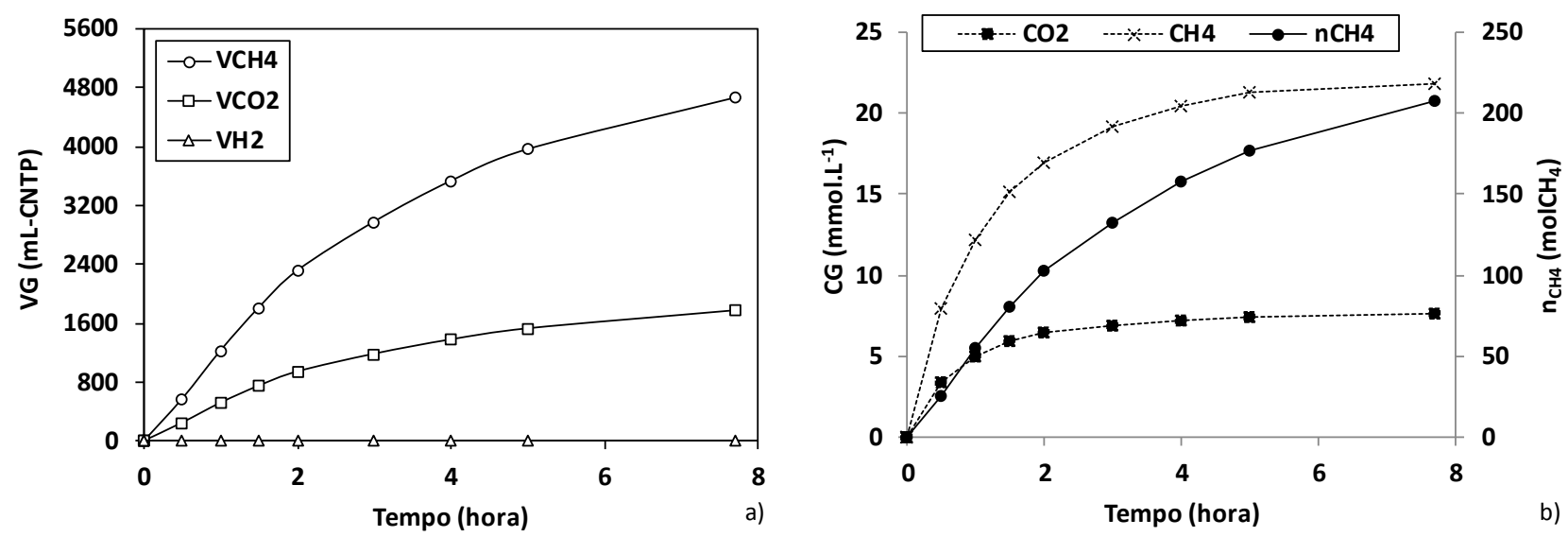

Produção e Composição do Biogás

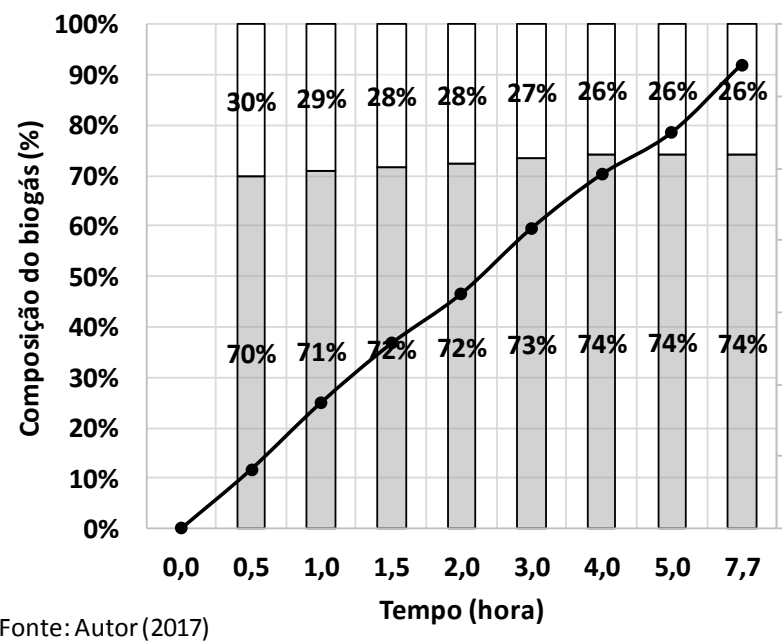

7000,0

6000,0

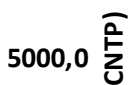

$4000,0 \frac{\vec{E}}{4}$

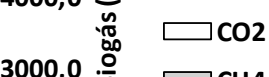

2000,0 $\frac{\text { है }}{\frac{\Xi}{9}} \rightarrow$ Vbiogás

1000,0

0,0

c)

Os dados do perfil indicam que o reator poderia ser operado eficientemente num ciclo de 5 horas. Os resultados indicam que houve remoção de $82 \%$ de matéria orgânica na forma de DQO e 99,9\% de carboidratos, ambos na forma filtrada. Houve consumo de apenas $18 \%$ da concentração máxima de ácidos voláteis. Além disso, houve a produção de 5484,4 mL-ciclo de biogás, contendo $74 \%$ de metano. 
5.2.8.3 Ajuste do modelo cinético

Os parâmetros cinéticos aparentes foram calculados (Tabela 5.16) e indicam maior produção de ácido acético através do substrato $\left(\mathrm{k}_{1 \mathrm{HAC}}\right)$ e também da conversão do ácido proprônico ( $\left.\mathrm{K}_{6 \mathrm{HAC}}\right)$. A produção de metano foi maior na rota metanogênica hidrogenotrófica $\left(\mathrm{K}_{11 \mathrm{M}}\right)$. Portanto, o modelo cinético foi ajustado de modo adequado pelos dados experimentais (Figura 5.43).

Tabela 5.16 - Parâmetros cinéticos da rota metabólica ao longo do ciclo na condição VIII

\begin{tabular}{ccc}
\hline Condição & Parâmetro & Condição VIII \\
\hline & $\mathrm{k}_{1 \mathrm{~S}}^{\prime}\left(\mathrm{h}^{-1}\right)$ & 0,57 \\
& $\mathrm{k}_{1 \mathrm{HAc}}\left(\mathrm{h}^{-1}\right)$ & 0,50 \\
& $\mathrm{k}_{1 \mathrm{H}}\left(\mathrm{h}^{-1}\right)$ & 0,00 \\
& $\mathrm{k}_{2 \mathrm{HPr}}\left(\mathrm{h}^{-1}\right)$ & 0,18 \\
Hidrólise e & $\mathrm{k}_{2 \mathrm{H}}\left(\mathrm{h}^{-1}\right)$ & 0,02 \\
Acidogênese & $\mathrm{k}_{3 \mathrm{HBu}}\left(\mathrm{h}^{-1}\right)$ & 0,05 \\
& $\mathrm{k}_{3 \mathrm{H}}\left(\mathrm{h}^{-1}\right)$ & 0,00 \\
& $\mathrm{k}_{4 \mathrm{HVa}}\left(\mathrm{h}^{-1}\right)$ & 0,02 \\
& $\mathrm{k}_{4 \mathrm{H}}\left(\mathrm{h}^{-1}\right)$ & 0,00 \\
& $\mathrm{k}_{5 \mathrm{ETOH}}\left(\mathrm{h}^{-1}\right)$ & 0,00 \\
\hline & $\mathrm{k}_{6 \mathrm{HPr}}\left(\mathrm{h}^{-1}\right)$ & 0,79 \\
& $\mathrm{k}_{6 \mathrm{HAc}}\left(\mathrm{h}^{-1}\right)$ & 24,92 \\
& $\mathrm{k}_{6 \mathrm{H}}\left(\mathrm{h}^{-1}\right)$ & 0,00 \\
& $\mathrm{k}_{7 \mathrm{HPr}}\left(\mathrm{h}^{-1}\right)$ & 1,59 \\
& $\mathrm{k}_{7 \mathrm{HBu}}\left(\mathrm{h}^{-1}\right)$ & 1,14 \\
& $\mathrm{k}_{7 \mathrm{H}}\left(\mathrm{h}^{-1}\right)$ & 0,00 \\
& $\mathrm{k}_{8 \mathrm{HBu}}\left(\mathrm{h}^{-1}\right)$ & 0,95 \\
& $\mathrm{k}_{8 \mathrm{HVa}}\left(\mathrm{h}^{-1}\right)$ & 0,00 \\
& $\mathrm{k}_{8 \mathrm{H}}\left(\mathrm{h}^{-1}\right)$ & 0,00 \\
$\mathrm{k}_{9 \mathrm{HAc}}\left(\mathrm{h}^{-1}\right)$ & 0,00 \\
\hline & $\mathrm{k}_{10 \mathrm{HAc}}\left(\mathrm{h}^{-1}\right)$ & 3,52 \\
$\mathrm{k}_{10 \mathrm{H}}\left(\mathrm{h}^{-1}\right)$ & 2,14 \\
& $\mathrm{k}_{11 \mathrm{H}}\left(\mathrm{h}^{-1}\right)$ & 0,12 \\
$\mathrm{k}_{11 \mathrm{M}}\left(\mathrm{h}^{-1}\right)$ & 94,25 \\
\hline & &
\end{tabular}


Figura 5.43- Dados experimentais (marcadores) e modelo (linha) do metano (a), substrato (b) e ácidos intermediários (c) na condição VIII
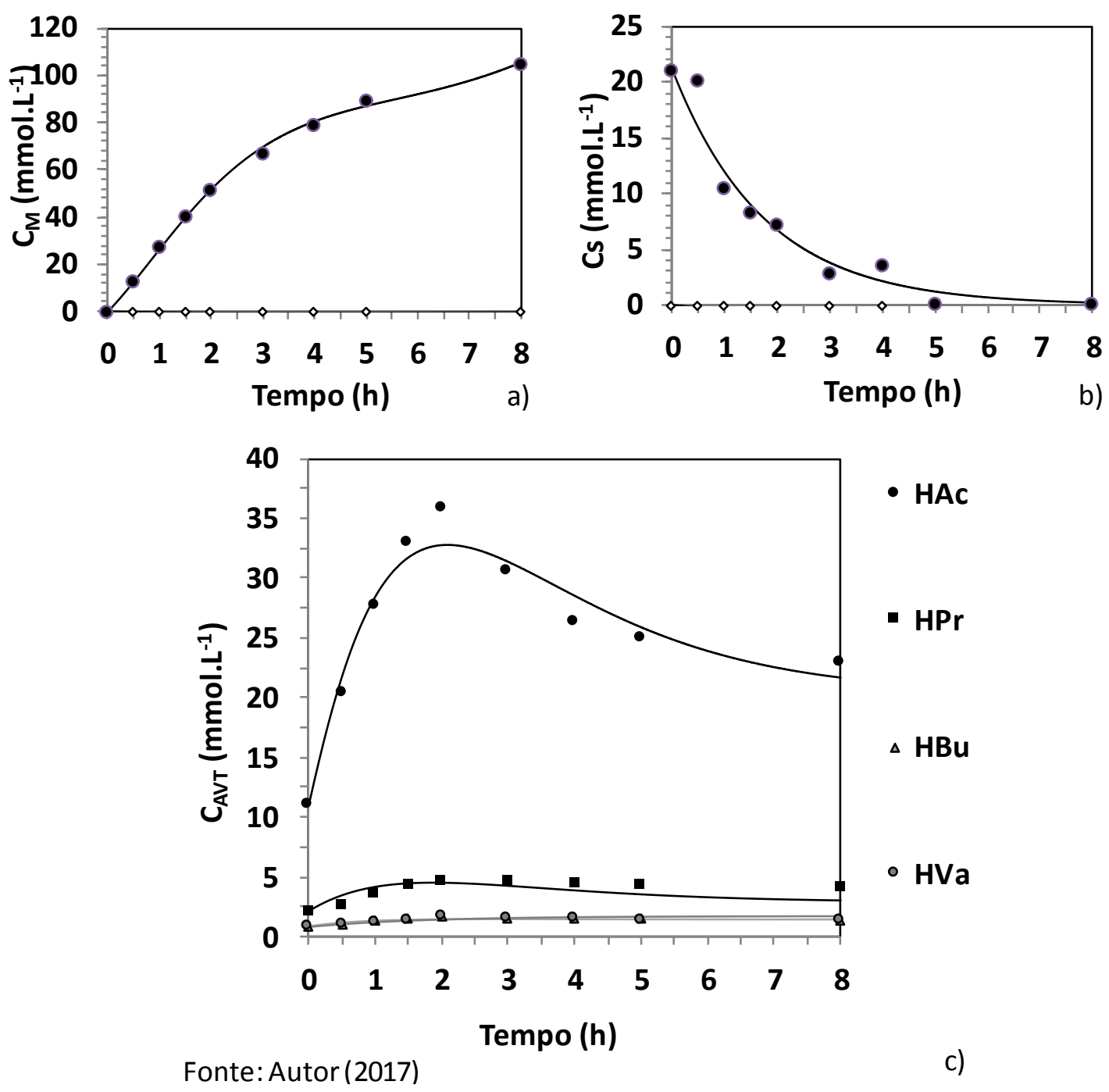

5.2.9 Condição IX - 18.000 mg DQO L ${ }^{-1} ; 100 \%$ Soro; $50 \%$ de bicarbonato; $55^{\circ} \mathrm{C}$; Batelada

Nesta condição de operação, o valor nominal de DQO alimentado ao reator foi de $18000 \mathrm{mg}$ $\mathrm{L}^{-1}$ com carga orgânica aplicada teórica de 21,60 g DQO L $\mathrm{g}^{-1} \mathrm{dia}^{-1}$. 


\subsubsection{Monitoramento}

O reator foi operado por 24 dias, em que a concentração média da matéria orgânica afluente

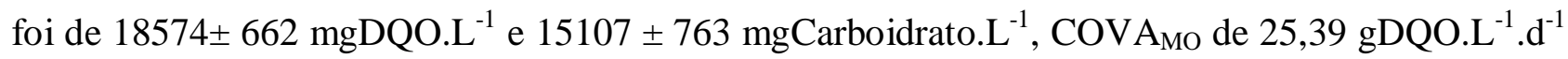
e COVA $A_{C}$ de 20,65 gCarboidrato.L $\mathrm{L}^{-1} \cdot \mathrm{d}^{-1}$. A quantidade de biomassa contida no reator foi de 109,7 g. Nesta condição, o reator operou com $50 \%$ de bicarbonato.

Os valores referentes ao monitoramento e aos indicadores desempenho encontram-se apresentados na Tabela 5.17 a seguir. A eficiência de remoção de matéria orgânica na forma de

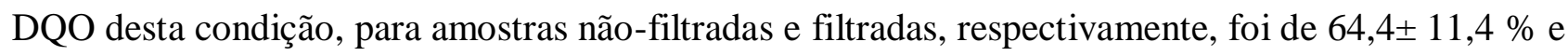
68,0 \pm 9,5\%. Para a matéria orgânica na forma de Carboidratos (lactose) a remoção foi de $99,1 \pm 0,4 \%$ e $99,5 \pm 0,2 \%$, respectivamente para não-filtradas e filtradas. $\mathrm{O} \mathrm{pH}$ afluente foi de $8,22 \pm 0,67$ e o efluente $7,72 \pm 0,35$. A alcalinidade a bicarbonato do afluente e efluente foram $5024 \pm 291 \mathrm{mgCaCO} 3 \cdot \mathrm{L}^{-1}$ e $1861 \pm 730 \mathrm{mgCaCO}_{3} \cdot \mathrm{L}^{-1}$. A alcalinidade referente aos ácidos voláteis do afluente e efluente foram $728 \pm 67$ mgHAc. $\mathrm{L}^{-1}$ e $4146 \pm 806 \mathrm{mgHac} . \mathrm{L}^{-1}$.

A concentração de sólidos suspensos voláteis (SSV) no efluente indica que houve pouca perda de biomassa no reator. A análise dos sólidos totais indica que a produção de polímero seguiu em crescente.

O rendimento de metano gerado por matéria orgânica consumida foi de 11,88 $\mathrm{mmolCH}_{4} \cdot \mathrm{gDQO}^{-1}$ e 14,61 $\mathrm{mmolCH}_{4} \cdot \mathrm{gCarboidrato}^{-1}$. A produção de biogás foi de $6916 \pm 393 \mathrm{~mL}-$ CNTP.ciclo ${ }^{-1}$, sendo a fração molar de metano equivalente a $71,83 \pm 0,68 \%$ e a produtividade molar de metano de $301,6 \mathrm{molCH}_{4} \cdot \mathrm{m}^{-3} \cdot \mathrm{d}^{-1}$.

Nesta condição, verificou-se instabilidade do reator indicado pela grande variação nos resultados. Os resultados indicam grande produção de ácidos voláteis, resultando em maior concentração no efluente do que no afluente, assim como de bicarbonato. A eficiência do reator na 
remoção de matéria orgânica na forma de DQO também diminuiu consideravelmente em relação à condição anterior, possivelmente pela acumulação de ácidos e a não formação de metano, como indicado nos resultados de rendimento molar de metano e composição do biogás. 
Tabela 5.17 - Resumo dos valores médios obtidos no monitoramento do reator com concentração afluente de $18000 \mathrm{mgDQO} . \mathrm{L}^{-1}$ na condição IX

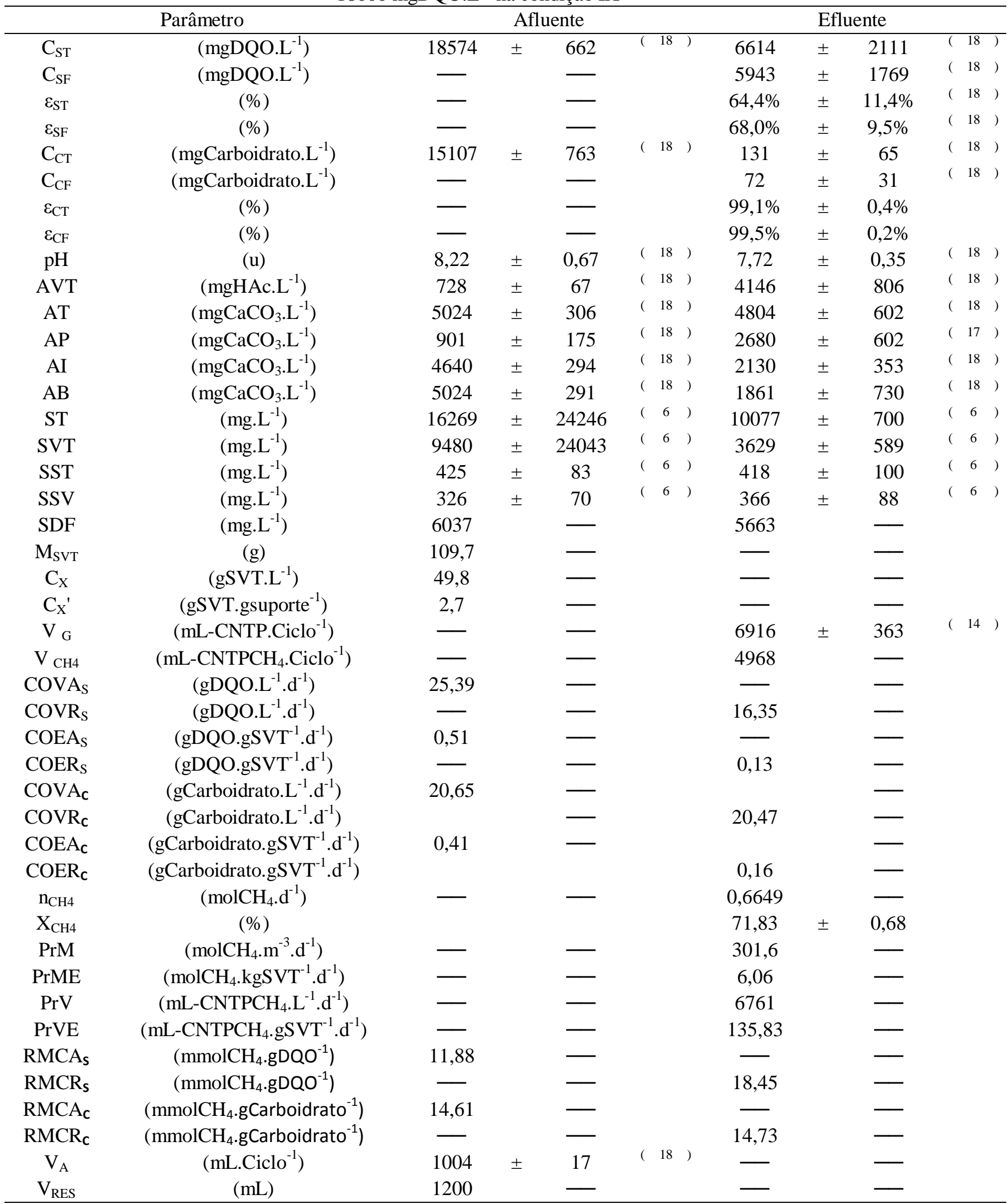

*Os valores entre parêntesis representam o número de amostras consideradas para o cálculo da média Fonte: Autor (2017) 


\subsubsection{Perfil ao longo do ciclo}

Durante o perfil, a concentração de matéria orgânica afluente na forma de DQO e de Carboidrato foi de $18236 \mathrm{mgDQO} . \mathrm{L}^{-1}$ e de $14290 \mathrm{mgCarboidrato.L^{-1 }}$, respectivamente. Após a

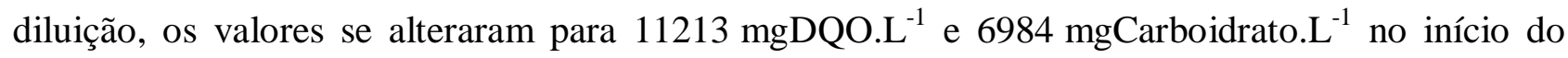
ciclo.

Observa-se na Figura 5.44 a variação do $\mathrm{pH}$ ao longo do ciclo, com valor de 8,24 no afluente, mínimo de 7,26 e 7,58 no efluente. Também é possível acompanhar a variação da alcalinidade a bicarbonato e ácidos voláteis totais durante o ciclo. Os ácidos voláteis totais têm o pico de produção (4823 mgHAc. $\mathrm{L}^{-1}$ ) em 5,0 horas de ciclo, mais tardio do que nas condições anteriores. Isto significa que a produção de ácidos se estendeu por mais tempo nesta condição, e como se vê na Figura 5.54b abaixo, seu consumo foi mínimo, resultando em $4285 \mathrm{mgHAc} . \mathrm{L}^{-1}$ no efluente do sistema. Este resultado indica que a capacidade de gerar ácidos intermediários do sistema estava sobrepujando a capacidade da comunidade metanogênica de consumi-los, indicando inibição das arquéias metanogênicas. O acúmulo de ácidos fez com que a alcalinidade a bicarbonato tivesse redução de sua concentração, resultando num valor mínimo de $1371 \mathrm{mg} \mathrm{CaCO} \mathrm{mg} \mathrm{L}^{-1}$, representando boa capacidade tamponante. 
Figura 5.44 - Perfis de pH (a), alcalinidade a bicarbonato e a ácidos voláteis totais (b) na condição IX
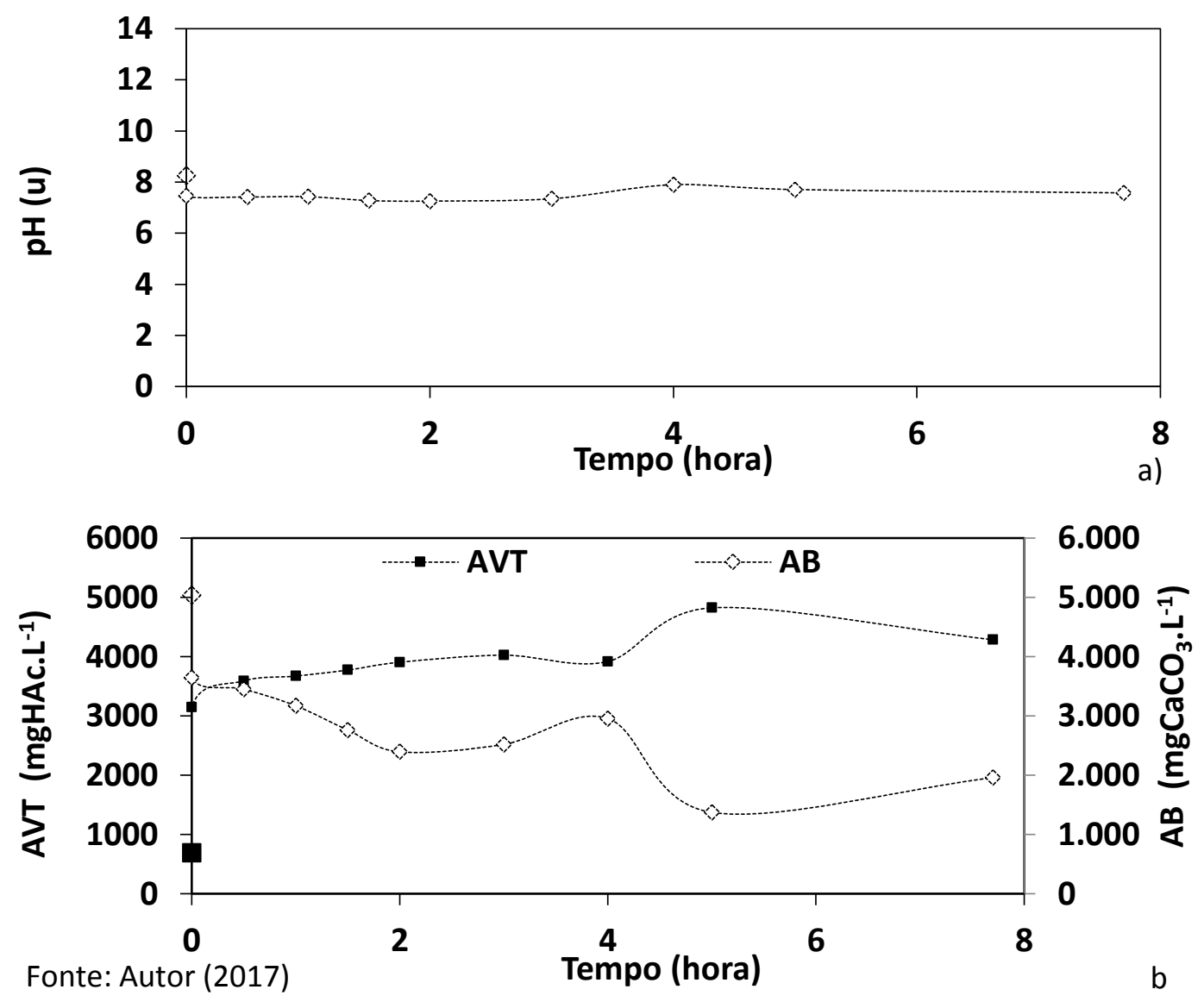

O consumo da matéria orgânica nas formas de DQO e Carboidrato ao longo do ciclo pode ser analisado através da Figura 5.45. Nesta condição, nota-se que a reação de consumo de carboidratos foi mais lenta do que na condição anterior. Isso é notado também na concentração da matéria orgânica na forma de DQO. Em 5 horas de ciclo houve consumo de $96 \%$ da fração de carboidratos, com $60 \%$ de consumo de DQO no mesmo período de tempo. Os resultados desta condição indicam que o reator já havia ultrapassado a capacidade de tratamento, sendo a carga aplicada maior do que a assimilável pela comunidade do reator nas condições de estudo, resultando em eficiência global diminuída. A concentração de DQO no final do ciclo foi de 6225 mg DQO.L¹, representando $66 \%$ de eficiência. 
Figura 5.45 - Perfis de concentração e eficiência de remoção de DQO (a) e carboidratos (b) na condição IX
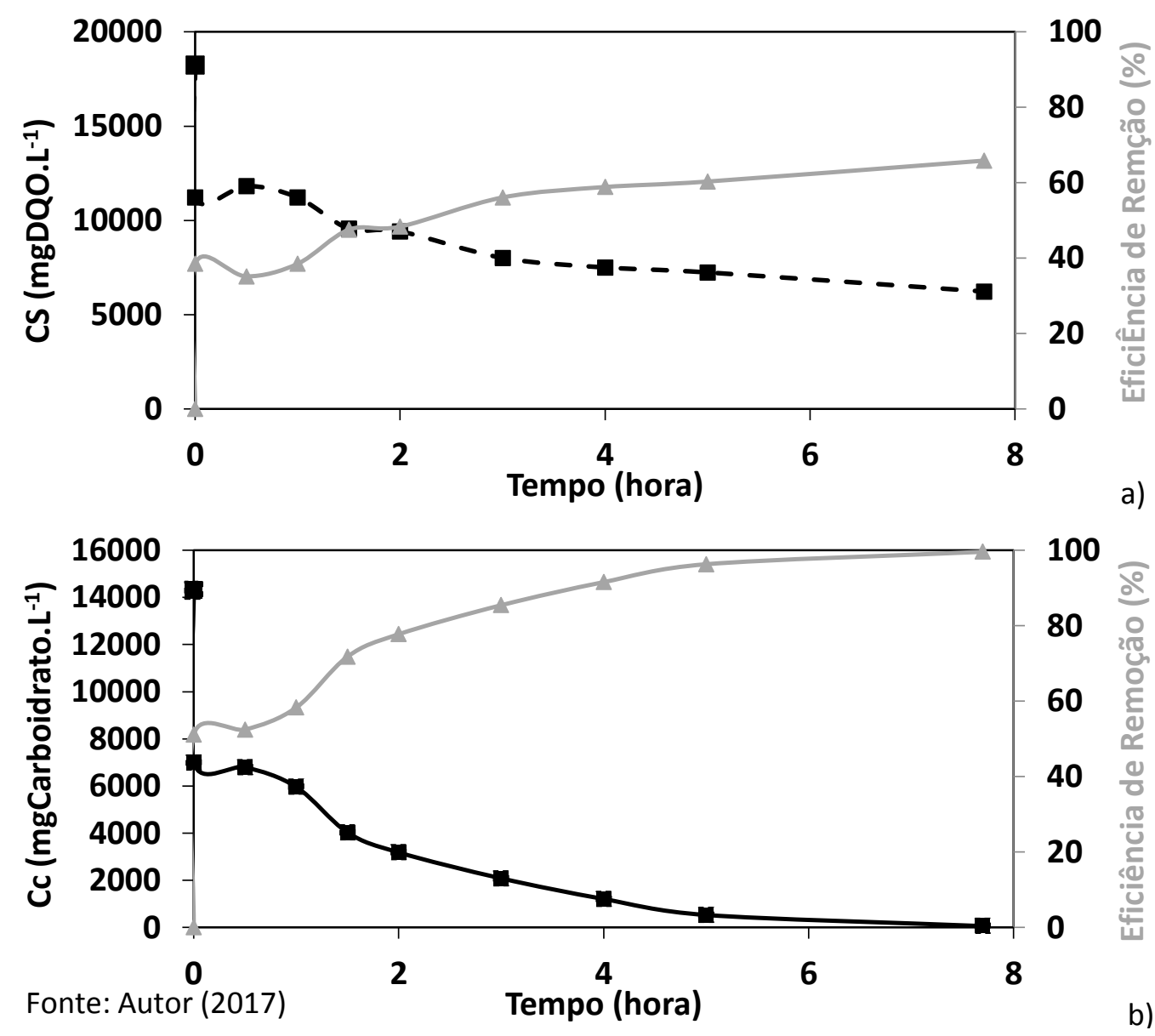

A variação da produção e consumo dos compostos metabólicos intermediários ao longo do ciclo pode ser observada pela Figura 5.46. O maior valor de ácido propiônico nesta condição foi de 442,4 mg. $\mathrm{L}^{-1}$, num pico que se deu após 2 horas de ciclo, o consumo deste ácido se manteve lento até o final do ciclo, resultando em concentração de $389,8 \mathrm{mg} \cdot \mathrm{L}^{-1}$ no efluente. A concentração remanescente de ácido acético representou $62 \%$ do valor do pico. 
Figura 5.46 - Perfil das concentrações dos compostos intermediários ao longo do ciclo na condição IX

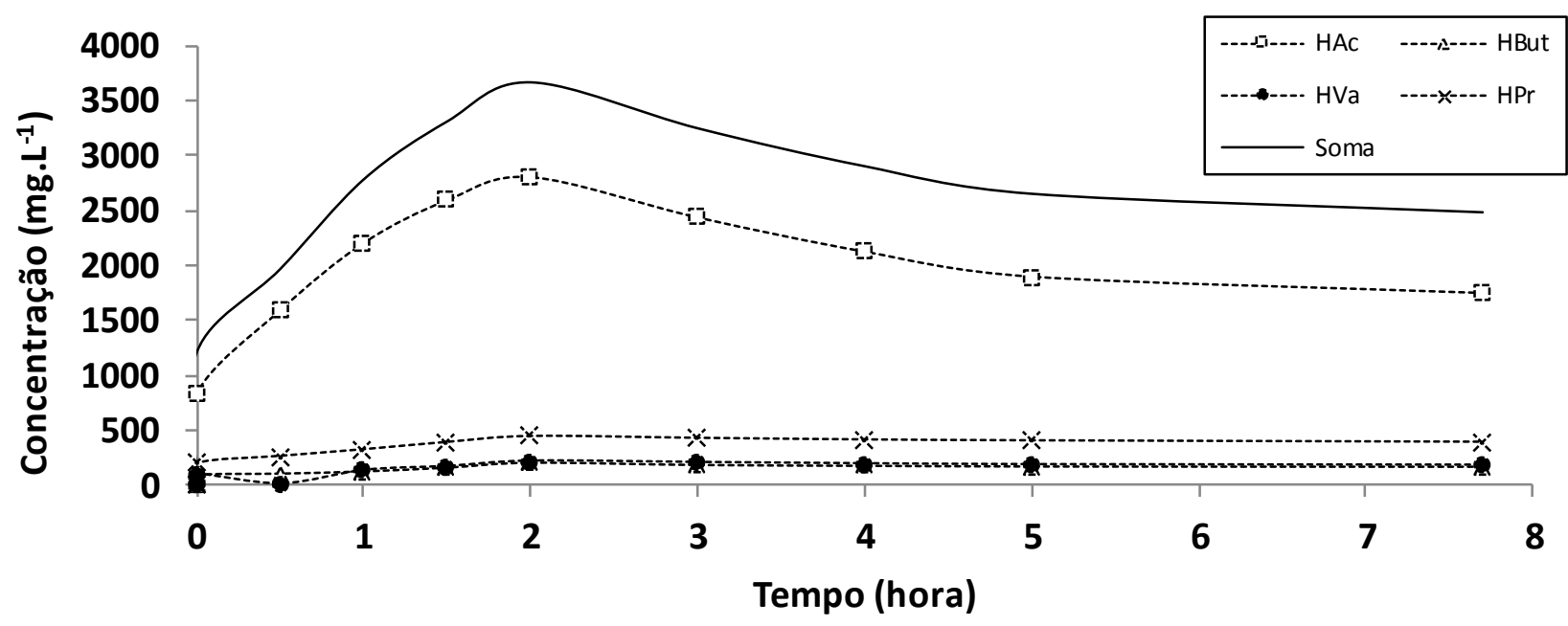

Fonte: Autor (2017)

A produção volumétrica de metano $\left(\mathrm{CH}_{4}\right)$ e dióxido de carbono $\left(\mathrm{CO}_{2}\right)$ ao longo do ciclo pode ser observada através da Figura 5.47. Nota-se que a produção volumétrica de metano foi predominante por todo o ciclo. Também se verifica a evolução das concentrações de metano e dióxido de carbono presente no biogás e a vazão molar de metano ao longo do ciclo além do volume total de biogás gerado durante o período. Durante os primeiros 30 minutos de ciclo o biogás gerado apresentava diferença considerável nas concentrações de metano $\left(7,61\right.$ mmol. $\left.\mathrm{L}^{-1}\right)$ e dióxido de carbono $\left(3,88\right.$ mmol. $\left.\mathrm{L}^{-1}\right)$, entretanto, esta diferença é menor do que na última condição. A produção de metano é maior do que a de dióxido de carbono durante todo o período, resultando numa concentração final de $71 \%$ dos 6472 mL-CNTP.ciclo ${ }^{-1}$ de biogás gerados durante o ciclo, demonstrando piora em relação à última condição. 
Figura 5.47 - Perfis de volume nas CNTP de metano e $\mathrm{CO}_{2}$ (a), concentração dos gases e vazão molar (b) e volume e concentração ao longo do ciclo (c) na condição IX
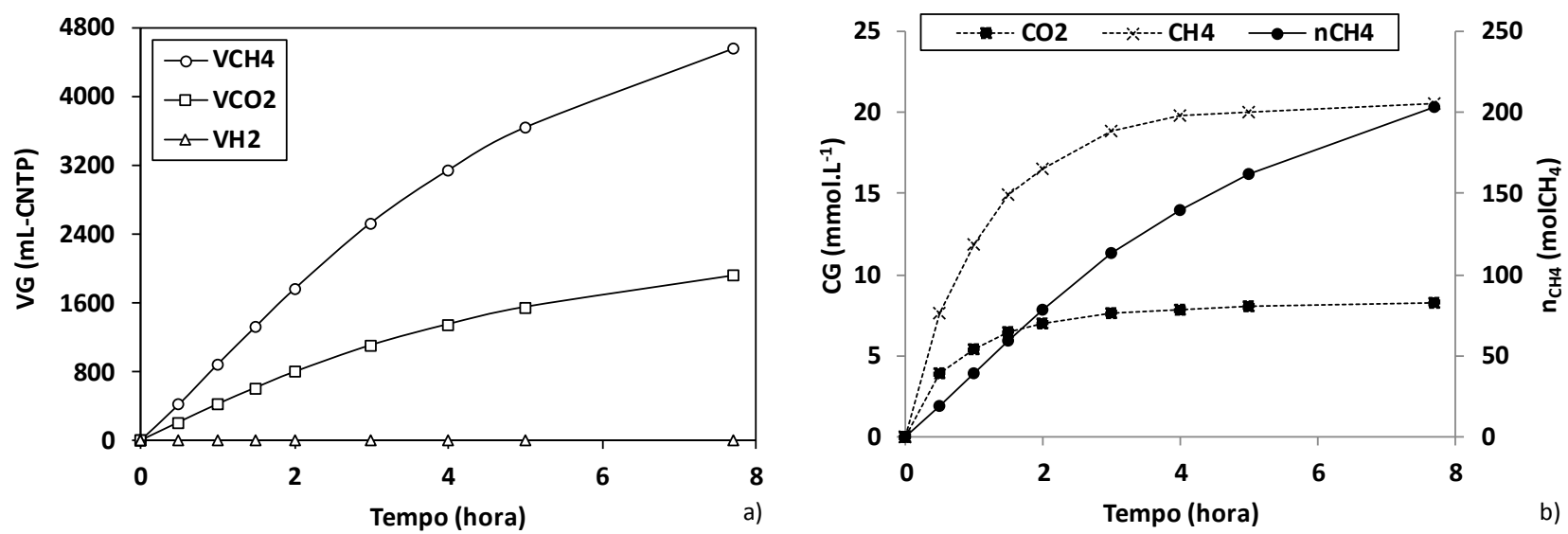

Produção e Composição do Biogás

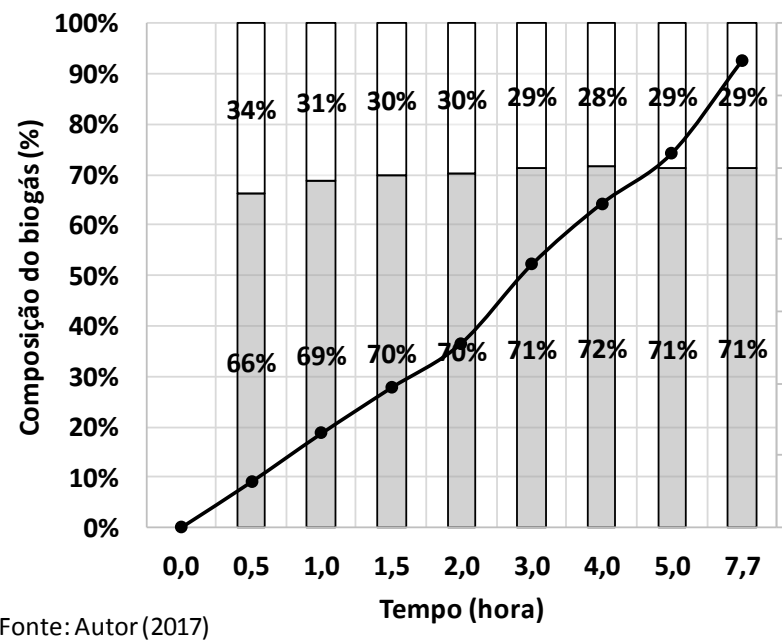

7000,0

6000,0

5000,0 玄

$4000,0 \frac{\vec{\varepsilon}}{4}$

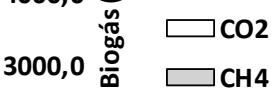

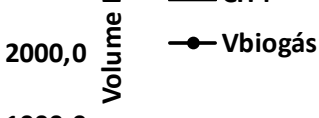

1000,0

0,0

c)

A maior carga orgânica aplicada nesta condição faz com que o desempenho do reator fosse ruim num ciclo de 5 horas, havendo a necessidade de maior tempo para assimilação da matéria orgânica por parte dos microrganismos. Os resultados obtidos num ciclo de 5 horas, indicam que haveria remoção de $60 \%$ de matéria orgânica na forma de DQO e $96 \%$ de carboidratos, ambos na forma filtrada. Não haveria consumo dos ácidos voláteis produzidos durante este tempo de ciclo. A produção de biogás seria de 5192,6 mL-ciclo, contendo $71 \%$ de metano. 
5.2.9.3 Ajuste do modelo cinético

Os parâmetros cinéticos aparentes foram calculados (Tabela 5.18) e indicam maior produção de ácido acético através do substrato $\left(\mathrm{k}_{1 \mathrm{HAC}}\right)$ e também da conversão do ácido proprônico ( $\left.\mathrm{K}_{6 \mathrm{HAC}}\right)$. A produção de metano foi maior na rota metanogênica hidrogenotrófica $\left(\mathrm{K}_{11 \mathrm{M}}\right)$. Portanto, o modelo cinético foi ajustado de modo adequado pelos dados experimentais (Figura 5.48).

Tabela 5.18 - Parâmetros cinéticos da rota metabólica ao longo do ciclo na condição IX

\begin{tabular}{ccc}
\hline Condição & Parâmetro & Condição IX \\
\hline & $\mathrm{k}_{1 \mathrm{~S}}^{\prime}\left(\mathrm{h}^{-1}\right)$ & 0,38 \\
& $\mathrm{k}_{1 \mathrm{HAc}}\left(\mathrm{h}^{-1}\right)$ & 1,16 \\
& $\mathrm{k}_{1 \mathrm{H}}\left(\mathrm{h}^{-1}\right)$ & 0,00 \\
& $\mathrm{k}_{2 \mathrm{HPr}}\left(\mathrm{h}^{-1}\right)$ & 0,03 \\
Hidrólise e & $\mathrm{k}_{2 \mathrm{H}}\left(\mathrm{h}^{-1}\right)$ & 0,01 \\
Acidogênese & $\mathrm{k}_{3 \mathrm{HBu}}\left(\mathrm{h}^{-1}\right)$ & 0,02 \\
& $\mathrm{k}_{3 \mathrm{H}}\left(\mathrm{h}^{-1}\right)$ & 0,00 \\
& $\mathrm{k}_{4 \mathrm{HVa}}\left(\mathrm{h}^{-1}\right)$ & 0,01 \\
& $\mathrm{k}_{4 \mathrm{H}}\left(\mathrm{h}^{-1}\right)$ & 0,00 \\
& $\mathrm{k}_{5 \mathrm{ETOH}}\left(\mathrm{h}^{-1}\right)$ & 0,00 \\
\hline & $\mathrm{k}_{6 \mathrm{HPr}}\left(\mathrm{h}^{-1}\right)$ & 0,02 \\
& $\mathrm{k}_{6 \mathrm{HAc}}\left(\mathrm{h}^{-1}\right)$ & 2,66 \\
& $\mathrm{k}_{6 \mathrm{H}}\left(\mathrm{h}^{-1}\right)$ & 0,00 \\
& $\mathrm{k}_{7 \mathrm{HPr}}\left(\mathrm{h}^{-1}\right)$ & 0,14 \\
& $\mathrm{k}_{7 \mathrm{HBu}}\left(\mathrm{h}^{-1}\right)$ & 1,59 \\
& $\mathrm{k}_{7 \mathrm{H}}\left(\mathrm{h}^{-1}\right)$ & 0,00 \\
& $\mathrm{k}_{8 \mathrm{HBu}}\left(\mathrm{h}^{-1}\right)$ & 1,70 \\
& $\mathrm{k}_{8 \mathrm{HVa}}\left(\mathrm{h}^{-1}\right)$ & 0,00 \\
& $\mathrm{k}_{8 \mathrm{H}}\left(\mathrm{h}^{-1}\right)$ & 0,00 \\
$\mathrm{k}_{9 \mathrm{HAc}}\left(\mathrm{h}^{-1}\right)$ & 0,00 \\
\hline & $\mathrm{k}_{10 \mathrm{HAc}}\left(\mathrm{h}^{-1}\right)$ & 0,77 \\
$\mathrm{k}_{10 \mathrm{H}}\left(\mathrm{h}^{-1}\right)$ & 0,79 \\
& $\mathrm{k}_{11 \mathrm{H}}\left(\mathrm{h}^{-1}\right)$ & 0,15 \\
$\mathrm{k}_{11 \mathrm{M}}\left(\mathrm{h}^{-1}\right)$ & 44,43 \\
\hline & &
\end{tabular}


Figura 5.48- Dados experimentais (marcadores) e modelo (linha) do metano (a), substrato (b) e ácidos intermediários (c) na condição IX
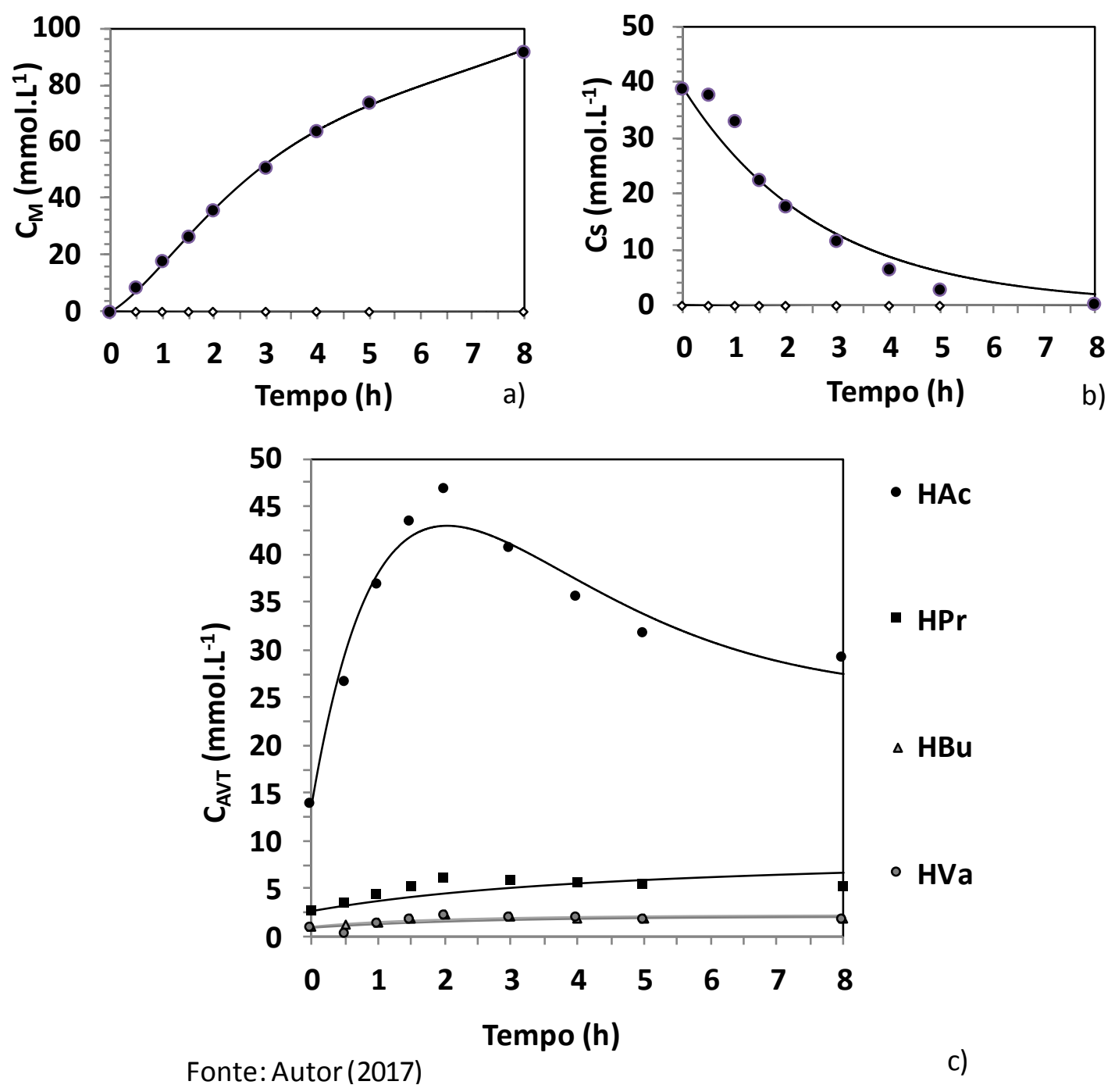

5.2.10 Condição X - $20.000 \mathrm{mg}$ DQO L ${ }^{-1} ; 100 \%$ Soro; $50 \%$ de bicarbonato; $55^{\circ} \mathrm{C}$; Batelada

Nesta condição de operação, o valor nominal de DQO alimentado ao reator foi de $20000 \mathrm{mg}$ $\mathrm{L}^{-1}$ com carga orgânica aplicada teórica de 24,00 g DQO L $\mathrm{g}^{-1} \mathrm{dia}^{-1}$. 


\subsubsection{Monitoramento}

O reator foi operado por 19 dias, em que a concentração média da matéria orgânica afluente foi de $21256 \pm 856 \mathrm{mgDQO} . \mathrm{L}^{-1}$ e $16538 \pm 611 \mathrm{mgCarboidrato.L^{-1 }}$, COVAMO de 30,34 gDQO.L ${ }^{-1} \cdot \mathrm{d}^{-1}$ e COVA $A_{C}$ de 23,63 gCarboidrato.L $\mathrm{L}^{-1} \cdot \mathrm{d}^{-1}$. A quantidade de biomassa contida no reator foi de 144,2 g. Nesta condição, o reator operou com $50 \%$ de bicarbonato.

Os valores referentes ao monitoramento e aos indicadores desempenho encontram-se apresentados na Tabela 5.19 a seguir. A eficiência de remoção de matéria orgânica na forma de DQO desta condição, para amostras não-filtradas e filtradas, respectivamente, foi de 58,3 $\pm 3,2 \%$ e $62,5 \pm 3,7 \%$. Para a matéria orgânica na forma de Carboidratos (lactose) a remoção foi de 98,9 $\pm 0,6 \%$ e 99,4 $\pm 0,4 \%$, respectivamente para não-filtradas e filtradas. $\mathrm{O} \mathrm{pH}$ afluente foi de $8,42 \pm 0,11$ e o efluente $7,85 \pm 0,36$. A alcalinidade a bicarbonato do afluente e efluente foram $6030 \pm 149 \mathrm{mgCaCO} 3 \cdot \mathrm{L}^{-1}$ e $1398 \pm 393 \mathrm{mgCaCO}_{3} \cdot \mathrm{L}^{-1}$. A alcalinidade referente aos ácidos voláteis do afluente e efluente foram $705 \pm 90 \mathrm{mgHAc} . \mathrm{L}^{-1}$ e $5527 \pm 456 \mathrm{mgHac} . \mathrm{L}^{-1}$.

A concentração de sólidos suspensos voláteis (SSV) no efluente indica que houve pouca perda de biomassa no reator. A análise dos sólidos totais indica que a produção de polímero seguiu em crescente.

O rendimento de metano gerado por matéria orgânica consumida foi de 10,17 $\mathrm{mmolCH}_{4} \cdot \mathrm{gDQO}^{-1}$ e 13,06 $\mathrm{mmolCH}_{4} \cdot \mathrm{gCarboidrato}^{-1}$. A produção de biogás foi de $7157 \pm 361 \mathrm{~mL}-$ CNTP.ciclo $^{-1}$, sendo a fração molar de metano equivalente a $67,63 \pm 0,63 \%$ e a produtividade molar de metano de $308,5 \mathrm{molCH}_{4} \cdot \mathrm{m}^{-3} \cdot \mathrm{d}^{-1}$.

Nesta condição, verificou-se que a queda no desempenho se manteve, mas nota-se que o reator apresentou maior estabilidade. Os resultados indicam grande produção de ácidos voláteis, resultando em maior concentração no efluente do que no afluente, assim como de bicarbonato. A 
eficiência do reator na remoção de matéria orgânica na forma de DQO apresentou uma pequena queda em relação à última condição. O baixo desempenho do reator implica na formação de um biogás com baixa porcentagem de metano e com produtividade bem menor do que o esperado, apesar de resultar num volume maior de biogás, o que é esperado devido à maior carga aplicada. 
Tabela 5.19 - Resumo dos valores médios obtidos no monitoramento do reator com concentração afluente de $20000 \mathrm{mgDQO} . \mathrm{L}^{-1}$ na condição X

\begin{tabular}{|c|c|c|c|c|c|c|c|c|c|c|c|c|c|}
\hline \multicolumn{2}{|r|}{ Parâmetro } & \multicolumn{6}{|c|}{ Afluente } & \multicolumn{6}{|c|}{ Efluente } \\
\hline $\mathrm{C}_{\mathrm{ST}}$ & $\left(\mathrm{mgDQO} \cdot \mathrm{L}^{-1}\right)$ & 21236 & \pm & 887 & & 13 & & 8861 & \pm & 675 & & & \\
\hline $\mathrm{C}_{\mathrm{SF}}$ & $\left(\mathrm{mgDQO} \cdot \mathrm{L}^{-1}\right)$ & - & & - & & & & 7970 & \pm & 794 & & 13 & \\
\hline$\varepsilon_{\mathrm{ST}}$ & $(\%)$ & - & & - & & & & $58,3 \%$ & \pm & $3,2 \%$ & ( & 13 & \\
\hline$\varepsilon_{\mathrm{SF}}$ & $(\%)$ & - & & - & & & & $62,5 \%$ & \pm & $3,7 \%$ & ( & 13 & ) \\
\hline $\mathrm{C}_{\mathrm{CT}}$ & (mgCarboidrato. $\left.\mathrm{L}^{-1}\right)$ & 16538 & \pm & 611 & ( & 14 & ) & 182 & \pm & 101 & ( & 14 & \\
\hline $\mathrm{C}_{\mathrm{CF}}$ & (mgCarboidrato. $\left.\mathrm{L}^{-1}\right)$ & - & & - & & & & 100 & \pm & 69 & ( & 14 & ) \\
\hline$\varepsilon_{\mathrm{CT}}$ & $(\%)$ & - & & - & & & & $98,9 \%$ & \pm & $0,6 \%$ & & & \\
\hline$\varepsilon_{\mathrm{CF}}$ & $(\%)$ & - & & - & & & & $99,4 \%$ & \pm & $0,4 \%$ & & & \\
\hline $\mathrm{pH}$ & (u) & 8,42 & \pm & 0,11 & ( & 14 & ) & 7,85 & \pm & 0,36 & ( & 14 & ) \\
\hline AVT & $\left(\mathrm{mgHAc} . \mathrm{L}^{-1}\right)$ & 705 & \pm & 90 & ( & 14 & ) & 5527 & \pm & 456 & ( & 14 & \\
\hline $\mathrm{AT}$ & $\left(\mathrm{mgCaCO}_{3} \cdot \mathrm{L}^{-1}\right)$ & 6030 & \pm & 168 & ( & 14 & ) & 5322 & \pm & 490 & ( & 14 & \\
\hline $\mathrm{AP}$ & $\left(\mathrm{mgCaCO}_{3} \cdot \mathrm{L}^{-1}\right)$ & 887 & \pm & 281 & ( & 14 & ) & 2363 & \pm & 346 & ( & 14 & ) \\
\hline AI & $\left(\mathrm{mgCaCO}_{3} \cdot \mathrm{L}^{-1}\right)$ & 5643 & \pm & 264 & ( & 14 & ) & 2960 & \pm & 293 & ( & 14 & ) \\
\hline $\mathrm{AB}$ & $\left(\mathrm{mgCaCO}_{3} \cdot \mathrm{L}^{-1}\right)$ & 6030 & \pm & 149 & ( & 14 & ) & 1398 & \pm & 393 & ( & 14 & \\
\hline ST & $\left(\mathrm{mg} . \mathrm{L}^{-1}\right)$ & 22251 & \pm & 1369 & ( & 5 & ) & 12478 & \pm & 633 & ( & 5 & \\
\hline SVT & $\left(\mathrm{mg} \cdot \mathrm{L}^{-1}\right)$ & 12990 & \pm & 992 & ( & 5 & ) & 5206 & \pm & 629 & ( & 5 & \\
\hline SST & $\left(\mathrm{mg} \cdot \mathrm{L}^{-1}\right)$ & 466 & \pm & 164 & ( & 5 & ) & 579 & \pm & 155 & & 5 & ) \\
\hline SSV & $\left(\mathrm{mg} \cdot \mathrm{L}^{-1}\right)$ & 378 & \pm & 155 & ( & 5 & ) & 492 & \pm & 95 & & 5 & \\
\hline SDF & $\left(\mathrm{mg} \cdot \mathrm{L}^{-1}\right)$ & 8417 & & - & & & & 6202 & & - & & & \\
\hline $\mathrm{M}_{\mathrm{SVT}}$ & (g) & 144,2 & & - & & & & - & & - & & & \\
\hline $\mathrm{C}_{\mathrm{X}}$ & $\left(\mathrm{gSVT} . \mathrm{L}^{-1}\right)$ & 68,7 & & - & & & & - & & - & & & \\
\hline $\mathrm{C}_{\mathrm{X}}^{\prime}$ & (gSVT.gsuporte $^{-1}$ ) & 2,8 & & 一 & & & & - & & - & & & \\
\hline $\mathrm{V}_{\mathrm{G}}$ & $\left(\mathrm{mL}-\mathrm{CNTP} . \mathrm{Ciclo}^{-1}\right)$ & - & & - & & & & 7157 & \pm & 361 & & 10 & \\
\hline $\mathrm{V}_{\mathrm{CH} 4}$ & $\left(\mathrm{~mL}-\mathrm{CNTPCH} 4 \cdot \mathrm{Ciclo}^{-1}\right)$ & - & & - & & & & 4840 & & - & & & \\
\hline $\mathrm{COVA}_{\mathrm{S}}$ & $\left(\mathrm{gDQO} \cdot \mathrm{L}^{-1} \cdot \mathrm{d}^{-1}\right)$ & 30,34 & & - & & & & - & & - & & & \\
\hline $\mathrm{COVR}_{\mathrm{S}}$ & $\left(\mathrm{gDQO} \cdot \mathrm{L}^{-1} \cdot \mathrm{d}^{-1}\right)$ & - & & - & & & & 17,68 & & - & & & \\
\hline $\mathrm{COEA}_{S}$ & $\left(\right.$ gDQO.gSVT $\left.{ }^{-1} \cdot d^{-1}\right)$ & 0,44 & & - & & & & - & & - & & & \\
\hline $\mathrm{COER}_{S}$ & $\left(\right.$ gDQO.gSVT $\left.{ }^{-1} \cdot \mathrm{d}^{-1}\right)$ & - & & - & & & & 0,09 & & - & & & \\
\hline $\mathrm{COVA}_{c}$ & (gCarboidrato. $\mathrm{L}^{-1} \cdot \mathrm{d}^{-1}$ ) & 23,63 & & 一 & & & & & & - & & & \\
\hline $\mathrm{COVR}_{\mathrm{c}}$ & (gCarboidrato. $\left.\mathrm{L}^{-1} \cdot \mathrm{d}^{-1}\right)$ & & & - & & & & 23,37 & & - & & & \\
\hline $\mathrm{COEA}_{c}$ & (gCarboidrato.gSVT $\left.{ }^{-1} \cdot \mathrm{d}^{-1}\right)$ & 0,34 & & - & & & & & & - & & & \\
\hline $\mathrm{COER}_{\mathrm{c}}$ & $\left(\right.$ gCarboidrato.gSVT $\left.{ }^{-1} \cdot \mathrm{d}^{-1}\right)$ & & & & & & & 0,12 & & - & & & \\
\hline $\mathrm{n}_{\mathrm{CH} 4}$ & $\left(\mathrm{molCH}_{4} \cdot \mathrm{d}^{-1}\right)$ & - & & - & & & & 0,6478 & & - & & & \\
\hline $\mathrm{X}_{\mathrm{CH} 4}$ & $(\%)$ & & & & & & & 67,63 & \pm & 0,63 & & & \\
\hline PrM & $\left(\mathrm{molCH}_{4} \cdot \mathrm{m}^{-3} \cdot \mathrm{d}^{-1}\right)$ & - & & - & & & & 308,5 & & - & & & \\
\hline PrME & $\left(\mathrm{molCH}_{4} \cdot \mathrm{kgSVT}^{-1} \cdot \mathrm{d}^{-1}\right)$ & - & & - & & & & 4,49 & & - & & & \\
\hline $\operatorname{PrV}$ & $\left(\mathrm{mL}-\mathrm{CNTPCH}{ }_{4} \cdot \mathrm{L}^{-1} \cdot \mathrm{d}^{-1}\right)$ & - & & - & & & & 6914 & & - & & & \\
\hline PrVE & 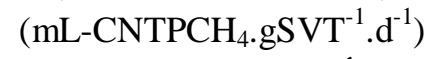 & - & & - & & & & 100,69 & & - & & & \\
\hline $\mathrm{RMCA}_{s}$ & $\left(\mathrm{mmolCH}_{4} \cdot \mathrm{gDQO}^{-1}\right)$ & 10,17 & & - & & & & - & & - & & & \\
\hline $\mathrm{RMCR}_{s}$ & $\left(\mathrm{mmolCH}_{4} \cdot \mathrm{gDQO}^{-1}\right)$ & - & & - & & & & 17,45 & & - & & & \\
\hline $\mathrm{RMCA}_{\mathrm{c}}$ & $\left(\mathrm{mmolCH}_{4} \cdot\right.$ gCarboidrato $\left.^{-1}\right)$ & 13,06 & & - & & & & - & & - & & & \\
\hline $\mathrm{RMCR}_{\mathrm{c}}$ & $\left(\mathrm{mmolCH}_{4} \cdot \mathrm{gCarboidrato}^{-1}\right)$ & - & & - & & & & 13,20 & & - & & & \\
\hline $\mathrm{V}_{\mathrm{A}}$ & $\left(\mathrm{mL} . \mathrm{Ciclo}^{-1}\right)$ & 1000 & \pm & 16 & ( & 14 & ) & - & & - & & & \\
\hline $\mathrm{V}_{\mathrm{RES}}$ & $(\mathrm{mL})$ & 1100 & & - & & & & - & & - & & & \\
\hline
\end{tabular}

*Os valores entre parêntesis representam o número de amostras consideradas para o cálculo da média Fonte: Autor (2017) 


\subsubsection{Perfil ao longo do ciclo}

Durante o perfil, a concentração de matéria orgânica afluente na forma de DQO e de

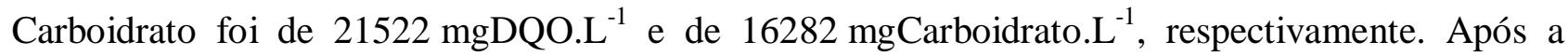
diluição, os valores se alteraram para $14148 \mathrm{mgDQO} . \mathrm{L}^{-1}$ e $7643 \mathrm{mgCarboidrato.L^{-1 }}$ no início do ciclo.

Observa-se na Figura 5.49 a variação do $\mathrm{pH}$ ao longo do ciclo, com valor de 8,50 no afluente, mínimo de 7,23 e 8,27 no efluente. Também é possível acompanhar a variação da alcalinidade a bicarbonato e ácidos voláteis totais durante o ciclo. Os ácidos voláteis totais têm o pico de produção (5432 mgHAc. $\mathrm{L}^{-1}$ ) em 4,0 horas de ciclo. O consumo dos ácidos foi mínimo, resultando em $5220 \mathrm{mgHAc} . \mathrm{L}^{-1}$ no efluente do sistema. Este resultado indica que a capacidade de formação de metano esteve bastante abaixo da geração de ácidos, o que se vê também pela incapacidade de reestabelecer a alcalinidade a bicarbonato do reator. O acúmulo de ácidos fez com que a alcalinidade a bicarbonato fosse reduzida a um valor mínimo de $995 \mathrm{mgCaCO} \cdot \mathrm{L}^{-1}$, apresentando quase nenhuma recuperação ao final do ciclo, resultando em $114 \mathrm{mgCaCO}_{3} \cdot \mathrm{L}^{-1}$ no efluente. 
Figura 5.49 - Perfis de pH (a), alcalinidade a bicarbonato e a ácidos voláteis totais (b) na condição $\mathrm{X}$
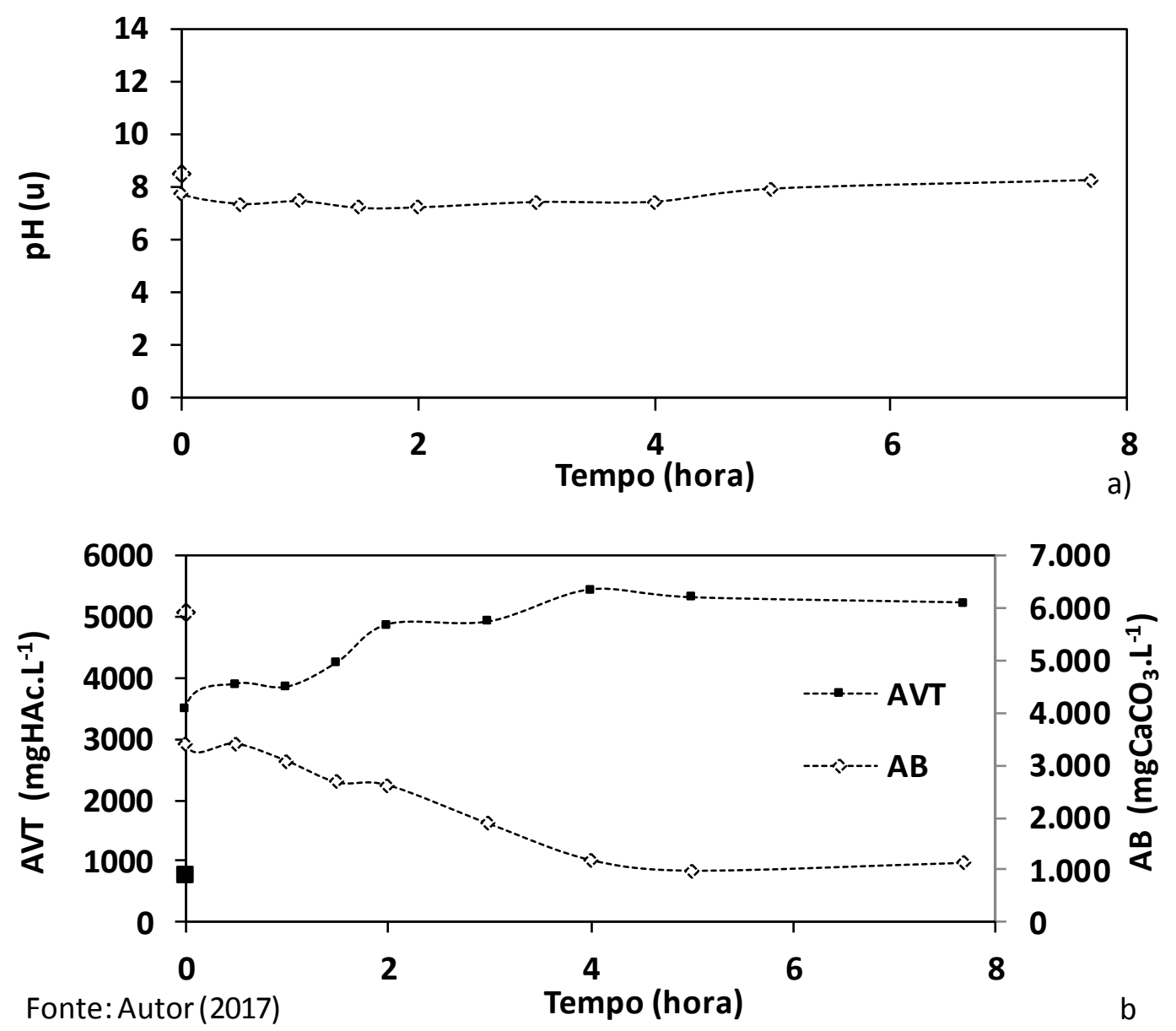

O consumo da matéria orgânica nas formas de DQO e Carboidrato ao longo do ciclo pode ser analisado através da Figura 5.50. Nesta condição, nota-se que a reação de consumo de carboidratos foi mais lenta do que na condição anterior. Isso é notado também na concentração da matéria orgânica na forma de DQO. A transformação dos carboidratos só atingiu seu valor máximo ao final do ciclo, em que sua eficiência foi de $98 \%$. A concentração de DQO do sistema se manteve bastante alta durante todo o ciclo, resultando em $59 \%$ de remoção. O aumento da carga orgânica diminuiu ainda mais a capacidade de tratamento do reator, o que era esperado. 
Figura 5.50 - Perfis de concentração e eficiência de remoção de DQO (a) e carboidratos (b) na condição X
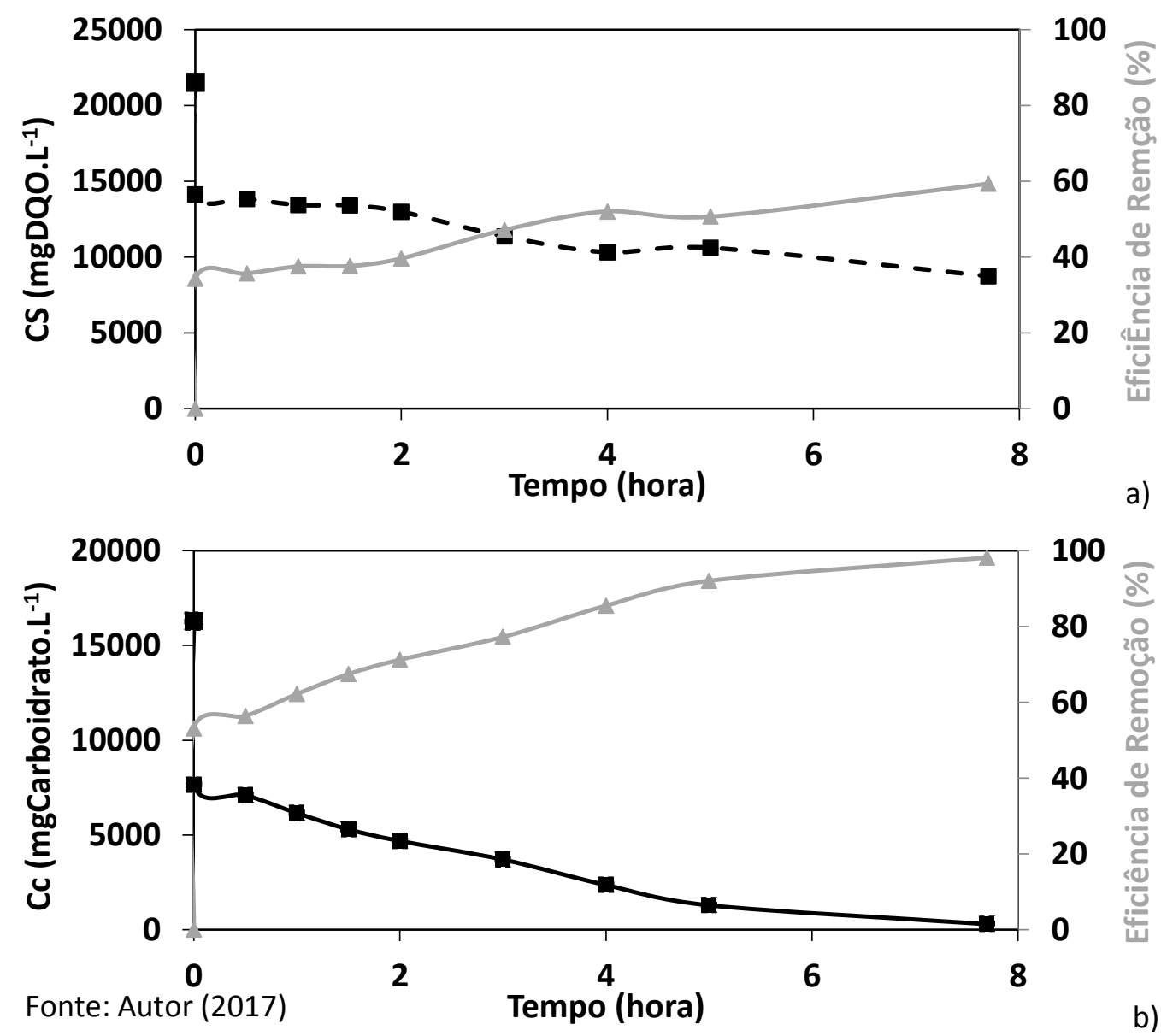

A variação da produção e consumo dos compostos metabólicos intermediários ao longo do ciclo pode ser observada pela Figura 5.51. O maior valor de ácido propiônico nesta condição foi de 602,64 mg. $\mathrm{L}^{-1}$, num pico que se deu após 2 horas de ciclo, o consumo deste ácido se manteve lento até o final do ciclo, resultando em concentração de 549,6 mg. $\mathrm{L}^{-1}$ no efluente, $91 \%$ do valor de pico. A concentração remanescente de ácido acético representou $62 \%$ do valor do pico. 
Figura 5.51 - Perfil das concentrações dos compostos intermediários ao longo do ciclo na condição $\mathrm{X}$

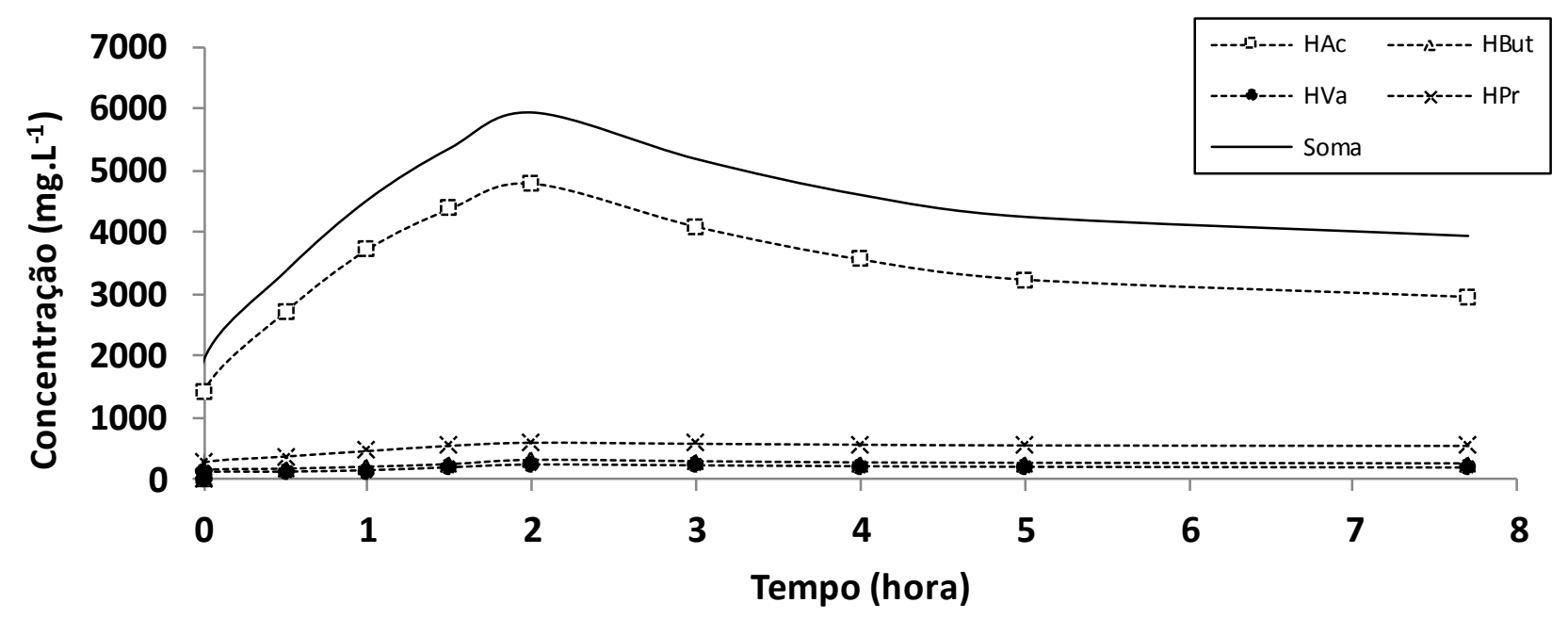

Fonte: Autor (2017)

A produção volumétrica de metano $\left(\mathrm{CH}_{4}\right)$ e dióxido de carbono $\left(\mathrm{CO}_{2}\right)$ ao longo do ciclo pode ser observada através da Figura 5.52. Nota-se que a produção volumétrica de metano foi predominante por todo o ciclo. Também se verifica a evolução das concentrações de metano e dióxido de carbono presente no biogás e a vazão molar de metano ao longo do ciclo além do volume total de biogás gerado durante o período. Durante os primeiros 30 minutos de ciclo o biogás gerado apresentava pequena diferença entre as concentrações de metano $\left(5,42 \mathrm{mmol} . \mathrm{L}^{-1}\right)$ e dióxido de carbono $\left(3,91 \mathrm{mmol} \cdot \mathrm{L}^{-1}\right)$. A produção de metano é maior do que a de dióxido de carbono durante todo o período, resultando numa concentração final de $68 \%$ dos 7157 mL-CNTP.ciclo ${ }^{-1}$ de biogás gerados durante o ciclo, demonstrando piora em relação à última condição e o pior cenário do projeto. 
Figura 5.52 - Perfis de volume nas CNTP de metano e $\mathrm{CO}_{2}$ (a), concentração dos gases e vazão molar (b) e volume e concentração ao longo do ciclo (c) na condição X
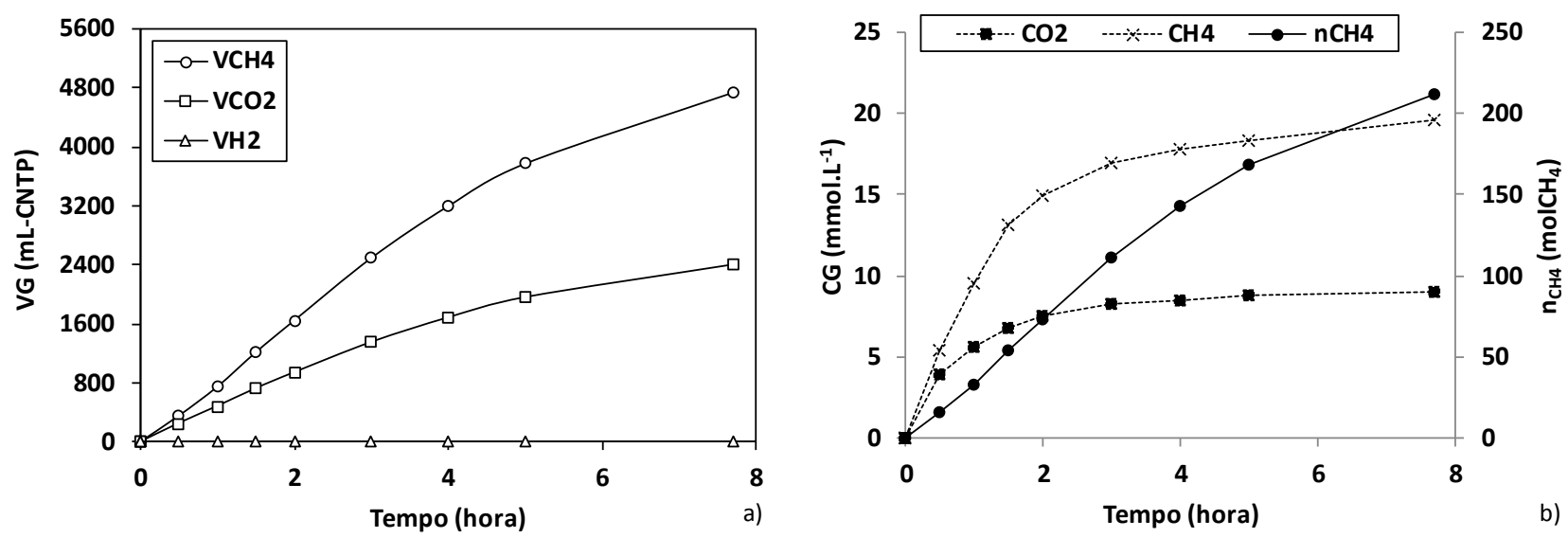

Produção e Composição do Biogás

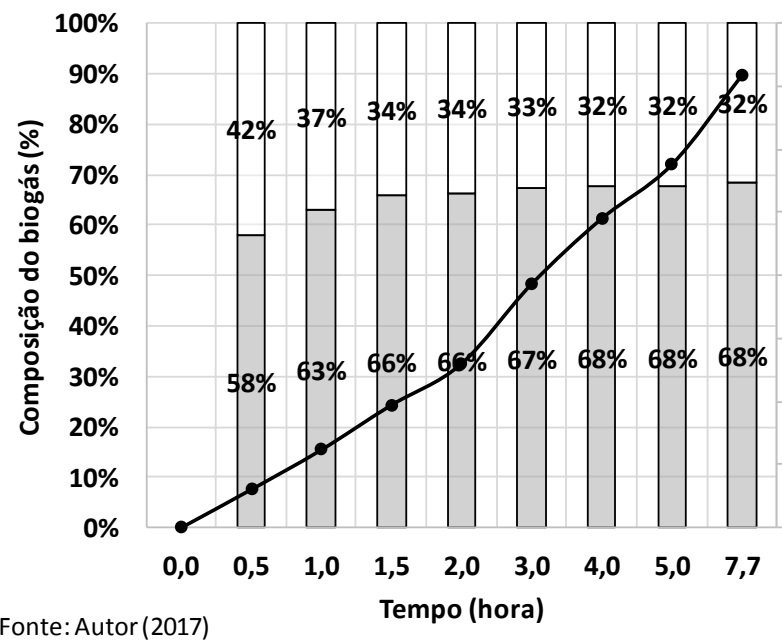

8000,0

7000,0

$6000,0 \widehat{\overline{0}}$

$5000,0 \stackrel{\vec{\varepsilon}}{\vec{\varepsilon}}$

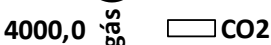

$3000,0 \stackrel{\circ}{\frac{0}{0}} \square \mathrm{CH} 4$

$2000,0 \frac{\mathrm{E}}{\frac{\mathrm{J}}{\mathrm{O}}} \rightarrow$-Vbiogás

1000,0

0,0

Fonte: Autor (2017)

Tempo (hora)

c)

A maior carga orgânica aplicada nesta condição faz com que o desempenho do reator fosse ruim num ciclo de 5 horas, havendo a necessidade de maior tempo para assimilação da matéria orgânica por parte dos microrganismos. Os resultados obtidos num ciclo de 5 horas, indicam que haveria remoção de $51 \%$ de matéria orgânica na forma de DQO e $92 \%$ de carboidratos, ambos na forma filtrada. Haveria consumo de $2 \%$ da concentração de pico dos ácidos voláteis produzidos durante este tempo de ciclo. A produção de biogás seria de 5746,0 mL-ciclo, contendo $68 \%$ de metano. 
5.2.10.3 Ajuste do modelo cinético

Os parâmetros cinéticos aparentes foram calculados (Tabela 5.20) e indicam maior produção de ácido acético através do substrato $\left(\mathrm{k}_{1 \mathrm{HAc}}\right)$. A maior geração de ácido acético é devido à conversão do ácido proprônico $\left(\mathrm{K}_{6 \mathrm{HAC}}\right)$. A produção de metano foi maior na rota metanogênica hidrogenotrófica $\left(\mathrm{K}_{11 \mathrm{M}}\right)$. Portanto, o modelo cinético foi ajustado de modo adequado pelos dados experimentais (Figura 5.53).

Tabela 5.20 - Parâmetros cinéticos da rota metabólica ao longo do ciclo na condição X

\begin{tabular}{ccc}
\hline Condição & Parâmetro & Condição X \\
\hline & $\mathrm{k}_{1 \mathrm{~S}}\left(\mathrm{~h}^{-1}\right)$ & 0,28 \\
& $\mathrm{k}_{1 \mathrm{HAc}}\left(\mathrm{h}^{-1}\right)$ & 0,34 \\
& $\mathrm{k}_{1 \mathrm{H}}\left(\mathrm{h}^{-1}\right)$ & 0,00 \\
& $\mathrm{k}_{2 \mathrm{HPr}}\left(\mathrm{h}^{-1}\right)$ & 0,33 \\
Hidrólise e & $\mathrm{k}_{2 \mathrm{H}}\left(\mathrm{h}^{-1}\right)$ & 0,00 \\
Acidogênese & $\mathrm{k}_{3 \mathrm{HBu}}\left(\mathrm{h}^{-1}\right)$ & 0,00 \\
& $\mathrm{k}_{3 \mathrm{H}}\left(\mathrm{h}^{-1}\right)$ & 0,00 \\
& $\mathrm{k}_{4 \mathrm{HVa}}\left(\mathrm{h}^{-1}\right)$ & 0,01 \\
& $\mathrm{k}_{4 \mathrm{H}}\left(\mathrm{h}^{-1}\right)$ & 0,00 \\
& $\mathrm{k}_{5 \mathrm{ETOH}}\left(\mathrm{h}^{-1}\right)$ & 0,00 \\
\hline & $\mathrm{k}_{6 \mathrm{HPr}}\left(\mathrm{h}^{-1}\right)$ & 1,45 \\
& $\mathrm{k}_{6 \mathrm{HAc}}\left(\mathrm{h}^{-1}\right)$ & 17,77 \\
& $\mathrm{k}_{6 \mathrm{H}}\left(\mathrm{h}^{-1}\right)$ & 0,00 \\
& $\mathrm{k}_{7 \mathrm{HPr}}\left(\mathrm{h}^{-1}\right)$ & 1,52 \\
& $\mathrm{k}_{7 \mathrm{HBu}}\left(\mathrm{h}^{-1}\right)$ & 0,00 \\
& $\mathrm{k}_{7 \mathrm{H}}\left(\mathrm{h}^{-1}\right)$ & 0,00 \\
& $\mathrm{k}_{8 \mathrm{HBu}}\left(\mathrm{h}^{-1}\right)$ & 0,17 \\
& $\mathrm{k}_{8 \mathrm{HVa}}\left(\mathrm{h}^{-1}\right)$ & 0,00 \\
& $\mathrm{k}_{8 \mathrm{H}}\left(\mathrm{h}^{-1}\right)$ & 0,00 \\
& $\mathrm{k}_{9 \mathrm{HAc}}\left(\mathrm{h}^{-1}\right)$ & 0,00 \\
\hline & $\mathrm{k}_{10 \mathrm{HAc}}\left(\mathrm{h}^{-1}\right)$ & 2,07 \\
& $\mathrm{k}_{10 \mathrm{H}}\left(\mathrm{h}^{-1}\right)$ & 0,38 \\
& $\mathrm{k}_{11 \mathrm{H}}\left(\mathrm{h}^{-1}\right)$ & 0,08 \\
& $\mathrm{k}_{11 \mathrm{M}}\left(\mathrm{h}^{-1}\right)$ & 109,85 \\
\hline & &
\end{tabular}


Figura 5.53- Dados experimentais (marcadores) e modelo (linha) do metano (a), substrato (b) e ácidos intermediários (c) na condição $\mathrm{X}$
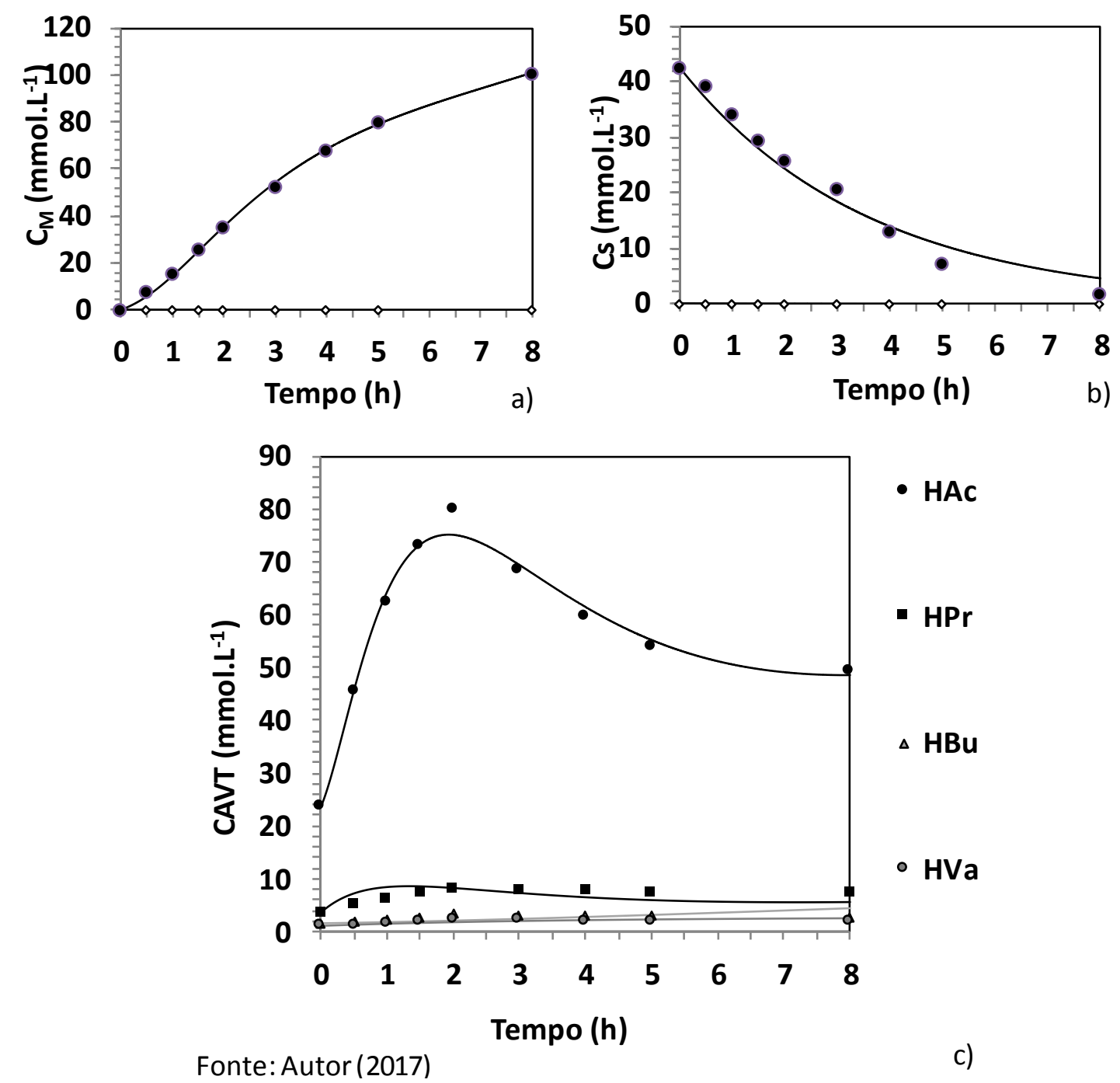

\subsection{Etapa III - Estratégia de alimentação}

5.3.1 Condição XI - 20.000 mg DQO L L ${ }^{-1} ; 100 \%$ Soro; $50 \%$ de bicarbonato; $55^{\circ} \mathrm{C}$; Batelada Alimentada

Nesta condição de operação, o valor nominal de DQO alimentado ao reator foi de $20000 \mathrm{mg}$ $\mathrm{L}^{-1}$ com carga orgânica aplicada teórica de 24,00 g DQO L $\mathrm{g}^{-1} \mathrm{dia}^{-1}$.

VERSÃO CORRIGIDA 


\subsubsection{Monitoramento}

O reator foi operado por 18 dias, em que a concentração média da matéria orgânica afluente

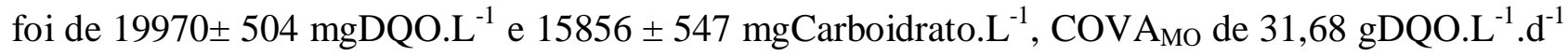
e COVA $\mathrm{C}$ de 25,15 gCarboidrato. $\mathrm{L}^{-1} \cdot \mathrm{d}^{-1}$. A quantidade de biomassa contida no reator foi de 93,3 g. Nesta condição, o reator operou com $50 \%$ de bicarbonato.

Os valores referentes ao monitoramento e aos indicadores desempenho encontram-se apresentados na Tabela 5.21 a seguir. A eficiência de remoção de matéria orgânica na forma de

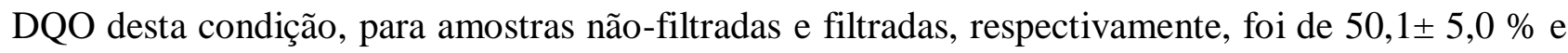
$57,2 \pm 6,4 \%$. Para a matéria orgânica na forma de Carboidratos (lactose) a remoção foi de $98,6 \pm 0,8 \%$ e $99,4 \pm 0,2 \%$, respectivamente para não-filtradas e filtradas. $\mathrm{O} \mathrm{pH}$ afluente foi de $8,48 \pm 0,07$ e o efluente $8,10 \pm 0,19$. A alcalinidade a bicarbonato do afluente e efluente foram $5953 \pm 173 \mathrm{mgCaCO} 3 . \mathrm{L}^{-1}$ e $692 \pm 596 \mathrm{mgCaCO} 3 . \mathrm{L}^{-1}$. A alcalinidade referente aos ácidos voláteis do afluente e efluente foram $707 \pm 59 \mathrm{mgHAc} . \mathrm{L}^{-1}$ e $6032 \pm 582 \mathrm{mgHac} . \mathrm{L}^{-1}$.

A concentração de sólidos suspensos voláteis (SSV) no efluente indica que houve pouca perda de biomassa no reator. A análise dos sólidos totais indica que a produção de polímero foi maior nessa etapa do que nas etapas anteriores. A foto apresentada na Figura 5.54 a seguir mostra a grande quantidade de polímeros no interior do reator. 
Figura 5.54 - Comparação entre o início de operação (Etapa I) e fim de operação (condição XI Etapa 3)

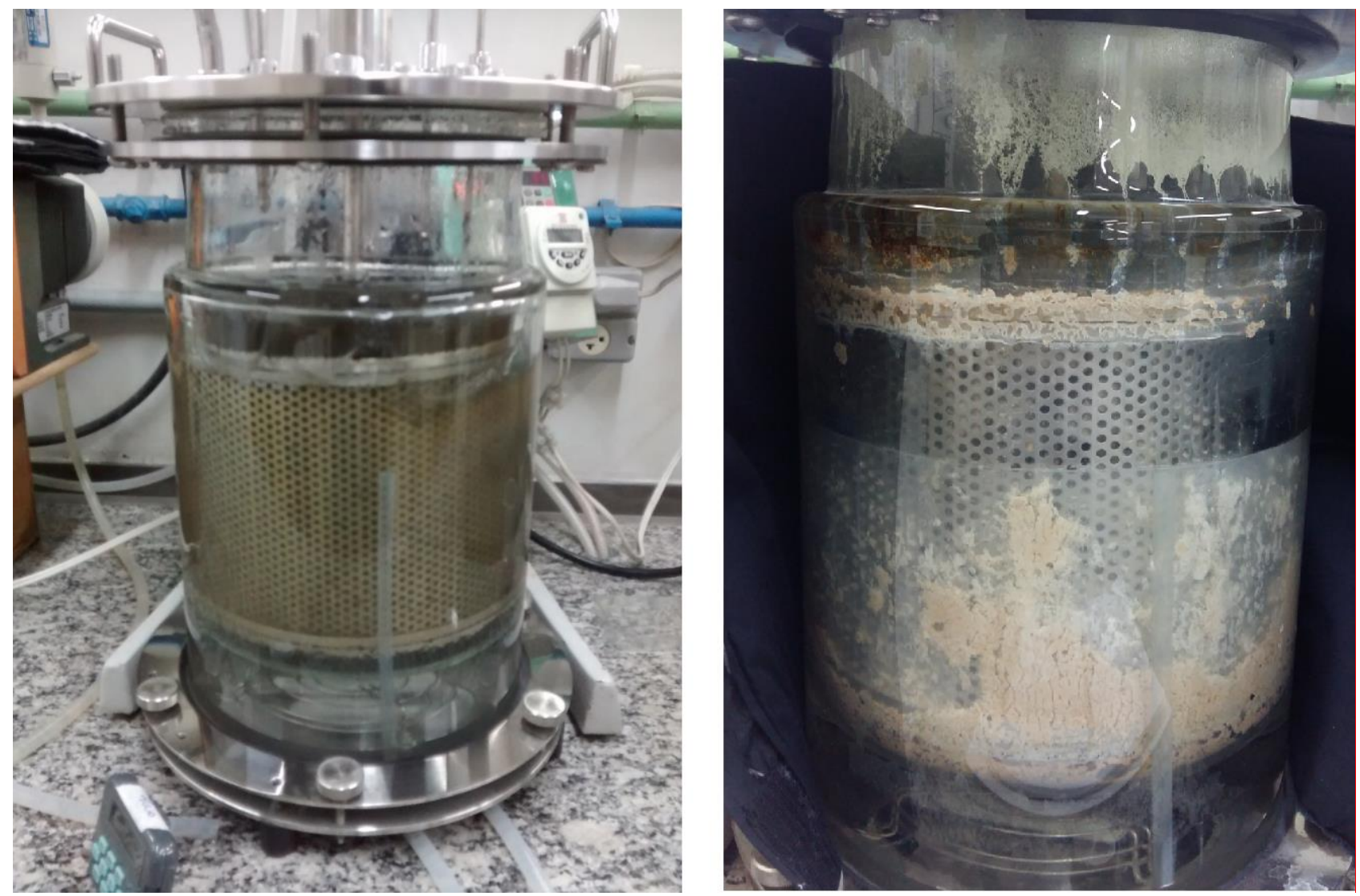

Fonte: Autor (2017)

O rendimento de metano gerado por matéria orgânica consumida foi de 8,60 $\mathrm{mmolCH}_{4} \cdot \mathrm{gDQO}^{-1}$ e $10,84 \mathrm{mmolCH}_{4} \cdot \mathrm{gCarboidrato}^{-1}$. A produção de biogás foi de $6216 \pm 554 \mathrm{~mL}-$ CNTP.ciclo ${ }^{-1}$, sendo a fração molar de metano equivalente a $62,58 \pm 0,29 \%$ e a produtividade molar de metano de $272,5 \mathrm{molCH}_{4} \cdot \mathrm{m}^{-3} \cdot \mathrm{d}^{-1}$.

Nesta condição, verificou-se que a queda no desempenho se manteve. Houve queda na eficiência de remoção de matéria orgânica, assim como na produção de biogás e de sua qualidade, resultando em menor concentração de metano e em menor volume. Os resultados indicam grande produção de ácidos voláteis, resultando em maior concentração no efluente do que no afluente. 
Tabela 5.21 - Resumo dos valores médios obtidos no monitoramento do reator operado em bateladas sequenciais com concentração afluente de $20000 \mathrm{mgDQO} . \mathrm{L}^{-1}$ na condição XI

\begin{tabular}{|c|c|c|c|c|c|c|c|c|c|c|c|c|c|}
\hline \multicolumn{2}{|r|}{ Parâmetro } & \multicolumn{6}{|c|}{ Afluente } & \multicolumn{6}{|c|}{ Efluente } \\
\hline $\mathrm{C}_{\mathrm{ST}}$ & $\left(\mathrm{mgDQO} . \mathrm{L}^{-1}\right)$ & 19970 & \pm & 504 & ( & 11 & ) & 9956 & \pm & 967 & ( & 11 & ) \\
\hline $\mathrm{C}_{\mathrm{SF}}$ & $\left(\operatorname{mgDQO} \cdot \mathrm{L}^{-1}\right)$ & - & & - & & & & 8553 & \pm & 1258 & ( & 11 & ) \\
\hline$\varepsilon_{\mathrm{ST}}$ & $(\%)$ & - & & - & & & & $50,1 \%$ & \pm & $5,0 \%$ & ( & 11 & ) \\
\hline$\varepsilon_{\mathrm{SF}}$ & $(\%)$ & - & & - & & & & $57,2 \%$ & \pm & $6,4 \%$ & ( & 11 & ) \\
\hline $\mathrm{C}_{\mathrm{CT}}$ & (mgCarboidrato.L $\mathrm{L}^{-1}$ ) & 15856 & \pm & 547 & ( & 11 & ) & 226 & \pm & 119 & ( & 11 & ) \\
\hline $\mathrm{C}_{\mathrm{CF}}$ & (mgCarboidrato. $\mathrm{L}^{-1}$ ) & - & & - & & & & 100 & \pm & 26 & ( & 11 & ) \\
\hline$\varepsilon_{\mathrm{CT}}$ & $(\%)$ & $\longrightarrow$ & & $\longrightarrow$ & & & & $98,6 \%$ & \pm & $0,8 \%$ & & & \\
\hline$\varepsilon_{\mathrm{CF}}$ & $(\%)$ & - & & - & & & & $99,4 \%$ & \pm & $0,2 \%$ & & & \\
\hline $\mathrm{pH}$ & $(\mathrm{u})$ & 8,48 & \pm & 0,07 & ( & 11 & ) & 8,10 & \pm & 0,19 & ( & 11 & ) \\
\hline AVT & $\left(\mathrm{mgHAc} . \mathrm{L}^{-1}\right)$ & 707 & \pm & 59 & ( & 11 & ) & 6032 & \pm & 582 & ( & 11 & ) \\
\hline $\mathrm{AT}$ & $\left(\mathrm{mgCaCO}_{3} \cdot \mathrm{L}^{-1}\right)$ & 5953 & \pm & 179 & ( & 11 & ) & 4970 & \pm & 323 & ( & 11 & ) \\
\hline AP & $\left(\mathrm{mgCaCO}_{3} \cdot \mathrm{L}^{-1}\right)$ & 958 & \pm & 161 & ( & 11 & ) & 1972 & \pm & 338 & ( & 11 & ) \\
\hline AI & $\left(\mathrm{mgCaCO}_{3} \cdot \mathrm{L}^{-1}\right)$ & 5497 & \pm & 193 & ( & 11 & ) & 2998 & \pm & 253 & ( & 11 & ) \\
\hline $\mathrm{AB}$ & $\left(\mathrm{mgCaCO}_{3} \cdot \mathrm{L}^{-1}\right)$ & 5953 & \pm & 173 & ( & 11 & ) & 692 & \pm & 596 & ( & 11 & ) \\
\hline ST & $\left(\mathrm{mg} \cdot \mathrm{L}^{-1}\right)$ & 19543 & \pm & 1360 & ( & 3 & ) & 13530 & \pm & 441 & ( & 3 & ) \\
\hline SVT & $\left(\mathrm{mg} \cdot \mathrm{L}^{-1}\right)$ & 10498 & \pm & 1188 & ( & 3 & ) & 6179 & \pm & 310 & ( & 3 & ) \\
\hline SST & $\left(\mathrm{mg} \cdot \mathrm{L}^{-1}\right)$ & 431 & \pm & 40 & ( & 3 & ) & 629 & \pm & 104 & ( & 3 & ) \\
\hline SSV & $\left(\mathrm{mg} \cdot \mathrm{L}^{-1}\right)$ & 347 & \pm & 39 & ( & 3 & ) & 577 & \pm & 108 & ( & 3 & ) \\
\hline SDF & $\left(\mathrm{mg} \cdot \mathrm{L}^{-1}\right)$ & 8267 & & - & & & & 6145 & & - & & & \\
\hline $\mathrm{M}_{\mathrm{SVT}}$ & (g) & 93,3 & & - & & & & - & & - & & & \\
\hline $\mathrm{C}_{\mathrm{X}}$ & $\left(\mathrm{gSVT} . \mathrm{L}^{-1}\right)$ & 48,8 & & - & & & & - & & - & & & \\
\hline $\mathrm{C}_{\mathrm{X}}^{\prime}$ & (gSVT.gsuporte ${ }^{-1}$ ) & 2,5 & & - & & & & - & & $\longrightarrow$ & & & \\
\hline $\mathrm{V}_{\mathrm{G}}$ & $\left(\mathrm{mL}-\mathrm{CNTP} . \mathrm{Ciclo}^{-1}\right)$ & - & & - & & & & 6216 & \pm & 554 & ( & 8 & ) \\
\hline $\mathrm{V}_{\mathrm{CH} 4}$ & $\left(\mathrm{~mL}-\mathrm{CNTPCH}{ }_{4} \cdot \mathrm{Ciclo}^{-1}\right)$ & - & & - & & & & 3889 & & - & & & \\
\hline $\mathrm{COVA}_{\mathrm{S}}$ & $\left(\mathrm{gDQO} \cdot \mathrm{L}^{-1} \cdot \mathrm{d}^{-1}\right)$ & 31,68 & & - & & & & - & & - & & & \\
\hline $\mathrm{COVR}_{\mathrm{S}}$ & $\left(\mathrm{gDQO} \cdot \mathrm{L}^{-1} \cdot \mathrm{d}^{-1}\right)$ & - & & - & & & & 15,89 & & - & & & \\
\hline $\mathrm{COEA}_{\mathrm{S}}$ & $\left(\mathrm{gDQO} \cdot \mathrm{gSVT}^{-1} \cdot \mathrm{d}^{-1}\right)$ & 0,65 & & - & & & & - & & - & & & \\
\hline $\mathrm{COER}_{\mathrm{S}}$ & $\left(\mathrm{gDQO} . \mathrm{gSVT}^{-1} \cdot \mathrm{d}^{-1}\right)$ & - & & - & & & & 0,10 & & - & & & \\
\hline $\mathrm{COVA}_{c}$ & (gCarboidrato. $\mathrm{L}^{-1} \cdot \mathrm{d}^{-1}$ ) & 25,15 & & 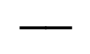 & & & & & & - & & & \\
\hline $\mathrm{COVR}_{\mathrm{c}}$ & (gCarboidrato. $\mathrm{L}^{-1} \cdot \mathrm{d}^{-1}$ ) & & & - & & & & 24,80 & & - & & & \\
\hline $\mathrm{COEA}_{c}$ & (gCarboidrato.gSVT ${ }^{-1} \cdot \mathrm{d}^{-1}$ ) & 0,51 & & - & & & & & & - & & & \\
\hline $\mathrm{COER}_{c}$ & (gCarboidrato.gSVT ${ }^{-1} \cdot \mathrm{d}^{-1}$ ) & & & & & & & 0,15 & & - & & & \\
\hline $\mathrm{n}_{\mathrm{CH} 4}$ & $\left(\mathrm{molCH}_{4} \cdot \mathrm{d}^{-1}\right)$ & $\longrightarrow$ & & - & & & & 0,5206 & & - & & & \\
\hline $\mathrm{X}_{\mathrm{CH} 4}$ & $(\%)$ & & & & & & & 62,58 & \pm & 0,29 & & & \\
\hline PrM & $\left(\mathrm{molCH}_{4} \cdot \mathrm{m}^{-3} \cdot \mathrm{d}^{-1}\right)$ & - & & - & & & & 272,5 & & - & & & \\
\hline PrME & $\left(\mathrm{molCH}_{4} \cdot \mathrm{kgSVT}^{-1} \cdot \mathrm{d}^{-1}\right)$ & - & & - & & & & 5,58 & & - & & & \\
\hline PrV & $\left(\mathrm{mL}-\mathrm{CNTPCH} \mathrm{H}_{4} \cdot \mathrm{L}^{-1} \cdot \mathrm{d}^{-1}\right)$ & - & & - & & & & 6109 & & - & & & \\
\hline PrVE & $\left(\mathrm{mL}^{-C N T P C H} \mathrm{H}_{4} \cdot \mathrm{gSVT}^{-1} \cdot \mathrm{d}^{-1}\right)$ & - & & - & & & & 125,06 & & - & & & \\
\hline $\mathrm{RMCA}_{\mathbf{S}}$ & $\left(\mathrm{mmolCH}_{4} \cdot \mathrm{gDQO}^{-1}\right)$ & 8,60 & & 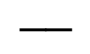 & & & & - & & - & & & \\
\hline $\mathrm{RMCR}_{\mathbf{S}}$ & $\left(\mathrm{mmolCH}_{4} \cdot \mathrm{gDQO}^{-1}\right)$ & - & & 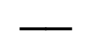 & & & & 17,16 & & - & & & \\
\hline $\mathrm{RMCA}_{\mathrm{c}}$ & $\left(\mathrm{mmolCH}_{4} \cdot\right.$ gCarboidrato $\left.^{-1}\right)$ & 10,84 & & 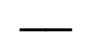 & & & & - & & - & & & \\
\hline $\mathrm{RMCR}_{\mathrm{C}}$ & $\left(\mathrm{mmolCH}_{4} \cdot\right.$ gCarboidrato $\left.^{-1}\right)$ & - & & - & & & & 10,99 & & - & & & \\
\hline $\mathrm{V}_{\mathrm{A}}$ & $\left(\mathrm{mL} . \mathrm{Ciclo}^{-1}\right)$ & 1010 & \pm & 82 & ( & 11 & ) & - & & $\longrightarrow$ & & & \\
\hline $\mathrm{V}_{\mathrm{RES}}$ & $(\mathrm{mL})$ & 900 & & - & & & & - & & - & & & \\
\hline
\end{tabular}

*Os valores entre parêntesis representam o número de amostras consideradas para o cálculo da média Fonte: Autor (2017) 


\subsubsection{Perfil ao longo do ciclo}

Durante o perfil, a concentração de matéria orgânica afluente na forma de DQO foi de 20737 mgDQO.L ${ }^{-1}$ e de 15498 mgCarboidrato.L ${ }^{-1}$, respectivamente. Nesta etapa, não houve efeito da diluição no início do ciclo devido ao método de operação em batelada alimentada.

Observa-se na Figura 5.55 a variação do $\mathrm{pH}$ ao longo do ciclo, com valor de 8,61 no afluente, mínimo de 7,34 e 8,46 no efluente. Também é possível acompanhar a variação da alcalinidade a bicarbonato e ácidos voláteis totais durante o ciclo. Os ácidos voláteis totais têm o pico de produção (7273 mgHAc. $\left.\mathrm{L}^{-1}\right)$ no início do ciclo. O consumo dos ácidos foi moderado, resultando em $4849 \mathrm{mgHAc} . \mathrm{L}^{-1}$ no efluente do sistema. Este resultado indica que a capacidade de formação de metano esteve bastante abaixo da geração de ácidos, o que se vê também pela incapacidade de reestabelecer a alcalinidade a bicarbonato do reator. A alcalinidade a bicarbonato não chegou a valores críticos devido à natureza do modo de operação. Como o volume de afluente é introduzido aos poucos no reator, há pouco consumo instantâneo do bicarbonato, o menor valor de alcalinidade a bicarbonato no reator foi de $1974 \mathrm{mgCaCO}_{3} \cdot \mathrm{L}^{-1}$. 
Figura 5.55 - Perfis de $\mathrm{pH}$ (a), alcalinidade a bicarbonato e a ácidos voláteis totais (b) na condição $\mathrm{X}$
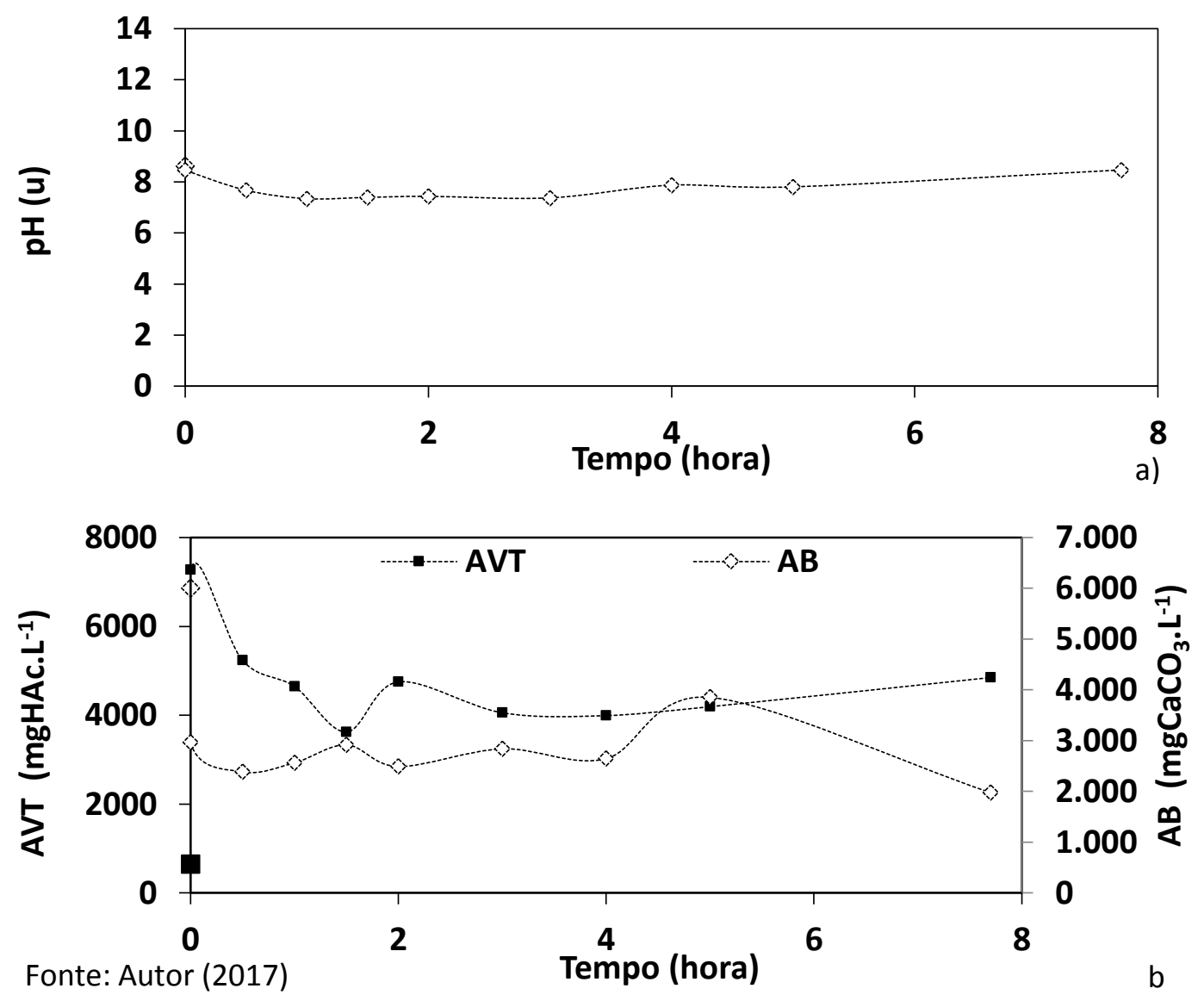

O consumo da matéria orgânica nas formas de DQO e Carboidrato ao longo do ciclo pode ser analisado através da Figura 5.56. Devido ao modo de operação em bateladas sequenciais, o comportamento das curvas de DQO e Carboidratos é completamente diferente das outras condições. Nesta etapa, há um acúmulo de matéria orgânica até metade do ciclo, quando cessa a alimentação do reator. A concentração de DQO do sistema se manteve alta durante todo o ciclo, resultando em 55\% de remoção durante o perfil. A eficiência de remoção de carboidratos se manteve em 99\%. 
Figura 5.56 - Perfis de concentração e eficiência de remoção de DQO (a) e carboidratos (b) na condição XI
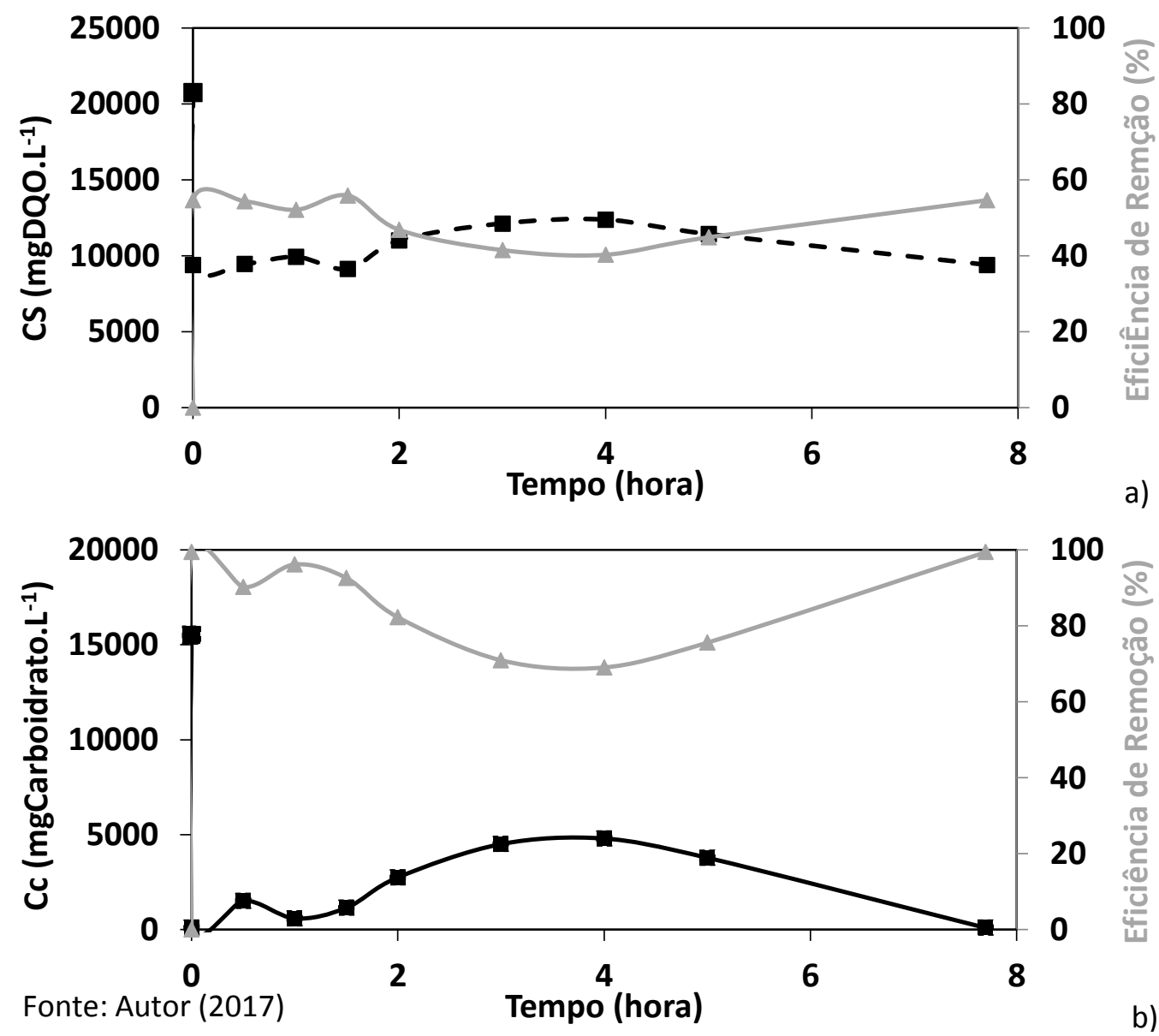

A variação da produção e consumo dos compostos metabólicos intermediários ao longo do ciclo pode ser observada pela Figura 5.57. O maior valor de ácido propiônico nesta condição foi de 442,9 mg. $\mathrm{L}^{-1}$, num pico que se deu após 2 horas de ciclo, o consumo deste ácido se manteve lento até o final do ciclo, resultando em concentração de $384,7 \mathrm{mg} . \mathrm{L}^{-1}$ no efluente, $87 \%$ do valor de pico. As concentrações deste ácido se mantiveram em valores menores do que na condição anterior. A concentração remanescente de ácido acético representou $61 \%$ do valor do pico. 
Figura 5.57 - Perfil das concentrações dos compostos intermediários ao longo do ciclo na condição XI

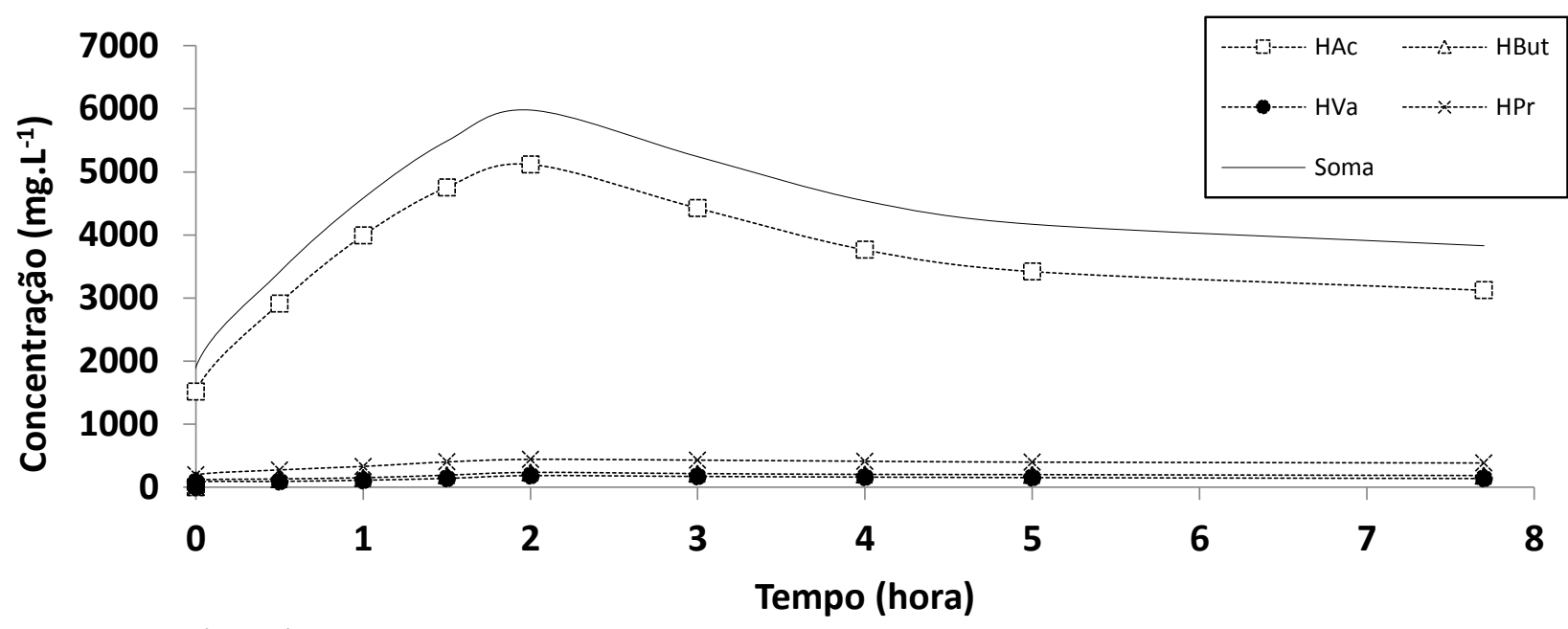

Fonte: Autor (2017)

A produção volumétrica de metano $\left(\mathrm{CH}_{4}\right)$ e dióxido de carbono $\left(\mathrm{CO}_{2}\right)$ ao longo do ciclo pode ser observada através da Figura 5.58.Nota-se que a produção volumétrica de metano foi predominante por todo o ciclo. Também se verifica a evolução das concentrações de metano e dióxido de carbono presente no biogás e a vazão molar de metano ao longo do ciclo além do volume total de biogás gerado durante o período. Durante os primeiros 30 minutos de ciclo o biogás gerado apresentava pequena diferença entre as concentrações de metano $\left(4,97 \mathrm{mmol} . \mathrm{L}^{-1}\right)$ e dióxido de carbono $\left(4,11 \mathrm{mmol} \cdot \mathrm{L}^{-1}\right)$. A produção de metano é maior do que a de dióxido de carbono durante todo o período, resultando numa concentração final de $63 \%$ dos 6216 mL-CNTP.ciclo-1 ${ }^{-1}$ de biogás gerados durante o ciclo, demonstrando piora da composição do biogás em relação à última condição. 
Figura 5.58 - Perfis de volume nas CNTP de metano e $\mathrm{CO}_{2}$ (a), concentração dos gases e vazão molar (b) e volume e concentração ao longo do ciclo (c) na condição XI
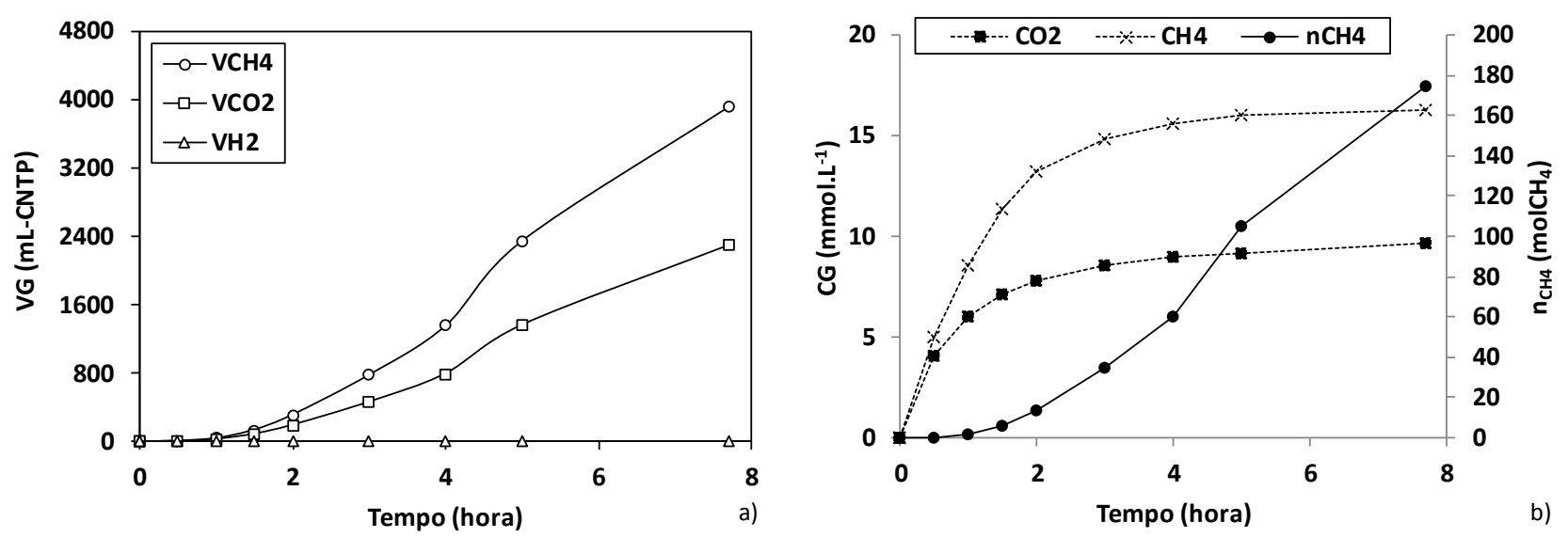

Produção e Composição do Biogás
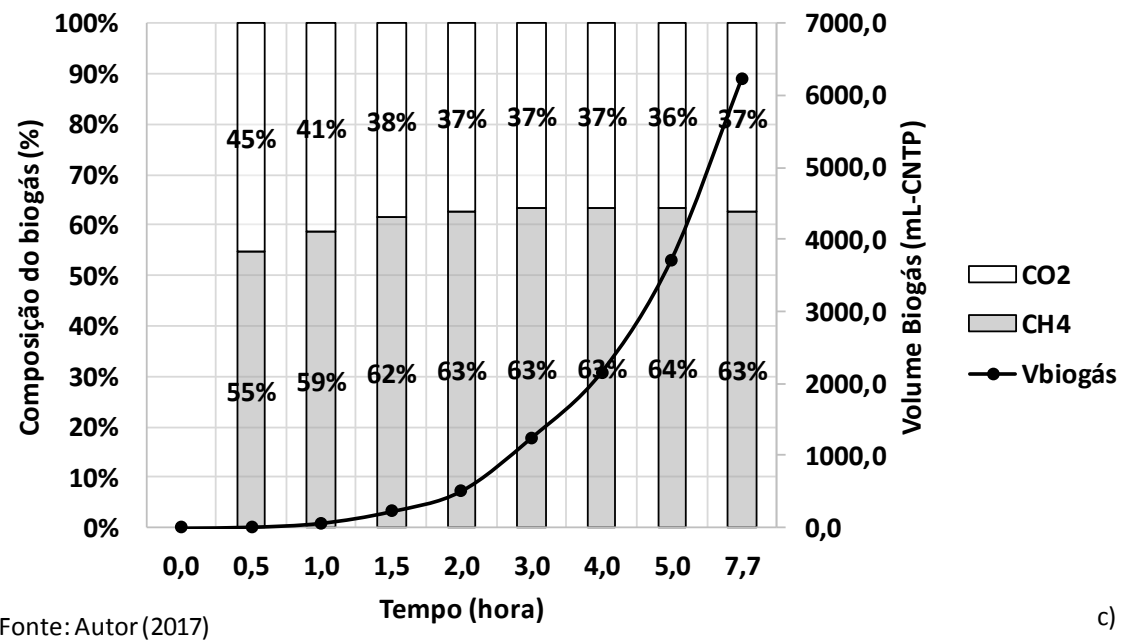

c)

\subsubsection{Ajuste do modelo cinético}

Os parâmetros cinéticos aparentes foram calculados (Tabela 5.22) e indicam maior produção de ácido acético através do substrato $\left(\mathrm{k}_{1 \mathrm{HAc}}\right)$. A maior geração de ácido acético é devido à conversão do ácido proprônico $\left(\mathrm{K}_{6 \mathrm{HAC}}\right)$. A produção de metano foi maior na rota metanogênica hidrogenotrófica $\left(\mathrm{K}_{11 \mathrm{M}}\right)$. $\mathrm{O}$ modelo cinético foi ajustado de modo adequado pelos dados experimentais (Figura 5.59). 
Tabela 5.22 - Parâmetros cinéticos da rota metabólica ao longo do ciclo na condição XI

\begin{tabular}{ccc}
\hline Condição & Parâmetro & Condição XI \\
\hline & $\mathrm{k}_{1 \mathrm{~S}}\left(\mathrm{~h}^{-1}\right)$ & 0,17 \\
& $\mathrm{k}_{1 \mathrm{HAc}}\left(\mathrm{h}^{-1}\right)$ & 0,20 \\
& $\mathrm{k}_{1 \mathrm{H}}\left(\mathrm{h}^{-1}\right)$ & 0,00 \\
& $\mathrm{k}_{2 \mathrm{HPr}}\left(\mathrm{h}^{-1}\right)$ & 0,00 \\
Hidrólise e & $\mathrm{k}_{2 \mathrm{H}}\left(\mathrm{h}^{-1}\right)$ & 0,00 \\
Acidogênese & $\mathrm{k}_{3 \mathrm{HBu}}\left(\mathrm{h}^{-1}\right)$ & 0,00 \\
& $\mathrm{k}_{3 \mathrm{H}}\left(\mathrm{h}^{-1}\right)$ & 0,00 \\
& $\mathrm{k}_{4 \mathrm{HVa}}\left(\mathrm{h}^{-1}\right)$ & 0,01 \\
& $\mathrm{k}_{4 \mathrm{H}}\left(\mathrm{h}^{-1}\right)$ & 0,00 \\
& $\mathrm{k}_{5 \mathrm{ETOH}}\left(\mathrm{h}^{-1}\right)$ & 0,00 \\
\hline & $\mathrm{k}_{6 \mathrm{HPr}}\left(\mathrm{h}^{-1}\right)$ & 1,28 \\
& $\mathrm{k}_{6 \mathrm{HAc}}\left(\mathrm{h}^{-1}\right)$ & 42,65 \\
& $\mathrm{k}_{6 \mathrm{H}}\left(\mathrm{h}^{-1}\right)$ & 0,00 \\
& $\mathrm{k}_{7 \mathrm{HPr}}\left(\mathrm{h}^{-1}\right)$ & 4,26 \\
& $\mathrm{k}_{7 \mathrm{HBu}}\left(\mathrm{h}^{-1}\right)$ & 0,99 \\
& $\mathrm{k}_{7 \mathrm{H}}\left(\mathrm{h}^{-1}\right)$ & 0,00 \\
& $\mathrm{k}_{8 \mathrm{HBu}}\left(\mathrm{h}^{-1}\right)$ & 5,65 \\
& $\mathrm{k}_{8 \mathrm{HVa}}\left(\mathrm{h}^{-1}\right)$ & 0,93 \\
& $\mathrm{k}_{8 \mathrm{H}}\left(\mathrm{h}^{-1}\right)$ & 0,00 \\
$\mathrm{k}_{9 \mathrm{HAc}}\left(\mathrm{h}^{-1}\right)$ & 0,00 \\
\hline & $\mathrm{k}_{10 \mathrm{HAc}}\left(\mathrm{h}^{-1}\right)$ & 2,84 \\
& $\mathrm{k}_{10 \mathrm{H}}\left(\mathrm{h}^{-1}\right)$ & 0,11 \\
& $\mathrm{k}_{11 \mathrm{H}}\left(\mathrm{h}^{-1}\right)$ & 0,00 \\
$\mathrm{k}_{11 \mathrm{M}}\left(\mathrm{h}^{-1}\right)$ & 185,87 \\
\hline & &
\end{tabular}


Figura 5.59- Dados experimentais (marcadores) e modelo (linha) do metano (a), substrato (b) e ácidos intermediários (c) na condição XI
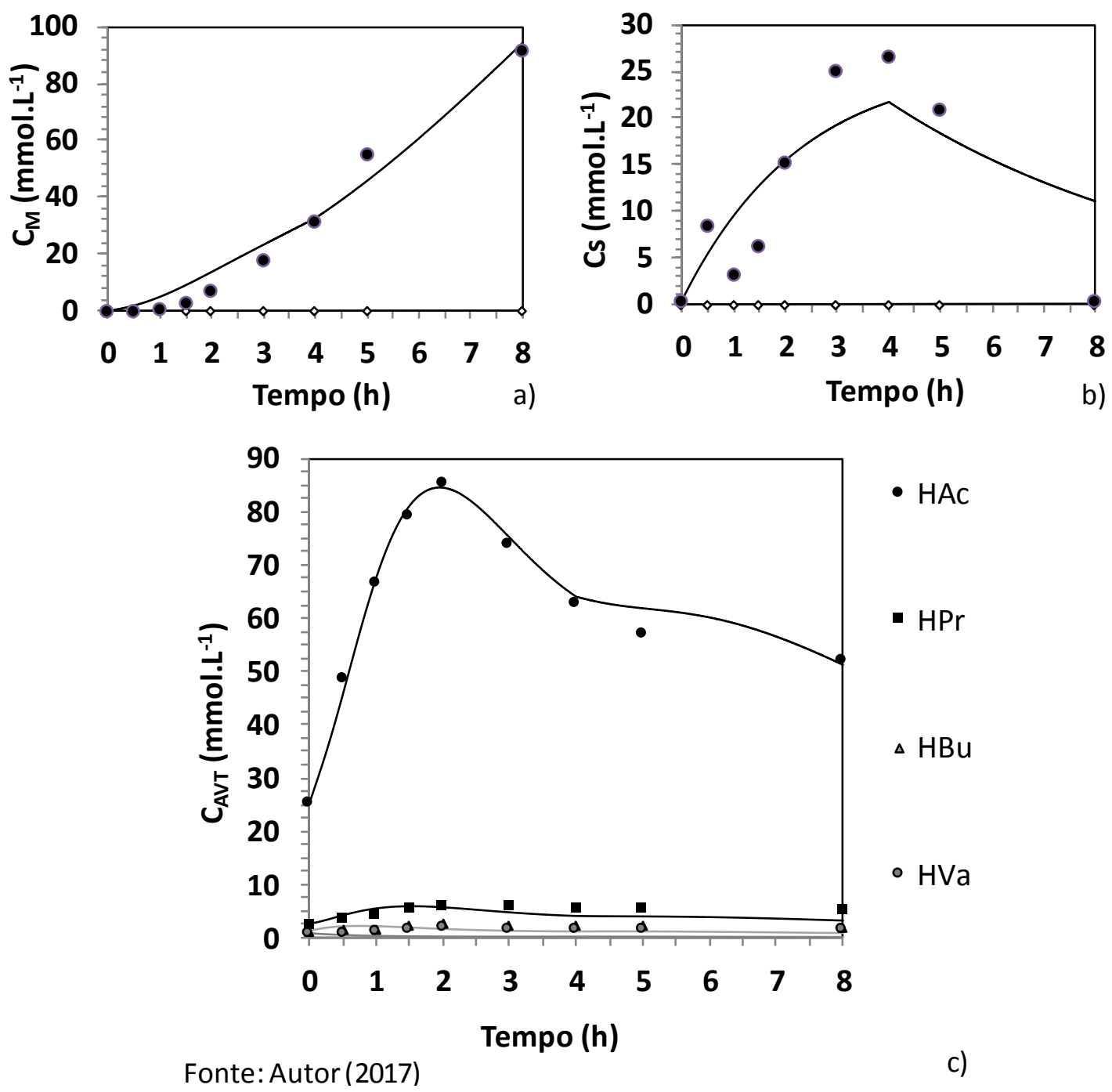

\subsection{Análise comparativa de resultados}

\subsubsection{Etapa de otimização}

Realizou-se a análise comparativa entre as 10 primeiras condições de estudo, visando estudar a influência do aumento da carga orgânica sobre os indicadores de estabilidade, remoção de 
matéria orgânica e produção de biogás. A Tabela 5.23 abaixo apresenta os valores médios dos indicadores de desempenho de cada uma das condições de estudo. 
Tabela 5.23 - Valores médios dos parâmetros e indicadores de desempenho do reator nas diferentes condições de otimização

\begin{tabular}{|c|c|c|c|c|c|c|c|c|c|c|c|}
\hline Parâmetro & Unidade & Condição I & II & III & IV & $\mathrm{V}$ & VI & VII & VIII & IX & $\mathrm{X}$ \\
\hline $\mathrm{C}_{\mathrm{ST} \text { af }}$ & $\left(\mathrm{mgDQO} . \mathrm{L}^{-1}\right)$ & 5101 & 5957 & 7272 & 8531 & 10279 & 12455 & 14808 & 16623 & 18559 & 21261 \\
\hline $\mathrm{C}_{\mathrm{SF}}$ & $\left(\operatorname{mgDQO} . L^{-1}\right)$ & 425 & 330 & 348 & 346 & 470 & 532 & 1317 & 2365 & 5689 & 7938 \\
\hline$\varepsilon_{\mathrm{ST}}$ & $(\%)$ & $88,2 \%$ & $92,1 \%$ & $93,3 \%$ & $93,9 \%$ & $92,8 \%$ & $93,3 \%$ & $89,8 \%$ & $84,3 \%$ & $65,7 \%$ & $58,3 \%$ \\
\hline$\varepsilon_{\mathrm{SF}}$ & $(\%)$ & $91,6 \%$ & $94,4 \%$ & $95,2 \%$ & $95,9 \%$ & $95,4 \%$ & $95,7 \%$ & $91,1 \%$ & $85,7 \%$ & $69,3 \%$ & $62,5 \%$ \\
\hline $\mathrm{C}_{\mathrm{CT} \text { af }}$ & (mgCarboidrato.L $\mathrm{L}^{-1}$ ) & 3934 & 4681 & 5675 & 6443 & 7443 & 10220 & 11595 & 12708 & 15107 & 16538 \\
\hline $\mathrm{C}_{\mathrm{CF}}$ & (mgCarboidrato. $\mathrm{L}^{-1}$ ) & 24 & 21 & 24 & 22 & 33 & 34 & 45 & 50 & 72 & 100 \\
\hline$\varepsilon_{\mathrm{CT}}$ & $(\%)$ & $98,8 \%$ & $99,3 \%$ & $99,3 \%$ & $99,3 \%$ & $99,1 \%$ & $99,4 \%$ & $99,4 \%$ & $99,3 \%$ & $99,1 \%$ & $98,9 \%$ \\
\hline$\varepsilon_{\mathrm{CF}}$ & $(\%)$ & $99,4 \%$ & $99,6 \%$ & $99,6 \%$ & $99,7 \%$ & $99,6 \%$ & $99,7 \%$ & $99,6 \%$ & $99,6 \%$ & $99,5 \%$ & $99,4 \%$ \\
\hline $\mathrm{pH}_{\mathrm{ef}}$ & (u) & 8,08 & 8,24 & 8,29 & 8,24 & 8,29 & 8,26 & 8,15 & 8,11 & 7,72 & 7,85 \\
\hline $\mathrm{AVT}_{\mathrm{ef}}$ & $\left(\mathrm{mgHAc} . \mathrm{L}^{-1}\right)$ & 97 & 87 & 55 & 47 & 110 & 78 & 632 & 1585 & 4146 & 5527 \\
\hline $\mathrm{AT}_{\mathrm{ef}}$ & $\left(\mathrm{mgCaCO}{ }_{3} \cdot \mathrm{L}^{-1}\right)$ & 1864 & 2232 & 1891 & 1786 & 1959 & 2281 & 4776 & 5480 & 4804 & 5322 \\
\hline $\mathrm{AB}_{\mathrm{ef}}$ & $\left(\mathrm{mgCaCO}_{3} \cdot \mathrm{L}^{-1}\right)$ & 1795 & 2170 & 1852 & 1753 & 1881 & 2226 & 4327 & 4355 & 1861 & 1398 \\
\hline $\mathrm{ST}_{\mathrm{ef}}$ & $\left(\mathrm{mg} \cdot \mathrm{L}^{-1}\right)$ & 2893 & 3090 & 2922 & 2733 & 3206 & 3218 & 6279 & 7796 & 10077 & 12478 \\
\hline $\mathrm{SVT}_{\mathrm{ef}}$ & $\left(\mathrm{mg} \cdot \mathrm{L}^{-1}\right)$ & 971 & 813 & 827 & 949 & 1409 & 1131 & 1488 & 2064 & 3629 & 5206 \\
\hline $\mathrm{SST}_{\mathrm{ef}}$ & $\left(\mathrm{mg} \cdot \mathrm{L}^{-1}\right)$ & 225 & 183 & 134 & 172 & 230 & 214 & 164 & 242 & 418 & 579 \\
\hline $\mathrm{SSV}_{\mathrm{ef}}$ & $\left(\mathrm{mg} \cdot \mathrm{L}^{-1}\right)$ & 173 & 127 & 103 & 160 & 225 & 196 & 146 & 217 & 366 & 492 \\
\hline $\mathrm{M}_{\mathrm{SVT}}$ & (g) & 28,3 & 36,7 & 37,3 & 52,8 & 51,2 & 61,3 & 73,1 & 95,6 & 109,7 & 144,2 \\
\hline $\mathrm{CX}$ & $\left(\mathrm{gSVT} . \mathrm{L}^{-1}\right)$ & 11,2 & 14,1 & 14,8 & 21,1 & 20,0 & 27,9 & 31,8 & 48,3 & 49,8 & 68,7 \\
\hline $\mathrm{CX}^{\prime}$ & (gSVT.gsuporte ${ }^{-1}$ ) & 0,8 & 0,9 & 1,0 & 1,2 & 1,2 & 1,6 & 1,9 & 2,1 & 2,7 & 2,8 \\
\hline $\mathrm{COVA}_{\mathrm{S}}$ & $\left(\mathrm{gDQO} \cdot \mathrm{L}^{-1} \cdot \mathrm{d}^{-1}\right)$ & 6,20 & 7,56 & 8,80 & 10,26 & 12,81 & 16,98 & 19,31 & 24,68 & 25,37 & 30,37 \\
\hline $\mathrm{COVR}_{\mathrm{S}}$ & $\left(\mathrm{gDQO} \cdot \mathrm{L}^{-1} \cdot \mathrm{d}^{-1}\right)$ & 5,48 & 6,96 & 8,21 & 9,64 & 11,89 & 15,85 & 17,35 & 20,81 & 16,66 & 17,73 \\
\hline $\mathrm{COVA}_{\mathrm{C}}$ & (gCarboidrato. $\mathrm{L}^{-1} \cdot \mathrm{d}^{-1}$ ) & 4,78 & 5,94 & 6,86 & 7,75 & 9,27 & 13,94 & 15,12 & 18,87 & 20,65 & 23,63 \\
\hline $\mathrm{COVR}_{\mathrm{C}}$ & (gCarboidrato. $\mathrm{L}^{-1} \cdot \mathrm{d}^{-1}$ ) & 4,73 & 5,89 & 6,82 & 7,70 & 9,19 & 13,84 & 15,03 & 18,73 & 20,47 & 23,37 \\
\hline $\mathrm{XCH}_{4}$ & $(\%)$ & 72,72 & 73,22 & 74,83 & 75,29 & 76,03 & 75,44 & 75,67 & 73,68 & 71,83 & 67,63 \\
\hline $\mathrm{V}_{\mathrm{G}}$ & (mL-CNTP.Ciclo $\left.{ }^{-1}\right)$ & 2504 & 3343 & 3635 & 4931 & 6311 & 6403 & 6453 & 6506 & 6916 & 7157 \\
\hline $\mathrm{V} \mathrm{CH}_{4}$ & $\left(\mathrm{~mL}_{-\mathrm{CNTPCH}} \cdot \mathrm{Ciclo}^{-1}\right)$ & 1821 & 2448 & 2720 & 3712 & 4798 & 4831 & 4883 & 4793 & 4968 & 4840 \\
\hline $\mathrm{nCH}_{4}$ & $\left(\mathrm{molCH}_{4} \cdot \mathrm{d}^{-1}\right)$ & 0,2438 & 0,3277 & 0,3640 & 0,4969 & 0,6422 & 0,6466 & 0,6536 & 0,6416 & 0,6649 & 0,6478 \\
\hline PrM & $\left(\mathrm{molCH}_{4} \cdot \mathrm{m}^{-3} \cdot \mathrm{d}^{-1}\right)$ & 96,6 & 126,1 & 144,8 & 198,4 & 250,3 & 293,9 & 284,2 & 324,0 & 301,6 & 308,5 \\
\hline $\mathrm{RMCA}_{\mathrm{MO}}$ & $\left(\mathrm{mmolCH}_{4} \cdot \mathrm{gDQO}^{-1}\right)$ & 15,57 & 16,69 & 16,47 & 19,33 & 19,54 & 17,30 & 14,71 & 13,13 & 11,89 & 10,16 \\
\hline $\mathrm{RMCA}_{\mathrm{C}}$ & $\left(\mathrm{mmolCH}_{4} \cdot \mathrm{gCarboidrato}^{-1}\right)$ & 20,19 & 21,23 & 21,10 & 25,59 & 26,99 & 21,09 & 18,79 & 17,17 & 14,61 & 13,06 \\
\hline
\end{tabular}




\subsubsection{Indicadores de desempenho relacionados à estabilidade}

Os valores do $\mathrm{pH}$ afluente e efluente, alcalinidade a bicarbonato e ácidos voláteis durante toda a etapa de otimização do reator estão apresentados na Figura 5.60.

A Figura 5.60a permite verificar que, tanto o aumento da concentração afluente de matéria orgânica, quanto o aumento da concentração de bicarbonato (mesmo que a suplementação tenha tido variável durante o projeto) pouco mudou o $\mathrm{pH}$ de entrada no reator, tendo este variado entre valores de 8,20 a 8,92. Sobre o pH efluente, nota-se que há uma queda nas duas últimas condições, sem atingir valores considerados inibitórios. Essa queda se deve a um pior desempenho do reator, que não se mostrou capaz de tratar eficientemente a carga orgânica aplicada nestas condições.

A Figura 5.60b permite observar os valores de alcalinidade a bicarbonato durante o período de atividade do reator enquanto em etapa de otimização. Percebe-se a alcalinidade a bicarbonato presente no afluente, na maioria do tempo, em concentração menor do que no efluente, com exceção das últimas três condições desta etapa de estudo. A biotransformação dos compostos orgânicos em metano é capaz de gerar alcalinidade a bicarbonato para o sistema. Segundo Speece (1996), águas residuárias que contém proteína tem a capacidade de gerar alcalinidade por meio da formação de $\mathrm{NH}_{4}{ }^{+}$-N. De acordo com os autores, a degradação completa de $1000 \mathrm{mg}$. $\mathrm{L}^{-1}$ de proteína gera, em alcalinidade equivalente, $360 \mathrm{mg} \mathrm{CaCO} \cdot \mathrm{L}^{-1}$. A concentração de alcalinidade a bicarbonato também é bastante influenciada pela formação dos ácidos nas etapas iniciais do metabolismo metanogênico. Ao verificar quantidade de alcalinidade a bicarbonato superior no efluente percebese que o reator foi eficiente na produção do biogás. O contrário pode ser visto nas últimas etapas, em que o desempenho do reator foi menor devido à inibição da biomassa. A diminuição da produção de biogás é concomitante à diminuição da concentração de bicarbonato no efluente.

A Figura 5.60c apresenta os valores de ácidos voláteis totais durante o período de estudo. Neste gráfico é possível perceber o aumento gradual da concentração dos ácidos com o aumento da 
carga. A maior produção de ácidos é esperada com o aumento da carga orgânica, entretanto, percebe-se que a partir da condição VII a concentração destes compostos no efluente aumenta bastante.

De modo a se estudar o comportamento do reator, não foram tomadas medidas que pudessem melhorar o desempenho, como extensão do tempo de operação, mudança do número de ciclos diários ou até mesmo aumento da concentração de bicarbonato afluente. Ainda assim, é possível dizer que o reator manteve estabilidade satisfatória durante a maioria do seu tempo de operação. Entre as condições I e VIII, o pH afluente flutuou em torno de 8,20 e 8,92, com o valor do efluente variando entre 7,16 e 8,86, chegando a 7,13 de valor mínimo nas últimas duas condições. Ainda assim, estes valores críticos estão dentro do valor ótimo de $\mathrm{pH}$ de 6,5 a 8,0 para microrganismos metanogênico termofílicos, relatado por Paulo (2003), ainda que em grande parte do tempo os valores estivessem acima desta faixa. Valores mais altos do que o ótimo também foram relatados por Albuquerque (2017) e Ribas (2010). A faixa de valores sugerida por Haandel e Lettinga (1993) é ainda mais restrita, definido valores entre 6,5 a 7,5 como os melhores na formação de metano, entretanto não há valores específicos para microrganismos termofílicos.

Os valores mais altos de alcalinidade a bicarbonato podem ser verificados nas últimas quatro etapas de operação do reator. O fato de haver bicarbonato em excesso no afluente aumentou a concentração de entrada do reator, mas não fez com que se retomasse a estabilidade e eficiência do reator. Nas últimas duas condições os valores de alcalinidade a bicarbonato do efluente variaram entre 374 e $2930 \mathrm{mg} \mathrm{CaCO}_{3} \cdot \mathrm{L}^{-1}$. Neste mesmo período, os valores de ácidos voláteis totais no efluente estiveram entre 2752 e $6301 \mathrm{mg} \mathrm{HAc.L^{-1 }}$. No período estável de operação, entre as condições I e VIII, os valores de alcalinidade a bicarbonato do efluente variaram entre 1514 e 5743 
$\mathrm{mg} \mathrm{CaCO}_{3} \cdot \mathrm{L}^{-1}$. Neste mesmo período, os valores de ácidos voláteis totais no efluente estiveram entre 6 e $2590 \mathrm{mg} \mathrm{HAc} . \mathrm{L}^{-1}$.

Percebe-se, pela análise de todas as variáveis, que o sistema teve a estabilidade prejudicada a partir da condição VIII, quando se observa variações maiores nos valores de alcalinidade a bicarbonato e ácidos voláteis do efluente que duram até o final do período de operação do reator. A estabilidade operacional é um dos fatores mais importantes num reator anaeróbio que tem como finalidade a geração de metano, uma vez que a comunidade metanogênica é bastante sensível a perturbações e tem uma resiliência mais baixa a problemas do que a comunidade acidogênica. 
Figura 5.60 - Dados de $\mathrm{pH}$ (a), alcalinidade a bicarbonato (b) e alcalinidade a ácidos voláteis totais (c) durante a etapa de otimização do reator
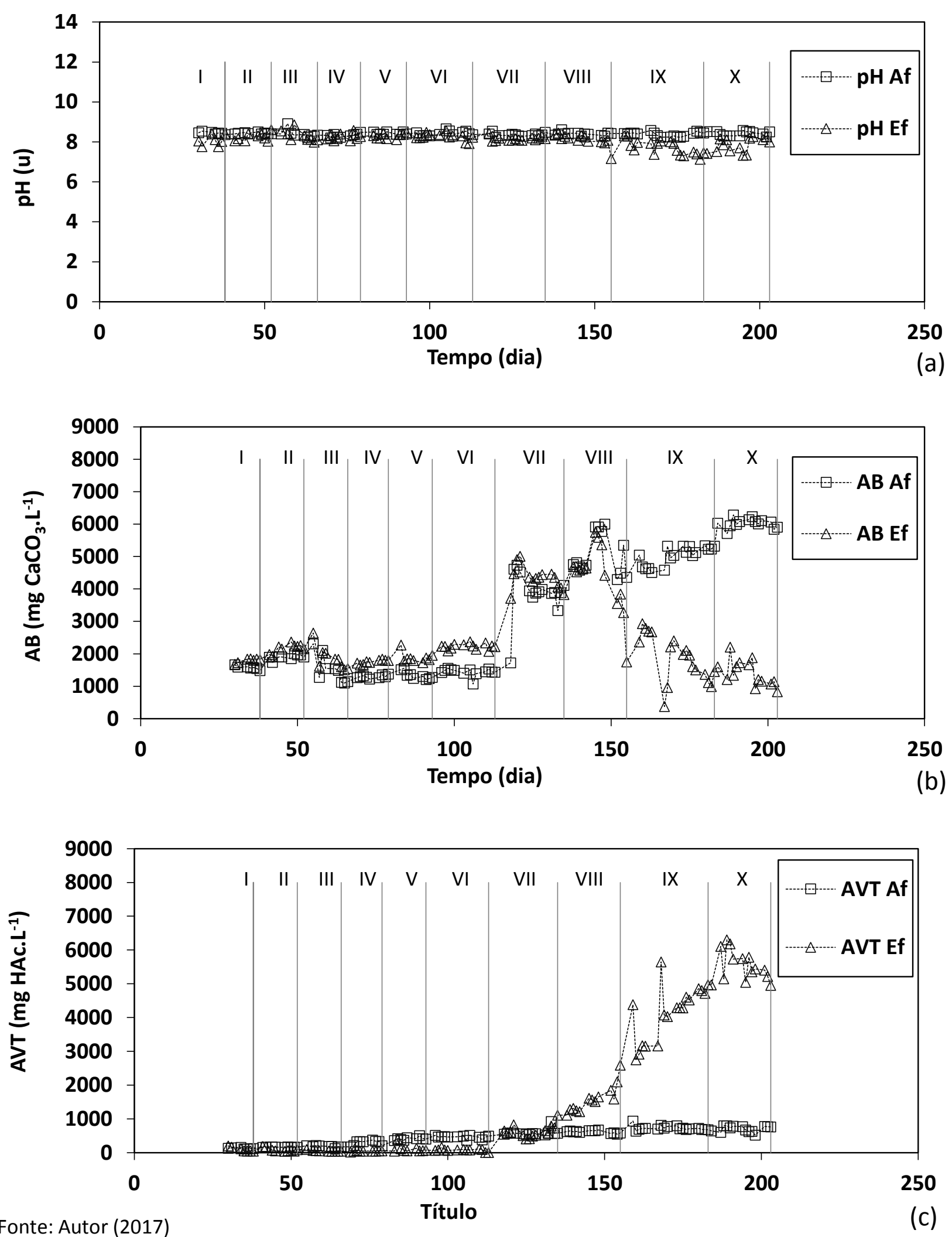

VERSÃO CORRIGIDA 
5.4.1.2 Indicadores de desempenho relacionados à remoção de matéria orgânica

A variação nas concentrações de matéria orgânica na forma de DQO e Carboidratos, bem como suas respectivas eficiências, podem ser verificadas nas Figuras 5.61 e 5.62.

Observa-se pela Figura 5.61 que a eficiência de remoção de DQO não-filtrada se manteve próxima à $93 \%$ até a condição VI, apresentando pequena queda na condição VII (90\%) e decaindo a $85 \%$ na condição VIII, até chegar a $58 \%$ na condição X. Para as amostras de DQO filtradas, a eficiência se manteve próxima à $95 \%$ até a condição VI, caindo para $91 \%$ na condição VII, $86 \%$ na condição VIII, até chegar a $62 \%$ na condição X. Esta queda de eficiência se deve ao aumento de carga, fazendo com que o reator perdesse a capacidade de assimilar toda a carga de DQO aplicada ao reator.

Também é possível perceber que o aumento da concentração de DQO é relacionado ao acúmulo de ácidos voláteis totais no efluente do reator. A remoção de matéria orgânica de um processo anaeróbio respeita todas as etapas do seu processo de redução. Como o reator perdeu parte de sua capacidade de transformar o acetato formado em metano, a matéria orgânica afluente não foi removida, mas sim transformada em ácidos, resultando em eficiência baixa de remoção de DQO, já que os ácidos são quantificados por esta análise, mas o metano, que se desprende do meio líquido, não. Neste contexto, a formação de metano pela via hidrogenotrófica não é influenciada.

Quanto à matéria orgânica na forma de carboidrato, houve sempre eficiências acima de 98\% em todas as condições, tanto para as amostras filtradas quanto para as não-filtradas. Comprovando a fácil biodegradabilidade do soro. Nessa análise não se nota o mesmo fato que ocorre na quantificação de DQO. Como a análise de Dubois analisa apenas os carboidratos, uma vez que estes 
foram transformados em ácidos na acidogênese, a eficiência se mantém bastante alta durante todo o período pois não há detecção dos açucares analisados. Por esse resultado, pode-se dizer que a formação de ácidos foi eficiente em todas as condições de estudo. Os resultados relacionados aos carboidratos estão apresentados na Figura 5.62.

A análise simultânea das curvas de ácidos voláteis e DQO aponta que os microrganismos limitantes do processo não foram os acidogênicos, mas sim a comunidade metanogênica. Como as arqueias metanogênicas tem tempo de crescimento muito menor do que os microrganismos acidogenicos, é esperado que, em sistemas perturbados, não haja recuperação suficiente desta comunidade, resultando em menor eficiência do sistema. Observa-se este fenômeno nas últimas etapas de operação do reator de estudo.

Assim como nas análises da alcalinidade a bicarbonato e de ácidos voláteis, percebe-se que a instabilidade dos resultados de remoção de DQO se iniciaram a partir da condição VIII, onde as flutuações ainda foram pequenas. Durante as condições IX e X as flutuações não só foram maiores, como houve uma queda bastante brusca na eficiência do início da condição até o seu final. 
Figura 5.61 - Dados de concentração de matéria orgânica na forma de DQO (a) e sua eficiência de remoção (b) na etapa de otimização do reator
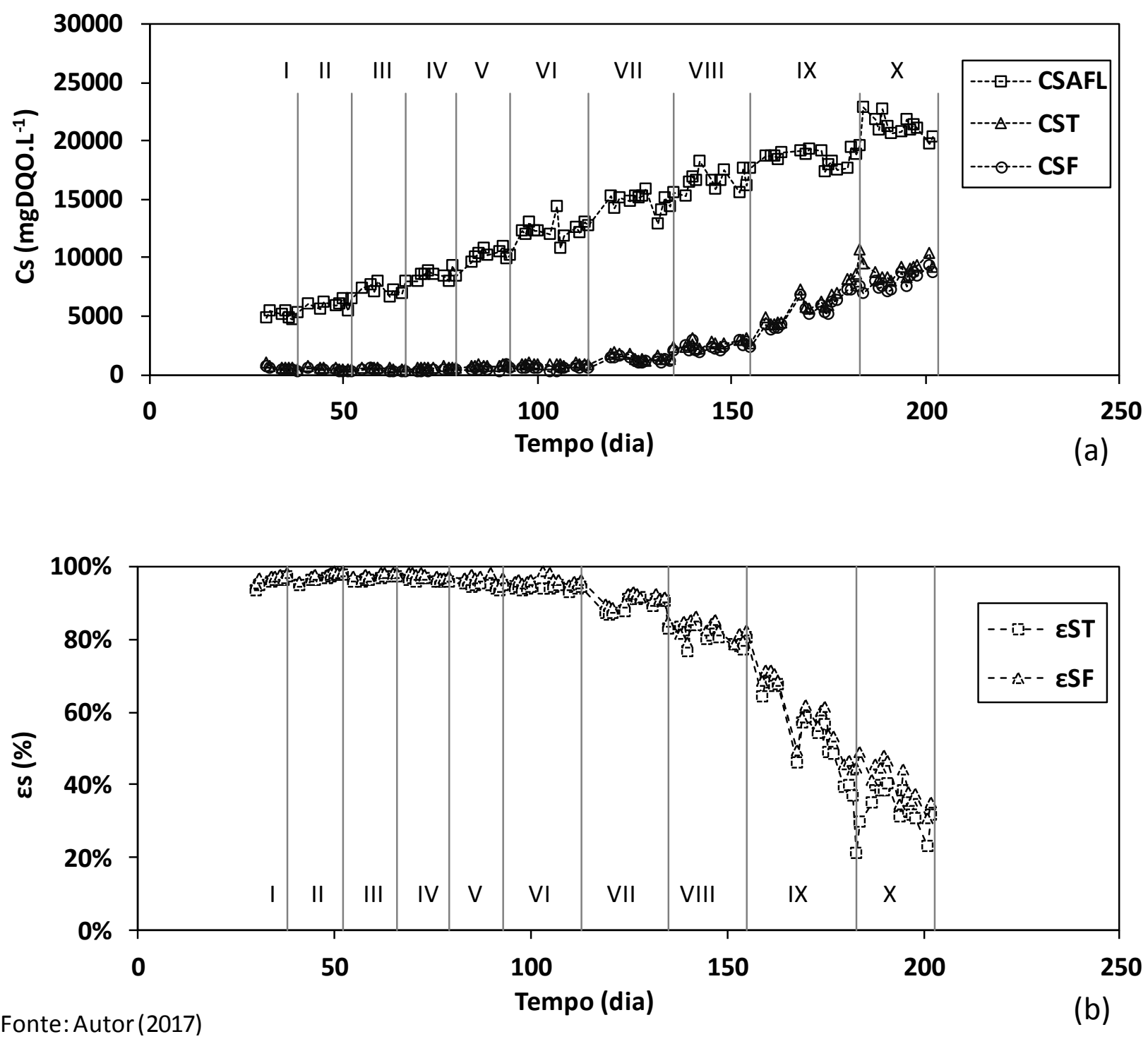
Figura 5.62 - Dados de concentração de matéria orgânica na forma de carboidratos (a) e sua eficiência de remoção (b) na etapa de otimização do reator
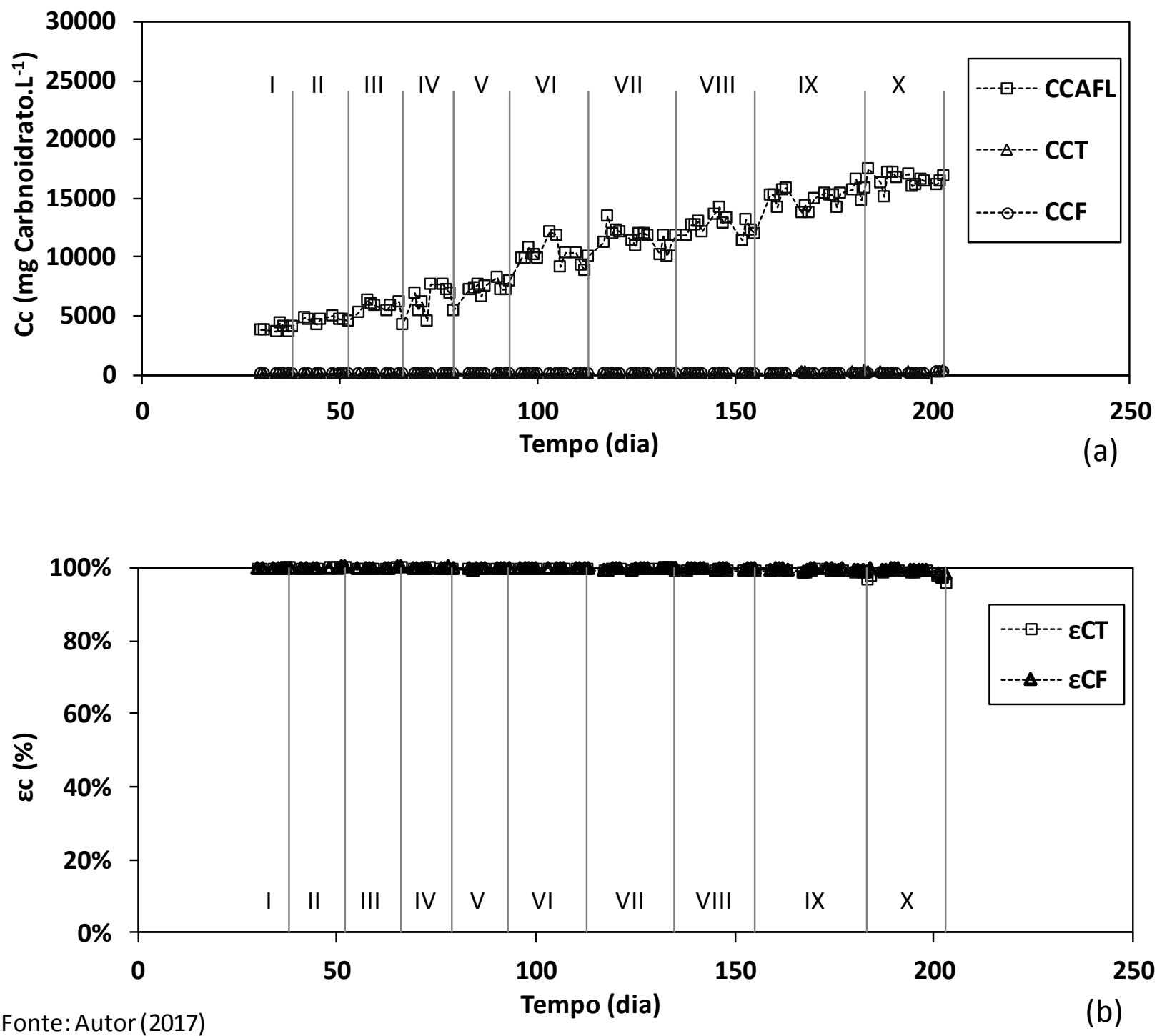

Os resultados dos sólidos totais e voláteis totais presente no afluente e efluente podem ser observados na Figura 5.63. O aumento na quantidade de sólidos presente no reator se deve ao aumento da concentração de soro na composição da água residuária afluente, consequente do aumento da carga orgânica. Apesar disso, houve pouca variação da fração orgânica dos sólidos. Importante notar que a concentração de sólidos totais do efluente tem grande aumento com o aumento da carga orgânica aplicada. Isso se deve ao fato da maior concentração de polímero VERSÃO CORRIGIDA 
biológico que é gerado no reator com o aumento da carga aplicada. Este polímero se mostrou um problema nas condições finais de estudo devido à sua grande concentração. A grande quantidade de polímeros ocupou um volume útil considerável, fazendo com que a carga orgânica aplicada no reator se tornasse maior do que a esperada, o que pode ter contribuído para o pior desempenho do reator nas últimas duas condições. Por este motivo, acredita-se que a manutenção tanto das mangueiras que ligam o reator às bombas de alimentação, que também desenvolveram grande quantidade de biofilme, quanto o interior do reator, deveriam ter sido limpos com maior frequência, já que esta era feita uma ou duas vezes por condição, apenas.

Miqueleto et al. (2006) estudaram a formação de polímeros (ou exopolissacarídeos - EPS) em reatores anaeróbios operado em bateladas sequenciais. Segundo os autores, os EPS são responsáveis pela aderência da comunidade em superfícies, agregação de bactérias em flocos ou biofilmes, estabilização da estrutura do biofilme, formação de uma barreira de proteção que aumenta a resistência contra efeitos considerados agressivos às células, retenção de água, sorção de compostos orgânicos exógenos para a acumulação de nutrientes que provêm do meio, acúmulo de atividades enzimáticas, assim como a digestão de macromoléculas exógenas para aquisição de nutrientes. Entretanto, os autores relacionaram a produção excessiva destes EPS com a colmatação dos leitos, quando a biomassa é imobilizada em leito fixo, ou então problemas com a floculação (ou granulação) do lodo, impedindo, desta forma, que os sistemas atinjam a eficiência necessária para o tratamento. Neste estudo, os autores testaram diferentes fontes de carbono (glicose, extrato de carne, óleo de soja, as três fontes de carbono juntas, e os ácidos acético, butírico e propiônico juntos) e diferentes relações $\mathrm{C} / \mathrm{N}\left(13,6(\mathrm{C} / \mathrm{N} 1), 6,8(\mathrm{C} / \mathrm{N} 2)\right.$ e 3,4 (C/N3) gC.gN $\left.{ }^{-1}\right)$. Além disso, testaram a influência da condição de microaerofilia ao borbulharem gás nitrogênio no meio, mantendo o reator sob anaerobiose estrita. Os autores concluíram que a elevada relação C/N, condição de microaerofilia e a fonte de carbono favorecem a formação dos EPS. Além disso, os 
autores observaram que a composição do EPS não variou conforme a mudança dos parâmetros analisados, formando basicamente celulose em todas as condições estudadas.

Figura 5.63 - Concentração de sólidos no afluente e efluente na etapa de otimização do reator

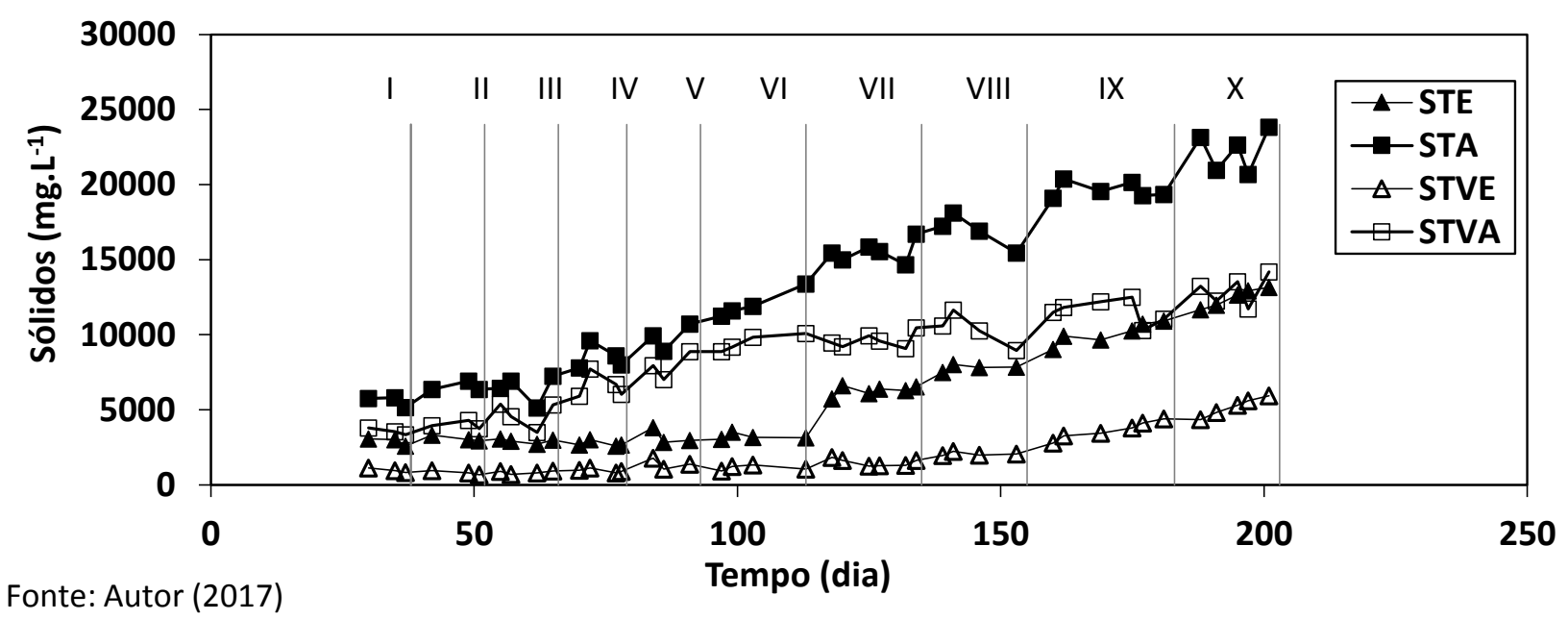

5.4.1.3 Indicadores de desempenho relacionados à produção de metano

Nas Figura 5.64 apresentam-se os dados de volume gerado e composição do biogás nas diferentes condições da etapa de otimização. A condição VIII apresentou o melhor resultado em relação à produtividade molar $\left(324 \mathrm{molCH}_{4} \cdot \mathrm{m}^{-3} \cdot \mathrm{d}^{-1}\right)$, sendo que a condição IX apresentou maior vazão molar de metano $\left(0,66 \mathrm{mmolCH}_{4} \cdot \mathrm{d}^{-1}\right)$, assim como o maior volume de metano gerado (4968 mL-CNTP.ciclo-1 $)$. O maior volume de biogás produzido foi na condição X (7157 mLCNTP.ciclo ${ }^{-1}$ ). O volume de biogás gerado acompanha o aumento da carga orgânica aplicada no reator, entretanto, nota-se que há uma pequena estagnação do crescimento na produção a partir da condição VI. A partir da condição VII percebe-se que há uma queda na concentração de metano no biogás, indicando início da piora no desempenho do reator. $\mathrm{O}$ aumento da fração de $\mathrm{CO}_{2}$ no biogás, 
com consequente diminuição da concentração de $\mathrm{CH}_{4}$, pode ser um indicativo da ineficiência da conversão dos compostos intermediários do metabolismo anaeróbio em metano. Como houve uma grande perturbação no sistema devido às altas cargas implementadas, a comunidade metanogênica, que possui tempo de crescimento menor do que a acidogênica, não pôde se recuperar totalmente, diminuindo a eficiência de conversão dos intermediários em metano. Isso pode ser constatado analisando todas as variáveis estudadas no projeto. A baixa remoção de DQO é reflexo da alta concentração de ácidos no sistema. O acúmulo destes ácidos indica que houve pouca transformação em metano, produto final do processo, o que indica o problema do sistema. 
Figura 5.64 - Volume de biogás gerado (a) e composição do biogás (b) durante etapa de otimização do reator
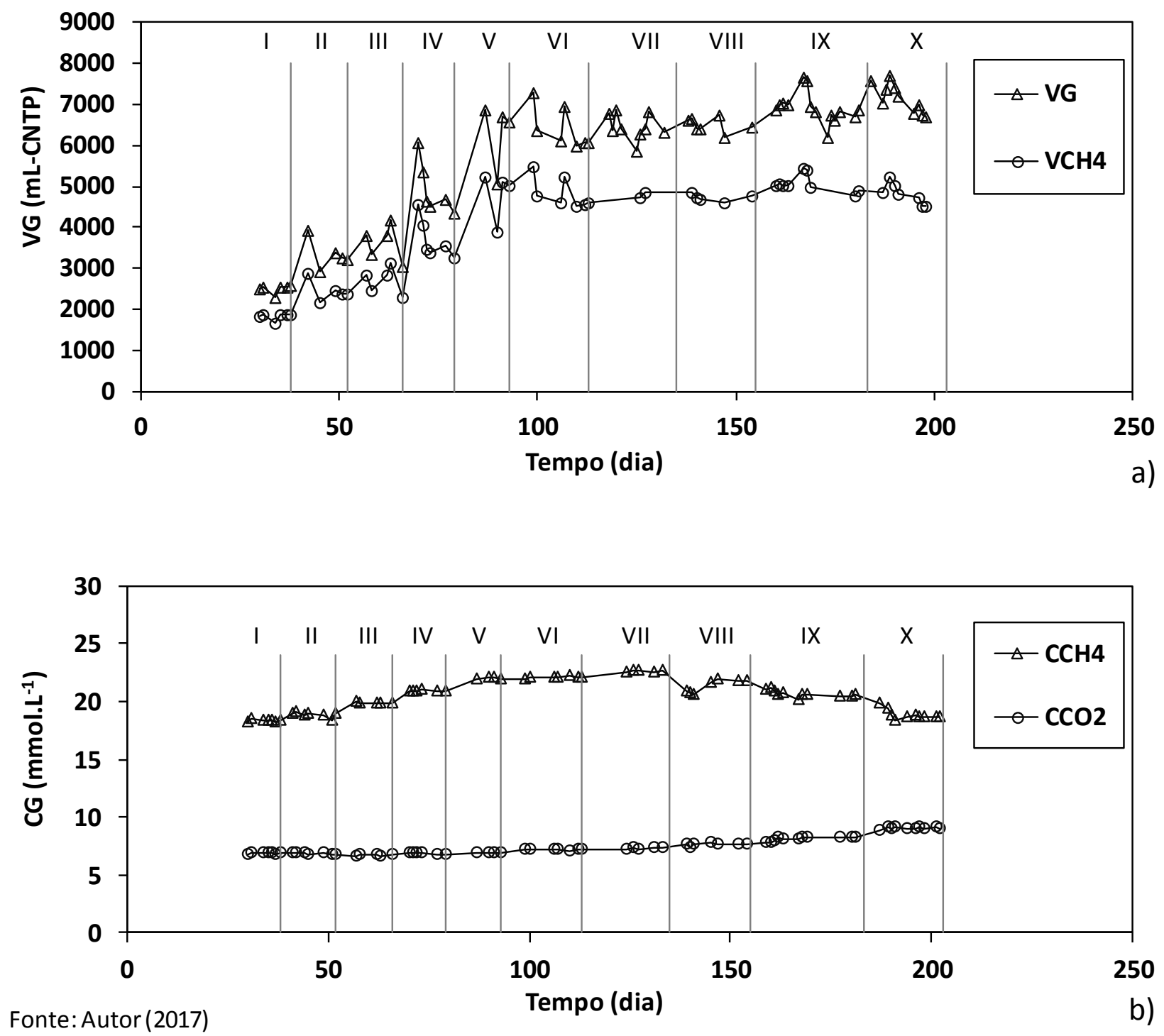

A Figura 5.65 apresenta os valores comparativos de carga removida por aplicada (a), produtividade molar de metano por carga aplicada (b) e rendimento molar de metano por carga aplicada (c). Estes fatores são importantes para se normalizar a análise do reator dentre todas as condições de estudo. 
A Figura 5.65a, apresenta a relação entre a carga orgânica removida pela aplicada. A análise deste gráfico mostra a capacidade do reator de assimilar a quantidade de DQO que foi aplicada no reator. Pelo resultado é possível notar claramente um ponto de inflexão na condição VIII, onde se obtém o valor máximo da relação entre as cargas removidas e aplicadas. Esse resultado indica que reator teve sua capacidade máxima de assimilação da matéria orgânica adicionada ao meio. Visto que as eficiências nas condições subsequentes demonstraram piora. Os mesmos resultados podem ser obtidos pela análise da Figura 5.65b, onde se nota que a relação entre a produtividade molar de metano e a carga orgânica aplicada também atingiu seu ponto máximo na condição VIII. Isso indica que, nesta condição, obteve-se os melhores valores gerais de remoção de matéria orgânica e transformação dos compostos intermediários em metano, obtendo um biogás com porcentagem de metano de $73,68 \pm 0,43 \%$.

A Figura 5.65c apresenta o gráfico do rendimento molar de metano em relação à carga orgânica aplicada. A curva tracejada no gráfico indica o valor da limitação teórica da conversão de metano através do consumo de DQO que é de 15,63 $\mathrm{mmolCH}_{4}-\mathrm{CNTP}_{\text {gDQO}}{ }^{-1}$. Esse cálculo se baseia na estequiometria do consumo de 2 mols de $\mathrm{O}_{2}$ na conversão completa de 1 mol de $\mathrm{CH}_{4}$. Verifica-se que nas três primeiras condições obteve-se valor de rendimento molar de metano próximo ao teórico. Nas três condições seguintes o rendimento foi acima do teórico. Isso pode ser explicado pelo fato de que a análise de DQO quantifica outros compostos que não só a matéria orgânica presente na amostra, principalmente nas amostras de efluente. Por causa dessa influência, quantifica-se um consumo menor de matéria orgânica do que o real, resultando num valor de rendimento maior do que o teórico. Nas condições VII e VIII foi obtido valores de rendimento molar de metano próximos ao teórico, entretanto, nas duas últimas condições o rendimento esteve sempre abaixo do limite teórico. O valor de rendimento molar de metano indica a capacidade do reator de gerar metano a partir do consumo de matéria orgânica. Como a digestão anaeróbia é um 
processo auto-regulado e quase linear, uma pequena perturbação em qualquer uma das etapas intermediárias tem influência no resultado final do processo, que é a geração de metano. Mais uma vez, percebe-se que as últimas condições resultaram em eficiências menores do que o restante de operação do reator, indicativo da perturbação do equilíbrio do reator nestas condições. 
Figura 5.65 - Relação entre Carga orgânica volumétrica removida (a), produtividade molar (b) e rendimento molar de metano (c) pela carga orgânica aplicada na forma de DQO
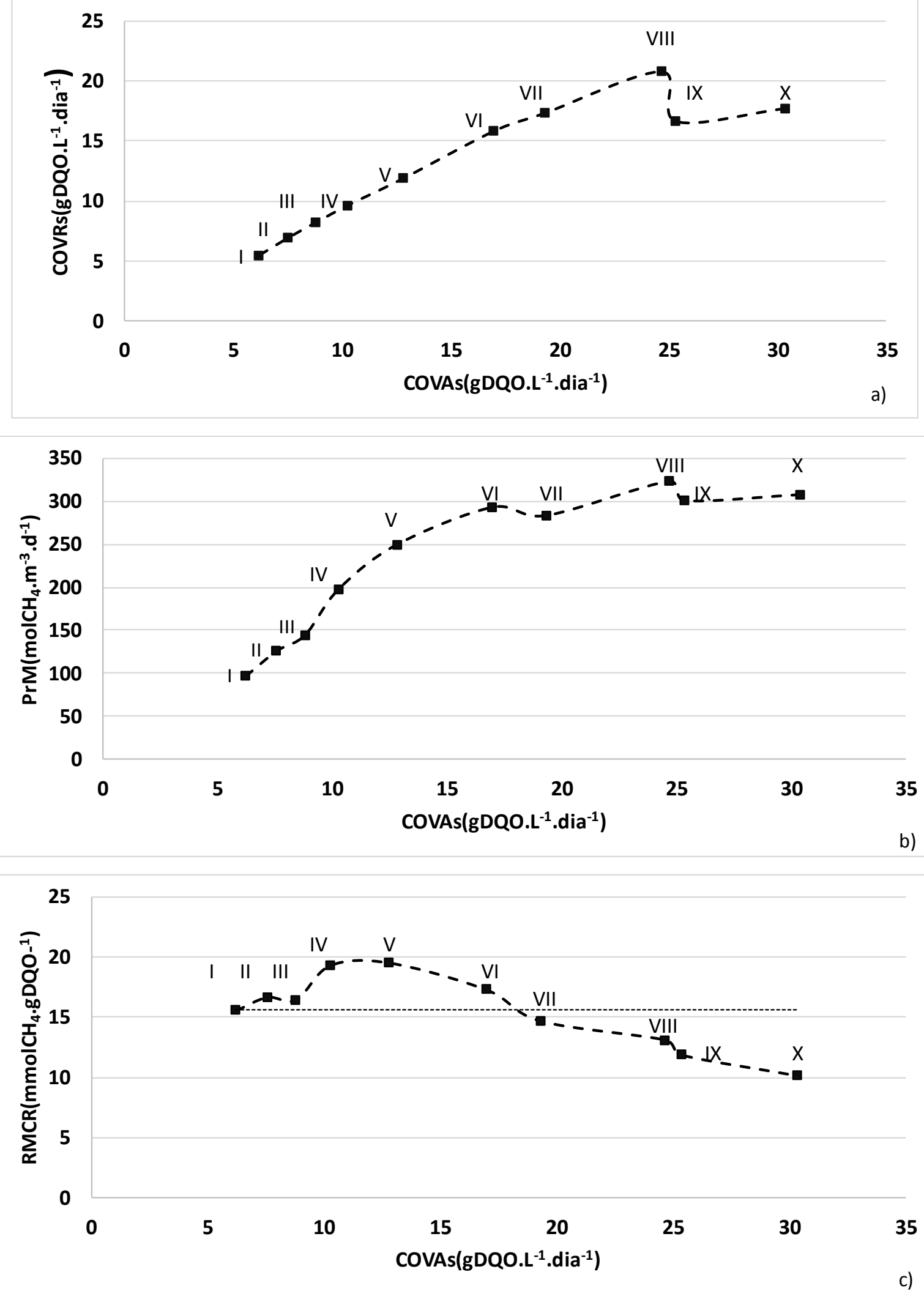
5.4.1.4 Indicadores de desempenho relacionados ao ajuste do modelo cinético

A Tabela 5.24 apresenta os resultados do ajuste cinético para todas as condições da etapa de otimização. É válido ressaltar que todas as modelagens obtiveram resultados satisfatórios no ajuste cinético dos dados experimentais.

A análise dos parâmetros cinéticos indica maior produção de ácido acético através do substrato $\left(\mathrm{k}_{1 \mathrm{HAC}}\right)$ e da conversão do ácido proprônico $\left(\mathrm{k}_{\mathrm{HAC}}\right)$. A produção de metano foi maior na rota metanogênica hidrogenotrófica $\left(\mathrm{k}_{11 \mathrm{M}}\right)$ em todas as condições.

Os resultados indicam que a hidrólise e acidificação formam grandes quantidade de acetato e ácido propiônico, principalmente. Este processo tende a ser muito rápido nos reatores que tratam soro, devido à grande biodegradabilidade deste substrato, comprovada pelos resultados do modelo e experimentais. Essa rápida produção de ácidos, possivelmente, tornou majoritária a rota metanogênica hidrogenotrófica, a qual é responsável pela combinação do hidrogênio, gerado em abundância na rápida acidogênese do reator, com o dióxido de carbono $\left(\mathrm{HCO}_{3}^{-}+\mathrm{H}^{+}\right)$para a formação de metano, resultado conflitante com o modelo da Figura 3.1, em que os autores classificam a rota acetoclástica como majoritária no processo anaeróbio (CHANDRA et al. (2012), adaptado de MCCARTY (1964). Vale ressaltar que a rota acetoclástica esteve presente em todas as condições de estudo no projeto. 
Tabela 5.24 - Resumo dos parâmetros cinéticos durante a etapa de otimização do reator

\begin{tabular}{|c|c|c|c|c|c|c|c|c|c|c|c|}
\hline Condição & Parâmetro & I & II & III & IV & V & VI & VII & VIII & IX & $X$ \\
\hline \multirow{10}{*}{$\begin{array}{l}\text { Hidrólise e } \\
\text { Acidogênese }\end{array}$} & $\mathrm{k}_{1 \mathrm{~S}}^{\prime}\left(\mathrm{h}^{-1}\right)$ & 1,54 & 1,54 & 1,55 & 2,29 & 2,29 & 3,27 & 1,52 & 0,57 & 0,38 & 0,28 \\
\hline & $\mathrm{k}_{1 \mathrm{HAc}}\left(\mathrm{h}^{-1}\right)$ & 11,65 & 3,00 & 3,03 & 2,67 & 2,59 & 3,90 & 1,73 & 0,50 & 1,16 & 0,34 \\
\hline & $\mathrm{k}_{1 \mathrm{H}}\left(\mathrm{h}^{-1}\right)$ & 0,03 & 0,00 & 0,00 & 0,00 & 0,00 & 0,00 & 0,00 & 0,00 & 0,00 & 0,00 \\
\hline & $\mathrm{k}_{2 \mathrm{HPr}}\left(\mathrm{h}^{-1}\right)$ & 0,01 & 0,00 & 0,00 & 0,30 & 0,21 & 0,13 & 0,23 & 0,18 & 0,03 & 0,33 \\
\hline & $\mathrm{k}_{2 \mathrm{H}}\left(\mathrm{h}^{-1}\right)$ & 0,21 & 0,03 & 0,12 & 0,05 & 0,02 & 0,01 & 0,04 & 0,02 & 0,01 & 0,00 \\
\hline & $\mathrm{k}_{3 \mathrm{HBu}}\left(\mathrm{h}^{-1}\right)$ & 0,75 & 0,24 & 0,28 & 0,26 & 0,15 & 0,15 & 0,12 & 0,05 & 0,02 & 0,00 \\
\hline & $\mathrm{k}_{3 \mathrm{H}}\left(\mathrm{h}^{-1}\right)$ & 0,02 & 0,00 & 0,00 & 0,00 & 0,00 & 0,00 & 0,00 & 0,00 & 0,00 & 0,00 \\
\hline & $\mathrm{k}_{4 \mathrm{HVa}}\left(\mathrm{h}^{-1}\right)$ & 0,08 & 0,07 & 0,15 & 0,16 & 0,00 & 0,03 & 0,05 & 0,02 & 0,01 & 0,01 \\
\hline & $\mathrm{k}_{4 \mathrm{H}}\left(\mathrm{h}^{-1}\right)$ & 0,00 & 0,00 & 0,00 & 0,00 & 0,00 & 0,00 & 0,00 & 0,00 & 0,00 & 0,00 \\
\hline & $\mathrm{k}_{5 \mathrm{ETOH}}\left(\mathrm{h}^{-1}\right)$ & 0,00 & 0,00 & 0,00 & 0,00 & 0,00 & 0,00 & 0,00 & 0,00 & 0,00 & 0,00 \\
\hline \multirow{10}{*}{ Acetogênese } & $\mathrm{k}_{6 \mathrm{HPr}}\left(\mathrm{h}^{-1}\right)$ & 1,20 & 0,49 & 3,67 & 0,63 & 5,81 & 4,36 & 0,37 & 0,79 & 0,02 & 1,45 \\
\hline & $\mathrm{k}_{6 \mathrm{HAc}}\left(\mathrm{h}^{-1}\right)$ & 124,04 & 2,21 & 20,58 & 12,03 & 17,56 & 11,43 & 9,14 & 24,92 & 2,66 & 17,77 \\
\hline & $\mathrm{k}_{6 \mathrm{H}}\left(\mathrm{h}^{-1}\right)$ & 0,00 & 0,00 & 0,00 & 0,00 & 0,00 & 0,00 & 0,00 & 0,00 & 0,00 & 0,00 \\
\hline & $\mathrm{k}_{7 \mathrm{HPr}}\left(\mathrm{h}^{-1}\right)$ & 2,95 & 2,94 & 10,97 & 2,85 & 11,79 & 10,93 & 0,73 & 1,59 & 0,14 & 1,52 \\
\hline & $\mathrm{k}_{7 \mathrm{HBu}}\left(\mathrm{h}^{-1}\right)$ & 5,98 & 1,11 & 2,39 & 2,33 & 0,11 & 0,22 & 1,02 & 1,14 & 1,59 & 0,00 \\
\hline & $\mathrm{k}_{7 \mathrm{H}}\left(\mathrm{h}^{-1}\right)$ & 0,06 & 0,00 & 0,00 & 0,00 & 0,00 & 0,00 & 0,00 & 0,00 & 0,00 & 0,00 \\
\hline & $\mathrm{k}_{8 \mathrm{HBu}}\left(\mathrm{h}^{-1}\right)$ & 7,24 & 0,08 & 2,06 & 1,28 & 0,08 & 0,27 & 0,83 & 0,95 & 1,70 & 0,17 \\
\hline & $\mathrm{k}_{8 \mathrm{HVa}}\left(\mathrm{h}^{-1}\right)$ & 0,35 & 0,00 & 0,14 & 0,00 & 2,34 & 2,64 & 0,05 & 0,00 & 0,00 & 0,00 \\
\hline & $\mathrm{k}_{8 \mathrm{H}}\left(\mathrm{h}^{-1}\right)$ & 0,20 & 0,03 & 0,03 & 0,00 & 0,00 & 0,00 & 0,00 & 0,00 & 0,00 & 0,00 \\
\hline & $\mathrm{k}_{9 \mathrm{HAc}}\left(\mathrm{h}^{-1}\right)$ & 0,00 & 0,00 & 0,00 & 0,00 & 0,00 & 0,00 & 0,00 & 0,00 & 0,00 & 0,00 \\
\hline \multirow{4}{*}{ Metanogênese } & $\mathrm{k}_{10 \mathrm{HAc}}\left(\mathrm{h}^{-1}\right)$ & 13,83 & 0,56 & 4,27 & 2,91 & 2,52 & 2,91 & 1,76 & 3,52 & 0,77 & 2,07 \\
\hline & $\mathrm{k}_{10 \mathrm{H}}\left(\mathrm{h}^{-1}\right)$ & 7,87 & 9,23 & 6,26 & 7,16 & 6,27 & 2,64 & 4,96 & 2,14 & 0,79 & 0,38 \\
\hline & $\mathrm{k}_{11 \mathrm{H}}\left(\mathrm{h}^{-1}\right)$ & 0,20 & 0,01 & 0,09 & 0,01 & 0,09 & 0,18 & 0,12 & 0,12 & 0,15 & 0,08 \\
\hline & $\mathrm{k}_{11 \mathrm{M}}\left(\mathrm{h}^{-1}\right)$ & 178,08 & 767,56 & 143,88 & 357,76 & 1197,51 & 828,11 & 217,12 & 94,25 & 44,43 & 109,85 \\
\hline
\end{tabular}

5.4.2 Etapa de estratégia de alimentação

Realizou-se a análise comparativa entre as duas últimas condições de estudo, visando estudar a influência da mudança da estratégia de alimentação sobre os indicadores de estabilidade e desempenho do reator. A Tabela 5.25 abaixo apresenta os valores médios dos indicadores de desempenho das duas condições de estudo. 
Tabela 5.25 - Valores médios dos parâmetros e indicadores de desempenho do reator utilizando diferentes

\begin{tabular}{|c|c|c|c|}
\hline Parâmetros & Unidades & $\begin{array}{l}\text { Condição X } \\
\text { (Batelada) }\end{array}$ & $\begin{array}{c}\text { Condição XI } \\
\text { (Batelada Alimentada) }\end{array}$ \\
\hline $\mathrm{C}_{\mathrm{ST}}$ & $\left(\mathrm{mgDQO} \cdot \mathrm{L}^{-1}\right)$ & 21261 & 19970 \\
\hline $\mathrm{C}_{\mathrm{SF}}$ & $\left(\operatorname{mgDQO} \cdot \mathrm{L}^{-1}\right)$ & 7938 & 8553 \\
\hline$\varepsilon_{\mathrm{ST}}$ & $(\%)$ & $58,3 \%$ & $50,1 \%$ \\
\hline$\varepsilon_{\mathrm{SF}}$ & $(\%)$ & $62,5 \%$ & $57,2 \%$ \\
\hline $\mathrm{C}_{\mathrm{CT}}$ & (mgCarboidrato. $\mathrm{L}^{-1}$ ) & 16538 & 15856 \\
\hline $\mathrm{C}_{\mathrm{CF}}$ & (mgCarboidrato. $\mathrm{L}^{-1}$ ) & 100 & 100 \\
\hline$\varepsilon_{\mathrm{CT}}$ & $(\%)$ & $98,9 \%$ & $98,6 \%$ \\
\hline$\varepsilon_{\mathrm{CF}}$ & $(\%)$ & $99,4 \%$ & $99,4 \%$ \\
\hline $\mathrm{pH}_{\mathrm{ef}}$ & (u) & 7,85 & 8,10 \\
\hline $\mathrm{AVT}_{\mathrm{ef}}$ & $\left(\mathrm{mgHAc} . \mathrm{L}^{-1}\right)$ & 5527 & 6032 \\
\hline $\mathrm{AT}_{\mathrm{ef}}$ & $\left(\mathrm{mgCaCO}_{3} \cdot \mathrm{L}^{-1}\right)$ & 5322 & 4970 \\
\hline $\mathrm{AB}_{\mathrm{ef}}$ & $\left(\mathrm{mgCaCO}_{3} \cdot \mathrm{L}^{-1}\right)$ & 1398 & 692 \\
\hline $\mathrm{ST}_{\mathrm{ef}}$ & $\left(m g . L^{-1}\right)$ & 12478 & 13530 \\
\hline $\mathrm{SVT}_{\mathrm{ef}}$ & $\left(\mathrm{mg} \cdot \mathrm{L}^{-1}\right)$ & 5206 & 6179 \\
\hline $\mathrm{SST}_{\mathrm{ef}}$ & $\left(\mathrm{mg} \cdot \mathrm{L}^{-1}\right)$ & 579 & 629 \\
\hline $\mathrm{SSV}_{\mathrm{ef}}$ & $\left(m g . L^{-1}\right)$ & 492 & 577 \\
\hline $\mathrm{M}_{\mathrm{SVT}}$ & (g) & 144,2 & 93,3 \\
\hline CX & $\left(\mathrm{gSVT} . \mathrm{L}^{-1}\right)$ & 68,7 & 48,8 \\
\hline $\mathrm{CX}^{\prime}$ & $\left(\right.$ gSVT.gsuporte $\left.{ }^{-1}\right)$ & 2,8 & 2,5 \\
\hline $\mathrm{COVA}_{\mathrm{S}}$ & $\left(\mathrm{gDQO} \cdot \mathrm{L}^{-1} \cdot \mathrm{d}^{-1}\right)$ & 30,37 & 31,68 \\
\hline $\mathrm{COVR}_{\mathrm{S}}$ & $\left(\mathrm{gDQO} \cdot \mathrm{L}^{-1} \cdot \mathrm{d}^{-1}\right)$ & 17,73 & 15,89 \\
\hline $\mathrm{COVA}_{\mathrm{C}}$ & (gCarboidrato. $\left.\mathrm{L}^{-1} \cdot \mathrm{d}^{-1}\right)$ & 23,63 & 25,15 \\
\hline $\mathrm{COVR}_{\mathrm{C}}$ & (gCarboidrato. $\left.\mathrm{L}^{-1} \cdot \mathrm{d}^{-1}\right)$ & 23,37 & 24,80 \\
\hline $\mathrm{XCH}_{4}$ & $(\%)$ & 67,63 & 62,58 \\
\hline $\mathrm{V}_{\mathrm{G}}$ & (mL-CNTP.Ciclo $\left.{ }^{-1}\right)$ & 7157 & 6216 \\
\hline $\mathrm{V} \mathrm{CH}_{4}$ & $\left(\mathrm{~mL}-\mathrm{CNTPCH}_{4} \cdot \mathrm{Ciclo}^{-1}\right)$ & 4840 & 3889 \\
\hline $\mathrm{nCH}_{4}$ & $\left(\mathrm{molCH}_{4} \cdot \mathrm{d}^{-1}\right)$ & 0,6478 & 0,5206 \\
\hline PrM & $\left(\mathrm{molCH}_{4} \cdot \mathrm{m}^{-3} \cdot \mathrm{d}^{-1}\right)$ & 308,5 & 272,5 \\
\hline $\mathrm{RMCA}_{\mathrm{MO}}$ & $\left(\mathrm{mmolCH}_{4} \cdot \mathrm{gDQO}^{-1}\right)$ & 10,16 & 8,60 \\
\hline $\mathrm{RMCA}_{\mathrm{C}}$ & $\left(\mathrm{mmolCH}_{4} \cdot \mathrm{gCarboidrato}^{-1}\right)$ & 13,06 & 10,84 \\
\hline
\end{tabular}

Fonte: Autor (2017)

5.4.2.1 Indicadores de desempenho relacionados à estabilidade

Através da Figura 5.66 a seguir tem-se os valores do pH afluente e efluente, alcalinidade a bicarbonato e ácidos voláteis durante a mudança de estratégia de alimentação. 
A Figura 5.66a indica que os valores de $\mathrm{pH}$ afluente e efluente apresentaram pouca variação durante o estudo. A Figura 5.66b, em que se apresentam os dados de alcalinidade a bicarbonato, percebe-se que há um pequeno decréscimo na concentração média da condição XI. Na Figura 5.66c tem-se que a concentração de ácidos voláteis no efluente aumentou quando se utilizou a batelada alimentada. Ambos os fatores indicam uma piora no desempenho do reator. Tal comportamento é contraditório com os estudos indicam que o reator operado em batelada alimentada apresenta melhor desempenho com maior carga orgânica aplicada (RODRIGUES et al., 2011; RATUSZNEI et al., 2003), indicando que a carga orgânica aplicada nesse ensaio foi muito alta, acarretando a não recuperação do desempenho do reator que ocorreu desde a condição IX. Dessa forma, a estratégia batelada alimentada, na qual ocorre o efeito de diluição de altas cargas orgânicas, não permitiu a melhoria do desempenho do reator.

Os valores de $\mathrm{pH}$ efluente tiveram pequeno aumento quando se aplicou a batelada alimentada, passando de um valor médio de 7,85 para 8,10. Os ácidos voláteis totais tiveram um ligeiro aumento, passando de 5527 a $6032 \mathrm{mgHAc} . \mathrm{L}^{-1}$. A alcalinidade a bicarbonato foi menor na condição XI, passando de 1398 a $692 \mathrm{mgCaCO}_{3} \cdot \mathrm{L}^{-1}$. 
Figura 5.66 - Comparação entre dados de pH (a), alcalinidade a bicarbonato (b) e a ácidos voláteis totais (c) após mudança de estratégia de alimentação
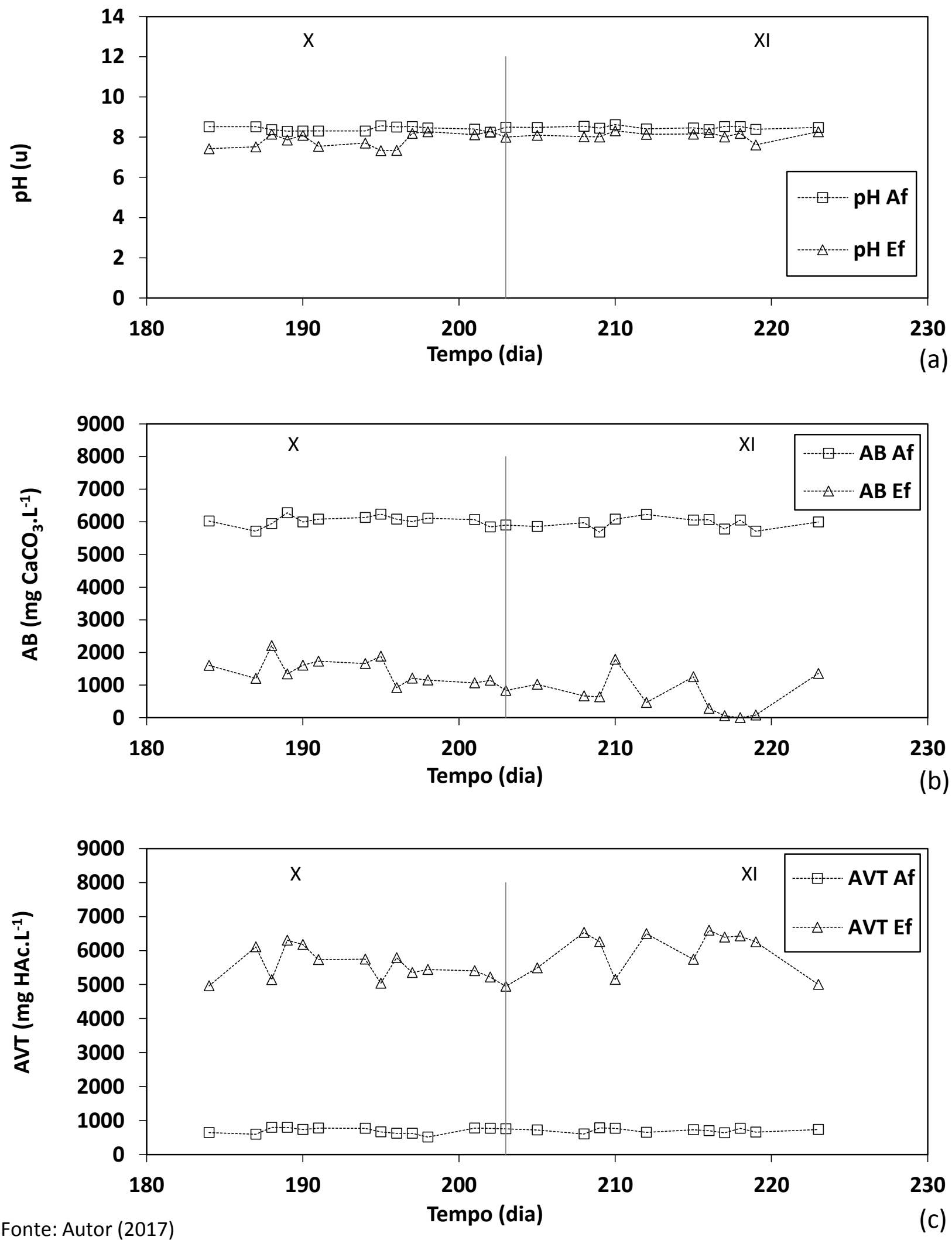

VERSÃO CORRIGIDA 
5.4.2.2 Indicadores de desempenho relacionados à remoção de matéria orgânica

As concentrações de matéria orgânica na forma de DQO e Carboidratos, respectivamente, bem como suas eficiências de remoção estão apresentadas nas Figuras 5.67 e 5.68.

Pode-se observar que em relação à DQO, houve pequena piora na eficiência de remoção quando se utilizou a batelada alimentada, reduzindo a eficiência média de remoção de 58,3\% para 50,1\%. Esta diferença pode ser atribuída à maior concentração de ácidos voláteis totais (AVT) contida no efluente quando operado em batelada alimentada. A remoção de carboidratos se manteve de forma bastante satisfatória, devido à alta biodegradabilidade do soro. Na forma filtrada, a eficiência média de remoção de carboidratos se manteve a mesma nas duas etapas, 99,4\%.

Ratusznei et al. (2003) notaram que, para um reator utilizando espuma de poliuretano como meio suporte, pode haver diminuição da eficiência de remoção e que o reator pode não atingir a estabilidade se o tempo de enchimento for muito longo. Os autores creditaram estes fatores devido ao stress da biomassa e a falta de matéria orgânica no material suporte devido à falta de substrato durante o período de alimentação. 
Figura 5.67 - Comparação entre dados de concentração de matéria orgânica na forma de DQO (a) e sua eficiência de remoção (b) após mudança de estratégia de alimentação
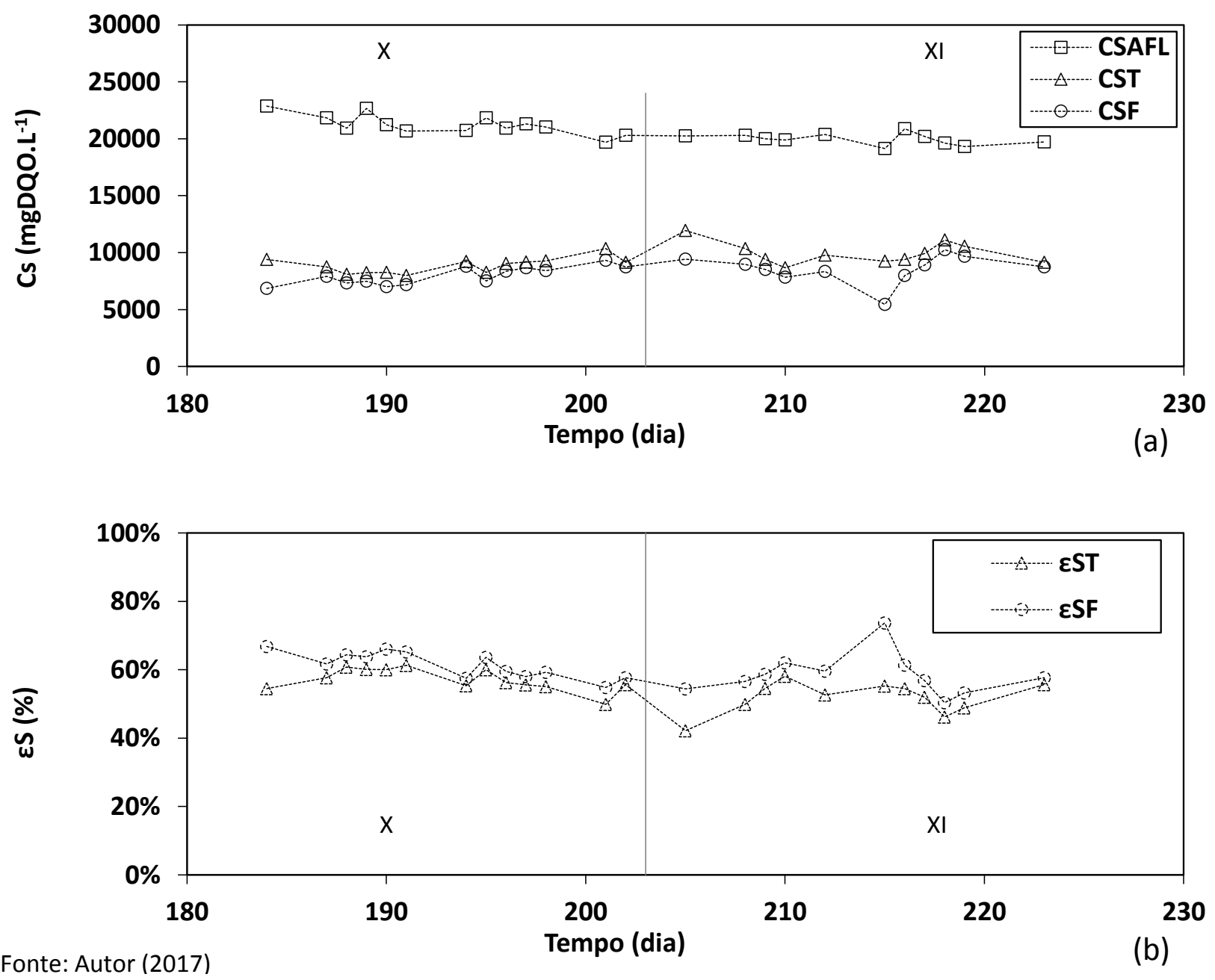
Figura 5.68 - Comparação entre dados de concentração de matéria orgânica na forma de Carboidratos (a) e sua eficiência de remoção (b) após mudança de estratégia de alimentação
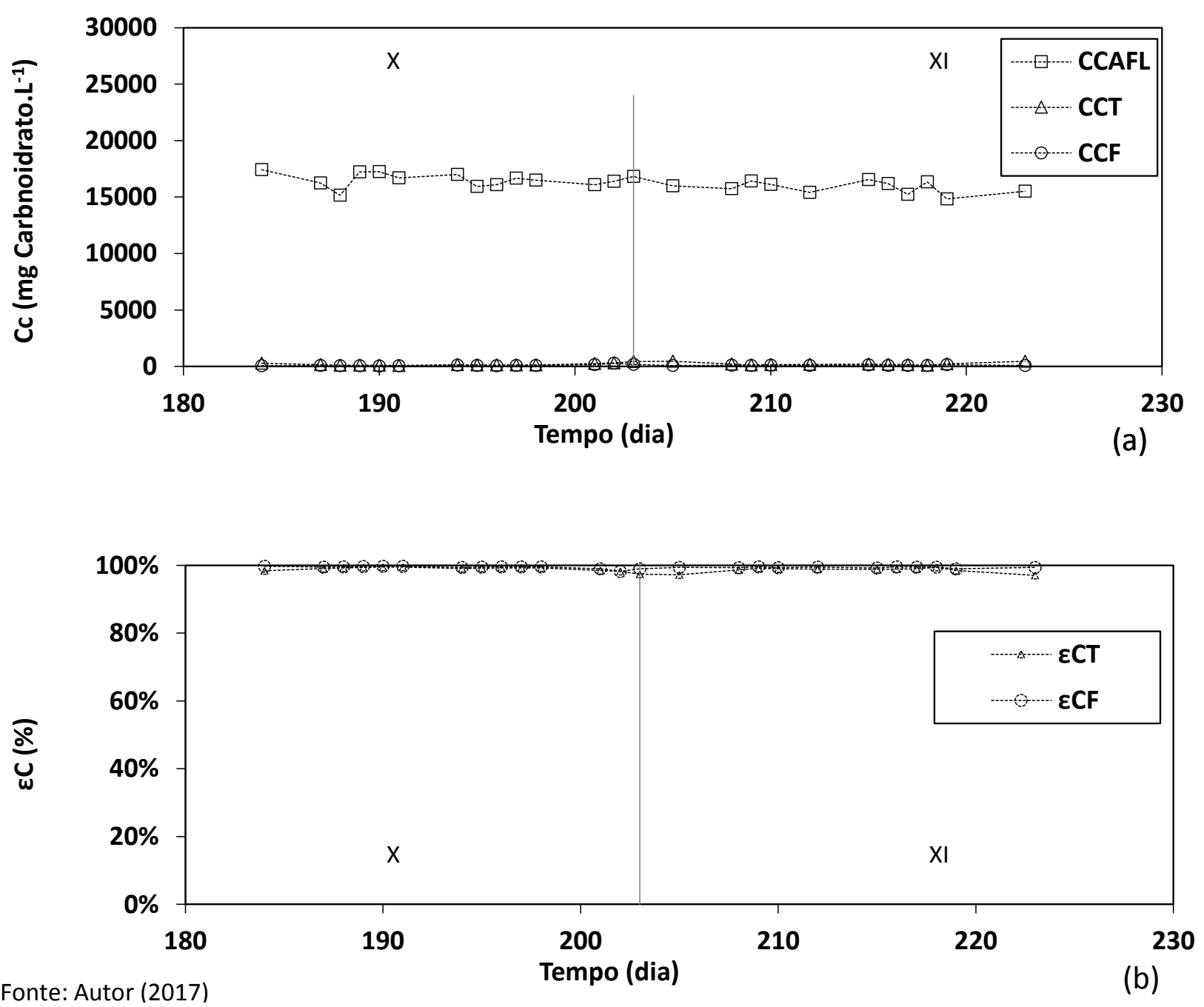

A Figura 5.69 apresenta as concentrações de sólidos do afluente e efluente para as duas etapas de operação. Observa-se que houve pequena aumento nas concentrações de sólidos totais do efluente, provavelmente devido à alta produção de polímeros. Visivelmente, a produção destes compostos foi maior durante a operação em batelada alimentada. Outro fator que comprova tal evidência foi a redução do volume útil do reator, que passou de 1,1 litros na condição X para $0,9 \mathrm{~L}$ na condição XI. Essa redução no volume útil devido à presença de polímeros no meio fez com que a carga orgânica aplicada fosse de 31,68 gDQO.L $\mathrm{L}^{-1} \cdot \mathrm{d}^{-1}$ na batelada alimentada, enquanto que a 
batelada foi de $30,34 \mathrm{gDQO} \cdot \mathrm{L}^{-1} \cdot \mathrm{d}^{-1}$, sendo a concentração afluente mantida. Dessa forma, deve-se controlar a concentração de polímeros quando se opera o reator com altas cargas tanto em batelada quanto em batelada alimentada. Uma maneira de executar este processo seria a limpeza periódica das mangueiras de alimentação e do reator.

Figura 5.69 - Comparação entre concentração de sólidos no afluente e efluente após mudança de estratégia de alimentação

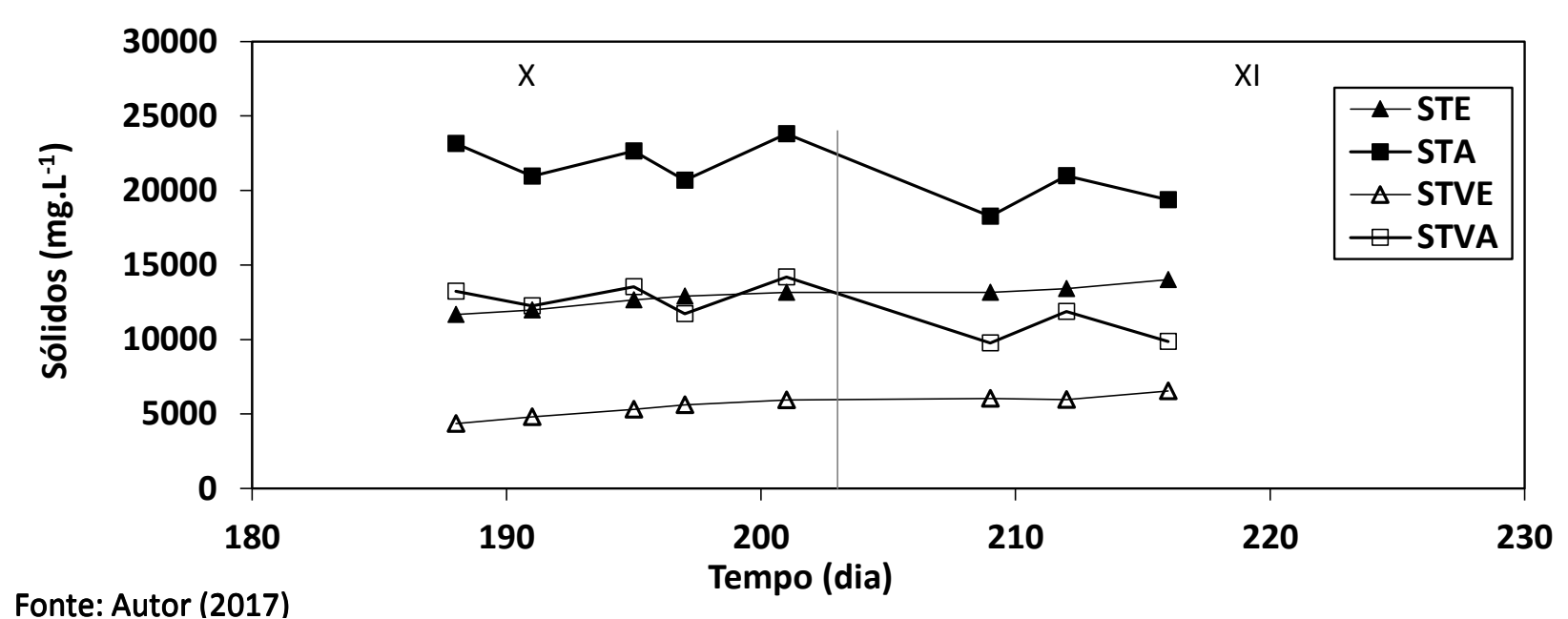

5.4.2.3 Indicadores de desempenho relacionados à produção de metano

A Figura 5.70 apresenta os valores de volume e composição do biogás gerados nas duas etapas. Percebe-se que houve piora significativa em relação ao volume e composição de biogás durante a batelada alimentada. Em relação a produção de metano, a batelada gerou $4840 \mathrm{~mL}-$ $\mathrm{CNTPCH}_{4} \cdot \mathrm{Ciclo}^{-1}$, representando $67,63 \%$ da produção de biogás. A batelada alimentada teve produção média de $3889 \mathrm{~mL}-\mathrm{CNTPCH}_{4} \cdot \mathrm{Ciclo}^{-1}$ de metano, 62,58\% da produção total de biogás. Além disso, o rendimento molar de metano foi de 10,16 contra 8,60 $\mathrm{mmolCH}_{4} . \mathrm{gDQO}^{-1}$, para batelada e batelada alimentada, respectivamente. Tais resultados são decorrentes da interpretação VERSÃO CORRIGIDA 
anterior, ou seja, a produção de biogás está relacionada com o aproveitamento da matéria orgânica (RODRIGUES et al., 2011, LOVATO, ALBANEZ e FONTES LIMA et al, 2015).

Figura 5.70 - Comparação entre volume de biogás gerado (a) e composição do biogás (b) após mudança de estratégia de alimentação
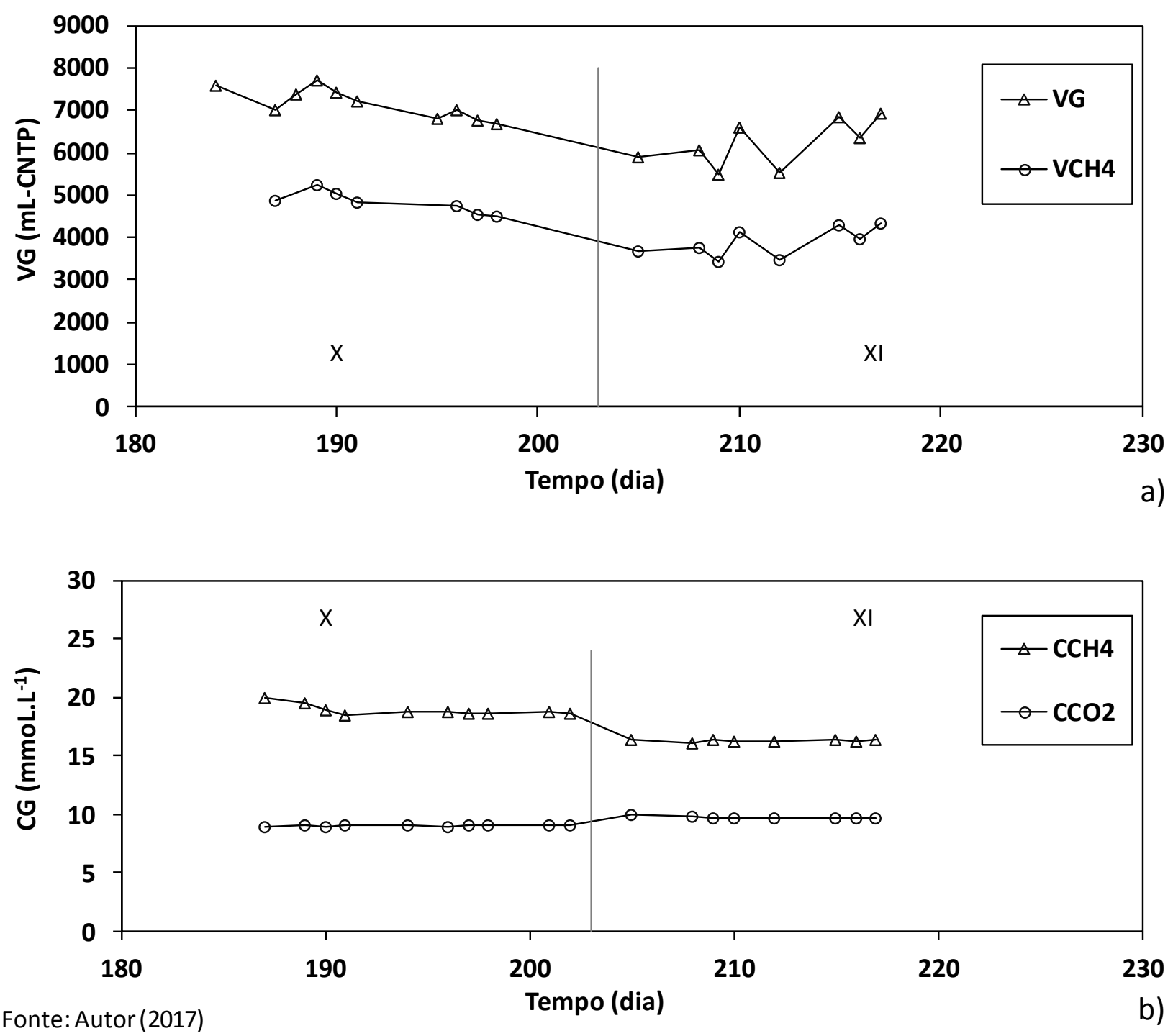
5.4.2.4 Indicadores de desempenho relacionados ao ajuste do modelo cinético

A Tabela 5.26 apresenta os resultados do ajuste cinético após mudança da estratégia de alimentação. Em ambas as condições de estudo o modelo cinético foi ajustado de modo adequado aos dados experimentais. Percebe-se que, tanto na batelada, quanto na batelada alimentada, a rota preferencial de consumo do substrato foi a de geração do ácido acético. Durante a acetogênese, em ambas as condições a formação do acetato foi predominante devido à degradação do ácido propiônico e a rota hidrogenotrófica foi predominante, entretanto, houve também a presença da rota acetoclástica. 
Tabela 5.26 - Resumo dos parâmetros cinéticos durante a mudança da estratégia de alimentação

\begin{tabular}{cccc}
\hline Condição & Parâmetro & Condição X & Condição XI \\
\hline & $\mathrm{k}_{1 \mathrm{~S}}\left(\mathrm{~h}^{-1}\right)$ & 0,28 & 0,17 \\
& $\mathrm{k}_{1 \mathrm{HAc}}\left(\mathrm{h}^{-1}\right)$ & 0,34 & 0,20 \\
& $\mathrm{k}_{1 \mathrm{H}}\left(\mathrm{h}^{-1}\right)$ & 0,00 & 0,00 \\
& $\mathrm{k}_{2 \mathrm{HPr}}\left(\mathrm{h}^{-1}\right)$ & 0,33 & 0,00 \\
Hidrólise e & $\mathrm{k}_{2 \mathrm{H}}\left(\mathrm{h}^{-1}\right)$ & 0,00 & 0,00 \\
& $\mathrm{k}_{3 \mathrm{HBu}}\left(\mathrm{h}^{-1}\right)$ & 0,00 & 0,00 \\
& $\mathrm{k}_{3 \mathrm{H}}\left(\mathrm{h}^{-1}\right)$ & 0,00 & 0,00 \\
& $\mathrm{k}_{4 \mathrm{HVa}}\left(\mathrm{h}^{-1}\right)$ & 0,01 & 0,01 \\
& $\mathrm{k}_{4 \mathrm{H}}\left(\mathrm{h}^{-1}\right)$ & 0,00 & 0,00 \\
& $\mathrm{k}_{5 \mathrm{ETOH}}\left(\mathrm{h}^{-1}\right)$ & 0,00 & 0,00 \\
\hline & $\mathrm{k}_{6 \mathrm{HPr}}\left(\mathrm{h}^{-1}\right)$ & 1,45 & 1,28 \\
& $\mathrm{k}_{6 \mathrm{HAc}}\left(\mathrm{h}^{-1}\right)$ & 17,77 & 42,65 \\
& $\mathrm{k}_{6 \mathrm{H}}\left(\mathrm{h}^{-1}\right)$ & 0,00 & 0,00 \\
& $\mathrm{k}_{7 \mathrm{HPr}}\left(\mathrm{h}^{-1}\right)$ & 1,52 & 4,26 \\
& $\mathrm{k}_{7 \mathrm{HBu}}\left(\mathrm{h}^{-1}\right)$ & 0,00 & 0,99 \\
& $\mathrm{k}_{7 \mathrm{H}}\left(\mathrm{h}^{-1}\right)$ & 0,00 & 0,00 \\
& $\mathrm{k}_{8 \mathrm{HBu}}\left(\mathrm{h}^{-1}\right)$ & 0,17 & 5,65 \\
& $\mathrm{k}_{8 \mathrm{HVa}}\left(\mathrm{h}^{-1}\right)$ & 0,00 & 0,93 \\
& $\mathrm{k}_{8 \mathrm{H}}\left(\mathrm{h}^{-1}\right)$ & 0,00 & 0,00 \\
& $\mathrm{~K}_{9 \mathrm{HAc}}\left(\mathrm{h}^{-1}\right)$ & 0,00 & 0,00 \\
\hline & $\mathrm{k}_{10 \mathrm{HAc}}\left(\mathrm{h}^{-1}\right)$ & 2,07 & 2,84 \\
& $\mathrm{k}_{10 \mathrm{H}}\left(\mathrm{h}^{-1}\right)$ & 0,38 & 0,11 \\
& $\mathrm{k}_{11 \mathrm{H}}\left(\mathrm{h}^{-1}\right)$ & 0,08 & 0,00 \\
$\mathrm{k}_{11 \mathrm{M}}\left(\mathrm{h}^{-1}\right)$ & 109,85 & 185,87 \\
\hline & & &
\end{tabular}

\subsection{Estimativa de produção energética}

A estimativa da recuperação energética da aplicação do reator AnSBBR termofílico estudado no projeto no tratamento do soro gerado foi realizada levando em consideração a capacidade produtiva de pequenos, médios e grandes produtores de laticínios. Para os devidos cálculos, foi considerada uma produção mensal de $200 \mathrm{~kg} \cdot \mathrm{mês}^{-1}$ de queijo para pequenos produtores, normalmente de produção artesanal familiar. A produção mensal de médios produtores foi estimada em $20.000 \mathrm{~kg} \cdot \mathrm{mês}^{-1}$, representando de industrias de laticínio e cooperativas 
regionais. A produção dos grandes produtores foi obtida de relatório anuais de grandes empresas de laticínios (https://www.brf-global.com/ - acesso em julho de 2017), com capacidade de distribuição para todo o Brasil, sendo a produção de uma única planta estimada em 1.000.000 kg.mês ${ }^{-1}$. Para os cálculos de volume de soro gerado, adotou-se a relação de 9 $\mathrm{kg}$ de soro para cada $1 \mathrm{~kg}$ de queijo produzido (LOVATO et al., 2016). Sendo assim, a produção de efluente gerado para pequenos, médios e grandes produtores, respectivamente, foram de $0,06,6,0$ e $300 \mathrm{~m}^{3} \cdot \mathrm{d}^{-1}$ de soro.

A concentração adotada para a água residuária de estudo foi de $20.000 \mathrm{mgDQO} . \mathrm{L}^{-1}$ valor máximo do projeto em estudo (a concentração do soro obtido na indústria é de até $80 \mathrm{gDQO} \cdot \mathrm{L}^{-1}$ ) (BEZERRA et al., 2007; LOVATO et al., 2016). A entalpia de combustão do metano foi adotada como 803 kJ/mol $\mathrm{CH}_{4}$ (PERRY \& GREEN, 1997). Os valores das concentrações de matéria orgânica na forma de DQO afluente e efluente, rendimento molar de metano por matéria orgânica removida (RMCR), bem como os volumes residual e alimentado foram referentes às condições de estudo.

Para o cálculo da produção de metano para recuperação energética foi realizada uma estimativa de aumento de escala do reator de bancada para um reator de escala industrial, seguindo a metodologia apresentada por Albanez et al. (2016b). O volume total representa todo o volume necessário para o tratamento do soro gerado, o Volume líquido é representante do volume de reação do reator, descontado o volume de material suporte do volume total. O volume do reator é o volume em escala real do sistema de tratamento de soro estimado, representado por 4 reatores em paralelo com o volume especificado. Os quatro reatores operam de forma sequencial, no momento de alimentação de um reator, dois estão em período de reação e o outro está em período de descarga. Desta forma, mantém-se operação constante durante o dia inteiro com três ciclos em cada reator. Os 
valores calculados foram utilizados nos cálculos de produção de metano em escala real e, por conseguinte, para o cálculo da recuperação energética, população abastecida e economia.

A Tabela 5.27 apresenta os resultados dos cálculos da produção de energia pela combustão do metano gerado no tratamento de soro em condição termofílica. A condição em que houve maior recuperação energética foi a condição $\mathrm{V}$, por apresentar os melhores resultados de rendimento molar entre metano produzido e matéria orgânica consumida, ou seja, balanço entre produção de metano e consumo de matéria orgânica. Apesar disso, a condição VIII foi tida como a melhor condição quando se analisa todas as variáveis, pois apresentou melhores resultados globais no estudo do reator. Também é notável que a mudança de estratégia de alimentação acarretou em perdas para o sistema quando é comparada a recuperação energética, visto que a condição $\mathrm{X}$ apresentou maior recuperação energética para as três escalas de produção de queijo.

Tabela 5.27 - Estimativa da recuperação energética para diferentes escalas de produção de queijo

\begin{tabular}{cccccccccccc}
\hline Condição & I & II & III & IV & V & VI & VII & VIII & IX & X & XI \\
\hline $\begin{array}{c}\text { Pequeno Produtor } \\
\text { (MWh.mês }\end{array}$ ) & 0,14 & 0,14 & 0,14 & 0,16 & 0,17 & 0,15 & 0,12 & 0,11 & 0,11 & 0,08 & 0,08 \\
$\begin{array}{c}\text { Médio Produtor } \\
\left(\text { MWh mês }^{-1} \text { ) }\right.\end{array}$ & 13,86 & 14,10 & 13,73 & 16,27 & 16,52 & 14,55 & 12,24 & 10,97 & 10,60 & 8,45 & 7,89 \\
$\begin{array}{c}\text { Grande Produtor } \\
\left(\text { MWh mês }^{-1} \text { ) }\right.\end{array}$ & 692,81 & 705,24 & 686,44 & 813,56 & 826,10 & 727,33 & 612,11 & 548,40 & 530,05 & 422,56 & 394,33 \\
\hline
\end{tabular}

Com esses dados estimados, foi possível calcular os valores de abastecimento urbano e economia mensal em relação ao uso de combustíveis bastante utilizados na geração de energia (Tabela 5.28). A estimativa foi calculada a partir dos dados de consumo per capita de energia elétrica no Brasil (valor médio de $160 \mathrm{kWh} \cdot \mathrm{hab}^{-1}$ - dados fornecidos pela ANEEL http://www.aneel.gov.br/ - acessado em novembro de 2017) e dos valores do $\mathrm{m}^{3}$ e poder calorífico inferior do gás natural (R\$ 1,88 por $\mathrm{m}^{3}$ - COMGAS - https://www.comgas.com.br/tarifas/ - 
acessado em novembro de 2017 e $8800 \mathrm{kcal} \cdot \mathrm{kg}^{-1}$ - ANP - http://www.anp.gov.br - acessado em novembro de 2017) e do óleo diesel (R\$ 3303 por $\mathrm{m}^{3}$ e $\left.10100 \mathrm{kcal}^{\mathrm{k}} \mathrm{kg}^{-1}-\mathrm{ANP}\right)$. Os resultados mostraram que, com a recuperação energética obtida considerando os dados da Condição VIII e a produção de um grande produtor, seria possível abastecer uma população de 3427 habitantes. Além disso, seria possível a economia de 135 mil reais por mês em comparação ao uso de gás natural para geração de energia, ou então, 183 mil reais em relação ao uso do óleo diesel. Com os resultados encontrados na melhor condição de recuperação energética (condição V), seria possível abastecer 5163 habitantes, economizando 204 e 275 mil reais por mês em substituição ao gás natural e óleo diesel, respectivamente. A Tabela 5.28 apresenta os valores de abastecimento e economia para todas as condições de estudo em referência à produção de grande escala.

Tabela 5.28 - Resumo da estimativa de aumento de escala e de abastecimento de população equivalente e economia em relação a uso de gás natural e óleo diesel na geração de energia para um grande produtor

\begin{tabular}{cccccccc}
\hline Condição & $\begin{array}{c}\text { Volume } \\
\text { Total }\left(\mathrm{m}^{3}\right)\end{array}$ & $\begin{array}{c}\text { Volume } \\
\text { Líquido }\left(\mathrm{m}^{3}\right)\end{array}$ & $\begin{array}{c}\text { Volume do } \\
\text { Reator }\left(\mathrm{m}^{3}\right)\end{array}$ & $\begin{array}{c}\text { População } \\
\text { Abastecida }\end{array}$ & \multicolumn{2}{c}{$\begin{array}{c}\text { Economia } \\
\text { Gás Natural }\end{array}$} & \multicolumn{2}{c}{$\begin{array}{c}\text { Economia } \\
\text { Óleo Diesel }\end{array}$} \\
\hline I & 2046 & 1032 & 512 & 4.330 & $\mathrm{R} \$ 171.438,94$ & $\mathrm{R} \$$ & $231.192,60$ \\
II & 1590 & 827 & 398 & 4.408 & $\mathrm{R} \$ 174.514,20$ & $\mathrm{R} \$$ & $235.339,72$ \\
III & 1401 & 704 & 350 & 4.290 & $\mathrm{R} \$ 169.863,85$ & $\mathrm{R} \$$ & $229.068,53$ \\
$\mathrm{IV}$ & 1196 & 599 & 299 & 5.085 & $\mathrm{R} \$ 201.319,84$ & $\mathrm{R} \$$ & $271.488,25$ \\
$\mathrm{~V}$ & 934 & 479 & 233 & 5.163 & $\mathrm{R} \$ 204.422,39$ & $\mathrm{R} \$$ & $275.672,16$ \\
VI & 816 & 359 & 204 & 4.546 & $\mathrm{R} \$ 179.982,83$ & $\mathrm{R} \$$ & $242.714,40$ \\
VII & 692 & 319 & 173 & 3.826 & $\mathrm{R} \$ 151.468,69$ & $\mathrm{R} \$$ & $204.261,88$ \\
VIII & 631 & 250 & 158 & 3.427 & $\mathrm{R} \$ 135.703,29$ & $\mathrm{R} \$$ & $183.001,58$ \\
$\mathrm{IX}$ & 554 & 244 & 138 & 3.313 & $\mathrm{R} \$ 131.163,87$ & $\mathrm{R} \$$ & $176.879,97$ \\
$\mathrm{X}$ & 453 & 190 & 113 & 2.641 & $\mathrm{R} \$ 104.564,24$ & $\mathrm{R} \$$ & $141.009,26$ \\
$\mathrm{XI}$ & 496 & 190 & 124 & 2.465 & $\mathrm{R} \$ 97.577,84$ & $\mathrm{R} \$$ & $131.587,80$ \\
\hline
\end{tabular}

Para se realizar a comparação entre os resultados descritos na literatura e a do presente projeto, foi utilizado no cálculo da recuperação energética os volumes de produção obtidos nos trabalhos de Albanez et al. (2016a), Albuquerque (2017) e Almeida et al. (2017), que foi de 7753,3 $\mathrm{m}^{3} \cdot \mathrm{d}^{-1}$ de vinhaça, mas mantendo-se a concentração de $20.000 \mathrm{mgDQO} . \mathrm{L}^{-1}$ adotada para o soro.

\section{VERSÃO CORRIGIDA}


No trabalho de Albanez et al. (2016a), obteve-se produção de 13,1 GWh.mês ${ }^{-1}$ no aproveitamento do biogás de um reator AnSBBR tratando vinhaça em condições mesofílicas. A concentração afluente foi de $5000 \mathrm{mgDQO} . \mathrm{L}^{-1}$, COVR de 4,6 gDQO.L ${ }^{-1} \cdot \mathrm{d}^{-1}$, em que obteve-se $83 \%$ de remoção de matéria orgânica na forma de DQO e rendimento molar removido de 9,74 $\mathrm{mmolCH}_{4} . \mathrm{gDQO} . \mathrm{L}^{-1}$. Nas mesmas proporções de produção de efluente, o presente projeto obteria recuperação de 17,9 GWh.mês ${ }^{-1}$, calculado utilizando a condição I, que obteve $93 \%$ de eficiência de remoção de DQO, 21,07 $\mathrm{mmolCH}_{4} . \mathrm{gDQO} . \mathrm{L}^{-1}$ de rendimento molar removido de metano $\left(\mathrm{RMCR}_{\mathrm{MO}}\right)$ e COVR de $5,48 \mathrm{gDQO} \cdot \mathrm{L}^{-1} \cdot \mathrm{d}^{-1}$.

Almeida et al. (2017) encontraram recuperação energética de 17,9 GWh.mês ${ }^{-1}$ em um AnSBBR aplicado ao tratamento de vinhaça em condição mesofílica. O resultado foi obtido quando o reator operou com concentração afluente de $10000 \mathrm{mgDQO} \cdot \mathrm{L}^{-1}$. Nesta condição, os autores obtiveram COVR de 9,8 gDQO.L $\mathrm{L}^{-1} \cdot \mathrm{d}^{-1}$, eficiência de remoção de matéria orgânica na forma de DQO de $97 \%$ e rendimento de metano gerado por matéria orgânica removida de 12,6 $\mathrm{mmolCH}_{4} \cdot \mathrm{gDQO} . \mathrm{L}^{-1}$. Em condições semelhantes (condição V), o presente projeto apresentou recuperação energética de 21,3 GWh.mês ${ }^{-1}$, apresentando eficiência de remoção de DQO de $99 \%$, com COVR de 11,88 gDQO.L ${ }^{-1} \cdot \mathrm{d}^{-1}$ e $\mathrm{RMCR}_{\mathrm{S}}$ de 21,07 $\mathrm{mmolCH}_{4} \cdot \mathrm{gDQO} \cdot \mathrm{L}^{-1}$. Ressalta-se que a condição V apresentou os melhores resultados em termos de recuperação energética.

Albuquerque (2017) obteve produção de 21,8 GWh.mês ${ }^{-1}$ no aproveitamento do biogás de um reator AnSBBR tratando vinhaça em condição termofílica. A concentração afluente foi de 20000 mgDQO.L ${ }^{-1}$, COVR de 19,4 gDQO.L ${ }^{-1} \cdot \mathrm{d}^{-1}$, em que obtiveram $90 \%$ de remoção de matéria orgânica na forma de DQO e rendimento molar removido de 18,10 mmolCH $4 . \mathrm{gDQO}^{-1}$, sendo a COVA $_{S}$ de 25,1 gDQO.L $L^{-1} \cdot d^{-1}$. Para efeito de comparação, utilizou-se a condição VIII, em que a $\mathrm{COVA}_{\mathrm{S}}$ do presente projeto foi de $24,78 \mathrm{gDQO} \cdot \mathrm{L}^{-1} \cdot \mathrm{d}^{-1}$. Nas mesmas proporções de produção de efluente, o presente projeto obteria recuperação de $14,2 \mathrm{GWh}_{\mathrm{m}} \mathrm{e}^{-1}$, obtendo $84 \%$ de eficiência de 
remoção de DQO, 15,49 $\mathrm{mmolCH}_{4} . \mathrm{gDQO} . \mathrm{L}^{-1}$ de rendimento molar removido de metano $\left(\mathrm{RMCR}_{\mathrm{MO}}\right)$ e COVR de 20,91 gDQO.L ${ }^{-1}$.

Dessa forma, comprovou-se que a condição termofílica em elevadas cargas orgânicas proporcionou maior geração de energia pelo reator AnSBBR tratando tanto vinhaça, como soro. Vale ressaltar que os aspectos relacionados à manutenção da temperatura de operação em $55^{\circ} \mathrm{C}$ e a quantidade de bicarbonato adicionada não foram analisados neste projeto.

\subsection{Análise microbiológica}

A análise da biomassa aderida ao material suporte permitiu identificar a comunidade responsável pelas biotransformações ocorridas no reator. Constatou-se grande concentração de microrganismos em todas as condições, sendo que houve predominância de filamentosas, bastonetes e cocos. Em algumas condições pôde ser observado estruturas brilhantes internas aos bastonetes, indicando presença de endósporos, que podem representar condições ambientais desfavoráveis à comunidade por serem uma forma de resistência dos microrganismos à estas adversidades. Pela aplicação da técnica da fluorescência foi possível identificar bastonetes fluorescentes devido a presença da proteína F420, característica observada em arqueias metanogênicas. Dessa forma, é possível concluir que o material suporte foi efetivo na manutenção dos microrganismos, uma vez que estas análises foram realizadas removendo a biomassa do interior das espumas de poliuretano.

O exame das Figuras 5.71 a 5.75, indica que houve pouca mudança na composição dos microrganismos no interior do reator. A maior quantidade visível é a de microrganismos na forma de bastonetes, os quais abrigam muitas vezes pequenos pontos brancos, atribuídos aos endósporos

\section{VERSÃO CORRIGIDA}


de Clostridium sp. A visualização de filamentosas pode indicar a presença de Methanosaetas, que são os microrganismos responsáveis pela assimilação do acetato (GARCIA et al., 2000).

A densidade de microrganismos nas últimas condições aparenta ser menor mais isto não significa que a concentração de biomassa era menor nestas condições de fato. Isso aconteceu devido ao método de preparação das placas para visualização em microscópio, uma vez que foi necessário realizar maiores diluições quando a concentração de soro era maior, isso porque, além da provável maior concentração de biomassa nestas condições, o soro, que é um coloide, também está presente na visualização. Nas imagens, as nuvens brancas disformes ou grandes círculos brancos foram atribuídos aos coloides do soro.

Figura 5.71 - Morfologia dos microrganismos presentes na biomassa imobilizada contida no reator na Condição I: 1000X sem fluorescência (a), 1000X com fluorescência (b)
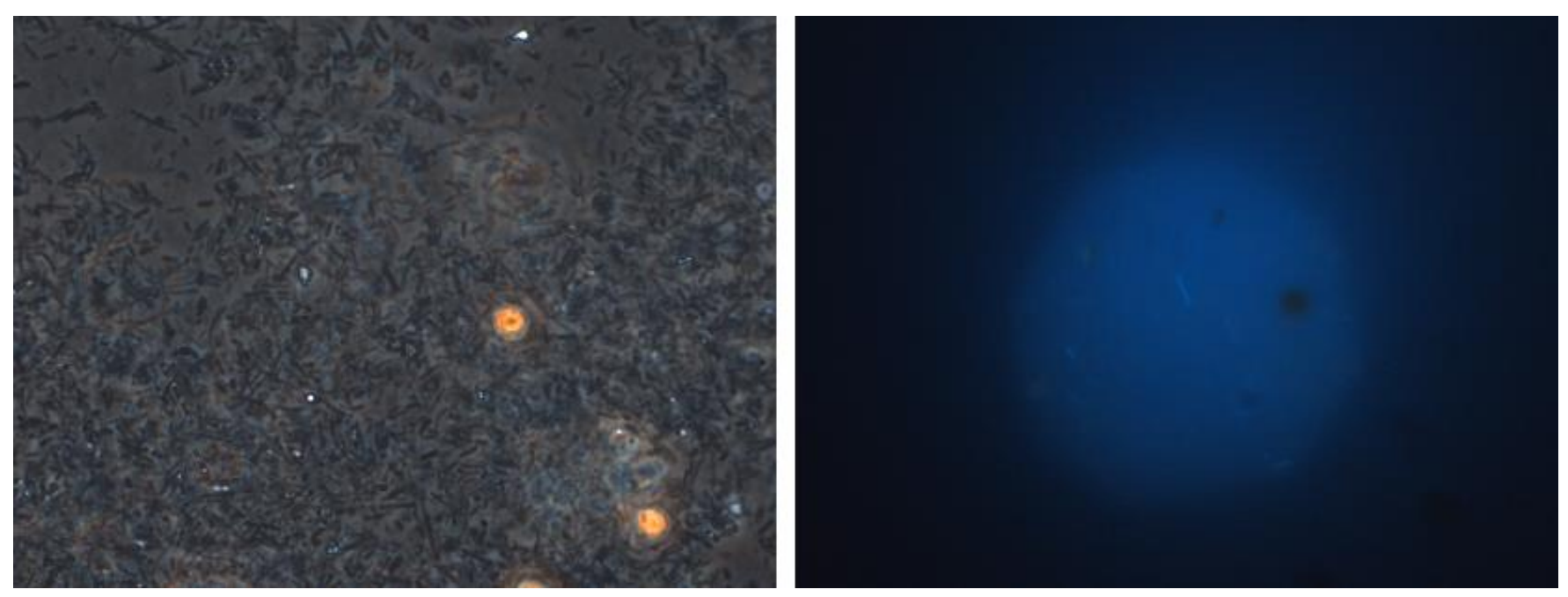

Fonte: Autor (2017) 
Figura 5.72 - Morfologia dos microrganismos presentes na biomassa imobilizada contida no reator na Condição III: 1000X sem fluorescência (a), 1000X com fluorescência (b)
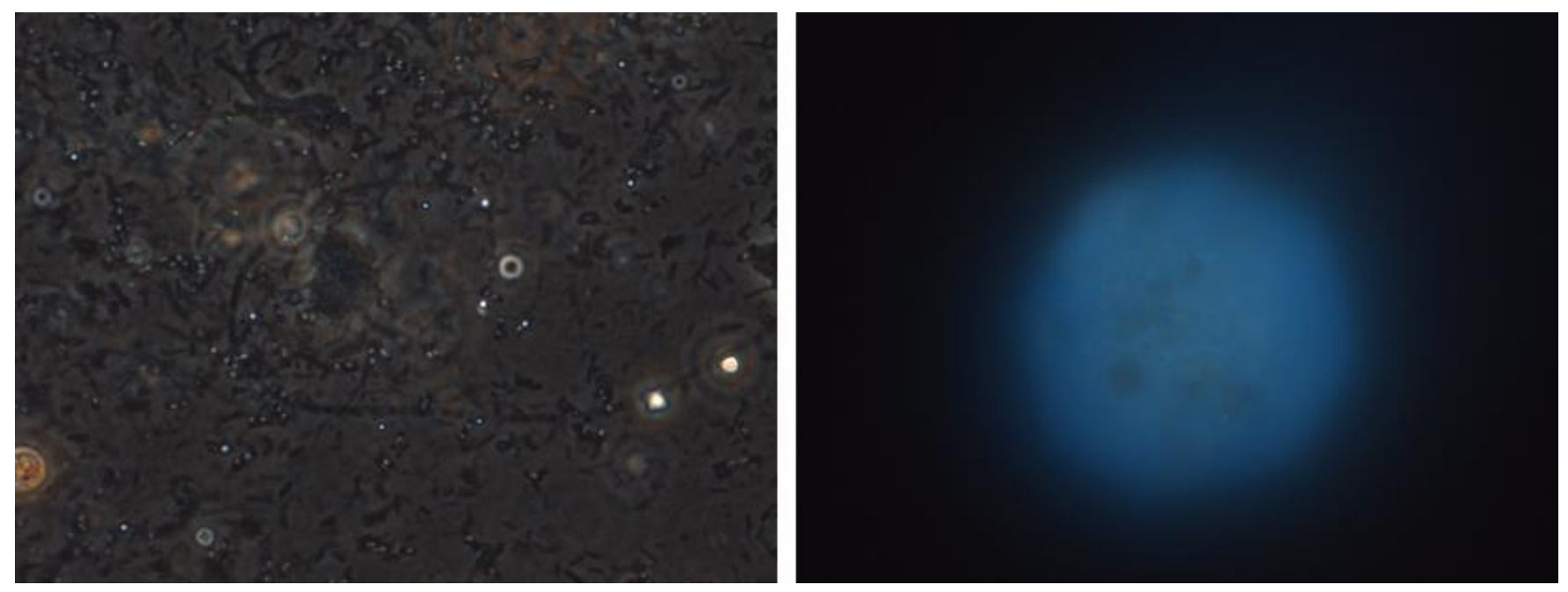

Fonte: Autor (2017)

Figura 5.73 - Morfologia dos microrganismos presentes na biomassa imobilizada contida no reator na Condição IX: 1000X sem fluorescência (a), 1000X com fluorescência (b)
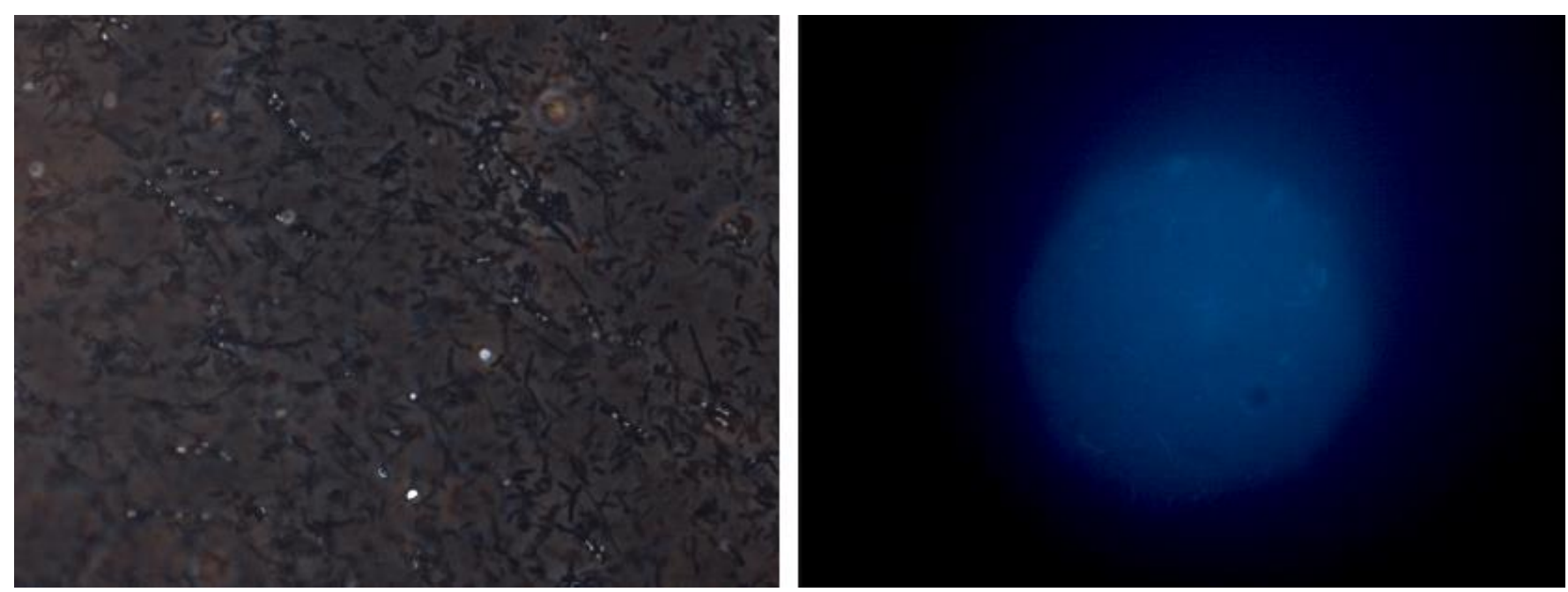

Fonte: Autor (2017) 
Figura 5.74 - Morfologia dos microrganismos presentes na biomassa imobilizada contida no reator na Condição X: 1000X sem fluorescência (a), 1000X com fluorescência (b)
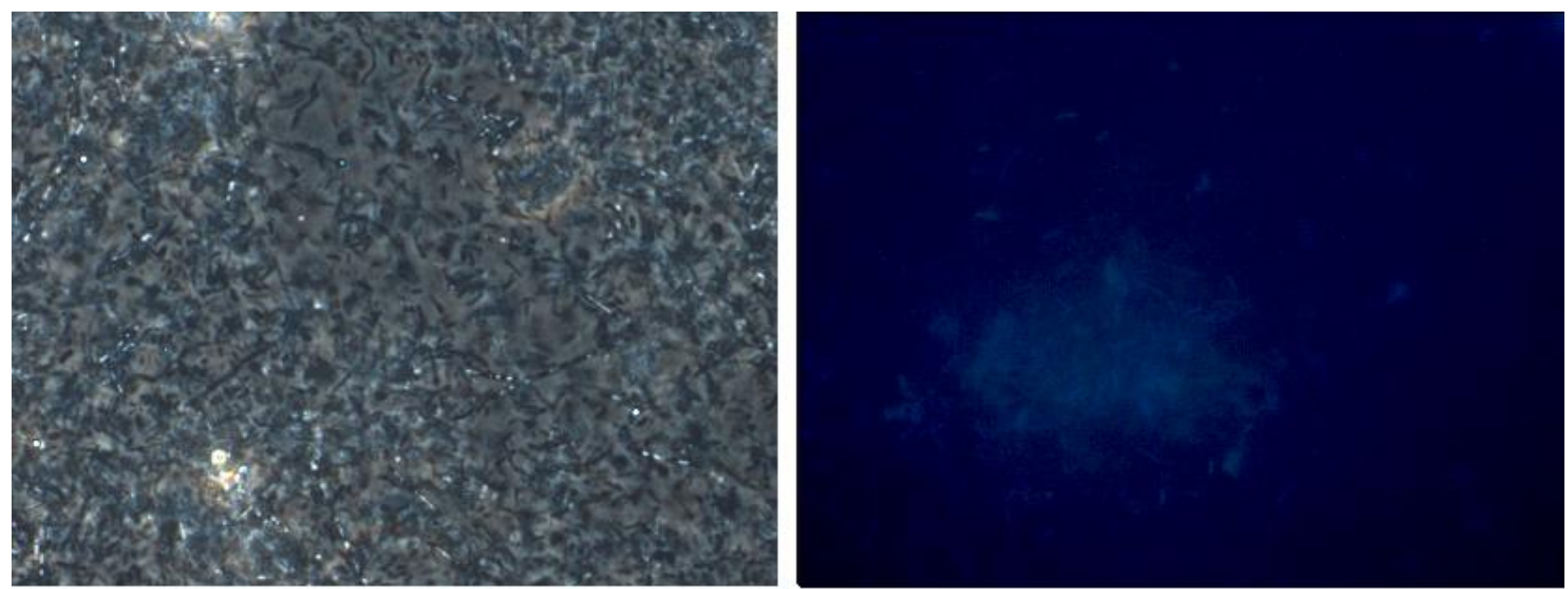

Fonte: Autor (2017)

Figura 5.75 - Morfologia dos microrganismos presentes na biomassa imobilizada contida no reator na Condição XI: 1000X sem fluorescência (a), 1000X com fluorescência (b)
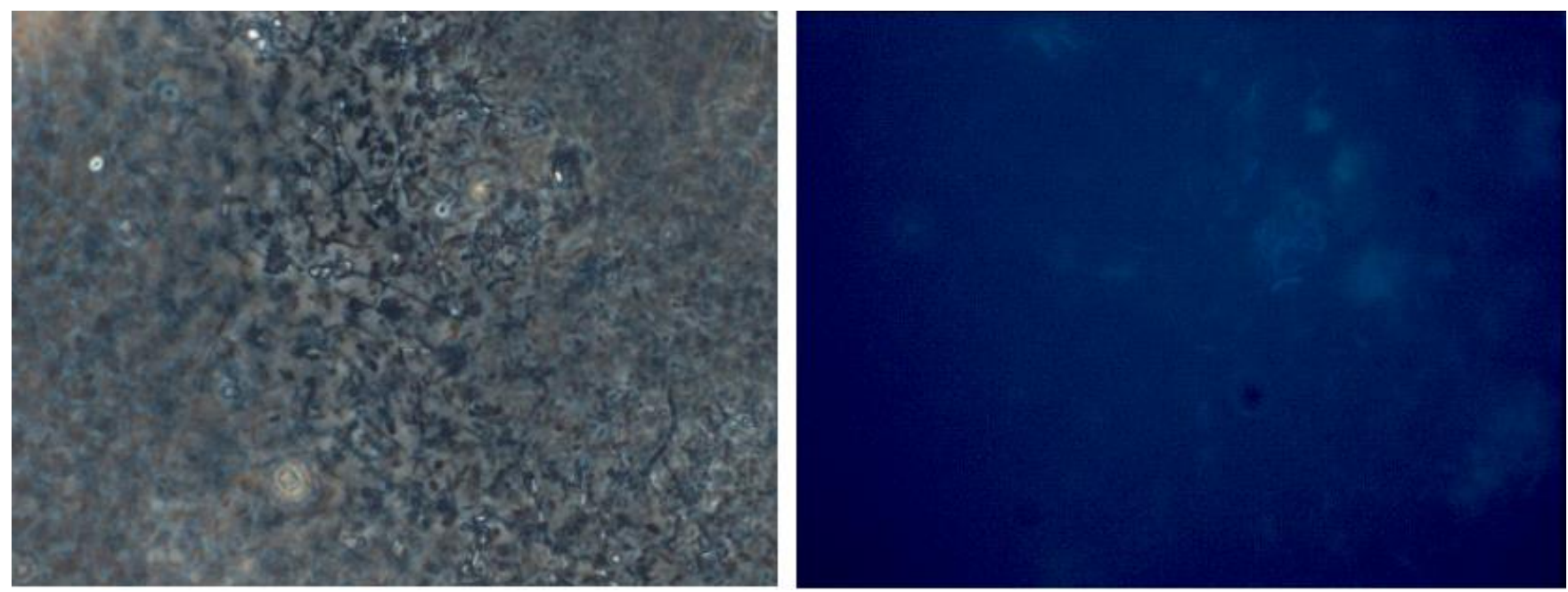

Fonte: Autor (2017) 


\subsection{Comparação com a literatura}

Comparou-se o desempenho do reator deste projeto com outros reatores tratando soro ou outros efluentes, como a vinhaça.

A melhor condição global do presente projeto se foi na COVA de 24,78 gDQO.L ${ }^{-1} \cdot \mathrm{d}^{-1}$ (condição VIII). Nesta condição, a eficiência de remoção de matéria orgânica na forma de DQO foi de $85,8 \%$, para amostras filtradas, com eficiência de remoção de 99,6 \% de carboidratos, também na forma filtrada. O rendimento de metano gerado por matéria orgânica consumida foi de 13,07 $\mathrm{mmolCH}_{4} \cdot \mathrm{gDQO}^{-1}$, sendo a produção de biogás de $6506 \mathrm{~mL}-\mathrm{CNTP}$. ciclo $^{-1}$, com fração molar de metano equivalente a 73,7 \%. A produtividade molar de metano alcançada nesta condição foi de $324,0 \mathrm{molCH}_{4} \cdot \mathrm{m}^{-3} \cdot \mathrm{d}^{-1}$.

Lovato et al. (2016) operando um reator AnSBBR com recirculação de fase líquida utilizando 7,5 gDQO. $\mathrm{L}^{-1} \cdot \mathrm{d}^{-1}$ em condição mesofílica $\left(30^{\circ} \mathrm{C}\right)$, obteve eficiência média de remoção de DQO de 90,0 $\pm 4,0 \%$, rendimento molar de metano de $12,6 \mathrm{mmolCH}_{4} \cdot \mathrm{gDQO}^{-1}, 73 \%$ de metano no biogás e produtividade molar de $93,7 \mathrm{molCH}_{4} \cdot \mathrm{m}^{-3} \cdot \mathrm{d}^{-1}$, ácidos voláteis totais e $\mathrm{pH}$ do efluente de 266 mgHAc. $L^{-1}$ e 7,7, respectivamente. Além disso, foi obtido uma relação de 73,3 \% de ácido acético e 26,7\% de ácido propiônico no efluente do reator, sem presença de ácido butírico ou valérico. Em condições semelhantes, quando se se aplicou COVA de 7,63 gDQO. $\mathrm{L}^{-1} . \mathrm{d}^{-1}$, o presente projeto apresentou eficiência de remoção de matéria orgânica na forma de DQO de $95 \%$, rendimento de metano gerado por matéria orgânica consumida de $16,52 \mathrm{mmolCH}_{4} \cdot \mathrm{gDQO}^{-1}$, fração molar de metano foi de $73,2 \%$ e produtividade molar de metano de $126,1 \mathrm{molCH}_{4} \cdot \mathrm{m}^{-3} \cdot \mathrm{d}^{-1}$. Respectivamente, os valores de ácidos voláteis totais e $\mathrm{pH}$ do efluente foram de $87 \mathrm{mgHAc} . \mathrm{L}^{-1}$ e 8,2 . A fração de ácidos intermediários no efluente do reator foi de 50,6 \% de ácido acético, 27,9 \% de ácido propiônico 13,4 \% de ácido valérico e 8,3 \% de ácido butírico, indicando uma variedade maior de VERSÃO CORRIGIDA 
ácidos produzidos em condição termofílica. O ganho de desempenho pode ser creditado à utilização da condição termofílica, em que as velocidades de reação são maiores, podendo-se obter eficiências maiores. Apesar do ganho técnico, a operação em condição termofílica possui um maior custo econômico e dificuldade de operação que não foram levados em consideração.

Damasceno et al. (2007) trataram soro em reator AnSBBR em condição mesofílica para estudar a influência do tempo de alimentação e carga aplicada sobre a eficiência do reator. Os autores obtiveram remoção média de DQO de $78 \%$, com 66,4 \% de metano no biogás resultante quando a carga orgânica aplicada foi de $12 \mathrm{gDQO} \cdot \mathrm{L}^{-1} \cdot \mathrm{d}^{-1}$ operado em batelada convencional. O presente projeto, com COVA de 12,80 gDQO.L $\mathrm{L}^{-1} \cdot \mathrm{d}^{-1}$, obteve remoção média de DQO de $95 \%$ e 76,0 \% de metano no biogás. Além disso, a concentração de ácidos voláteis no efluente dos autores (527 mgHAc. $\mathrm{L}^{-1}$ ) foi maior do que no presente projeto $\left(110 \mathrm{mgHAc} . \mathrm{L}^{-1}\right)$. Os dados indicam que houve grande recuperação de alcalinidade a bicarbonato tanto no trabalho dos autores, em que a concentração do efluente foi de 1582 mgHAc. $L^{-1}$, mesmo com suplementação de $50 \%$ de bicarbonato. Em contrapartida, o presente, suplementando a água residuária com $20 \%$ de bicarbonato, apresentou valores de $1881 \mathrm{mgHAc} . \mathrm{L}^{-1}$ no efluente. Estes fatores são outro indício da maior estabilidade e eficiência do reator operado em condição termofílica.

Albuquerque (2017) estudou um reator AnSBBR tratando vinhaça em condição termofílica. Na melhor condição encontrada, a carga orgânica aplicada foi de 25,9 gDQO.L $\mathrm{L}^{-1} \cdot \mathrm{d}^{-1}$ em que o reator apresentou eficiência média de remoção de DQO de $85 \%$. A alcalinidade a bicarbonato no efluente foi de $3991 \mathrm{mgCaCO}_{3} \cdot \mathrm{L}^{-1}$ e a de ácidos voláteis totais foram d $1210411 \mathrm{mgHAc} . \mathrm{L}^{-1}$, com concentração de ácido acético de $720 \mathrm{mg} . \mathrm{L}^{-1}$ e de ácido propiônico de $257 \mathrm{mg} . \mathrm{L}^{-1}$ no efluente, sem presença de outros intermediários. O rendimento de metano gerado por carga orgânica aplicada foi de 11,7 mmolCH4.gDQO-1 ${ }^{-1}$ a produção de biogás foi de $6718 \mathrm{~mL}^{-C N T P}$.ciclo ${ }^{-1}$, com $78 \%$ de metano no biogás e produtividade molar de metano de $305 \mathrm{molCH}_{4} \cdot \mathrm{m}^{-3} \cdot \mathrm{d}^{-1}$. Ao se comparar com a 
condição em que houve COVA semelhante deste projeto, percebe-se que houve maior eficiência de remoção de DQO $(85,8 \%)$. A alcalinidade a bicarbonato no efluente do projeto foi de 4355 $\mathrm{mgCaCO}_{3} \cdot \mathrm{L}^{-1}$. e a de ácidos voláteis totais foram de $1585 \mathrm{mgHAc} . \mathrm{L}^{-1}$, com concentração de ácido acético de $1371 \mathrm{mg} . \mathrm{L}^{-1}$, $308 \mathrm{mg} . \mathrm{L}^{-1}$ de ácido propiônico, $137 \mathrm{mg} \mathrm{L} \mathrm{L}^{-1}$ de ácido valérico e $122 \mathrm{mg} . \mathrm{L}^{-1}$ de ácido butírico no efluente. O rendimento de metano gerado por matéria orgânica consumida foi maior $\left(13,07 \mathrm{mmolCH}_{4} \cdot \mathrm{gDQO}^{-1}\right)$, sendo a produtividade molar de metano também maior, 324,0 molCH $4 \cdot \mathrm{m}^{-3} \cdot \mathrm{d}^{-1}$. Contudo, houve menor produção de biogás e composição metano. Coincidentemente, as melhores condições encontradas em ambos os projetos foram com COVA semelhante, cerca de $25 \mathrm{gDQO} . \mathrm{L}^{-1} \cdot \mathrm{d}^{-1}$, o que pode ser um indicativo da carga ótima aplicável em reatores AnSBBR.

De modo geral, percebe-se que o AnSBBR aplicado ao tratamento de soro em condição termofílica foi bastante eficiente em comparação com outros trabalhos relacionados ao tratamento anaeróbio de águas residuárias visando a recuperação de energia através do aproveitamento do biogás gerado no reator. Entretanto, quando a carga orgânica aplicada foi elevada o reator apresentou indícios de piora da qualidade do efluente tratado e do biogás gerado, bem como a perda da estabilidade operacional. A Tabela 5.29 apresenta o resumo da comparação com a literatura.

Tabela 5.29 - Resumo da comparação do trabalho com a literatura

\begin{tabular}{cccccccccc}
\hline Autor & COVA & $\varepsilon_{\mathrm{SF}}$ & $\mathrm{pH}$ & $\mathrm{AVT}$ & $\mathrm{AB}$ & $\mathrm{V}_{\mathrm{CH} 4}$ & $\mathrm{X}_{\mathrm{CH} 4}$ & $\mathrm{RMCA}_{\mathrm{s}}$ & PrM \\
\hline $\begin{array}{c}\text { Lovato } \text { et al. } \\
\quad(2016)\end{array}$ & 7,5 & $90,0 \pm 4,0$ & $7,7 \pm 0,3$ & $266 \pm 143$ & - & - & 73,0 & 12,6 & 93,7 \\
$\begin{array}{c}\text { Condição II } \\
\text { Damasceno }\end{array}$ & 7,63 & $95,0 \pm 2,0$ & $8,2 \pm 0,2$ & $87 \pm 55$ & $2170 \pm 138$ & 2448 & $73,2 \pm 0,2$ & 16,52 & 126,1 \\
et al. (2007) & & $78 \pm 8$ & $7,1 \pm 0,1$ & $527 \pm 181$ & $1582 \pm 173$ & - & 66,4 & - & - \\
$\begin{array}{c}\text { Condição V } \\
\text { Albuquerque }\end{array}$ & 12,80 & $95 \pm 2$ & $8,3 \pm 0,1$ & $110 \pm 109$ & $1881 \pm 161$ & 4798 & $76,0 \pm 0,1$ & 19,56 & 250,3 \\
$\quad(2017)$ & $85 \pm 2$ & $8,5 \pm 0,1$ & $1210 \pm 411$ & $3991 \pm 116$ & 5196 & 78 & 11,7 & 305 \\
$\begin{array}{c}\text { Condição } \\
\quad \text { VIII }\end{array}$ & 24,78 & $85,8 \pm 2,0$ & $8,1 \pm 0,3$ & $1585 \pm 409$ & $4355 \pm 1068$ & 4793 & $73,7 \pm 0,4$ & 13,07 & 324 \\
\hline
\end{tabular}




\section{CONCLUSÕES}

Os resultados obtidos no presente trabalho permitiram as seguintes conclusões:

- O reator se mostrou apto ao tratamento de soro em condição termofílica, promovendo produção de metano e adequação ambiental desta água residuária;

- O aumento gradual da concentração de matéria orgânica e da temperatura na partida do reator foi uma técnica eficiente, fazendo com que a biomassa se mostrou ativa em pouco tempo de operação, garantindo bom desempenho do sistema;

- Houve grande estabilidade de remoção de matéria orgânica até a condição VIII, em que as eficiências de remoção se mantiveram acima de $93 \%$ até a condição VI, apresentando pequena queda na condição VII $(90 \%)$ e decaindo a $85 \%$ na condição VIII, indicando que as maiores cargas orgânicas aplicadas derivaram em problemas durante a operação do reator, resultando em $62 \%$ na condição IX e $58 \%$ na condição $\mathrm{X}$, sendo a queda no desempenho creditada à alta carga aplicada, o que fez com que o reator perdesse a capacidade de assimilar a matéria orgânica, entretanto, em todas as condições a eficiência de remoção de carboidratos na forma filtrada se manteve acima de 99\%;

- Entre as condições I e VIII, o pH afluente foi entre 8,20 e 8,92, com o valor do efluente entre 7,16 e 8,86, chegando a 7,13 de valor mínimo nas últimas duas condições, sendo que neste mesmo período, os valores de alcalinidade a bicarbonato do efluente entre 1514 e 5743 $\mathrm{mg} \mathrm{CaCO}_{3} \cdot \mathrm{L}^{-1}$ e os de ácidos voláteis totais no efluente estiveram entre 6 e $2590 \mathrm{mg}$ HAc.L ${ }^{-}$ ${ }^{1}$, havendo nas duas últimas condições menor estabilidade do reator, com os valores de 
alcalinidade a bicarbonato do efluente entre 374 e $2930 \mathrm{mgCaCO}_{3} \cdot \mathrm{L}^{-1}$ e os valores de ácidos voláteis totais no efluente entre 2752 e $6301 \mathrm{mg} \mathrm{HAc.L^{-1 }}$.

- O volume de biogás gerado cresceu em cada uma das condições, chegando a $7157 \mathrm{~mL}-$ CNTP.ciclo $^{-1}$ na condição $X$, entretanto, a porcentagem de metano no biogás teve aumento até a condição VII, em que a fração de metano no biogás foi de $76 \%$;

- A produtividade molar aumentou até a condição VIII em que alcançou o valor de 324 molCH $4 \cdot m^{-3} \cdot d^{-1}$, sendo na condição IX a maior vazão molar de metano $\left(0,66 \mathrm{mmolCH}_{4} \cdot \mathrm{d}^{-1}\right) \mathrm{e}$ o maior volume de metano gerado (4968 mL-CNTP.ciclo ${ }^{-1}$ ), obtendo-se em todas as condições valores de rendimento molar de metano próximos ao limite teórico;

- O estudo das rotas metabólicas pelo ajuste cinético, obteve-se maior produção de ácido acético pelo substrato e também da conversão do ácido propiônico, sendo a produção de metano maior pela rota metanogênica hidrogenotrófica com presença da rota metanogênica acetoclástica em todas as condições;

- Quanto à recuperação energética pela produção de metano, a condição VIII apresentou resultados satisfatórios nas três escalas de produção estudadas, sendo a condição V que apresentou os melhores resultados de recuperação energética de $826,10 \mathrm{MWh}$ por dia admitindo o tratamento do soro de um grande produtor do setor de laticínios, representando o consumo estimado de uma cidade de 5163 habitantes. Com os resultados, comprovou-se que a condição termofílica em elevadas cargas orgânicas proporcionou maior geração de energia pelo reator AnSBBR tratando tanto vinhaça, como soro;

- A mudança de estratégia de alimentação para batelada alimentada não apresentou melhora em relação à estratégia em batelada, havendo piora no desempenho do reator creditado ao 
stress da biomassa enquanto o reator não tinha seu volume completo e também à alta carga aplicada; 


\section{SUGESTÕES PARA TRABALHOS FUTUROS}

Para complementação do estudo de reator AnSBBR aplicado ao tratamento de soro em condição termofílica, indica-se:

- Estudo da co-digestão de soro com outra água residuária complementar, pois a literatura indica diversas vantagens da aplicação da co-digestão, sendo o soro um ótimo efluente a ser integrado neste processo devido à sua alta biodegradabilidade e disponibilidade de nutrientes;

- Estudar a mudança de estratégia de alimentação em cargas orgânicas menores.

- Estudo de tempos maiores de operação nas condições com maior concentração de matéria orgânica afluente;

- Estudo de tempos de ciclo menores nas condições de projeto estudadas 


\section{REFERÊNCIAS BIBLIOGRÁFICAS}

ALBANEZ, R.; CHIARANDA, B.C.; FERREIRA, R.G.; FRANÇA, A.L.P.; HONÓRIO, C.D.; RODRIGUES, J.A.D.; RATUSZNEI, S.M.; ZAIAT, M. Anaerobic biological treatment of vinasse for environmental compliance and methane production. Applied Biochemistry and Biotechnology, 178, 2143, 2016a.

ALBANEZ, R.; LOVATO, G.; ZAIAT, M.; RATUSZNEI, S.M.; RODRIGUES, J.A.D. Optimization, metabolic pathways modeling and scale-up estimative of na AnSBBR applied to biohydrogen production by co-digestion of vinasse and mmolasses. International Journal of Hydrogen Energy, 41, 20473-20484, $2016 b$

ALBUQUERQUE, J.N. Produção de metano em AnSBBR tratando vinhaça em condição termofílica. Dissertação de mestrado - Programa de Pós-graduaação em Hidráulica e Saneamento, Escola de Engenharia de São Carlos - Universidade de São Paulo, 2017.

ALMEIDA, W.A.; RATUSZNEI, S.M.; ZAIAT, M.; RODRIGUES, J.A.D. AnSBBR Applied to Biomethane Production for Vinasse Treatment: Effects of Organic Loading, Feed Strategy and Temperature. Brazilian Journal of Chemical Engineering, 2017.

APHA, AWWA, WPCF. STANDARD METHODS FOR THE EXAMINATION OF WATER AND WASTEWATER. $19^{\text {th }}$ edition, American Public Health Association, Washington, 1995.

BACKUS, B.D.; CLANTON, C. J.; GOODRICH, P. R.; MORRIS, H. A. Carbon-to-nitrogen ratio and hydraulic retention time effect on the anaerobic digestion of cheese whey. Transactions of the ASAE, 31, 1274-82, 1988.

BEZERRA, R.A.; RODRIGUES, J.A.D.; RATUSZNEI, S.M.; ZAIAT, M.; FORESTI, E. Whey Treatment by AnSBBR with Circulation: Effects of Organic Loading, Shock Loads, and Alkalinity Supplementation. Appl Biochem Biotechnol 143:257-275, 2007; 
BEZERRA, R.A.; RODRIGUES, J.A.D.; RATUSZNEI, S.M.; ZAIAT, M.; FORESTI, E. Effects of feed time, organic loading and shock loads in the anaerobic whey treatment by an AnSBBR with circulation. Applied Biochemistry and Biotechnology, 157, 140-158, 2009.

BEZERRA, R.A.; RODRIGUES, J.A.D.; RATUSZNEI, S.M.; CANTO, C.S.A.; ZAIAT, M. Effect of organic load on the performance and methane production of an AnSBBR treating effluent from biodiesel production. Applied Biochemistry and Biotechnology, 165, 347-368, 2011.

BRAILE, P.M.; CAVALCANTI, J.E.W.A. Manual de tratamento de aguas residuárias. CETESB, São Paulo, 764p., 1993.

CHAMCHOI, N.; NITISORAVUT, S.; SCHMIDT, J.E. Inactivation of ANAMMOX communities under concurrent operation of anaerobic ammonium oxidation (ANAMMOX) and denitrification. Bioresource Technology 99 3331-3336, 2008.

CHANDRA, R., TAKEUCHI, H.; HASEGAWA, T. Methane production from lignocellulosic agricultural crop wastes: A review in context to second generation of biofuel production. Renewable and Sustainable Energy Reviews. 16, 1462-1476, 2012.

DAMASCENO, L.H.S. Tratamento de soro de queijo no ASBR: Influência da estratégia de alimentação. Dissertação de Mestrado, EESC-USP, Departamento de Hidráulica e Saneamento, 2004.

DAMASCENO, L.H.S.; RODRIGUES, J.A.D.; RATUSZNEI, S.M.; ZAIAT, M.; FORESTI, E. Effects of feeding time and organic loading in an anaerobic sequencing batch biofilm reactor (ASBBR) treating diluted whey. Journal of Environmental Management, v. 85 927-935, 2007.

DAMASCENO, L.H.S.; RODRIGUES, J.A.D.; RATUSZNEI, S.M.; ZAIAT, M.; FORESTI, E. Effect of mixing mode on the behavior of an ASBBR with immobilized biomass in the treatment of cheese whey. Brazilian Journal of Chemical Engineering, 25, 291-298, 2008.

DILALLO, R.; ALBERTSON, O.E. Volatile acids by direct titration. Journal of Water Pollution Control Federation, 3, 356-365, 1961.

VERSÃO CORRIGIDA 
DINSDALE, R. M.; HAWKES, F. R., HAWKES, D. L. Comparision of mesophilic and termophilic Upflow Anaerobic Sludge Blanket Reactors treating instant coffee production wastewater. Water Research, 31, $163^{-1} 69,1996$.

DUBOIS, S.M.; GILLES, K.A.; HAMILTON, J.L.; REBERS, P.A.; SMITH, F. Colorimetric methods for determination of sugar and related substance. Analytical Chemistry, 228, 13-21, 1956.

FERRAZ JÚNIOR, A.D.N.; KOYAMA, M.H.; ARAÚJO JÚNIOR, M.M.; ZAIAT, M. Thermophilic anaerobic digestion of raw sugarcane vinasse. Renewable Energy, 89, 245-252, 2016.

GARCIA, J.L; PATEL, B.K.C.; OLLIVIER, B. Taxonomic, phylogenetic and ecological diversity of methanogenic archaea. Anaerobe, 6, p. 205-226 2000.

GARCIA, M.L.; LAPA, K.R.; FORESTI, E.; ZAIAT, M. Effects of bed materials on the performance of an anaerobic sequencing batch biofilm reactor treating domestic sewage. Journal of environmental management, 88, 1471-7, 2008.

GIOANNIS, G.; MUNTONI, A.; POLETTINI, A.; POMI, R. A review of dark fermentative hydrogen production from biodegradable municipal waste fractions. Waste Management, 33, 1345 $361,2013$.

HAWKINS G.L.; RAMAN, D.R.; BURNS, R.T. Enhancing dairy lagoon performance with high-rate anaerobic digesters. Transactions of the ASAE, 44, $1825^{-1} 831,2001$.

HICKEY, R.F.; WU, W.M.; VEIGA, M.C.; JONES, R. Start-up, operation, monitoring and control of highrate anaerobic treatment systems. Water Science and Technology, 24, 207-255, 1991.

HINO, T.; MIYAZAKI, K.; KURODA, S. Role of extracellular acetate in the fermentation of glucose by a ruminal bacterium, Megasphaera elsdenii. J. Gen. Appl. Microbiol., 37, 121ㄹ2, 1991.

KUMAR, S. Anaerobic Biotechnology for Bioenergy Production. Principles and Aplications. WileyBlackwell, Nova Deli, 2008.

LETTINGA, G.; HAANDEL, A.C. Anaerobic Digestion for Energy Production and Environmental Protection. In: Johansson, T.B. et al. (Ed.) Renewable Energy; Sources for Fuels and Electricity. Island Press, California, 1993. 
LIMA, D.M.F.; LAZARO, C.Z.; RODRIGUES, J.A.D.; RATUSZNEI, S.M.; M. ZAIAT. Optimization performance of an AnSBBR applied to biohydrogen production treating whey. Journal of Environmental Management, 169, 191-201, 2016.

LULLIO, T. G.; RATUSZNEI, S.M; RODRIGUES, J.A.D.; ZAIAT, M. Biomethane production in an AnSBBR treating biohydrogen process wastewater. Applied Biochemistry and Biotechnology, 174, 1873 ${ }^{1} 896,2014$.

LO, K.V.; LIAO, P.H. Digestion of Cheese Whey with Anaerobic Rotating Biological Contact Reactor. Biomass, 10, 243-52, 1986.

LOVATO, G.; BEZERRA, R.A.; RODRIGUES, J.A.D.; RATUSZNEI, S.M.; ZAIAT,M. Effect of feed strategy on methane production and performance of an AnSBBR treating effluent from biodiesel production. Applied Biochemistry and Biotechnology, 166, 2007-2029, 2012.

LOVATO, G.; ALBANEZ, R.; FONTES LIMA, D.M.; BRAVO, I.S.M.; ALMEIDA, W.A.; RATUSZNEI, S.M.; RODRIGUES, J.A.D. Application and environmental compliance of anaerobic sequencing batch reactors applied to hydrogen/methane bioenergy production. Capítulo 5 em: Wastewater Treatment: Processes, Management Strategies and Environmental/Health Impacts. .ed.Hauppauge, NY.: Nova Science Publishers, $111^{-1} 61,2015$.

LOVATO, G.; RATUSZNEI, S.M. ; RODRIGUES, J.A.D.; ZAIAT, M. Co-digestion of whey with glycerin in an AnSBBR for biomethane production. Applied Biochemistry and Biotechnology, 178, 126 $123,2016$.

LULLIO, T.G.; SOUZA, L.P.; RATUSZNEI, S.M.; RODRIGUES, J.A.D.; ZAIAT, M. Biomethane production in an AnSBBR treating wastewater from biohydrogen process. Applied Biochemistry and Biotechnology, 174, 1873-1896, 2014.

MAlASPINA, F.; CELlAMARE, C.M.; STANTE, L.; TILCHE, A. Anaerobic treatment of cheese whey with a downflow-upflow hybrid reactor. Bioresource Technology, v.55, p.131-9, 1996.

MAWSON, A.J. (1994). Bioconversions for whey utilization and waste abatement. Bioresource Technology, 47, 195-203.

\section{VERSÃO CORRIGIDA}


MCCARTY, P.L. One hundred years of anaerobic treatment. In: Anaerobic Digestion, 1981. D.E. Hughes, D.A. Stafford, B.I. Wheatley, W. Baader, G. Lettinga, E.J. Nyns, W. Verstraete, and R.L. Wentworth (Eds.), Elsevier Biomedical Press B.V., Amsterdam, 1982.

MICHELAN, R.; ZIMMER, T.R.; RODRIGUES, J.A.D.; RATUSZNEI, S.M.; MORAES, D.; ZAIAT, M.; FORESTI E. Effect of impeller type and mechanical agitation on the mass transfer and power consumption aspects of ASBR operation treating synthetic wastewater. Journal of Environmental Management, 90, $1357^{-1} 364,2009$.

MOCKAITIS, G.; Ratusznei, S.M.; Rodrigues, J.A.D.; Zaiat, M.; Foresti, E. ANAEROBIC WHEY TREATMENT BY A STIRRED SEQUENCING BATCH REACTOR (ASBR): EFFECTS OF ORGANIC LOADING AND SUPPLEMENTED ALKALINITY. Journal of Environmental Management, v.79 198-206, 2006.

MOSEY, F.E.; Mathematical modeling of the anaerobic process: regulatory mechanisms for the formation of short-chain volatile acids from glucose. Water Science Technology 15, 209-232, 1983.

NOVAES, L.F.; SARATT, B.L.; RODRIGUES, J.A.D.; RATUSZNEI, S.M.; MORAES, D.; RIBEIRO, R.; ZAIAT, M.; FORESTI, E. Effect of impeller type and agitation on the performance of pilot scale ASBR and AnSBBR applied to sanitary wastewater treatment. Journal of Environmental Management, 91, 1647 ${ }^{1} 656,2010$.

OLIVEIRA, D.S.; PRINHOLATO, A.C.; RATUSZNEI, S.M.; RODRIGUES, J.A.D.; ZAIAT, M.; FORESTI, E. AnSBBR applied to the treatment of wastewater from a personal care industry: effect of organic load and fill time. Journal of Environmental Management, 90, 3070-3081, 2009.

PAULO, P. L.; VILLA, G; VAN LIER, J. B., LETTINGA, G. The anaerobic conversion of methanol under thermophilic conditions: $\mathrm{pH}$ and bicarbonate dependence. Journal of Bioscience and Bioengineering, 96, 213-218, 2003.

PERRY, R. H., GREEN, D. W. Perry's chemical engineers' handbook (70th ed.). New York: McGraw Hill, 1997. 
PODLECH, P.A.S.; LUNA, M.F.; JERKE, P.R.; SOUZA, O.; SOUZA NETO, C.A.C.; PASSOS, R.F.; BORZANI, W. Fermentação semi-contínua de soro de leite por Lactobacillus bulgaricus em Instalação Piloto. Revista do Instituto Cândido Tostes, 46, 26-33, 1991.

POHLAND, F. G. Anaerobic Treatment: Fundamental Concept, Application and New Horizons. In: Malina Jr., J.F.; Pohland, F.G. (Ed.) Design of Anaerobic Processes for the Treatment of Industrial and Municipal Wastes. Technomic Publishing, Lancaster, 1992.

RAMOS, A. C. T. et al. Mass transfer improvement of a fixed-bed anaerobic sequencing batch reactor with liquid-phase circulation. Interciencia, 28, 214-219, 2003.

RATUSZNEI, S.M.; RODRIGUES, J.A.D.; CAMARGO, E.F.M.; ZAIAT, M.; BORZANI, W. Feasibility of a stirred anaerobic sequencing batch reactor containing immobilized biomass for wastewater treatment. Bioresource Technology, 75, 127 32, 2000.

RATUSZNEI, S.M.; RODRIGUES, J.A.D.; CAMARGO, E.F.M.; RIBEIRO, R.; ZAIAT, M. Effect of feeding strategy on a stirred anaerobic sequencing fed-batch reactor containing immobilized biomass. Bioresource Technology, 90, 199-205, 2003.

RIBAS, M.M.F.; CHINALIA, F.; GIANOTTI, E.P.; POZZI, E.; FORESTI, E. Microbial succession within an anaerobic sequencing batch biofilm reactor (ASBBR) treating cane vinasse at $55^{\circ} \mathrm{C}$. Brazilian Archives of Biology and Technology, 42, 1027-1036, 2009.

RIPLEY, L.E.; BOYLE, W.C.; CONVERSE, J.C. Improved Alkalimetric Monitoring for Anaerobic Digestor of High-Strength Wastes. Journal of Water Pollution Control Federation, 58, 406-411, 1986.

RODRIGUES, J.A.D.; OLIVEIRA, R.P.; RATUSZNEI, S.M.; ZAIAT, M.; FORESTI, E. AnSBBR applied to a personal care industry wastewater treatment: effects of fill time, volume treated per cycle and organic load. Applied Biochemistry and Biotechnology, 163, 127 42 2011.

SPEECE, R.E. Anaerobic biotechnology for industrial wastewaters. Archae Pr.,cap 8, p.190-191, 1996. 
SARTI, A.; SAKAMOTO, I.K.; VARESCHE, M.B.A.; ZAIAT, M.; FORESTI, E. Domestic sewage treatment in pilot-scale anaerobic sequencing batch reactors. Engenharia Sanitária e Ambiental. v. 11, p. 73-82, 2006.

SARTI, A.; DA SILVA, A. J.; CÔRTES, R. S.; FORESTI, E. Remoção de sulfato de águas residuárias indrustriais em reator anaeróbio de leito fixo operado em bateladas sequenciais. Engenharia Sanitária Ambiental. Vol. 13, nº 1, p. 15-22, 2008.

SCOTT, R.; ROBINSON R.K.; WILBEY, R.A. Cheesemaking Practice. $3^{\mathrm{a}}$ Ed., Aspen Publishers, Gaithersburg, 449p., 1998.

SILVA, R.C.; RATUSZNEI, S.M.; RODRIGUES, J.A.D.; ZAIAT, M. Anaerobic treatment of industrial biodiesel wastewater by an ASBR for methane production. Applied Biochemistry and Biotechnology, 170, $105^{-1} 18,2013$.

SONG, Y.C.; KWON, S.J.; WOO, J.H. Mesophilic and thermophilic temperature co-phase anaerobic digestion compared with single-stage mesophilic and thermophilic digestion of sewage sludge. Water Research, 38, $1653^{-1} 662,2004$.

STAMS, A. J. M. \& PLUGGE, C. M. Electron transfer in syntrophic communities of anaerobic bacteria and archaea. Nature Reviews on Microbiology 7, 568-577, 2009.

SUNG, S.W.; DAGUE, R.R. Laboratory studies on the anaerobic sequencing batch reactor. Water Environment Research. 67, 294-301, 1995.

TANG, C.; ZHENG P.; CHAI L.; MIN X. Thermodynamic and kinetic investigation of anaerobic bioprocesses on ANAMMOX under high organic conditions. Chemical Engineering Journal 230 149157,2013

TATARA, M.; YAMAZAWA, A.; UENO, Y.; FUKUI, H.; GOTO, M.; SODE, K. High-rate thermophilic methane fermentation on short-chain fatty acids in a down-flow anaerobic packed-bed reactor. Bioprocess Biosystem Engineering, 27, 105 13, 2005. 
UENO, Y.; TATARA, M.; FUKUI H.; MAKIUCHI, T.; GOTO, M.; SODE, K. Production of hydrogen and methane from organic solid wastes by phase-separation of anaerobic process. Bioresource Technology, 98, $1861^{-1} 865,2007$.

WILDENAUER, F.X.; WINTER, J. Anaerobic digestion of High Strength Acidic Whey in a pH- Controlled Up-Flow Fixed-Film Loop Reactor. Applied Biochemistry and Biotechnology, 22, 367-72, 1985.

YAN, J. Q.; LIAO, P.H.; LO, K.V. Methane production from cheese whey. Biomass, 17, 185-202, 1988.

YANG, Y.; TSUKAHARA, K.; SAWAYAMA, S. Biodegradation and methane production from glycerolcontaining synthetic wastes wwith fixed-bed bioreactor under mesophilic and thermophilic anaerobic conditions. Process Biochemistry, 43, 362-367, 2008.

ZAIAT, M.; CABRAL, A.K.A.; FORESTI, E. Horizontal-flow anaerobic immobilized sludge reactor for wastewater treatment: conception and performance evaluation. Brazilian Journal of Chemical Engineering, 11, 33-42, 1994.

ZAIAT, M.; RODRIGUES, J.A.D.; RATUSZNEI, S.M.; CAMARGO, E.F.M.; BORZANI, W.. Anaerobic sequencing batch reactors for wastewater treatment: a developing technology. Applied Microbiology and Biotechnology, 55, 29-35, 2001.

ZIMMER, T.R.; MICHELAN, R; CANTO, C.M.S.; RODRIGUES, J.A.D.; RATUSZNEI, S.M. Feed dtrategy study of a mchanically stirred anaerobic sequencing batch reactor (ASBR) equipped with a draft tube applied to whey treatment. Brazilian Journal of Food Technolology., 11, 288-298, 2008.

VERSÃO CORRIGIDA

SÃO CARLOS

FEVEREIRO 2018 